Universitat Politècnica de València Departamento de Máquinas y Motores Térmicos

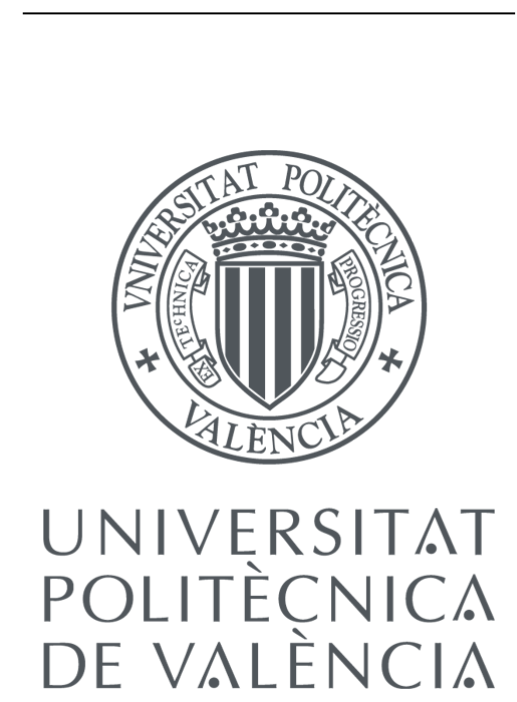

\title{
EXPERIMENTAL AND ANALYTICAL STUDY OF THE MECHANICAL FRICTION LOSSES IN THE PISTON-CYLINDER LINER TRIBOLOGICAL PAIR IN INTERNAL COMBUSTION ENGINES (ICE)
}

\author{
Doctoral Thesis \\ Presented by: \\ Kared Sophia Bastidas Moncayo \\ Directed by: \\ Dr. Bernardo Tormos Martínez
}

Valencia, July 2021 



\section{DoCTORAL THESIS}

\section{EXPERIMENTAL AND ANALYTICAL STUDY OF THE MECHANICAL FRICTION LOSSES IN THE PISTON-CYLINDER LINER TRIBOLOGICAL PAIR IN INTERNAL COMBUSTION ENGINES (ICE)}

Presented by: Kared Sophia Bastidas Moncayo Directed by: Dr. Bernardo Tormos Martínez

Tribunal:

President: $\quad$ Dr. José María Desantes

Secretary: Dr. Antolin Hernández

Vocal: $\quad$ Dr. Eduardo Tomanik

External Evaluators:

Dr. Hannes Allmaier

Dr. Luís António de Andrade Ferreira

Dr. Eduardo Tomanik

Valencia, July 2021 



\section{Resumen}

Con el aumento de la demanda de soluciones más amigables con el medio ambiente en la industria de la automoción, el motor de combustión interna alternativo (MCIA) enfrenta actualmente grandes desafíos para minimizar su consumo de recursos no renovables y especialmente, para reducir sus emisiones contaminantes. Debido a que el aporte de los MCIAs es fundamental para cubrir las necesidades de movilidad y de generación de energía alrededor de todo el mundo, y el hecho de que diferentes alternativas, como los motores eléctricos e hibrido, están y continuaran enfrentado múltiples obstáculos para su implementación masiva en el futuro cercano, la investigación continua en MCIA es fundamental para cumplir con los propósitos de reducción de emisiones.

En este aspecto, una aproximación para el aumento de la eficiencia del motor y la reducción del consumo de combustible es mediante la implementación de alternativas dirigidas a reducir las perdidas mecánicas por fricción. Estas alternativas tribológicas incluyen aquellas que requieren modificaciones en los componentes del motor, como materiales y acabados superficiales, y el uso de formulaciones de aceite lubricante de menor viscosidad o aditivos que mejoren las condiciones de lubricación del motor. Con la contante evolución y mejoras en el MCIA y las condiciones de trabajo cada vez mas severas, también surgen nuevas alternativas tribológicas para enfrentar los nuevos desafíos del motor, y por tanto se requiere de investigaciones adicionales en este tema.

Durante el desarrollo de esta Tesis, uno de los objetivos consistió en contribuir a la investigación del uso de aceites de baja viscosidad para el ahorro de combustible como un efecto conjunto con las condiciones de conducción del vehículo. Para llevar a cabo este objetivo, se desarrollaron ensayos experimentales bajo condiciones estacionarias en un banco de motor con formulaciones de aceite de diferente viscosidad HTHS, algunas de ellos con aditivo modificador de fricción para expandir el rango de reducción de fricción a condiciones de lubricación más severas. Los mapas de consumo de combustible resultantes de estos ensayos fueron utilizados en un modelo de simulación del vehículo para estimar su consumo de combustible como función del aceite y las condiciones de trabajo de tres ciclos de conducción.

Con el objetivo de expandir los conocimientos en los fundamentos de lubricación de los MCIAs y tener la capacidad de evaluar otras alternativas para reducir las perdidas por fricción, se consideró necesario enfocar la investigación en el conjunto pistón-camisa, que es el par tribológico con mayor aporte a las perdidas por fricción. Para conseguir este objetivo, durante esta Tesis se desarrolló una maqueta especifica para el ensamble piston-camisa, y un modelo teórico para simular la lubricación del segmento de compresión. Para la primera parte, la maqueta se desarrolló basada en el método de camisa flotante, en el cual la camisa fue aislada del resto del motor y la fuerza de fricción generada en la interfaz piston-camisa pudo ser medida mediante sensores de fuerza. En esta instalación se desarrollaron diferentes ensayos los cuales permitieron llevar a cabo un análisis exhaustivo de los fundamentos de lubricación de este par tribológico como función de diferentes parámetros que tiene impacto en las condiciones de lubricación. Este estudio se complementó con el desarrollo 
de un modelo de lubricación para el segmento de compresión basado en el método de diferencias finitas. Finalmente, se llevó a cabo una comparativa de resultados experimentales y teóricos para el segmento de compresión, lo cual permitió validar los ensayos experimentales en la maqueta de camisa flotante, así como el modelo de simulación desde el punto de vista de datos de entrada, condiciones de contorno y supuestos. 


\section{Resum}

Amb l'augment de la demanda de solucions més amigables amb el medi ambient en la indústria de l'automoció, el motor de combustió interna alternatiu (MCIA) s'enfronta actualment a grans desafiaments per minimitzar el seu consum de recursos no renovables i especialment, per reduir les seves emissions contaminants . Tenint en compte que l'aportació dels MCIA és fonamental per a cobrir les necessitats de mobilitat i generació d'energia arreu de tot el món, i el fet que diferents alternatives, com els motors elèctrics i híbrids, estan i continuaran enfrontat múltiples obstacles per a la seva implementació massiva al proper futur, la investigació contínua en MCIA és fonamental per complir amb els propòsits de reducció d'emissions.

En aquest aspecte, una aproximació per a l'augment de l'eficiència del motor i la reducció de consum de combustible és mitjançant la implementació d'alternatives dirigides a reduir les pèrdues mecàniques per fricció. Aquestes alternatives tribològiques inclouen aquelles que requereixen modificacions de components del motor, com materials i acabats superficials, i l'ús de formulacions d'oli lubricant de menor viscositat o additius que milloren les condicions de lubricació del motor. Amb la constant evolució i millores en el MCIA i les condicions de treball cada vegada més severes, també sorgeixen noves alternatives tribològiques per enfrontar els nous desafiaments del motor, i per tant es requereix d'investigacions addicionals en aquest tema.

Durant el desenvolupament d'aquesta Tesi, un dels objectius va consistir a contribuir a la investigació de l'ús d'olis de baixa viscositat per a l'estalvi de combustible com un efecte conjunt amb les condicions de conducció de vehicle. Per dur a terme aquest objectiu, es van desenvolupar assajos experimentals sota condicions estacionàries en un banc de motor amb formulacions d'oli de diferent viscositat HTHS, algunes d'elles amb additiu modificador de fricció per expandir el rang de reducció de fricció a condicions de lubricació més severes . Els mapes de consum de combustible resultants d'aquests assajos van ser utilitzats en un model de simulació del vehicle per estimar el seu consum de combustible com a funció de l'oli i les condicions de treball de tres cicles de conducció.

Amb l'objectiu d'expandir els coneixements en els fonaments de lubricació dels MCIAs i tenir la capacitat d'avaluar altres alternatives per reduir les pèrdues per fricció, es va considerar necessari enfocar la recerca al conjunt pistó-camisa, que és el parell tribològic amb major aportació a les perdudes per fricció. Per aconseguir aquest objectiu, durant aquesta Tesi es va desenvolupar una maqueta específica per al acoblament pistó-camisa, i un model teòric per simular la lubricació del segment de compressió. Per a la primera part, la maqueta es va desenvolupar basada en el mètode de camisa flotant, en el qual la camisa va ser aïllada de la resta del motor i la força de fricció generada en la interfície pistó-camisa va poder ser mesurada mitjançant sensors de força. En aquesta instal-lació es van desenvolupar diferents assajos els quals van permetre dur a terme una anàlisi exhaustiva dels fonaments de lubricació d'aquest parell tribològic com a funció de diferents paràmetres que tenen impacte en les condicions de lubricació. Aquest estudi es va complementar amb el desenvolupament d'un model de lubricació per al segment de compressió basat en 
el mètode de diferències finites. Finalment, es va dur a terme una comparativa de resultats experimentals i teòrics per al segment de compressió, la qual cosa va permetre validar els assajos experimentals a la maqueta de camisa flotant, així com el model de simulació des del punt de vista de dades d'entrada, condicions de contorn i hipòtesis. 


\section{Abstract}

With the increasing demand for greener solutions in the automotive industry, the ICE is currently facing great challenges to minimize the consumption of nonrenewable resources and specially to reduce its harmful emissions. Given that the contribution of the ICE is fundamental to cover the actual mobility and power generation needs worldwide, and the fact that different power-train alternatives, such as electric and hybrid vehicles, are and will continue facing multiple obstacles for their large-scale implementation in the near future, the continuous research on the ICE is fundamental in order to meet the emissions reduction targets.

In this regard, one approach to increase the engine efficiency and reduce the fuel consumption, is through the implementation of alternatives aimed to reduce the friction mechanical losses. These tribological alternatives include those that require modifications to the engine components, such as materials and surface finishes, and the use of lubricant oil formulation of lower viscosity or additives that improve the lubrication performance of the engine. With the ongoing evolution and improvement of the ICE and the increasingly severe working conditions, new tribological solutions also emerge to face the new challenges in the ICE, and therefore further research is required on this subject.

During the development of this Thesis, one of the objectives was to contribute to the research on low viscosity engine oils for fuel economy as a joint effect with the driving conditions of the vehicle. To accomplish this, experimental tests were performed under stationary conditions in an engine bench test for oil formulations of different HTHS viscosity, some of them with friction modifier additive to expand the friction reduction effect to more severe lubrication conditions. The resultant fuel consumption maps were then employed in a vehicle model to estimate the fuel consumption of the vehicle as function of the oil formulation and the working conditions of the three driving cycles.

With the aim of expanding the knowledge on the lubrication fundamentals of the engine and to have the capability to assess other alternatives to further reduce the friction mechanical losses, it was deemed necessary to focus the research on the pistoncylinder liner assembly, the tribo-pair of major friction share. In order to achieve this objective, a test rig was developed in this Thesis specific for the piston-liner assembly, and a theoretical model to estimate the lubrication of the piston compression ring. For the first part, the test rig was designed based on the floating liner method, where the cylinder liner was isolated from the rest of the engine and the friction force generated in the piston-liner conjunction could be measured by means of force sensors. Different tests were developed in this test rig which allowed a comprehensive analysis of the piston lubrication fundamentals as function of different parameters having an impact on the lubrication performance of this assembly. This study was complemented with the development of a piston compression ring lubrication model based on the finite differences method. A comparison of experimental and theoretical results was performed for the piston compression ring that helped to validate both the experimental tests in the floating liner and the simulation model from the point of view of input data, boundary conditions and assumptions. 

A mis abuelitos y mis padres 



\section{Agradecimientos}

En este pequeño espacio, me gustaría dedicar unas palabras de agradecimiento a las personas que me han acompañado en esta etapa y que de una forma u otra han contribuido a la culminación de este proyecto.

Un especial agradecimiento a mi tutor de Tesis, Bernardo Tormos, por todo su apoyo, guía y dedicación durante todas las etapas de desarrollo de esta tesis, principalmente cuando la experiencia era fundamental. Gracias al Instituto CMTMotores Térmicos, en especial a José María Desantes por la oportunidad de formar parte de este prestigioso centro de investigación; de igual forma, mi más sincero agradecimiento a Vicente Macián por permitirme formar parte de su grupo de trabajo y disponer de todos los recursos necesarios para el desarrollo de esta tesis. Quiero agradecer también el apoyo y consejos de Vicente Bermúdez, su experiencia ha sido de gran ayuda para el desarrollo experimental de esta Tesis. En esta misma línea, quiero agradecer a todos los técnicos que me han ayudado en el desarrollo de la maqueta o en los ensayos experimentales, su experiencia a sido esencial.

My most sincere gratitude to Prof. Edward Smith who received me at UCLan during my research stay and shared his knowledge with me with great dedication. Without his guidance, this Thesis could not be complete.

I would like to acknowledge an thank the collaboration of Repsol for formulating and supplying the lubricant oils employed during the project on low viscosity engine oils for fuel economy. I would also like to express my gratitude to ICONIC and MAHLE for supporting the experimental research on the floating liner test rig by supplying the resources, oil formulations and piston ring packs, for some of the tests presented here.

Un millón de gracias a todos mis compañeros de despacho, Santi, Guillermo, Leo, y en especial a Antonio y Toni, con quienes además de proyectos, he compartido muchos momentos de amistad y risas. Extiendo este agradecimiento a los estudiantes de TFM, Daniel, Salvador y Paul que han apoyado diferentes partes del desarrollo de esta Tesis.

En estas ultimas líneas quiero agradecer profundamente el apoyo de mi familia y en especial a mis padres por todo su esfuerzo para que yo pudiera cumplir mis metas, su confianza en mi ha sido el motor principal para perseverar. Gracias por montón a Angela y Melissa, mis amigas de toda la vida, aunque nos separan kilómetros de distancia, nuestra amistad incondicional me ha hecho sentir muy cercana cuando más lo he necesitado. 



\section{Table of Contents}

1 Introduction $\quad 1$

1.1 Background and context $\ldots \ldots \ldots \ldots \ldots \ldots \ldots \ldots \ldots \ldots \ldots \ldots \ldots$

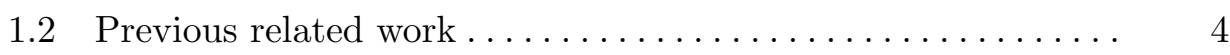

1.3 Objectives of the thesis $\ldots \ldots \ldots \ldots \ldots \ldots \ldots \ldots \ldots \ldots \ldots \ldots$

1.4 Thesis document structure $\ldots \ldots \ldots \ldots \ldots \ldots \ldots \ldots \ldots$

Bibliography $\ldots \ldots \ldots \ldots \ldots \ldots \ldots \ldots \ldots \ldots \ldots \ldots \ldots \ldots \ldots \ldots \ldots$

2 Literature review $\quad 11$

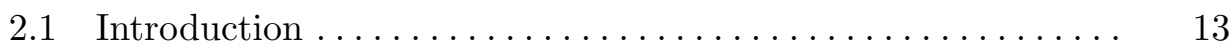

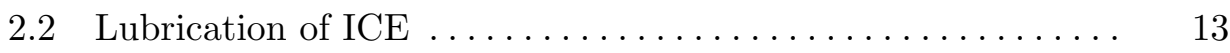

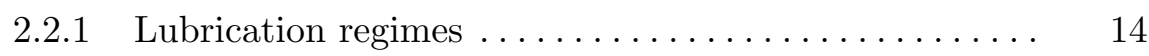

2.2.1.1 Hydrodynamic lubrication ............ 15

2.2.1.2 Boundary lubrication.............. 15

2.2.1.3 Mixed lubrication ................... 15

2.2.1.4 Elastohydrodynamic lubrication ......... 15

2.2.2 Lubrication of the main tribological pairs in ICE .... 16

2.2.2.1 Piston-cylinder liner assembly ......... 16

2.2.2.2 Journal bearings . . . . . . . . . . . . 18

$2.2 .2 .3 \quad$ Valve train .................... 19

$2.2 .3 \quad$ Engine oil rheology ..................... 20

2.2.3.1 Engine oil composition ............ 20

2.2.3.2 Dynamic viscosity $\ldots \ldots \ldots \ldots \ldots \ldots \ldots .22$ 
2.2.3.3 Kinematic viscosity $\ldots \ldots \ldots \ldots \ldots \ldots \ldots .23$

2.2.3.4 Density ....................... 26

2.3 Friction mechanical losses $\ldots \ldots \ldots \ldots \ldots \ldots \ldots \ldots \ldots . \ldots \ldots$

2.3 .1 Piston-cylinder liner assembly $\ldots \ldots \ldots \ldots \ldots \ldots .26$

2.3.2 Journal bearings .......................... 29

2.3 .3 Valve train ............................. 29

2.3.4 Parameters affecting friction force ............. 29

2.4 Theoretical models to estimate the lubrication of the pistoncylinder liner assembly ....................... 32

2.4.1 Analytical approach . . . . . . . . . . . . . . . 33

2.4.2 Numerical approach . . . . . . . . . . . . . . . . 39

2.4.3 Commercial models for piston lubrication .......... 43

2.5 Experimental measurement of friction in the piston-cylinder liner assembly........................... 44

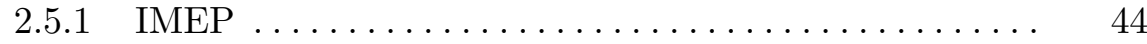

2.5.2 Floating Liner ..................... 45

2.6 Use of low viscosity engine oils to reduce friction losses ..... 52

2.6 .1 HTHS viscosity . . . . . . . . . . . . . . . . 53

2.6.2 Engine oil standards for fuel economy $\ldots \ldots \ldots \ldots \ldots 53$

2.6.3 Research on LVEOs . . . . . . . . . . . . . . . . . . . 54

2.6.3.1 Use of friction modifiers . . . . . . . . . . . 60

2.6.4 LVEOs current and future market share ........ 61

2.7 Discussion .................................. 62

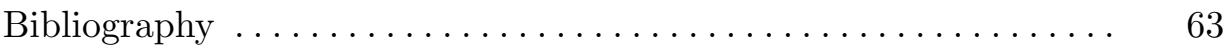

3 Low viscosity engine oils evaluation for fuel economy $\quad 75$

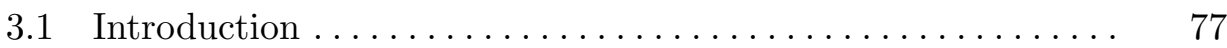

3.2 Experimental setup . . . . . . . . . . . . . . . . 77

3.3 Methodology for the engine bench tests $\ldots \ldots \ldots \ldots \ldots \ldots \quad 79$

3.3 .1 Test points ........................ 80

3.3 .2 Oil formulations $\ldots \ldots \ldots \ldots \ldots \ldots \ldots \ldots \ldots \ldots$ 


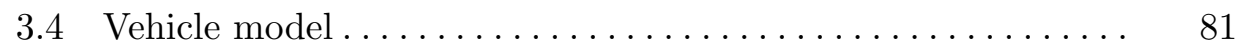

3.4 .1 Driving cycles $\ldots \ldots \ldots \ldots \ldots \ldots \ldots \ldots \ldots \ldots \ldots$

3.5 Results under stationary conditions . . . . . . . . . . . . 89

3.6 Results for real driving conditions $\ldots \ldots \ldots \ldots \ldots \ldots \ldots . . \ldots 3$

3.7 Results' discussion . . . . . . . . . . . . . . . . . . . . . . 96

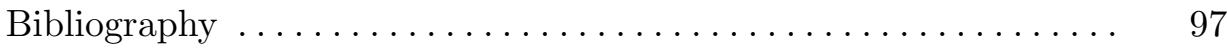

4 Development of a Floating Liner test rig $\quad 99$

4.1 Introduction . . . . . . . . . . . . . . . . . . . . . . . . . 101

4.2 Description of the floating liner measurement principle ..... 101

4.3 Design of the test rig . . . . . . . . . . . . . . . . . . 102

$4.3 .1 \quad$ Engine selection . . . . . . . . . . . . . . . . 103

4.3.2 Force sensors selection .................. 105

4.3.3 Designed and modified components............ 107

4.3.3.1 Considerations for the structural analysis ... 109

4.3.3.2 Upper locking system . . . . . . . . . . . 111

4.3.3.3 Radial support . . . . . . . . . . . . . . . . 114

4.3.3.4 External structure . . . . . . . . . . . . 117

4.3.3.5 Base plate . . . . . . . . . . . . . . 120

4.4 Auxiliary systems . . . . . . . . . . . . . . . . . . . 122

4.4 .1 Lubrication system . . . . . . . . . . . . . . . 123

4.4.2 Transmission system . . . . . . . . . . . . . . . 125

4.4.3 Data acquisition system $\ldots \ldots \ldots \ldots \ldots \ldots \ldots \ldots$

4.5 Friction force measurement analysis............... 128

4.6 Performance assessment of the floating liner test rig . . . . . 130

4.6.1 Tests reproducibility . . . . . . . . . . . . . . . . . 131

4.6 .2 Tests repeatability $\ldots \ldots \ldots \ldots \ldots \ldots \ldots \ldots \ldots \ldots$

4.7 Experimental results . . . . . . . . . . . . . . . . . 133

4.7.1 Engine speed and oil temperature ............ 134

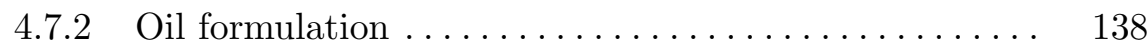


4.7.3 OCR tangential force ...................... 143

4.8 Discussion . . . . . . . . . . . . . . . . . . . . . . 151

4.A Appendix: Kinematics and dynamics of the floating liner engine 153

4.A. 1 Kinematics ............................. 153

4.A. 1.1 Kinematics of the point A ........... 154

4.A. 1.2 Kinematics of the point B ........... 155

4.A. 1.3 Kinematics of the point G ........... 155

4.A. 2 Dynamics ................................ 157

4.A. 2.1 Dynamics of the connecting rod ......... 158

4.A. 2.2 Dynamics of the piston ............... 159

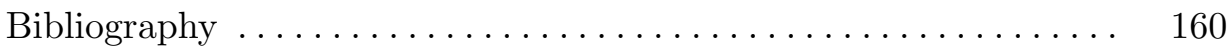

5 Theoretical model to estimate the friction losses in the piston compression ring and cylinder liner interface 163

$5.1 \quad$ Introduction . . . . . . . . . . . . . . . . . . . . . . 165

5.2 One-dimensional model description $\ldots \ldots \ldots \ldots \ldots \ldots \ldots . \quad 165$

5.2.1 Non-dimensional Reynolds equation ............ 168

5.2 .2 Pressure distribution $\ldots \ldots \ldots \ldots \ldots \ldots \ldots \ldots \ldots . \ldots \ldots$

5.2.2.1 Finite differences method ............. 169

5.2 .3 Load carrying capacity $\ldots \ldots \ldots \ldots \ldots \ldots \ldots \ldots . \quad 171$

5.2 .4 Oil flow rate......................... 174

5.2 .5 Lubricant oil starvation .................. 176

5.2 .6 Friction force $\ldots \ldots \ldots \ldots \ldots \ldots \ldots \ldots \ldots \ldots \ldots \ldots \ldots$

$5.2 .7 \quad$ Engine oil rheology . . . . . . . . . . . . . . . . . 181

5.2.8 Piston compression ring and liner surface topography . 181

5.2.8.1 Piston compression ring . . . . . . . . . 182

5.2.8.2 Cylinder liner . . . . . . . . . . . . 183

$5.3 \quad$ Results.................................. 184

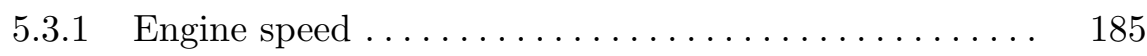

5.3 .2 Oil temperature $\ldots \ldots \ldots \ldots \ldots \ldots \ldots \ldots \ldots \ldots \ldots$

5.3 .3 Oil formulation .......................... 191 
5.3.4 Piston ring radius of curvature . . . . . . . . . . . 193

5.3.5 Piston ring tangential force................ 197

5.4 Discussion . . . . . . . . . . . . . . . . . . . . . . . . . . 198

5.A Verification of the oil pressure distribution on an inclined pad 201

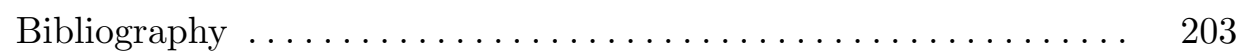

6 Comparison of experimental results obtained in the Floating $\begin{array}{ll}\text { Liner and the lubrication model } & 207\end{array}$

6.1 Introduction . . . . . . . . . . . . . . . . . . . . 209

6.2 Experimental tests in the floating liner for the compression ring 209

6.3 Simulation of the compression ring lubrication ......... 215

6.4 Comparison of results . . . . . . . . . . . . . . . . . . . . 217

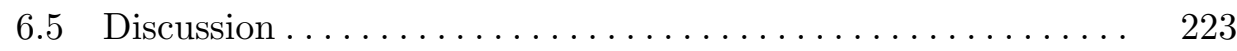

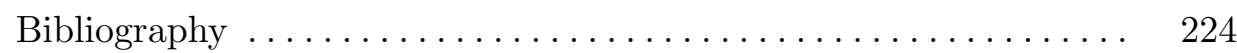

7 Conclusions and future work $\quad 225$

7.1 Introduction ................................ 227

7.2 Conclusions and main contributions $\ldots \ldots \ldots \ldots \ldots \ldots \ldots .227$

7.2.1 LVEOs evaluation for fuel economy............ 227

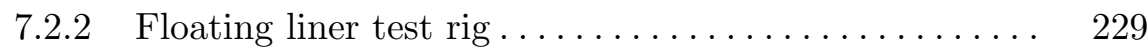

7.2.3 Compression ring simulation model............. 230

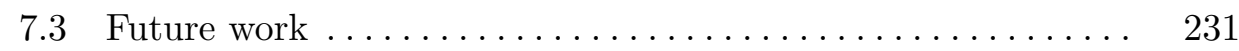

7.3.1 Experimental work .................... 231

7.3 .2 Theoretical work ...................... 232

Appendix: Publications $\quad 235$

$\begin{array}{ll}\text { Bibliography } & 241\end{array}$ 


\section{Index of Figures}

2.1 Stribeck curve as function of the Sommerfeld number $S$ and the oil film parameter $\lambda \ldots \ldots \ldots \ldots \ldots \ldots \ldots \ldots \ldots \ldots, 14$

2.2 Lubrication regimes of the main tribological pairs in ICE . . . 17

2.3 Minimum oil film thickness for the piston compression ring as function of the temperature at the liner ............ 18

2.4 Oil pressure distribution in an ICE journal bearing ....... 19

2.5 Lubricant oil viscosity definition .................. 23

2.6 Oil viscosity variation with temperature, pressure and shear rate 24

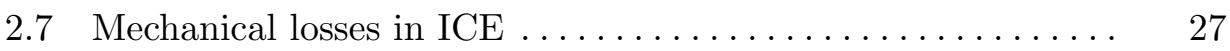

2.8 Radial force balance in a piston ring . . . . . . . . . . . 28

2.9 Abbott-Firestone curve and surface finish parameters ...... 32

2.10 Piston ring lubrication $\ldots \ldots \ldots \ldots \ldots \ldots \ldots \ldots \ldots \ldots \ldots \ldots$

2.11 Piston ring pack lubrication $\ldots \ldots \ldots \ldots \ldots \ldots \ldots \ldots \ldots \ldots \ldots \ldots$

2.12 Floating liner components and forces in the axial direction... 45

2.13 Solutions proposed by different authors to seal the combustion chamber of a floating liner test rig . . . . . . . . . . 47

2.14 LVEOs market share for Light-duty diesel vehicles. ........ 61

2.15 LVEOs market share for Hight-duty diesel vehicles. ........ 62

3.1 Schematic diagram of the experimental setup for the engine

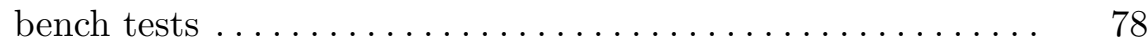

3.2 Diagram of the testing methodology for the engine bench tests 81

3.3 Stationary points for the engine bench tests........... 82

3.4 Vehicle speed profile for the three driving cycles ......... 86 
3.5 Altitude profile for the three driving cycles ........... 86

3.6 Bivariate histogram of the urban cycle in Spain ......... 87

3.7 Bivariate histogram of the urban cycle in the UK ........ 88

3.8 Bivariate histogram of the rural cycle in Spain ......... 88

3.9 Fuel consumption difference between the candidate oil $\mathrm{C} 1$ and

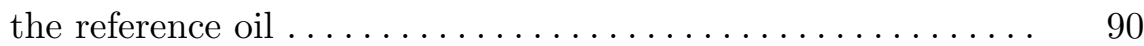

3.10 Fuel consumption difference between the candidate oil C2 and the reference oil $\ldots \ldots \ldots \ldots \ldots \ldots \ldots \ldots \ldots \ldots \ldots$

3.11 Fuel consumption difference between the candidate oil C3 and the reference oil $\ldots \ldots \ldots \ldots \ldots \ldots \ldots \ldots \ldots \ldots \ldots \ldots \ldots \ldots \ldots$

3.12 Fuel consumption difference between the candidate oil $\mathrm{C} 4$ and

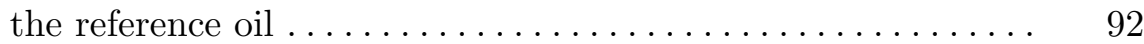

3.13 Fuel consumption difference between the candidate oil C5 and the reference oil ........................... 93

3.14 Accumulated fuel consumption for the urban cycle in Spain and the six oil formulations ........................ 94

3.15 Accumulated fuel consumption for the urban cycle in the UK and the six oil formulations .................. 94

3.16 Accumulated fuel consumption for the rural cycle in Spain and the six oil formulations ........................ 95

4.1 ICE selected for the floating liner test rig . . . . . . . . . . 104

4.2 ICE with sections to be removed and kept for the floating liner assembly .............................. 108

4.3 Mechanical solution to measure the friction force in the floating

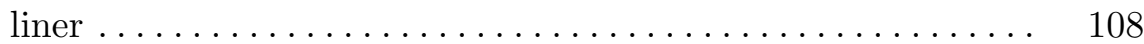

4.4 CAD of the floating liner test rig . . . . . . . . . . . . . 110

4.5 NAFEMS 4-point convergence curve ............... 111

4.6 Upper locking system assembly for the structural analysis ... 112

4.7 Mesh convergence curve for the plug structural study ...... 113

4.8 Upper locking system mesh . . . . . . . . . . . . . . . . . . 114

4.9 Upper locking system Von Mises stress results............ 115

4.10 Radial support components ........................ 116 


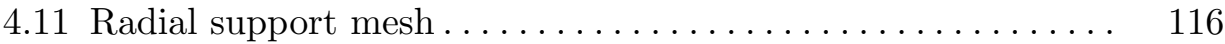

4.12 Radial support Von Mises stress results . . . . . . . . . . 117

4.13 External cylinder mesh ........................ 118

4.14 External cylinder Von Mises stress results .............. 119

4.15 Top plate mesh . . ........................... 120

4.16 Top plate Von Mises stress results . . . . . . . . . . .... 121

4.17 Base plate mesh . . . . . . . . . . . . . . . . . . . . 122

4.18 Von Mises stress results for the base plate with different

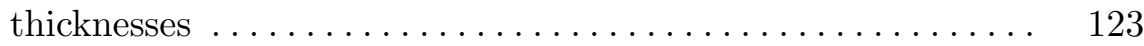

4.19 Von Mises stress results for the base plate ............ 123

4.20 Auxiliary systems of the floating liner test rig . . . . . . . . . 124

4.21 Transmission system assembly $\ldots \ldots \ldots \ldots \ldots \ldots \ldots \ldots . \ldots \ldots$

4.22 Final assembly of the floating liner test rig $\ldots \ldots \ldots \ldots \ldots 127$

4.23 Ring pack characteristics in the floating liner test rig....... 128

4.24 Friction force measured in the floating liner test rig and corresponding piston velocity $\ldots \ldots \ldots \ldots \ldots \ldots \ldots \ldots, 130$

4.25 Reproducibility and repeatability assessment of tests developed

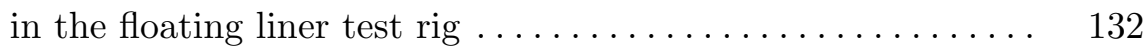

4.26 Properties of the oil formulations used in the parametric tests 135

4.27 Friction force variation with the oil temperature under engine speeds of 100 to $800 \mathrm{rpm} \ldots \ldots \ldots \ldots \ldots \ldots \ldots \ldots \ldots \ldots . \ldots \ldots$

4.28 FMEP variation with the oil temperature and engine speed . . 138

4.29 Location of the thermocouples in the floating liner test rig ... 140

4.30 Oil temperature at the crankcase and liner at constant engine

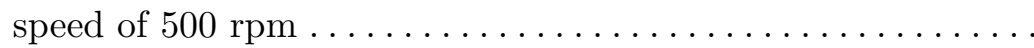

4.31 Oil temperature at the crankcase and liner at constant engine

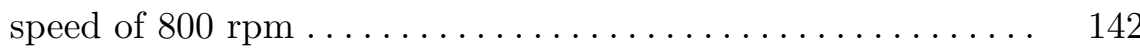

4.32 Friction force variation with different oil formulations and oil temperatures at constant engine speed of $500 \mathrm{rpm}$......... 144

4.33 Friction force variation with different oil formulations and oil temperatures at constant engine speed of $800 \mathrm{rpm}$........ 145

4.34 FMEP variation with the oil formulation and temperature at

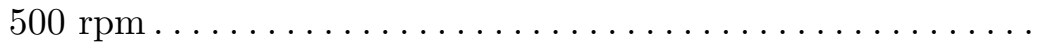


4.35 FMEP variation with the oil formulation and temperature at

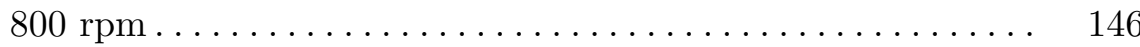

4.36 FMEP variation during the breaking-in of the piston ring packs 147

4.37 Friction force variation with the OCR tangential force at constant oil temperature of $60^{\circ} \mathrm{C} \ldots \ldots \ldots \ldots \ldots \ldots \ldots$

4.38 Stribeck-like curve for the FMEP variation with speed and oil temperature comparing two OCR $F t$ levels ........... 150

4.39 Kinematics of the connecting rod-crank mechanism ........ 154

4.40 Piston position .............................. 156

4.41 Piston speed at 500 and $1500 \mathrm{rpm} \ldots \ldots \ldots \ldots \ldots \ldots \ldots$

4.42 Piston acceleration at 500 and $1500 \mathrm{rpm} \ldots \ldots \ldots \ldots \ldots . \ldots$

4.43 Dynamics of the connecting rod-crank mechanism ........ 158

4.44 Piston lateral force under ambient pressure and compressed conditions for $500 \mathrm{rpm} \ldots \ldots \ldots \ldots \ldots \ldots \ldots \ldots \ldots \ldots$

4.45 Piston lateral force under ambient pressure and compressed conditions for $3000 \mathrm{rpm} \ldots \ldots \ldots \ldots \ldots \ldots \ldots \ldots \ldots \ldots$

5.1 Piston compression ring lubrication $\ldots \ldots \ldots \ldots \ldots \ldots \ldots, 166$

5.2 Parabolic profile of the compression ring used in the lubrication model................................. 167

5.3 First and second derivatives for the finite differences method. 170

$5.4 \quad F_{5 / 2}$ and $F_{2}$ statistical functions and their polynomial fit $\ldots \quad 173$

5.5 Volume flow on the piston ring-liner interface . . . . . . . . 175

5.6 Flow diagram of the piston compression ring lubrication model implementation in mathematical software............ 178

5.7 Piston ring lubrication regions $\ldots \ldots \ldots \ldots \ldots \ldots \ldots \ldots . \ldots \ldots$

5.8 Compression ring surface roughness profile............ 183

5.9 Picture of the cylinder liner surface texture ............ 184

5.10 MOFT variation with engine speed at constant oil temperature

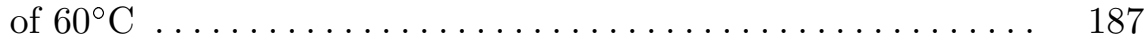

5.11 Friction force variation with engine speed at constant oil

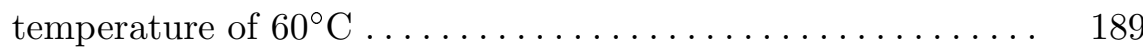


5.12 MOFT variation with oil temperature at constant engine speed

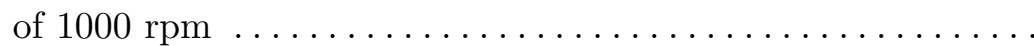

5.13 Friction force variation with oil temperature at constant engine

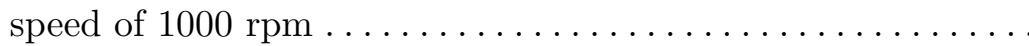

5.14 MOFT variation with the engine oil formulation at constant engine speed of $1500 \mathrm{rpm}$ and temperature of $80^{\circ} \mathrm{C} \ldots \ldots \ldots$

5.15 Friction force variation with the engine oil formulation at constant engine speed of $1500 \mathrm{rpm}$ and temperature of $80^{\circ} \mathrm{C}$.

5.16 Parabolic profile of the compression ring for different values of curvature radius . . . . . . . . . . . . . . . .

5.17 MOFT variation with the piston ring radius of curvature at constant engine speed of $3000 \mathrm{rpm}$ and temperature of $60^{\circ} \mathrm{C}$.

5.18 Friction force variation with the piston ring radius of curvature at constant engine speed of $3000 \mathrm{rpm}$ and temperature of $60^{\circ} \mathrm{C}$

5.19 MOFT variation with the ring tangential force at constant engine speed of $1500 \mathrm{rpm}$ and temperature of $80^{\circ} \mathrm{C} \ldots \ldots$.

5.20 Friction force variation with the ring tangential force at constant engine speed of $1500 \mathrm{rpm}$ and temperature of $80^{\circ} \mathrm{C} \ldots \ldots \ldots$

5.21 Geometry of a slider bearing with inclined pad . . . . . . . . 201

5.22 Oil pressure distribution of an inclined pad slider bearing for

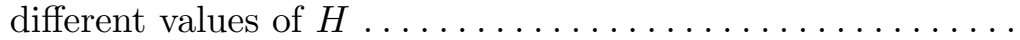

5.23 Load carrying capacity on an inclined pad for different ratios of

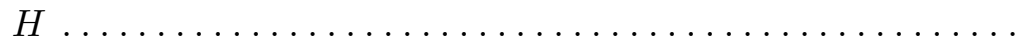

6.1 Measured axial profile of the ring pack

6.2 Oil temperature at the crankcase and liner at constant engine

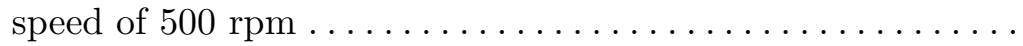

6.3 Oil temperature at the crankcase and liner at constant engine

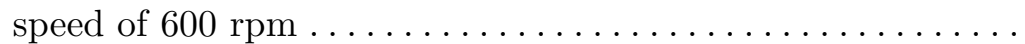

6.4 Oil temperature at the crankcase and liner at constant engine

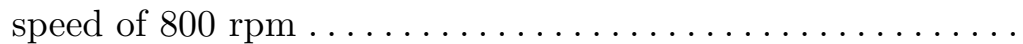

6.5 Instantaneous friction force for the piston configuration A (with compression ring) and $\mathrm{B}$ (without compression ring) at $40^{\circ} \mathrm{C}$.

6.6 Instantaneous friction force for the piston configuration A (with compression ring) and $\mathrm{B}$ (without compression ring) at $60^{\circ} \mathrm{C}$. 
6.7 Instantaneous friction force for the piston configuration A (with compression ring) and $\mathrm{B}$ (without compression ring) at $80^{\circ} \mathrm{C} .216$

6.8 Oil temperature and dynamic viscosity variation at the cylinder liner for one engine cycle $\ldots \ldots \ldots \ldots \ldots \ldots \ldots \ldots \ldots$

6.9 Experimental and theoretical compression ring friction force and estimated MOFT for fully flooded and starved lubrication conditions at $500 \mathrm{rpm} \ldots \ldots \ldots \ldots \ldots \ldots \ldots \ldots \ldots \ldots \ldots$

6.10 Experimental and theoretical compression ring friction force and estimated MOFT for fully flooded and starved lubrication conditions at $600 \mathrm{rpm} \ldots \ldots \ldots \ldots \ldots \ldots \ldots \ldots \ldots \ldots \ldots \ldots$

6.11 Experimental and theoretical compression ring friction force and estimated MOFT for fully flooded and starved lubrication conditions at $800 \mathrm{rpm} \ldots \ldots \ldots \ldots \ldots \ldots \ldots \ldots$

6.12 Experimental and theoretical compression ring friction losses in terms of FMEP . . . . . . . . . . . . . . . . . . . 


\section{Index of Tables}

2.1 Share of friction losses of the main tribological pairs by different

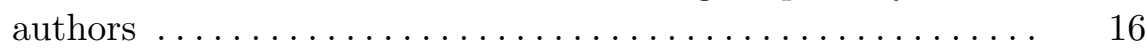

2.2 Viscosity-temperature equations by different authors ....... 25

2.3 SAE J-300 standard chart for engine lubricant oils ........ 55

3.1 Main characteristics of the medium-duty diesel engine...... 78

3.2 Testing points for the oil flushing and conditioning procedures 80

3.3 Main characteristics of the oil formulations for the engine bench tests ................................. 82

3.4 Vehicle main specifications $\ldots \ldots \ldots \ldots \ldots \ldots \ldots \ldots \ldots . \ldots \ldots$

3.5 Results of fuel consumption under real driving conditions. ... 96

4.1 Main specifications of the ICE selected for the floating liner.. 105

4.2 Decision aid matrix to select the piezoelectric force sensor for friction measurement in the floating liner . . . . . . . . 106

4.3 Mechanical properties of structural steel.............. 111

4.4 Specifications of the measuring components of the data acquisition system ....................... 127

4.5 Specifications of the piston-cylinder liner assembly in the

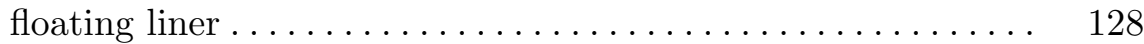

4.6 Test points for the performance assessment of the floating liner

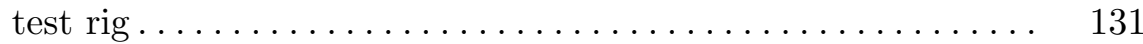

4.7 Results of the reproducibility analysis . . . . . . . . . . . . 132

4.8 Results of the repeatability analysis.............. 133 
4.9 Test points for the engine speed and oil temperature parametric tests ............................. 136

5.1 Data used in the piston compression ring lubrication model . . 168

5.2 Limit for the oil film parameter $(\lambda)$ defined by different authors for purely hydrodynamic lubrication ................ 172

5.3 Surface parameters for the piston compression ring ....... 183

5.4 Surface parameters for the cylinder liner .............. 184

5.5 Compression ring lubrication model simulation parameters .. 185

5.6 Dynamic viscosity of the oil formulations used in the simulations 192

5.7 FMEP variation as function of the oil formulation for fully flooded and starved lubrication conditions .............. 194

5.8 Data used for the inclined pad bearing lubrication model ... . 202

6.1 Characteristics of the piston assembly for the experimental tests

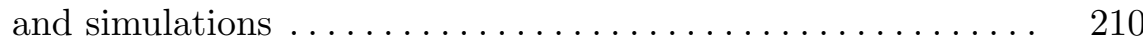





\section{Nomenclature}

\section{Latin}

A

$a$

$b$

$C_{d}$

$C_{r}$

D

$E, F, G$

$f$

$F_{a}$

$F_{b}$

$\widehat{F}_{b}$

$f_{c}$

$F_{G}$

$F_{i}$

$F_{r}$

Ft

$F_{t}$

$F_{z}$

$g$

$h$

$h_{\text {in }}$

$h_{\text {left }}$

$h_{m}$

$h_{\text {min }}=h_{o}$
Ring contact area, vehicle frontal area

Acceleration

Circumferential length of the ring

Drag coefficient

Road friction coefficient

Cylinder liner bore

Constants

Friction force

Aerodynamic drag

Braking force

Maximum braking force

Friction coefficient

Force due to the in-cylinder gas pressure

Vehicle inertia

Rolling resistance

Tangential force

Driving force

Load carrying capacity of the oil per unit width

Gravity

Oil film thickness

Oil film thickness available to the ring

Oil film thickness left for the next stroke

Film thickness at $d p / d x=0$

Minimum oil film thickness 


\begin{tabular}{|c|c|}
\hline$h_{s}$ & Piston ring profile \\
\hline$h^{*}$ & Oil film thickness at the inlet of the ring \\
\hline$I_{c}$ & Connecting rod moment of inertia \\
\hline$i$ & Thermodynamic cycles per engine revolution, nodes in the axial direction \\
\hline$j$ & Crank angle iteration \\
\hline$l$ & Piston ring height \\
\hline$L$ & Connecting rod length \\
\hline$N$ & Engine speed \\
\hline$n$ & Number of nodes \\
\hline$m$ & Iterations, mass \\
\hline$m_{c}$ & Connecting rod mass \\
\hline$p$ & Oil pressure \\
\hline$p_{c}$ & Contact pressure \\
\hline$p_{\text {sat }}$ & Saturation pressure \\
\hline$q_{\text {in }}$ & Oil flow rate available to the ring at a specific crank angle \\
\hline$q_{m}$ & Oil flow rate at $d p / d x=0$ \\
\hline$q_{x}$ & Oil flow rate in the axial direction, $\mathrm{x}$ \\
\hline$R$ & Crank length \\
\hline$R_{f 1}$ & Piston ring radius of curvature \\
\hline$r_{w}$ & Wheel radius \\
\hline$S$ & Sommerfeld number \\
\hline$s$ & Stroke \\
\hline$T_{w}$ & Driving torque \\
\hline$t$ & Time \\
\hline$U$ & Velocity of the moving surface, piston speed \\
\hline$u_{b}$ & Brake actuation \\
\hline$V_{d}$ & Engine displaced volume \\
\hline$v$ & Speed, Vehicle speed \\
\hline$\dot{v}$ & Vehicle acceleration \\
\hline$W$ & Ring tension force \\
\hline$W_{i}$ & Indicated work \\
\hline$W_{e}$ & Effective work \\
\hline$x$ & Axial coordinate of the ring height \\
\hline$x_{1}$ & Oil film inlet position \\
\hline
\end{tabular}




$\begin{array}{ll}x_{1}^{\prime} & \text { Oil film inlet position under starved conditions } \\ x_{2} & \text { Oil film rupture point } \\ x_{3} & \text { Oil film reformation point } \\ x_{4} & \text { Oil film outlet position } \\ x^{*} & \text { Point where pressure }=p_{\text {sat }} \\ y & \text { Circumferential coordinate } \\ \hat{z} & \text { Fraction of radial clearance space filled with oil }\end{array}$

\section{Greek}

$\begin{array}{ll}\alpha & \text { Crank angle } \\ \beta & \text { Connecting rod angle, Road gradient, composite asperity } \\ \beta_{l} & \text { average radius of curvature } \\ \beta_{r} & \text { Asperity average radius of curvature of the liner } \\ & \text { Asperity average radius of curvature of the compression } \\ \epsilon_{P} & \text { ring } \\ \epsilon_{Q} & \text { Tolerance for pressure convergence } \\ \epsilon_{W} & \text { Tolerance for oil flow rate convergence } \\ \zeta & \text { Tolerance for load convergence } \\ \eta & \text { coefficient of asperity shear strength } \\ \eta_{s} & \text { Dynamic viscosity of the oil } \\ \eta_{s l} & \text { Composite asperity density } \\ \eta_{s r} & \text { Asperity density of the liner } \\ \lambda & \text { Asperity density of the compression ring } \\ \nu & \text { Oil film parameter } \\ \rho & \text { Kinematic viscosity } \\ \sigma & \text { Density } \\ \sigma_{l} & \text { Composite surfaces roughness } \\ \sigma_{r} & \text { Asperity height standard deviation of the liner } \\ \tau & \text { Asperity height standard deviation the compression ring } \\ \Omega=\omega & \text { Shear stress } \\ & \text { Angular speed of the engine }\end{array}$

\section{Non-dimensional terms}
$F z_{n}$
Load carrying capacity
$F z_{n}=\frac{F z}{\eta U}\left(\frac{h_{o}}{l}\right)^{2}$
$H$
Oil film thickness
$H_{m}$
Oil film thickness at $d P / d X=0$
$H=h / h_{o}$
$P$
Oil pressure
$H_{m}=h_{m} / h_{o}$
$P=\frac{p h_{o}^{2}}{\eta U l}$ 
$Q_{\text {in }}$

$Q_{m}$

$W_{n}$

X

\section{Acronyms}

API

ACEA

ASTM

BDC

BSFC

CAD

CNG

CR

ECU

EGR

EU

FM

FMEP

HDD

HTHS

ICE

IMEP

LDD

LVEO

MCIA

MOFT

OCR

$\mathrm{PM}$

SAE

STD

TDC
Oil flow rate available to the ring at a specific crank angle

$Q_{\text {in }}=h_{\text {in }} / h_{o}$

Oil flow rate at $d P / d X=0$

$Q_{m} H_{m} / 2$

Ring tension force

Axial coordinate of the ring height
$W_{n}=\frac{W}{\eta U}\left(\frac{h_{o}}{l}\right)^{2}$

$X=x / l$

American Petroleum Institute

European Automobile Manufacturers' Association

American Society of the International Association for Testing and Materials

Bottom Dead Center

Brake Specific Fuel Consumption

Computer-Aided Design

Compressed Natural Gas

Compression ring, Compression Ratio

Electronic Control Unit

Exhaust Gas Recirculation

European Union

Friction Modifier

Friction Mean Effective Pressure

Heavy-duty Diesel

High Temperature High Shear

Internal Combustion Engine

Indicated Mean Effective Pressure / Instantaneous Mean Effective Pressure

Light-duty Diesel

Low Viscosity Engine Oil

Motor de combustión interna alternativo

Minimum Oil Film Thickness

Oil Control Ring

Particulate Matter

Society of Automotive Engineers

Standard deviation

Top Dead Center 


\section{Chapter 1}

\section{Introduction}

Contents

1.1 Background and context.............. 3

1.2 Previous related work ............... 4

1.3 Objectives of the thesis............... 5

1.4 Thesis document structure $\ldots \ldots \ldots \ldots \ldots \ldots \ldots$

Bibliography $\ldots \ldots \ldots \ldots \ldots \ldots \ldots \ldots \ldots \ldots \ldots \ldots \ldots$ 



\subsection{Background and context}

The internal combustion engine (ICE) has been the preferred power source for the road transportation sector for many decades and therefore, its evolution and improvements have been linked to the world power generation needs, but also to the reduction of pollutant emissions as required by international protocols $[1,12,13]$. With the arriving of new power-train solutions to the transport sector, such as electric and hybrid vehicles, the challenge faced by the ICE is even greater in order to mitigate its impact on the climate change. These new technologies however, currently face multiple barriers for their large-scale implementation and adoption, which make the continuous research and improvements of the ICE even more necessary to deal with the emissions reduction targets in the short and medium term [10]. The contribution of the ICE to this objective comes in hand with its efficiency increase, resulting in a lower demand of fuel and associated emissions.

In the ICE, to increase the engine efficiency means to improve the thermodynamic processes and/or reduce the mechanical losses, which consist of friction losses originated in the interface of the engine components under relative motion, pumping losses and the power lost to drive the auxiliary systems. In this regard, one of the approaches to improve the engine efficiency is through tribological alternatives aimed to tackle the friction mechanical losses of the three main assemblies with the greatest friction share; those are the piston assembly, engine bearings and the valve train.

For the piston tribo-pair, which is the subject of study in this Thesis, extensive research work has been developed on the design of the ring pack, including the running profile, tension, materials and coatings $[3,4]$ to find the optimum characteristics for friction reduction. Improvements to the cylinder liner have been mainly dedicated to coatings and surface finishes to increase the lubricant retention and therefore promote better lubrication conditions [5, 11]. On the other hand, one of the main cost-effective solutions to reduce the overall engine friction losses is the use of low viscosity oils (LVEOs) [2, 8], as their implementation does not require any modifications to the engine or the vehicle. Its proven benefit to fuel economy has led to the emergence of new SAE grades of lower HTHS viscosity; this oil property is the one commonly used to reference the potential for fuel consumption reduction [14]. Due to the significant reduction of the oil viscosity, the risk of greater asperity contact increases, specially in the engine components with severe working conditions, like the piston assembly and the valve train. To counteract this drawback of the LVEOs, additives can be added to the formulation, such as friction 
modifiers (FMs) that help to reduce the direct contact between the surfaces when the oil film thickness is not sufficient.

In order to assess the effect of using these tribological solutions to reduce the friction mechanical losses, different test methods can be employed, most of them involving the complete ICE mounted on a test bench. In this regard, one of the main targets of this Thesis was to contribute to the ongoing research on LVEOs combined with the use of FM additives, and to evaluate the contribution to fuel economy from the interaction between the lubricant oil formulation and the driving conditions of the vehicle. The approach to this purpose was a combined methodology of tests in an engine bench and simulations with a vehicle model. The main advantage of this analysis was the possibility of performing tests under real working conditions covering most of the engine map; however, the obtained results consisted of an overall estimation of the friction losses reduction in terms of fuel consumption savings, without the possibility of a detailed analysis of the lubrication performance on a specific assembly or component.

In this way, the next motivation in this Thesis was to be able to perform a more fundamental analysis of the friction losses in the piston assembly and to have the capability to evaluate the effect of different parameters on the friction force phenomenon. To this end, a test rig for the in-situ measurement of the friction force in the piston assembly was developed based on the floating liner method. Furthermore, this experimental approach was completed and supported with theoretical estimations of the piston compression ring lubrication by means of a numerical model based on the finite differences method.

\subsection{Previous related work}

The institute CMT-Motores Térmicos and specifically the Maintenance, Fuels and Lubricants research line has dedicated several years to the research and testing of engine oil formulations for fuel economy, including the analysis of oil performance, degradation and wear. In this regard, the research work developed by Dr. Leonardo Ramirez [9] was focused on the evaluation of new low viscosity oils for the reduction of fuel consumed by the engine; this assessment was primarily developed under real working conditions of a public service bus fleet. In parallel, Dr. Guillermo Miró [7] developed a comprehensive analysis of the lubricant oil performance, its degradation and wear throughout the oil drain interval (ODI) of the same public service bus fleet. For this research work, oil samples were taken from the public service 
buses at pre-defined mileage intervals that allowed to monitor the performance of the oil. Up to this point, research was focused on the contribution of low viscosity oils to the reduction of fuel consumption and associated $\mathrm{CO}_{2}$ emissions through the reduction of the overall friction mechanical losses in the engine. The next step, consisted on focusing the studies on the tribo-pair of greater friction losses share, the piston assembly. This approach would allow to better understand the lubrication performance of this assembly under different working conditions of the engine and as function of changes in the design characteristics of the components. For this purpose, it was acknowledged the need of a dedicated laboratory test rig that allowed to isolate and measure the friction losses in the piston-liner interface. As a first approximation, the Master thesis developed by Eduardo Iniesta [6] consisted on developing a test rig for the friction force measurement based on the instantaneous mean effective pressure (IMEP) method, which gives an indirect measurement of the friction force relying on the accurate measurement or calculation of the other forces involved in the crankshaft mechanism. In order to avoid this issue and improve the friction measurement, it was proposed to develop a floating liner test rig that allowed to isolate the friction force generated in the pistonliner interface. This purpose was one of the main objectives of this thesis, as described in the following Section 1.3.

\subsection{Objectives of the thesis}

The main objective of this research work is the experimental and theoretical study of the friction losses generated in the piston-cylinder liner assembly of internal combustion engines (ICE) along with the evaluation of the potential of different low viscosity oil formulations for friction reduction and fuel economy. This main objective comprises the following specific objectives:

\section{To develop an initial evaluation of the friction losses reduction} potential of different low viscosity engine oil formulations: for this initial assessment parametric tests were developed in a medium-duty diesel engine mounted on a test bench. The varying parameters were the engine speed, load and lubricant oil formulation, which included formulations with different High Temperature High Shear (HTHS) viscosity and molybdenumbased FM additive. The experimental tests were developed under stationary conditions covering regions of the engine map of importance for this study.

To determine the interaction between the engine oil formulation and the vehicle driving conditions on the reduction of fuel consumption: 
In order to analyze this joint effect, a vehicle model was adapted and implemented in mathematical software to evaluate the performance of the oil formulations under the working conditions of real driving cycles of a freight transport vehicle. The input data to the model included the experimental fuel consumption maps obtained in the tests developed for the previous objective.

To design and develop a Floating Liner test rig for the friction force measurement in the piston-cylinder liner assembly: that allows a deeper understanding of the friction phenomenon occurring in this tribo-pair and the effect of different parameters, such as engine working conditions and design characteristics of the components, on the increase or decrease of the friction losses.

To simulate the lubrication performance of the piston compression ring by means of a theoretical model: with the aim of estimating the friction losses generated in the piston ring-liner interface, evaluate the effect that different parameters have on this phenomenon and to complement and better understand the experimental results obtained in the floating liner test rig.

To compare the piston compression ring friction losses obtained experimental and theoretically: this in order to complement and support the two approaches, experimental and simulation, by measuring the instantaneous friction force of the piston compression ring in the floating liner and compare the results with the estimations obtained with the model developed in the previous objective.

\subsection{Thesis document structure}

In order to achieve the objectives proposed for this thesis, as described in the previous Section 1.3, different tasks were performed, which have been gathered in six chapters for a better comprehension of the work developed and for the presentation and analysis of results.

- Chapter 2: This chapter was dedicated to the literature review of the main subjects included in this thesis. It begins with a description of the lubrication in ICEs and the main properties of the lubricant oil related to this thesis. The friction mechanical losses were addressed for the main tribological pairs in the engine, with special attention to the piston-cylinder liner assembly. The following sections were focused on the theoretical models to estimate the lubrication in the piston assembly 
and the experimental test rigs employed to measure the friction losses in this interface. Finally, the last section of this chapter briefly presents the current and future trends of using LVEOs and FMs for the reduction of the friction mechanical losses in the engine and fuel economy.

- Chapter 3: This chapter presents the first approximation developed in this thesis for the evaluation of different low viscosity oil formulations on the reduction of the friction mechanical losses and also the potential of the FM additive to extend this effect to working conditions of the engine where the lubrication conditions promote the asperity contact. The experimental tests were developed in an engine test bench with oils of different SAE grade, HTHS viscosity and some of them with the addition of molybdenum-based FM. These oil formulations were tested under stationary conditions that covered different points of the engine map. The experimental fuel consumption maps were then employed in a vehicle simulation model with the aim of evaluating the performance of these oils under working conditions of real driving cycles of a freight transport vehicle.

- Chapter 4: In this chapter is described the development of a dedicated test rig for the measurement of the instantaneous friction force in the piston-cylinder liner tribo-pair based on the floating liner method. The chapter includes the design of the rig and structural analysis, selection of components and instrumentation, and the auxiliary systems needed for the operation of the test rig. The chapter continues with experimental tests developed in the floating liner, which includes in the first place, an assessment of the reproducibility and repeatability of the tests, followed by parametric tests to study their effect on the friction losses of the piston-liner interface.

- Chapter 5: The lubrication of the piston compression ring was also studied in this thesis by means of a theoretical model based on the finite differences method, it was developed for both fully flooded and starved lubrication conditions. The model approach, its implementation in mathematical software and the required input data are described in this chapter. The last section of this chapter includes some simulation results with different parameters that have an effect on the friction force generated in the piston ring-liner interface, such as the engine speed and oil temperature, and the ring tangential force. A comparison of results between the two lubrication conditions, fully flooded and starved, was also developed for each parametric simulation. 
- Chapter 6: This chapter presents a comparison of experimental and theoretical results on the friction losses of the piston compression ring. Here are included the experimental tests performed in the floating liner to obtain the instantaneous friction force share of this ring, and the corresponding simulations developed with the lubrication model. The inputs to the model included geometric characteristics and surface roughness of the liner and compression ring, as well as the oil viscosity and the woking conditions of the experimental tests. The comparison of results is presented in terms of instantaneous friction force and FMEP for fully flooded and starved lubrication conditions.

- Chapter 7: The last chapter of this Thesis summarizes the main conclusions drawn from this research study and the analysis of results; the main contributions of this work are also presented here. Finally, the last section comprises some proposals for future work both experimental and theoretical.

\section{Bibliography}

[1] C. Calvo Ambel. Roadmap to climate-friendly land freight and buses in Europe. Transport and Environment, 2017.

[2] Cambridge Econometrics. Trucking into a Greener Future: the economic impact of decarbonizing goods vehicles in Europe. European Climate Foundation, 2018.

[3] R. Ferreira, J. Martins, A. Carvalho, L. Sobral, S. Carvalho, and F. Silva. Tribological solutions for engine piston ring surfaces: an overview on the materials and manufacturing. Materials and Manufacturing Processes, 35(5):498-520, 2020. doi:10.1080/10426914.2019.1692352.

[4] A. Frommer, T. Deub, H. Ehnis, and R. Künzel. Design of the tangential force of the oil control ring - oil emission versus friction. MTZ worldwide, 77:48-53, 2016. doi:10.1007/s38313-015-0077-8.

[5] S. Howell-Smith, H. Rahnejat, P. D. King, and D. Dowson. Reducing in-cylinder parasitic losses through surface modification and coating. Proceedings of the Institution of Mechanical Engineers, Part D: Journal of Automobile Engineering, 228(4):391-402, 2014. doi:10.1177/0954407013512626.

[6] E. Iniesta Gómez. Estudio y validación de una metodología de ensayo para el análisis experimental de la fuerza de fricción en el bloque pistón-camisa-segmentos de un MCIA. Master's thesis, Universitat Politècnica de València, 2016.

[7] G. Miró Mezquita. Estudio del comportamiento y de la influencia en el desgaste de los aceites lubricantes de baja viscosidad en MCIA. PhD thesis, Universitat Politècnica de València, 2017.

[8] J. Norris and G. Escher. Heavy duty vehicles technology potential and cost study. Ricardo Energy and Environment, 2017. 
[9] L. A. Ramirez Roa. Contribution to the assessment of the potential of low viscosity engine oils to reduce ICE fuel consumption and $\mathrm{CO}_{2}$ emissions. $\mathrm{PhD}$ thesis, Universitat Politècnica de València, 2016.

[10] R. D. Reitz, H. Ogawa, R. Payri, T. Fansler, S. Kokjohn, and et al. IJER editorial: The future of the internal combustion engine. International Journal of Engine Research, 21(1):3-10, 2020. doi:10.1177/1468087419877990.

[11] M. Söderfjäll, R. Larsson, P. Marklund, and A. Almqvist. Texture-induced effects causing reduction of friction in mixed lubrication for twin land oil control rings. Proceedings of the Institution of Mechanical Engineers, Part J: Journal of Engineering Tribology, 232(2):166-178, 2018. doi:10.1177/1350650117709152.

[12] Transport and Environment Reporting Mechanism (TERM). Progress of EU transport sector towards its environment and climate objectives. European Environment Agency, 2018.

[13] Transport and Environment Reporting Mechanism (TERM). Transport: increasing oil consumption and greenhouse gas emissions hamper EU progress towards environment and climate objectives. European Environment Agency, 2020.

[14] W.. Van Dam, T. Miller, G. M. Parsons, and Y. Takeuchi. The impact of lubricant viscosity and additive chemistry on fuel economy in heavy duty diesel engines. In Powertrains, Fuels 86 Lubricants Meeting. SAE International, aug 2011. doi:10.4271/ 2011-01-2124. 



\section{Chapter 2}

\section{Literature review}

\section{Contents}

$2.1 \quad$ Introduction $\ldots \ldots \ldots \ldots \ldots \ldots \ldots \ldots \ldots \ldots \ldots, 13$

2.2 Lubrication of ICE .................. 13

2.2 .1 Lubrication regimes .................... 14

2.2.1.1 Hydrodynamic lubrication ........... 15

2.2.1.2 Boundary lubrication............... 15

2.2.1.3 Mixed lubrication ................. 15

2.2.1.4 Elastohydrodynamic lubrication ....... 15

2.2.2 Lubrication of the main tribological pairs in ICE . 16

2.2.2.1 Piston-cylinder liner assembly ........ 16

$2.2 .2 .2 \quad$ Journal bearings ................... 18

$2.2 .2 .3 \quad$ Valve train ..................... 19

$2.2 .3 \quad$ Engine oil rheology $\ldots \ldots \ldots \ldots \ldots \ldots \ldots \ldots \ldots$

2.2.3.1 Engine oil composition $\ldots \ldots \ldots \ldots \ldots .20$

$2.2 .3 .2 \quad$ Dynamic viscosity $\ldots \ldots \ldots \ldots \ldots \ldots . \quad 22$

2.2.3.3 Kinematic viscosity .............. 23

$2.2 .3 .4 \quad$ Density ....................... 26

2.3 Friction mechanical losses $\ldots \ldots \ldots \ldots \ldots \ldots \ldots .26$

2.3 .1 Piston-cylinder liner assembly $\ldots \ldots \ldots \ldots \ldots \ldots \quad 26$

$2.3 .2 \quad$ Journal bearings $\ldots \ldots \ldots \ldots \ldots \ldots \ldots \ldots \ldots \ldots \ldots$

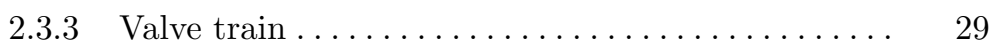

2.3.4 Parameters affecting friction force ........... 29

2.4 Theoretical models to estimate the lubrication of the piston-cylinder liner assembly ......... 32 
2.4 .1 Analytical approach . . . . . . . . . . . 33

2.4 .2 Numerical approach . . . . . . . . . . . . . 39

2.4.3 Commercial models for piston lubrication ....... 43

2.5 Experimental measurement of friction in the piston-cylinder liner assembly ........... 44

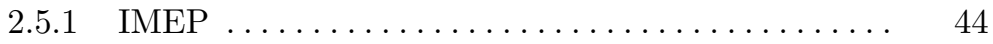

2.5.2 Floating Liner .................. 45

2.6 Use of low viscosity engine oils to reduce friction losses ......................... 52

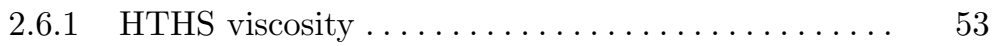

2.6.2 Engine oil standards for fuel economy . . . . . . . 53

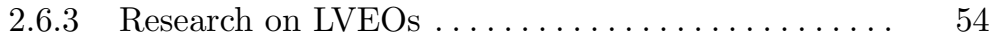

2.6.3.1 Use of friction modifiers ......... 60

2.6.4 LVEOs current and future market share ....... 61

2.7 Discussion ........................ 62

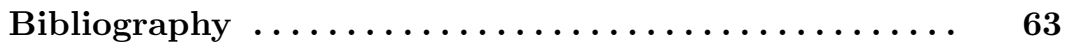




\section{$2.1 \quad$ Introduction}

This chapter was dedicated to the literature review of the main subjects addressed in this Thesis, being a basis for the development of the research work. The lubrication fundamentals and the friction mechanical losses of the ICE are presented here for the main tribo-pairs, that is the piston-cylinder liner, journal bearings and the valve train, with a description of the lubrication regimes and the main properties of the lubricant oil, related to this Thesis. Focusing on the piston-cylinder liner, the theoretical models developed by different authors to estimate the lubrication of this assembly were revised, along with the methods employed for the solution, assumptions and boundary conditions; this analysis was the basis for the development of the lubrication model in this Thesis. On the other hand, a review of the existing test rigs for the experimental study of the friction losses in the piston assembly was also performed; this with the aim of evaluating the best solution for the development of a test rig that could satisfy the research requirement and objectives defined for this Thesis. Finally, the use of LVEOs and FM additives for fuel economy was briefly revised with attention to the current and future trends for their application in the automotive industry.

\section{$2.2 \quad$ Lubrication of ICE}

Basic lubrication theory states that the friction force generated between two surfaces in relative motion is determined by the normal load applied to the contact, and the friction coefficient of the interface. In internal combustion engines, this resistance to motion between the mechanical components is reduced using lubricant oil. In this way, the opposing force is determined by the shear strength of the oil film, instead of the dry friction coefficient, on the hydrodynamic lubrication regime (Section 2.2.1).

The lubrication of internal combustion engines has two main goals, one is the reduction of direct contact between surfaces in reciprocating motion and therefore, to reduce the friction force generated in the interface, and second, protect the engine against wear maintaining or extending its useful life. Alongside, the lubricant oil plays an important role in the engine cooling, protection against corrosion and on the removal of contaminants [80]. 


\subsubsection{Lubrication regimes}

The lubricant oil viscosity and the working conditions of the tribological pairs of internal combustion engines, speed and load, determine the lubrication regime or mode of lubrication that experience each engine component. Due to the variability of these operating conditions, the engine components may experience all the lubrication regimes in one cycle.

The relationship between the friction coefficient and operating conditions of the tribological pairs of ICEs can be depicted using the Stribeck curve, as shown in Figure 2.1. In the lower horizontal axis is represented the Sommerfeld number $S$, which correlates the oil viscosity $\eta$, velocity of motion $U$ and load $W$ applied to the interface, as follows:

$$
S=\frac{\eta U}{W}
$$

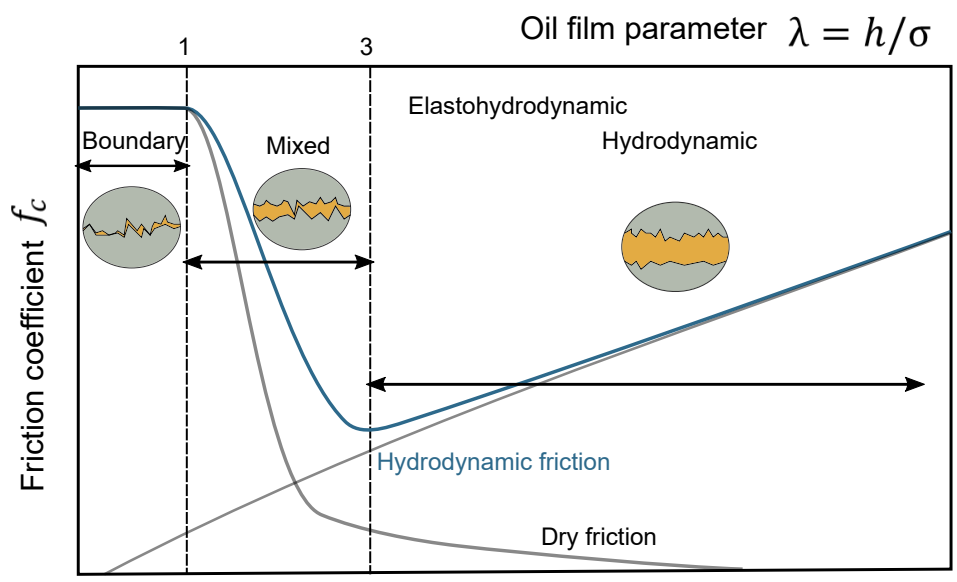

Sommerfeld number $S=\eta U / W$

Figure 2.1. Stribeck curve as function of the Sommerfeld number $S$ and the oil film parameter $\lambda$. Adapted from [89].

Alternatively, the Sommerfeld parameter in the Stribeck curve can be replaced by the oil film parameter $\lambda$, defined as the ratio between the oil film thickness $h$ and the composite roughness of the surfaces $\sigma$, as presented in the upper horizontal axis of Figure 2.1. From the Stribeck curve, four regions can be identified, representative of the lubrication regimes: hydrodynamic, boundary, mixed and elastohydrodynamic. 


\subsubsection{Hydrodynamic lubrication}

In this lubrication regime, the oil film thickness is sufficiently thick to avoid any direct contact between the moving surfaces. It is therefore the ideal regime of lubrication, with a low friction coefficient and protection against wear, as it is significantly reduced. As it can be seen from the Stribeck curve, Figure 2.1, hydrodynamic lubrication is promoted by certain working conditions, such as low load, high relative speed and a lubricant oil of high viscosity. In this regime, the load applied to the surfaces is supported by the opposing load developed by the oil film. Friction force is determined by the viscosity of the oil and the shearing of the oil film [119].

\subsubsection{Boundary lubrication}

In the boundary lubrication regime, asperity contact appears between the surfaces in relative motion. This contact is primarily determined by the characteristics of the surfaces, such as the surface roughness, and properties of the lubricant oil at a molecular level, specifically the film formed by the additives of the oil. The friction coefficient is determined by the materials of the surfaces and the shearing strength of the film formed by the additives, and is independent of the working conditions, relative speed and load [119].

\subsubsection{Mixed lubrication}

This lubrication regime represents the transition between the boundary and hydrodynamic lubrication conditions. That is, surfaces are partially under asperity contact, and the lubricant oil fills some of the space between them. Given that the two modes of lubrication are present, the friction coefficient is determined by both the oil viscosity and the characteristics of the surfaces.

\subsubsection{Elastohydrodynamic lubrication}

This lubrication regime appears mostly in tribological pairs under high loads. The surfaces in relative motion experience local elastic deformations in their materials. This condition of high applied load, promotes an increase in the oil viscosity, creating a fluid film of lubricant [80]. 


\subsubsection{Lubrication of the main tribological pairs in ICE}

As it was mentioned in Section 2.2.1, the working conditions of the moving surfaces determine the characteristics of the contact and therefore, the lubrication regime that they experience. Given the high variability of the working conditions inside a reciprocating internal combustion engine, there are three main tribological pairs with the highest share of friction losses. They are the piston-cylinder assembly, journal bearings and the valve train. Their share to the total friction losses has been widely studied by different authors, some of these results are summarised in the following Table 2.1.

\begin{tabular}{|r|c|c|c|}
\hline Author & Piston-cylinder liner & Journal bearings & Valve train \\
\hline \hline Hoshi [43] & $63 \%$ & $19 \%$ & $8 \%$ \\
Taraza [118] & $40-50 \%$ & $20-30 \%$ & $7-15 \%$ \\
Holmberg [41] & $38-68 \%$ & $20-44 \%$ & $3-34 \%$ \\
James [49] & $40-55 \%$ & $20-30 \%$ & $7-15 \%$ \\
Holmberg [42] & $45-55 \%$ & $20-40 \%$ & $7-17 \%$ \\
\hline
\end{tabular}

Table 2.1. Share of friction losses of the main tribological pairs by different authors.

Given the dependency of the lubrication regime on engine speed, load and oil viscosity, these three tribological pairs can experience any or all the lubrication modes in one cycle. A brief description of the lubrication characteristics of these pairs is presented below. Figure 2.2 shows the lubrication regimes of each tribo-pair in the Stribeck curve as function of their working conditions.

\subsubsection{Piston-cylinder liner assembly}

The piston cylinder assembly is one of the most important subsystems in an internal combustion engine, as it is responsible for converting the energy from the combustion process to mechanical energy, and transmit it to the crankshaft through the connecting rod. In this reciprocating motion, the speed of the piston changes from zero velocity in the dead centers, to maximum velocities in the mid-stroke. The load applied to the conjunction between the piston and the liner is also variable. It depends on the in-cylinder pressure and the tangential force of the piston rings. These variable working conditions 


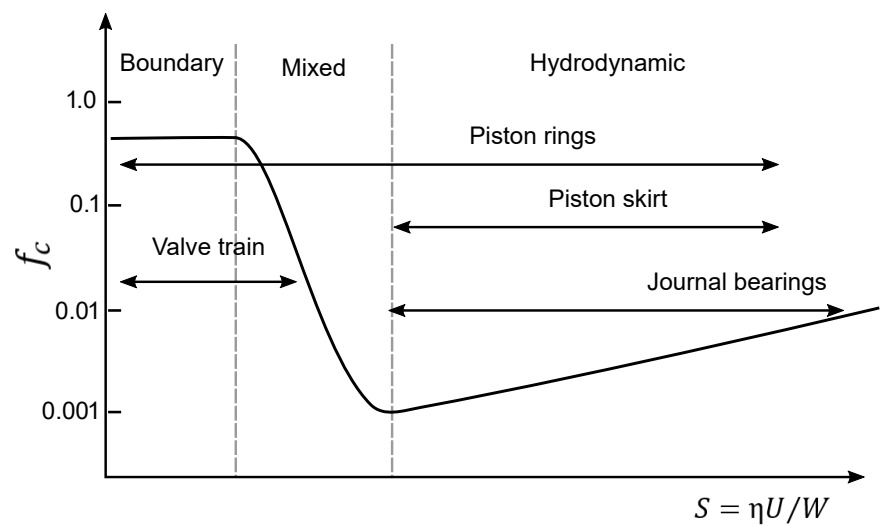

Figure 2.2. Lubrication regimes of the main tribological pairs in ICE. Adapted from [131].

as a whole with the temperature of the conjunction and the oil viscosity, determine the lubrication regimes of the piston-cylinder liner assembly. In this way, boundary and mixed lubrication can be found in the dead centers, where the piston speed does not help to create a fluid oil film, and there is a high in-cylinder pressure due to compression and combustion in the power stroke. Once the piston stars to enter in the mid-stroke region, the entrainment velocity increases, promoting the creation of a fluid oil film with sufficient load carrying capacity, and able to completely separate the surfaces in relative motion. Under these conditions, the piston-cylinder liner assembly can be placed in the hydrodynamic region of the Stribeck curve. These variations in the lubrication regime that experiences the piston assembly in one engine cycle, can also be observed in the minimum oil film thickness (MOFT) developed between the piston (rings and skirt) and the liner wall. Figure 2.3 shows the MOFT variation of the compression ring as function of the liner temperature in the research work by Rahmani et al. [88]; in this figure, 0 crank angle degree position references the TDC in the transition between the compression and power stroke. These results were obtained under combustion conditions, $1500 \mathrm{rpm}$ and for three levels of temperature at the liner; the figure shows the limits for mixed and boundary lubrication regimes, affecting mostly the dead centers and their vicinity; while hydrodynamic lubrication prevails at the mid-stroke regions. 


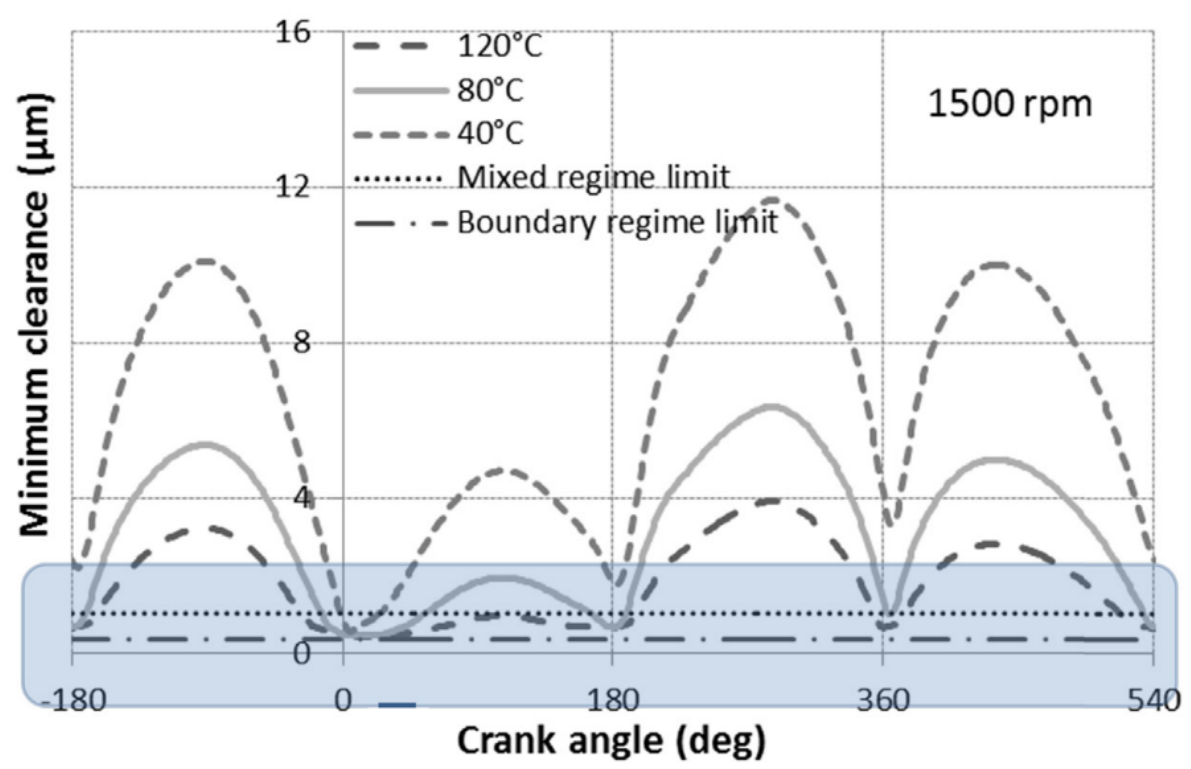

Figure 2.3. Minimum oil film thickness for the piston compression ring as function of the temperature at the liner. Adapted from [88].

\subsubsection{Journal bearings}

The journal bearings in ICEs comprise the main crankshaft bearings and the connecting rod bearings in the interface with the piston pin and the interface with the crankshaft. During normal engine operation, the journal bearings are capable of withstanding the high loads from the crankshaft thanks to the load carrying capacity of the fluid film of lubricant oil that is developed between the surfaces in relative motion [28, 113]. Its operation is therefore characterised by hydrodynamic lubrication with low friction losses. During engine startup and shutdown however, lubrication modes can be mixed and even boundary, due to the low relative velocity. Once the velocity starts to increase, the rotating shaft separates from the outer bearing, asperity contact stops, creating an annulus for the oil to flow though it and therefore, promoting a hydrodynamic lubrication regime [24]. Typical minimum oil film thickness found at this regime and during the power stroke is of about $2 \mu \mathrm{m}[24,80]$, although this value highly depends on the design of the bearing. Given that friction losses generated in the bearings depend on the sharing of the lubricant oil film, operating the journal bearing in the transition zone between the hydrodynamic and mixed lubrication regime, where the friction coefficient is at its minimum value, would help to diminish the viscous friction. This 
condition however, comes with the risk of asperity contact appearance and wear [99]. In ICEs, journal bearings experience oil leakage during operation, therefore they normally have a drilled hole to supply oil from the lubrication system to the bearing annulus. This oil supply can also help to remove wear particles and contaminants from the bearing.

Figure 2.4 shows a schematic diagram of a journal bearing and the oil pressure distribution. This pressure is function of the load, velocity, oil viscosity, diameter of the shaft and clearance between the shaft and the bearing [28].

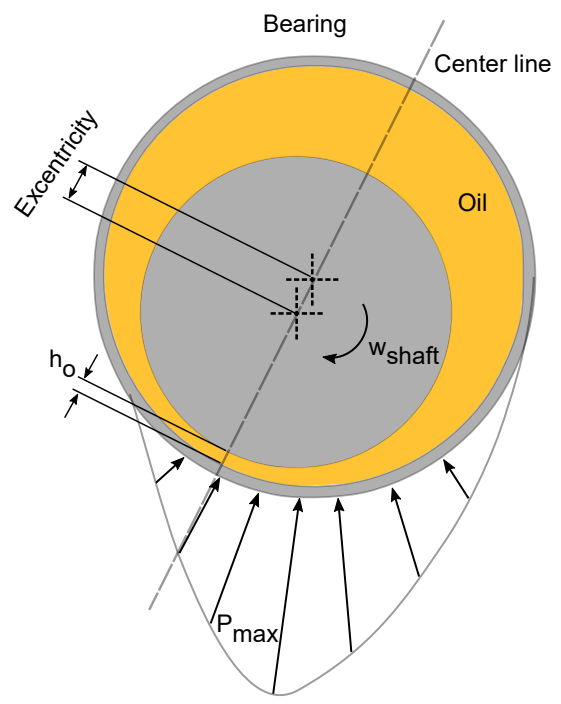

Figure 2.4. Oil pressure distribution in an ICE journal bearing. Adapted from [6].

\subsubsection{Valve train}

This tribological pair presents high variability in the relative speed of its components and experiences high loads during all the engine working cycles. The mass of the components and the velocity of the interfaces help to increase the elastic stress and inertia, which in turn increases friction. All these working conditions promote boundary/mixed lubrication regime, where the cam-follower conjuntion has the highest share of friction in this tribopair due to its non-conformal contact, the high applied loads and the small contact area $[40,80]$. Furthermore, it has been found that elastohydrodynamic 
lubrication is also present in the valve train. With the high load on the cam nose, and the decrease of the relative velocity in the transition from the flank of the cam to its nose, the oil film thickness is reduced and it is sustained only by the squeeze effect. The contact experiences high peak pressures and elastic deformation $[55,89]$.

\subsubsection{Engine oil rheology}

Lubricant oil in an ICE must serve to multiple purposes, including proper lubrication of all the mechanical components, heat transfer and cooling, and removal of contaminants. Furthermore, engine oil must be capable of withstanding the high loads of the contacts without breaking down and maintaining or extending its oil drain interval (ODI). The high variation in temperatures inside the engine is another factor that the oil formulation must take into account, in order to provide proper lubrication during the engine cold start and during normal operation [87]. The basic composition of an engine oil includes a base oil, hydrocarbon components obtained from crude oil or synthetic compounds, and different additives to enhance its performance. This composition however, has been evolving to comply with the requirements of modern engines' operation, such as higher temperatures and loads, along with environmental requirements such as the reduction of fuel consumption and exhaust emissions, and the possibility to extend the ODI.

\subsubsection{Engine oil composition}

Engine oils are formed by two components, the base stock and the additives package. Base stocks can be mineral, a blend of mineral and synthetic oil, or purely synthetic, along with another group of synthetic fluids, such as polyalphaolefins (PAOs) or diesters, mainly employed for the formulation of multigrade oils. Base stocks are classified in five groups, according to their chemical composition, by the American Petroleum Institute (API). In this way, base oil Groups I, II and III are referred to as mineral oils, as they are manufactured from crude oil in refineries. Group I oils are produced through solvent refining technologies, which makes them the cheapest base in the market. Group II and III are manufactured through hydroprocessing; the last one subjected to higher pressures and temperatures to make it purer. Group IV gathers PAO base stocks, which have been manufactured through specific chemical processes. Finally, Group V includes all base stocks not classified in the previous groups, such as esters and silicone base oils [45]. As well as the base oil, described previously, the engine oil requires chemical 
additives for it to work effectively. Although the addition of additives depends on the oil application, heavy-duty or light-duty vehicles, some of the most important and common additives are the following:

- Detergents: this additive is mainly used to protect the metallic components of the engine by neutralising the acidity of the combustion byproducts. Among the functions of the detergent additive, is to suspend and disperse the contaminants that reach the oil but cannot be dissolved in it. These contaminants can be soot, sludge and oxidation residues. Detergents also help to control rust, corrosion and to neutralize acid products from the oil's own degradation process [95].

- Dispersants: the purpose of this additive is fairly similar to the detergent additive; it helps to disperse contaminants from the engine and reduce the rate at which they deposit in the metallic surfaces, allowing the oil to flow freely and keep the engine clean [85]. In modern engine oil formulations, dispersant additives account for about $50 \%$ of the total additives in the oil [95].

- Antiwear: this additive is used in lubricant oils' formulation to reduce wear, friction, scuffing and scoring when the lubrication regime of the surfaces is boundary. When working conditions promote the appearance of boundary lubrication, surfaces start to experience asperity contact, friction and possibly welding. As the surfaces keep moving, this welding of the asperities is broken forming new asperities and wear particles. To reduce this phenomenon, lubricant oil formulations employ zinccontaining additives, such as zinc dialkyl dithiophosphate (ZDDP). This material forms a tribofilm on the metal surfaces, in such a way that the contact during boundary lubrication occurs between the molecules of this additive. Increases in temperature and pressure in the asperity contacts help to maintain these tribofilms and to regenerate them if they are damaged. Furthermore, ZDDP is also used in engine oils as antioxidant additive [46].

- Antioxidant: oxidation of the engine oil is a consequence of its contact with oxygen at high temperatures and its normal degradation with use. This phenomenon is worsen with the presence of wear materials and acid components in the oil, that increase the degradation rate of the oil. The main results of oil oxidation are an increase of the viscosity and the corrosive effect of the lubricant due to the increase of its acidification [80]. Additives employed to inhibit oxidation can be, for 
example, zinc dithiophosphates; they react with the metal surfaces of the engine forming a protective coating to prevent oxidation [85].

- Viscosity index improver: this additive added to the engine oil formulation is used to reduce the viscosity decrease with temperature. It is formed by long-chain hydrocarbon polymers that gather in tight balls when the temperature is low, and separate when the temperature increases, causing a rise in the oil viscosity [104].

- Friction modifier: There exist different types of FMs, some of them are organic friction modifiers (OFMs), functionalised polymers, soluble organo-molybdenum additives and dispersed nanoparticles. In modern engine oils, OFMs are highly employed during boundary lubrication. Its working principle consists in creating an adsorbed molecular film on the metallic surfaces of the engine components. The repulsive forces originated between those films help to reduce and limit the direct contact between the surfaces in relative motion, and therefore to reduce friction. Although direct contact may occur along with wear, it is significantly less severe than if the surfaces were unprotected [46]. On the other hand, organo-molybdenum compounds, initially developed as an antiwar additive, have proven to be effective in reducing boundary friction, and are also frequently used in the automotive industry [112].

\subsubsection{Dynamic viscosity}

Viscosity is one of the most important properties of a lubricant oil. It can be defined as the resistance of the fluid to shearing flow due to the internal friction of its own molecules. This property can be explained taking two plane surfaces with the fluid between them, as shown in Figure 2.5. If one of the surfaces move with velocity $U$ relative to the other surface, the velocity gradient can be defined as $d U / d y$, which is constant and uniform between the surfaces:

$$
\frac{d U}{d y}=\frac{U}{h}
$$

Where $h$ is the separation between the surfaces or the film thickness of the fluid. The shear stress $\tau$ applied to the surfaces is then defined by the viscosity of the fluid $\eta$ and the velocity gradient as follows:

$$
\tau=\eta \frac{d U}{d y}
$$



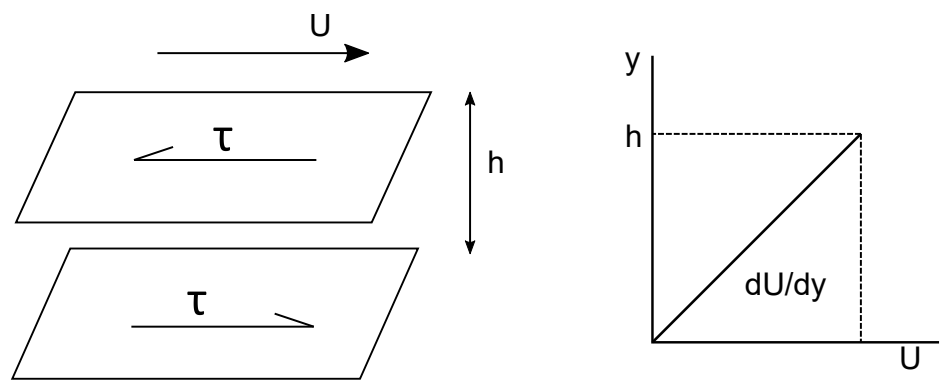

Figure 2.5. Lubricant oil viscosity definition. Adapted from [46].

\subsubsection{Kinematic viscosity}

This oil property is more frequently measured in laboratory under ambient pressure conditions and without external shear forces. It is defined as the ratio between the oil dynamic viscosity and its density, measured at the same pressure and temperature conditions, as shown in Equation 2.4:

$$
\nu=\frac{\eta}{\rho}
$$

Lubricant oil viscosity is not a property with a constant value, instead, it varies as function of different parameters, being the most important, the temperature, pressure and shear stress. This variation of the oil viscosity is described below, and is presented in Figure 2.6; the graphs in this figure were extracted from the work by Sander et al. [100] were the oil viscosity variation with temperature, pressure and shear rate were investigated for a SAE 0W20 engine oil though experimental measurements and estimated theoretically.

Viscosity variation with temperature: Oil viscosity is highly dependent of the working temperature of the oil; as the temperature increases, the viscosity decreases rapidly. Multiple equations have been formulated to estimate the viscosity variation with temperature, some of them rely on experimental measurements, while others are the result of theoretical models. The ASTM chart by instance, found in the standard ASTM D341 [4], relies completely on experimental measurements and was derived from Walther's equation 2.5 [113].

$$
(\eta+a)=b d^{1 / T^{c}}
$$



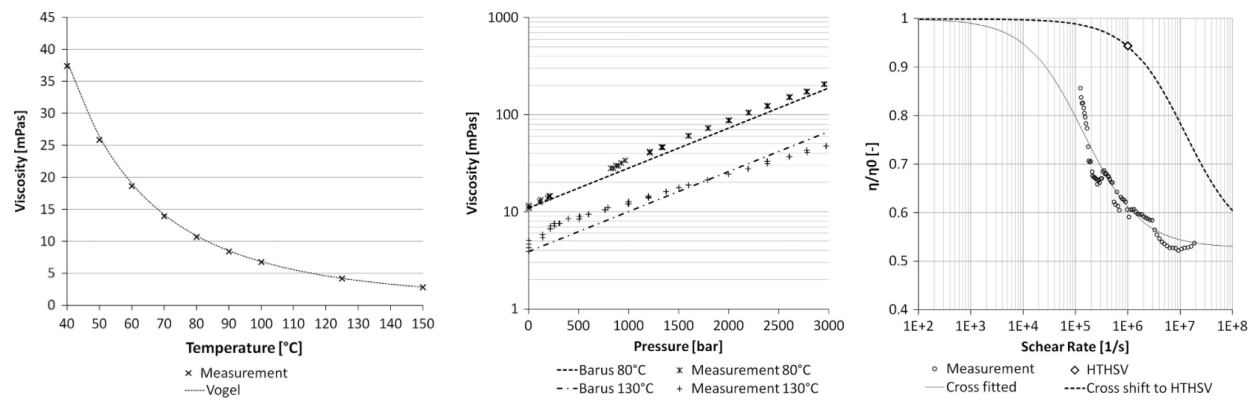

Figure 2.6. Oil viscosity variation with temperature (left), pressure (center) and shear rate (right) for a SAE 0W20 engine oil ( $\eta_{o}$ is the oil viscosity at zero shear rate). ${ }^{*}$ Adapted from [100].

Below, in Table 2.2 are summarized some of the most frequently used expressions to estimate the oil viscosity $[8,89]$.

Viscosity variation with pressure: variation of this oil property with pressure under isothermal conditions was determined by Barus with the following expression [89]:

$$
\eta=\eta_{o} e^{(\alpha p)}
$$

$\eta$ is the gauge pressure, $\eta_{o}$ is the oil viscosity at pressure $p=0$ and $\alpha$ is the pressure-viscosity coefficient dependent of the oil. Equation 2.6 however, is inadequate for high pressure applications. The product $(\alpha p)$ can be considered equal to zero, yielding an iso-viscous behaviour of the oil, where the pressure does not affect the viscosity of the fluid. Later on, Roelands [93] and Houpert [44] developed a more accurate expression for the viscosity-pressure relation, including the effect of both pressure and temperature:

$$
\begin{gathered}
\eta=\eta_{o} e^{\left(\alpha^{*} p\right)} \\
\alpha^{*}=\frac{1}{p}\left[\ln \left(\eta_{o}\right)+9.67\right]\left\{-1+\left(\frac{\Theta-138}{\Theta_{o}-138}\right)^{-S_{o}}\left(1+5.1 x 10^{-9} p\right)^{Z}\right\} \\
Z=\frac{\alpha_{o}}{5.1 \times 10^{-9}\left[\ln \left(\eta_{o}\right)+9.67\right]} \quad S_{o}=\frac{\beta_{o}\left(\Theta_{o}-138\right)}{\ln \left(\eta_{o}\right)+9.67}
\end{gathered}
$$




\begin{tabular}{|c|c|c|c|}
\hline Author & Equation & Variable/constant & Comments \\
\hline \multirow{3}{*}{ Reynolds } & \multirow{3}{*}{$\eta=\eta_{o} e^{(-\beta \triangle \theta)}$} & $\begin{array}{l}\eta_{o}=\text { known vis- } \\
\text { cosity }\end{array}$ & \multirow{3}{*}{$\begin{array}{l}\text { Applicable to a low } \\
\text { temperature range }\end{array}$} \\
\hline & & $\begin{array}{l}\beta=\text { viscosity- } \\
\text { temperature } \\
\text { coefficient }\end{array}$ & \\
\hline & & $\begin{array}{l}\triangle \theta=\text { tempera- } \\
\text { ture rise }\end{array}$ & \\
\hline \multirow{2}{*}{ Vogel } & \multirow{2}{*}{$\eta=a e^{\left(\frac{b}{\Theta-c}\right)}$} & $\begin{array}{l}a, b, c=\text { data from } \\
\text { the oil manufac- } \\
\text { turer or obtained } \\
\text { experimentally }\end{array}$ & \multirow{2}{*}{$\begin{array}{l}\text { Applicable to a } \\
\text { wider range of } \\
\text { temperatures. Three } \\
\text { sets of data } \\
\text { (temperature, } \\
\text { viscosity) are } \\
\text { necessary to obtain } \\
a, b, c\end{array}$} \\
\hline & & $\begin{array}{l}\Theta=\text { required } \\
\text { absolute } \\
\text { temperature } \\
\text { in Kelvin }\end{array}$ & \\
\hline \multirow[b]{2}{*}{ ASTM chart } & \multirow{2}{*}{$\begin{array}{l}\log \log (\eta+0.6)= \\
a^{\prime}-\operatorname{clog}(T)\end{array}$} & $a^{\prime}, c=$ constants & \multirow{2}{*}{$\begin{array}{l}\text { Viscosity at two } \\
\text { temperatures must } \\
\text { be known }\end{array}$} \\
\hline & & $\begin{array}{l}T=\text { supplied tem- } \\
\text { perature }\end{array}$ & \\
\hline
\end{tabular}

Table 2.2. Viscosity-temperature equations by different authors.

Viscosity variation with shear stress: Engine lubricant oils can be considered as Newtonian fluids if just the base stock is considered; its viscosity does not change with shear forces applied to its layers. However, when additives are added to the oil formulation, such as viscosity index improvers (VII), the lubricant oil has a non-Newtonian performance, varying its viscosity with shear rate. In this way, engine lubricant oils experience a shear thinning effect, decreasing its viscosity with the increase of the shear rate [50]. An overall description of this behaviour has been plotted in Figure 2.6, where an abrupt decrease of the oil viscosity can be observed once the shear rate exceeds $1 \times 10^{5} s^{-1}$. Depending on the working conditions of the lubricant, such as temperature and its molecular structure, the shear rate applied may permanently change the oil viscosity, due to the rupture of the oil molecules. The response of a lubricant to permanent viscosity loss due to shearing can be 
determined by the shear stability index and measured following the standard test method ASTM D6278 [5].

\subsubsection{Density}

Engine oil density is a property that varies with pressure, being this variation more significant under high pressure conditions. Its application is therefore significant for elastohydrodynamic lubrication conditions. An expression showing this variation was developed by Dowson et al. [19], as show in Equation 2.9. Later on, Cui et al. [11] added the temperature effect over density to the previously developed equation (Equation 2.10).

$$
\begin{gathered}
\rho=\rho_{o}\left[1+\frac{0.6 \times 10^{-9} p}{1+1.7 \times 10^{-9} p}\right] \\
\rho=\rho_{o}\left[1+\frac{0.6 \times 10^{-9} p}{1+1.7 x 10^{-9} p}\right]\left[1-0.65 \times 10^{-3}\left(T-T_{0}\right)\right]
\end{gathered}
$$

\subsection{Friction mechanical losses}

In internal combustion engines, the indicated work $W_{i}$ developed in the combustion chamber during combustion, is not completely available at the crankshaft as useful work. It is distributed in mechanical processes inside the engine, resulting in a smaller useful work at the shaft, $W_{e}$. These mechanical processes are known as mechanical losses, and can be classified in friction losses, pumping losses (net work transfer between the piston and the incylinder gases during the intake stroke, to draw the air mixture into the combustion chamber, and the exhaust stroke, to take the burned gases out of the combustion chamber [40]) and auxiliaries drive losses. This distribution of the $W_{i}$ can be seen in Figure 2.7.

Friction mechanical losses are inherent to the working conditions of ICEs, as they comprise multiple tribological pairs with sliding and/or rotary motions. These friction losses can be further distributed in the three main tribo-pairs previously mentioned in Section 2.2.2, and described below.

\subsubsection{Piston-cylinder liner assembly}

The main function of the piston-cylinder liner assembly is the effective conversion of the chemical energy delivered by the fuel during combustion to 


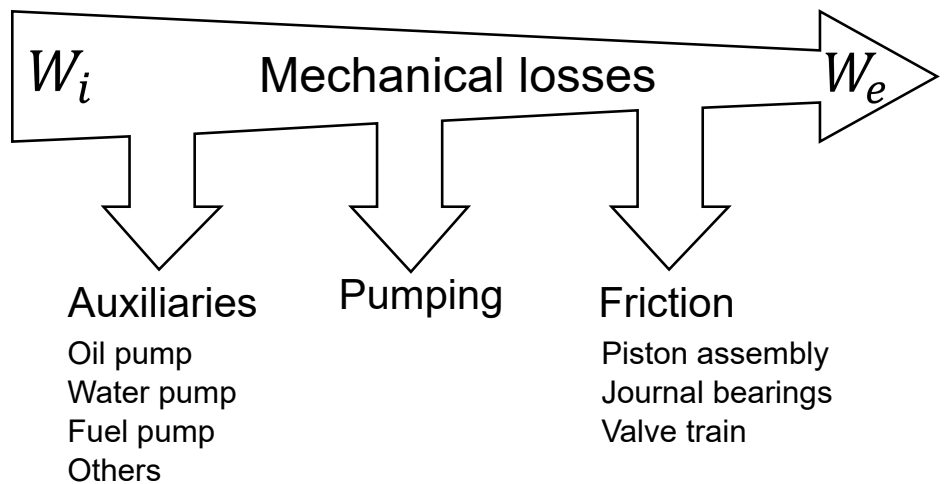

Figure 2.7. Mechanical losses in ICE.

useful mechanical energy at the crankshaft [89]. Its working conditions during normal engine operation and the interaction of its components, make this pair the one with the biggest share of friction. Lubrication of this assembly can experience all the lubrication regimes along the cycle: hydrodynamic at the mid-stroke regions favored by the high relative speed helping to create a fluid oil film. This lubricant film is capable of separating completely the surfaces of the piston and the liner, and to avoid any asperity contact. Under this lubrication mode, viscous friction appears determined solely by the oil viscosity. As the piston reaches the vicinity of the dead centers, and the piston speed reaches zero velocity, mixed and boundary lubrication regimes appear. Friction losses in the piston-cylinder liner assembly are determined by the dynamics of the system, including piston rings twist, inertia, gas and oil flows, and design parameters, such as materials and surface finish. Contribution to the friction force in this assembly can be separated in the piston ring pack and the skirt.

Piston ring pack: The main function of the piston ring pack is to seal the combustion chamber, restricting the flow of combustion gases to the engine crankcase, as well as restricting the flow of lubricant oil to the combustion chamber. ICEs normally comprise three rings: the compression ring, the scraper ring and the oil control ring. In this way, the compression ring primary function is to seal the combustion chamber thanks to the pressure exerted by the gases on its back face and its own tension force. The scraper ring helps to scrap the oil from the cylinder liner in addition to the function of sealing. Finally, the oil control ring distributes the oil, sprayed or thrown up from the 
crankcase, to the rest of the rings for them to have the appropiate amount of oil. Its appropiate operation is therefore very important for oil consumption and the overall lubrication of the ring pack. Piston rings also help to maintain the piston in the radial plane, reducing its lateral motion and slap noise, specially during cold starts [10].

In addition to the factors mentioned above, friction is determined by the forces applied to the ring pack-liner conjunction. The balance of these forces is shown in Figure 2.8 for a single piston ring. $F t$ is the ring tension force and $F_{G}$ is the force exerted by the in-cylinder gas in the back of the piston ring. The load applied to the ring is then supported by the force developed by the lubricant oil film $F_{z}$ and the force due to the asperity contact $F_{a s p} . F_{g a s}$ is the force exerted by the in-cylinder gas to the ring where it is not wetted by the lubricant oil.

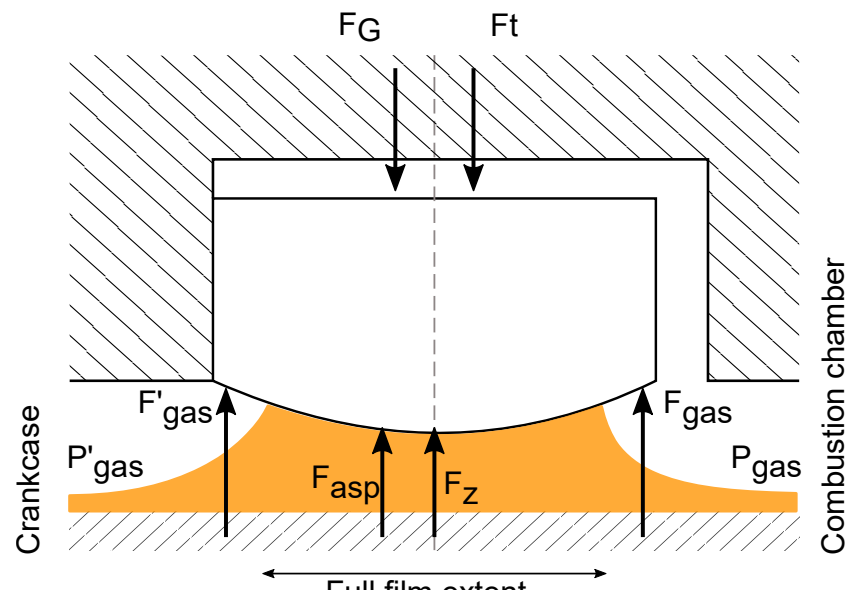

Full film extent

Figure 2.8. Radial force balance in a piston ring. $F_{\text {gas }}, P_{\text {gas }}$ at side of the combustion chamber and $F_{g a s}^{\prime}, P_{g a s}^{\prime}$ at the crankcase side.

Piston skirt: lubrication of the piston skirt is normally hydrodynamic during most of the engine cycle. Friction generated with the cylinder liner is mainly determined by the clearance of the conjunction, the skirt design and the piston secondary motion and slap. Some studies however, have analyzed the skirt lubrication as elastohydrodynamic, due to the thermal expansion of the skirt during engine operation. resulting in an interference fit with the liner $[20,66$, $74,144]$. 


\subsubsection{Journal bearings}

Journal bearings are the second friction losses source of ICEs. Friction losses in this tribological pair are mostly dependent on the viscosity of the engine oil; given that bearings are designed to work under hydrodynamic lubrication during normal engine operation, friction losses due to asperity contact with the crankshaft may be present during the engine start up. The material used for the bearings also has an effect on the friction losses, specifically when the lubrication regime is mixed or boundary; this material should have a high wear resistance and help to reduce the energy loss [33].

\subsubsection{Valve train}

Valve train systems in ICEs comprise multiple mechanical components, such as the cam, tappet, pushrod, rocker arm and the valve, which interact with each other under all the lubrication regimes. Friction losses in this tribo-pair are mostly concentrated in the cam-tappet conjunction due to the transient nature of the applied load. In addition to the load effect, the dynamics and kinematics of the mechanism and design parameters of the components, such as materials and coatings, also determine the friction losses $[118,123,124]$.

\subsubsection{Parameters affecting friction force}

In this section, the most important factors having an effect on the overall friction losses of internal combustion engines are going to be addressed, however, special attention is given to their effect over friction in the pistoncylinder liner assembly.

Engine speed: friction losses increase significantly with the increase of engine speed, decreasing in turn the engine mechanical efficiency. In the pistoncylinder liner assembly, the relative speed of the piston helps to create a fluid film of lubricant between the contacting surfaces and therefore, to achieve a hydrodynamic lubrication regime. With the increase of this speed however, the working conditions of the assembly may move to the right side of the Stribeck curve (Figure 2.1), increasing the friction coefficient and thus the friction losses.

Load: the increase of this parameter in the engine operation is directly related with the appearance of mixed and boundary lubrication and therefore, with the increase of friction losses. In the piston-liner conjunction, increase of load 
is caused by the in-cylinder pressure and the force that it exerts on the back of the ring, specially during the power stroke with the combustion pressure. On the other hand, higher loads and friction on the interfaces of the engine, promote an increase of the temperature and therefore, a decrease of the oil viscosity. If the engine oil is thick enough to maintain a lubricant film between the surfaces, this viscosity decrease could result in a reduction of the friction losses.

Working temperature: the working temperature of the engine has a direct relationship with the mechanical friction losses, and specially during the cold start of the engine, when the lubricant oil has not reached all the mechanical components and the oil viscosity is high.

Piston ring tension: reducing the normal force exerted by the piston rings on the liner wall helps to reduce the friction force generated, however, if this tension force is not sufficient to seal the combustion chamber, oil leakage could occur, as well as the increase of pollutant emissions.

Piston-liner clearance: Increasing the clearance space between the liner and the piston has been found to decrease the friction force, due to the reduction of the shearing stress applied to the oil film $[15,48]$. Nonetheless, this clearance could also result in an increase of friction, due to the high impact forces that the piston could exert on the liner. Reduction of the clearance on the other hand, can also have a negative impact on friction, given that boundary lubrication may begin to appear [65, 67].

Engine size: reduction of the size of the engine, known as engine downsizing, has a direct repercussion on friction losses, as there are smaller contacting surfaces. This also applies to the piston rings, studies have been developed on reducing their mass and axial length $[69,145]$, as a way of reducing the generated friction.

Oil formulation: tribological characteristics of the engine oil formulation play a key role in the lubrication condition of the engine; specifically the viscosity determines the lubrication regime of each mechanical component and at every point of the working cycle. Friction losses are therefore determined by the viscous friction during the hydrodynamic lubrication regime, while the characteristics of the surfaces determine the friction during boundary lubrication. To reduce these friction losses, the reduction of the oil viscosity appears as a potential alternative. Multiple studies have been developed in this regard showing significant reduction of fuel consumption and pollutant emissions [36, 61, 63, 64, 83, 111, 129, 130]. In addition to the oil viscosity, additives can also be added to the formulation, known as FMs, with the purpose of reducing friction when the oil film is not able to completely separate 
the surfaces. The use of low viscosity oil formulations and FM will be further discussed in Section 2.6

Design parameters: including components material, surface finish and coatings.

- Design: In piston rings, the overall design of the component plays a critical role in the lubrication and friction characteristics of the interface. The design of the compression ring, by instance, has seen a reduction of its axial length through the years, in order to reduce the contact area with the cylinder liner, and therefore, reduce friction losses.

- Ring running profile: the curvature of the compression ring profile has a significant effect on its tribological performance along the engine cycle; studies on this subject $[77,121]$ have reported that a smaller radius of curvature (higher curvature height) along with the high relative speed of the interfaces (ring-liner) during the mid-stroke promote the creation of a thicker oil film due to the increased wedge effect, improving the lubrication performance. Instead, a larger curvature radius (smaller curvature height) results in a lower film thickness; nonetheless, this flatness of the ring profile showed to be beneficial at the dead centers, where the oil film thickness is determined by the squeeze effect, which is favored with the increase of parallel surface area.

- Surface finish: an ideal surface for friction losses reduction would be perfectly smooth and with a pattern of grooves sufficiently deep to serve as oil reservoirs. Honing of the cylinder liners has been evolving through the years with the aim of reducing the surface roughness, while keeping a series of grooves at a predefined angle. To characterize a surface finish the Abbott-Firestone curve, presented in Figure 2.9, is currently employed along with the parameters obtained from the curve. These parameters are: $R p_{k}, R_{k}, R v_{k}, M_{r 1}, M_{r 2}$.

$R_{k}$ represents the roughness of the core profile, $R p_{k}$ gathers the peak heights, and $R v_{k}$ the valleys depth, $M_{r 1}$ is the part of the surface with small peaks above the plateau, and $M_{r 2}$ represents the surface that will carry the load during its useful life. Additionally, the oil reservoirs $V_{o}$ of the surface can be calculated from the previous parameters as follows:

$$
V_{o}=\left(100-M_{r 2}\right) * \frac{R_{v k}}{200}
$$

- Coatings: are a relatively new alternative to increase fuel efficiency, and have been mostly used in high performance racing engines. Piston 


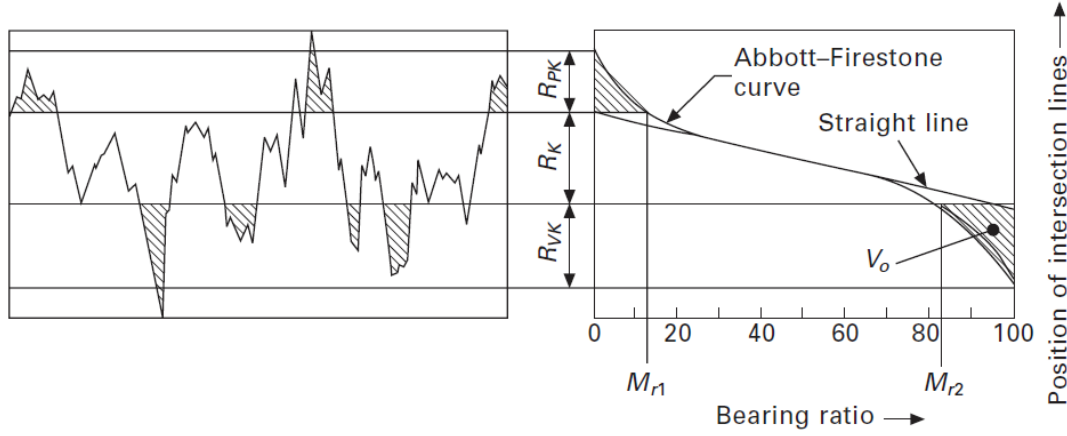

Figure 2.9. Abbott-Firestone curve and surface finish parameters [89].

rings by intansce, are commonly manufactured from cast iron and steel, with a surface treatment or coating of a material with a higher wear resistance. One of the most studied coatings is diamond-like carbon (DLC) for friction reduction, fuel efficiency and wear resistance. Results on this regard are however, contradictory. Rejowski et al. [91], studied the friction reduction potential of Heavy-duty cylinder liners coated with DLC, in comparison with non-coated cast iron liners. Bench tests showed a reduction of the friction coefficient of about $19 \%$ with the DLC coated liners. Sato et al. [102] also found a reduction of the friction mean effective pressure (FMEP) of around 10\%, and an improvement of the wear resistance of the liner. Dolatabadi et al. [16] on the other hand, found negative effects over friction with a DLC coated liner when compared to a non-coated steel liner; this performance was found to be caused by the low thermal conductivity of DLC, which in turn increased the oil film shear thinning and boundary friction. Nickel nanocomposite (NNC) was also studied, and found to improve the tribological performance of the piston ring by reducing the friction losses.

\subsection{Theoretical models to estimate the lubrication of the piston-cylinder liner assembly}

Theoretical models to describe the lubrication of the piston-ring pack have been developed extensively, the Reynolds equation being the basis for most of 
them. This equation, can be solved to estimate the oil pressure distribution, load carrying capacity, friction force and oil flow [13]. In order to take into account the different regimes of lubrication existing during the operation of the piston ring-pack, hydrodynamic, boundary and mixed lubrication, models can also include the direct contact between the surface by means of the asperity contact model developed by Greenwood and Tripp [37]. Furthermore, when the flow is considered to be hydrodynamic, surface roughness can be included using the flow factor method developed by Patir and Cheng [78].

The definition of the models for piston-ring lubrication can involve a wide variety of parameters that describe the performance of the piston ring-pack and therefore can make the model more realistic and accurate. However, modeling some of these parameters can be time-consuming in terms of computation or even their contribution to the model can not be sufficiently significant. Authors, then have to achieve an agreement on what parameters are relevant for their model and its purpose.

Methods used to model the lubrication of the piston ring-pack can be classified in two groups; one where the solution is analytical, and the second approach consisting of a numerical solution. Figure 2.10 presents a general diagram of the piston ring lubrication used in both analytical and numerical models; it considers the ring as fully flooded at the inlet, with film rupture and film reformation points, yielding to the appearance of three zones: first full film, cavitation and second full film. Force components applied to the ring are: the in-cylinder gas pressure $\left(F_{G}\right)$ and the ring elastic tension force $(F t)$. Another phenomenon included in some models is ring starvation, a more realistic approach than assuming fully flooded conditions, specially when modeling a complete ring pack. The oil film available to the ring at a crank angle, is not always sufficient to fill the gap between the ring and the liner, therefore this region is only partially filled with oil and the oil inlet position $\left(x_{1}\right)$ is moved inwards $\left(x_{1}^{\prime}\right)$ (shown as a dashed line in Figure 2.10).

\subsubsection{Analytical approach}

In the analytical approach it is assumed that the surfaces in contact are infinitely wide and the pressure variation along the circumference (ring perimeter) is negligible compared to the pressure variation along the ring face width. This method is therefore based on multiple assumptions to simplify the Reynolds equation to one-dimension:

$$
\frac{\partial}{\partial x}\left(h^{3} \frac{\partial p}{\partial x}\right)=6 \eta U \frac{\partial h}{\partial x}+12 \eta \frac{\partial h}{\partial t}
$$




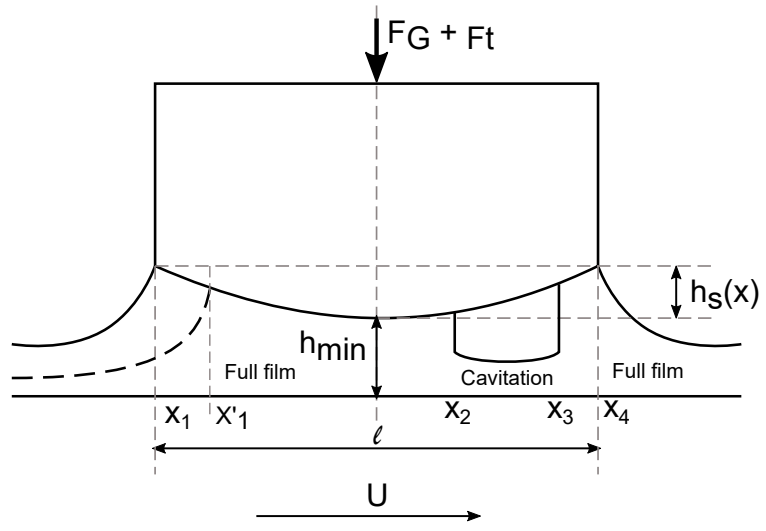

Figure 2.10. Piston ring lubrication. Adapted from [34].

Where the force that pushes the ring against the liner, elastic force and pressure acting behind the ring, is equal to the force generated by the oil film.

Furuhama et al. $[29,116]$ obtained the expressions to describe the oil pressure distribution, load carrying capacity and friction force for one ring where the oil flow in the circumference direction was neglected, the oil available between the ring and the cylinder had a constant viscosity and hydrodynamic lubrication was assumed. The model, based on the one-dimensional Reynolds equation (2.12), comprised two terms, one being the wedge action and the second related to the squeeze action. The expression for the pressure distribution was obtained through integration of the Reynolds equation using boundary conditions $(p=0$ at $x=0$ and $x=B$ ). The piston ring surface profile consisted of two quadratic sections and a straight line between them; in the analysis however, the domain only included the first quadratic part and the straight line, being $B$ the point where the domain ends. The load carrying capacity and the friction force were solved by numerical integration using dimensionless parameters that include the surface profile of the ring.

Dowson et al. [18] developed an analytical model to study lubrication in one piston ring, and then extended the model to the entire ring pack. In the approximation for one ring, hydrodynamic lubrication was assumed; the viscosity of the oil at any location of the stroke depended on the liner temperature, which can be approximated with a quadratic relationship, but it is not affected by the pressure; furthermore, the ring sat in the lower flank of the piston groove for the whole cycle. To obtain the pressure distribution, some boundary conditions were proposed: at the inlet of the ring, and during 


\subsection{Theoretical models to estimate the lubrication of the piston-cylinder}

the upstroke, the pressure was equal to that of the combustion chamber, while during the downstroke, the pressure was equal to that of the crankcase. At the outlet of the ring, pressure was determined from the inter-ring pressure. The Reynolds cavitation condition $\left(p=0 ; d p / d x=0\right.$ at $\left.x=x_{2}\right)$ was also employed in this analysis. With these boundary conditions, the Reynolds equation was solved repeatedly for a number of crank angles by means of a forward stepping process. To obtain the cyclic variation of the oil film thickness, an initial value of $h_{\min }$ was estimated at a point in the cycle, and $d h / d \theta$ was obtained. Subsequent values of $h_{\min }$ were calculated by means of the trapezium rule; this process was repeated until convergence was achieved. Given that hydrodynamic lubrication was assumed, viscous friction was calculated integrating the viscous stress for the three regions of the oil film, that is, full film, cavitation, and restoration of the film (Figure 2.10).

For the lubrication analysis of the ring pack, the inter-ring gas pressure was calculated, as it determines the loading of the rings. This was done by means of a gas flow analysis knowing the inter-ring volumes and gaps; otherwise it can also be obtained from experimental measurements. This inter-ring pressure is indicated in Figure 2.11, in this case, $p_{1}$ is equal to the combustion chamber pressure, $p_{2}$ is the pressure at the volume downstream the first ring, and $p_{3}$ is the pressure downstream the second ring, which is also equal to the crankcase pressure. Given that there was no external supply of oil, lubrication of the ring pack was governed by the condition of flow continuity; furthermore, it was assumed that the lubricant film encountered by any of the rings was that left by the preceding ring on the cylinder wall $\left(h^{*}\right)$, as it can be seen in the diagram of the piston ring pack lubrication in Figure 2.11. The calculation started determining the minimum oil film thickness at each crank angle for all rings assuming they were fully flooded. Then it was assumed that the thickness at the inlet of the second ring was equal to $h^{*}$, left by the first ring. A new calculation for the oil film thickness underneath the second ring was developed, yielding a new flow rate for this ring, which was checked for flow continuity.

Previous work by Dowson et al. [18] was completed by Ruddy et al. [94] including the piston groove profile in the lubrication analysis. It was found that this parameter has a great influence on the oil film thickness and net oil transport; furthermore, the study also included the cyclic variations of angular distortions of the ring, ring twist, and wear of the piston groove.

Later, Dowson [17] studied the lubrication of the piston-cylinder liner conjunction using incompressible lubricant and neglecting the flow of lubricant 


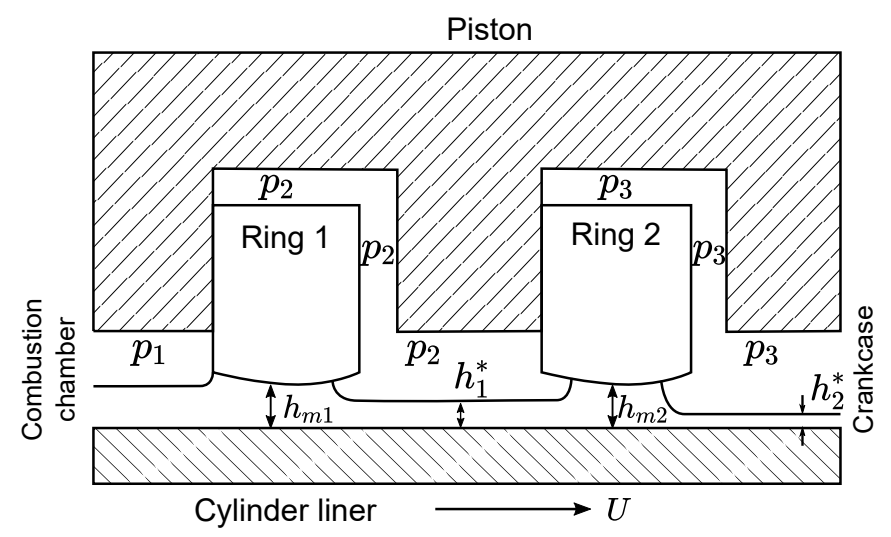

Figure 2.11. Piston ring pack lubrication. Adapted from [18].

in the circumferential ( $y$ ) direction. The Reynolds equation in one dimension used in the analysis is as follows:

$$
\frac{\partial}{\partial x}\left[\frac{h^{3}}{\eta}\left(\frac{\partial p}{\partial x}\right)\right]=12 u\left[\frac{\partial h}{\partial x}\right]+12 \frac{\partial h}{\partial t}
$$

- The first right hand side term represents the entrainment action $(u=$ $(U 1+U 2) / 2)$

- The second term is the squeeze film action, due to normal velocities and can be written as: $12 \Omega \frac{\partial h}{\partial \theta}$

Equation (2.13) was integrated twice to obtain the pressure distribution:

$$
\begin{array}{r}
p=12 \eta u\left[E+\frac{1}{R}\left(\frac{R \Omega}{u}\right) \frac{\partial h}{\partial \theta} F+C_{1} G+C_{2}[]\right. \\
E=\int \frac{d x}{h^{2}} \quad F=\int \frac{x}{h^{2}} d x \quad G=\int \frac{d x}{h^{3}}
\end{array}
$$

$\mathrm{E}, \mathrm{F}$ and $\mathrm{G}$ have analytical solutions for rings of parabolic profiles and the pressure distribution can be obtained after the constants of integration, $C_{1}$ and $C_{2}$, had been determined, using the following boundary conditions: 
- Inlet: $p=p_{1}$ at $x=x_{1}$

- Cavitation: Reynolds cavitation condition $p=0 ; d p / d x=0$ at $x=x_{2}$

- Reformation $p=0$ (or $p_{2}$, downstream the piston ring) at $x=x_{3}$

- Outlet $p=p_{2}$ at $x=x_{4}$

With the pressure distribution calculated, a further integral was applied to obtain the load carrying capacity (numerical integration) for a given minimum film thickness. This value was then compared to the external sealing force applied to the ring, if the balance failed, the film thickness needed to be adjusted until the force balance was achieved.

The oil film thickness variation was calculated starting from an estimated value at a specific crank angle, preferably at the mid-stroke where the squeeze velocity is lower. Then, the Reynolds equation (2.14) can be solved with the boundary conditions and taking the oil viscosity as a function of the liner temperature at the given crank angle. The initial squeeze film velocity was used to estimate the film thickness at the next crank angle. The Reynolds equation was applied again for the new crank angle until the force balance was achieved.

Sawicki et al. [103] proposed a system of 5 non-linear equations based on the one-dimensional Reynolds equation, used to obtain the oil film thickness, friction force, associated power loss and oil flow rate. It was assumed that the ring was fully flooded with enclosed cavitation, leading to the appearance of three regions: first full film, cavitation and second full film. The boundary conditions applied in this analysis assumed that pressure at the inlet and outlet of the conjunction were equal to that at the edges of the ring, respectively. The Reynolds cavitation condition was applied at the oil rupture point; and at the film reformation, the Jakobsson-Floberg-Olsson (JFO) theory [142] was used in the model.

D'Agostino et al. [12] proposed an analytical model based on the Reynolds equation for the top compression ring, where both the liner and ring had a smooth surface, the dynamic viscosity and density were constant, and the open-end boundary condition was used. The surface shape of the ring was defined with a parabola: $h(x)=h_{m i n}+c x^{2}$, and the one-dimensional Reynolds equation was employed (2.12). To solve the equation, they were imposed boundary conditions that allowed to find the point where the hydrodynamic pressure reaches the saturation pressure, for the upstroke and downstroke. The boundary conditions are: 


$$
p\left(x^{*}\right)=p_{\text {sat }} \quad \frac{\partial p}{\partial x}\left(x^{*}\right)=0
$$

The friction force in this model was assumed to be only due to viscous friction, and it was calculated integrating the viscous shear stress along the ring length.

Perera et al. [82] developed a model for the piston compression ring where there was no side leakage of the oil and thus the Reynolds equation can be simplified to one-dimension. For the analytical solution of the equation as presented in (2.12), the Reynolds boundary condition at the exit of the conjunction was applied and it was expressed in non-dimensional parameters. Furthermore, the model was extended to take into account the oil viscosity variation due to the heat generated between the contacts, by means of an analytical solution of the energy equation.

Previously, Perera et al. [81] also developed a model to study the lubrication in the piston skirt. The authors used the one-dimensional Reynolds equation (2.12) and a parabola to define the film thickness between the piston and the liner. In order to obtain the pressure distribution, the Reynolds equation was written in non-dimensional parameters and derived, assuming that the inlet and outlet regions of the skirt were fully flooded. Friction was calculated assuming only viscous friction and not the asperity contact.

Morris et al. [70] proposed an average flow model, based on the Reynolds equation, and previously developed by Patir and Cheng [78], for the top compression ring. The model included the surface topography of the ring and the liner using the approximation of Greenwood and Tripp [37]. For the analysis, it was assumed that the ring is fully flooded at the inlet and it conforms perfectly to the cylindrical bore, heat generated between the contacts was not taken into account, and boundary friction was determined by the asperity interactions. Furthermore, the oil film shape was determined by the minimum oil film thickness, the profile of the surface and two parameters describing the roughness amplitude of the ring and liner surfaces, which followed a Gaussian distribution. The one-dimensional Reynolds equation was integrated to obtain the pressure distribution based on the following boundary conditions: at the inlet, the pressure is equal to that of the combustion chamber or the crankcase, depending on the direction of motion of the piston; at the film rupture position, pressure is equal to the vaporization pressure of the oil; at the outlet the Swift-Stieber or Reynolds condition was applied where $p=p c$ and $d p / d x=0$ at $x=x c$, being $p c$ the cavitation pressure at 
the oil film rupture position $x c$. If $x c$ fell outside the edge of the ring, no cavitation occurred.

Later, Morris et al. [71] presented an extension of their previous work, including a thermal model to determine the effective oil temperature, and therefore the oil viscosity; which was obtained from the Vogel expression. The rate of heat generation comprised the heat conducted through the contacting surfaces, piston ring and liner, and that of the lubricant oil through convection. The boundary conditions previously mentioned, were kept for this analysis; however, the piston ring profile was assumed as asymmetrical, represented by a polynomial of 6 th order. The solution method consisted of an iterative process assuming an initial $h_{\min }$ value and oil viscosity, which were altered until the convergence criterion was met.

Gore et al. [34] developed a model for the lubrication of one piston ring assuming both hydrodynamic and boundary lubrication. The one-dimensional Reynolds equation was used in the analysis, and three lubrication zones were defined for the piston ring-liner conjunction, these were lubricant film rupture, cavitation and film reformation. The asperity contact between the parts was described by a Gaussian distribution using the approximation of Greenwood and Tripp. Rheological characteristics of the lubricant were taken into account in the model, the oil density was set to vary with pressure and temperature in the full film region, while viscosity depended on the temperature. Temperature taken for the calculations was defined as the difference between the liner temperature and the bulk oil temperature at the engine sump. The boundary conditions used in the model comprise five expressions to solve the Reynolds equation in each of the lubrication zones described previously, including Reynolds cavitation condition. The Reynolds equation was solved simultaneously with the film shape function $\left(h_{\min }+\right.$ the parabolic shape of the ring profile) in a transient manner, and for the three regions using the corresponding boundary conditions. The Newton-Raphson iteration method was employed in the analysis to find the points where the oil film ruptures and restores.

\subsubsection{Numerical approach}

Overall, the following numerical methods to solve the Reynolds equation consist of dividing a continuous area into finite subdivisions, forming a mesh, and finding approximate solutions in these subdivisions. Solutions are obtained by means of interpolation. These methods can be classified in three 
groups, the main differences between them are the way to find the solution, definition of boundary conditions and method of analysis:

- Finite difference method

- Finite element method

- Finite volume method

Hamilton et al. [39] developed an iterative method to solve the onedimensional Reynolds equation for one piston ring, assuming hydrodynamic lubrication. The main objective of this model was to estimate the oil film thickness distribution in the piston-liner conjunction. The solution procedure consisted of integrating the Reynolds equation analytically to obtain the pressure distribution and then replacing the terms by their equivalent finite differences. The pressure distribution is then solved iteratively with the overrelaxation method. The axial variation of the film thickness was obtained by numerical differentiation of the profile data and $h_{\min }$ was determined by successive approximations until the force balance was achieved. Furthermore, at the beginning of the calculation, the squeeze velocity term was estimated at the mid-stroke, where is close to zero, and then it was estimated for the next crank angles based on the change of $h_{\min }$. During the calculation of the pressure distribution, every negative value was set to zero.

Miltsios et al. [68] developed a model for three piston rings based on the two-dimensional Reynolds equation and solved by the finite elements method (FEM). The model assumed that all the rings had circular profiles, there was bore distortion and the rings tilted due to moments generated by the acting forces. The boundary conditions in the axial direction assumed that pressure at the inlet and outlet of the conjunction were equal to the pressure at the edges of the ring; in the y direction, boundary conditions were applied to the ring gap, which was assumed to be very small and therefore there was no oil flow through them. For the finite element formulation, the Reynolds equation was written in non-dimensional terms and was solved by Newton-Raphson iterations assuming an initial value of the minimum film thickness.

A different approach for piston ring lubrication was applied for the first time by Ma et al. [60], known as the flow continuity algorithm. It is based on the work developed by Paydas and Smith [79] for journal bearings, which in turn is based on Elrod's cavitation algorithm [21]. It includes a switching function or cavitation index $(g)$ that changes depending on the region where the equation is applied, that is in the full film region or in the cavity. The 


\subsection{Theoretical models to estimate the lubrication of the piston-cylinder}

model developed by Ma et al. was intended for one piston ring in a distorted bore, and included ring starvation and cavitation along the ring circumferential direction; oil available to the ring was taken into account applying the principle of mass conservation and also considering oil accumulation in front of the ring. In this way, the oil inlet and film rupture positions could be determined. Two expression for the pressure distribution and degree of lubricant filling were derived and applied to the full film and cavitation regions respectively, according to the value of the cavitation index for each node. Once calculations were completed for all the nodes, the generated hydrodynamic pressure was checked, if it was nonexistent or lower than the boundary pressures, it was concluded that blow-by (flow of gas from the combustion chamber to the crankcase forced through any leakage path between the piston, piston rings and the liner wall due to the combustion pressure [40]) would occur.

Liu et al. [58] presented a numerical model for a pack of two rings based on the two-dimensional Reynolds equation, along with an asperity contact model defined by the approach of Greenwood and Tripp [37]. For the definition of the model it was assumed that the rings and piston grooves were always in contact, having the same tilt angle, the face profile of the rings was a parabola and the half-Sommerfeld boundary condition was employed. To consider starvation in the model, it was assumed that the oil available to one ring was equal to that left by the preceding ring. The solution method consisted in solving the Reynolds equation by the finite difference method, an initial value of minimum film thickness was assumed to start the calculation, and it was updated after the forces applied to the ring met the equilibrium condition. The film thickness for the next crank angle was initially obtained from the previous value and the time step between the angular positions. The process was repeated until the flow continuity condition was satisfied.

Stanley et al. [114] studied the lubrication of the piston ring pack and skirt developing a simplified model for each of them. Common assumption of the models was that the rings and piston skirt were fully flooded, therefore there was no starvation. The model for the piston ring pack was based on the one-dimensional Reynolds equation, assuming that the oil film thickness was constant in the circumferential direction; furthermore, the profile of the ring was described by two parabolas, being the meeting point the location of the minimum film thickness. For the piston skirt lubrication model, it was assumed that the oil film thickness was not equal along the circumference direction, therefore the two-dimensional Reynolds equation was applied, represented by finite differences and solved through an iteration process. The boundary condition defined to solve the finite difference expression assumed that the pressure at the inlet and outlet of the conjunction was atmospheric, 
furthermore it was assumed that there were no thermal or elastic deformations of the skirt. At the end of the iterations the oil film thickness at $0^{\circ}$ (crank angle degrees) had to be equal to that at $720^{\circ}$, a similar condition was applied to the pressure distribution. In this study, the piston ring friction was found from the construction of Stribeck diagrams, which were based only on the geometry of the ring; a similar approach was used to calculate the friction force of the piston skirt, that is, calculating a skirt characteristic parameter dependent on the skirt geometry.

Later on, Liu et al. [59] studied the lubrication of one piston ring based on the work by Ma et al. [60] and the flow continuity algorithm, adding some improvements to the model, which was solved by the finite volume method. On one hand, a transition zone, between the fully-filled region and the partiallyfilled region, was introduced with the aim of reducing the discontinuity in oil flow at the separation point of the two regions and thus improve the numerical solution. This transition region represents how the oil gradually attaches to the ring, and therefore half of the clearance between the ring and the liner is filled with oil. Another improvement to the model was made to determine if the cell was fully flooded or partially filled with oil. From the model by Ma et al. [60] the reference pressure was either that at the leading edge of the ring or the trailing edge, depending where the cell was located. However, near the point of minimum clearance between the ring and liner, numerical problems where found if the reference pressure was inadequate. Therefore, a piece-wise linear function was implemented to give a smooth transition between the two pressures.

Moughon [72] studied the lubrication of the piston and cylinder liner, and specifically for the piston skirt, the one-dimensional Reynolds equation was applied using the method of finite differences. The first derivative of the Reynolds equation was approximated as the slope between nodes, in three different ways depending on the nodes considered for the analysis; that is; forward difference, backward difference and centered difference. For the second derivative, two adjacent first differences are subtracted and divided by the distance between their centers. The complete Reynolds equation, written in finite differences, was applied to each node of the mesh, using local oil film thickness values. The resulting equations were gathered in a system of equations.

Wannatong et al. [143] developed a simulation algorithm for three dimensional piston ring motion, applied to the ring pack, where the ring was assumed to move freely in the piston groove in three directions, radial, lift and twist. Although the main objective of the model was to study the piston 
ring motion and blow-by/blow-back flow, it integrates piston ring lubrication by means of the one-dimensional Reynolds equation. For the hydrodynamic lubrication model, rough surfaces were taken into account, therefore, the Reynolds equation was expressed with a flow factor, as proposed by Patir and Cheng [78], and the equation was solved through backward and central finite difference method. For the lubrication model, it was assumed that for the first and second ring, the oil film thickness at the inlet was that available right before the ring; and at the outlet, the oil film thickness was equal to the minimum clearance between the ring and the liner. The oil control ring was assumed to be fully flooded. Furthermore, the gas pressure included in the model was taken from experimental measurements in the combustion chamber and a blow-by/blow-back model including volumes between the piston rings and flow through the ring gaps.

Overgaard et al. [77] developed a numerical model to study lubrication of the piston compression ring of a two-stroke marine diesel engine. The model is based on the one-dimensional Reynolds equation and was solved by the central finite differences method. The main objective of the study was to analyze the effect of the radius of curvature of the ring profile over the lubricant transport; in the analysis, the force exerted on the back of the ring due to the in-cylinder gases, was neglected. The solution method consisted in an iterative process, and to achieve the force equilibrium with the hydrodynamic force, perturbation of the Reynolds equation method was used to estimate a new minimum oil film thickness. Furthermore, to study the effect of the ring radius of curvature, the model assumed the ring to be fully flooded, although starvation was also considered by means of flow continuity conditions.

\subsubsection{Commercial models for piston lubrication}

Finally, in this section are mentioned some of the most well-known lubrication models commercially available dedicated specifically to the simulation of the lubrication in the piston assembly and for the complete ICE. These are the AVL EXCITE for powertrain analysis and specifically the AVL EXCITE Piston\&Rings employed by various authors [2, 23, 126], Garcia-Atance et al. [23] by instance, employed this software to investigate and compare the experimental measurements of piston-ring oil film thickness in a firing engine with simulation results from this model. The Virtual Engine software developed by FEV for the 3D simulation of the piston assembly dynamics, friction and wear [25], RINGPACK and PISDYN in the RICARDO software [52] for the lubrication estimation of the ring pack and the piston (skirt), were applied to study the effect of different parameters on the piston 
ring lubrication perfomance, potential friction reduction and fuel economy $[27,84]$, and for comparison with experimental friction measurements by Carden et al. [9]. GT-Suite also offers the possibility to study the lubrication performance of the complete ICE and specifically for the main tribological pairs, as well as to determine the distribution of the friction mechanical losses in the main tribo-pairs under different working conditions of the engine [127].

\subsection{Experimental measurement of friction in the piston-cylinder liner assembly}

Given that the piston-cylinder liner assembly is the tribo-pair with the biggest share of friction mechanical losses in ICEs, investigations to understand the mechanism behind this friction generation are multiple, and have been developed for decades now. Studies have been aimed at measuring the instantaneous friction force in this assembly by means of two methods, the instantaneous mean effective pressure method (IMEP) and the floating liner. Both methods require modifications in the ICE used for the experimental measurements, specially the floating liner; however, this last method has the advantage of offering a direct measurement of the friction force between the piston and the liner. The measuring principle of the two methods is presented below.

\subsubsection{IMEP}

The IMEP is an indirect method of measuring the friction force between the piston and the cylinder liner. Its measuring principle consists of measuring the forces acting on the connecting rod by means of strain gauges; therefore, this force consists of a lateral and an axial component, that can be later correlated with the friction force in the assembly. Forces acting on the piston along the central axis of the cylinder liner are the in-cylinder pressure, which can be measured experimentally, inertia forces, forces acting on the connecting rod and friction force. Theoretical calculations are developed to obtain the inertia force and force components on the connecting rod, leaving the friction force as the only unknown quantity. The difference between the theoretical calculations, including the in-cylinder pressure, and the experimental measurements from the strain gauges, are therefore the friction force in the piston-liner conjunction $[73,133]$. 


\subsubsection{Floating Liner}

The floating liner is a direct method to measure the friction force in the piston-cylinder liner assembly; that means, that the force collected by the sensing elements, directly corresponds to the instantaneous friction force between the components in relative motion. The measuring principle consists on isolating the liner from the rest of the engine block, including the cylinder head, allowing the liner to move freely in the axial direction. Movement in the lateral direction is usually constrained. This axial movement is the result of the reciprocating motion of the piston; therefore, the friction force generated in the contact can be captured by the selected sensors. In order to capture the friction force solely from the contact between the piston and the liner, this last component needs to "float" restricted only by the sensors. In this way, location of the sensors and the floating configuration of the liner, require multiple modifications on the engine structure. Figure 2.12 is a schematic diagram of the common components of a floating liner test rig and forces acting on the axial direction.

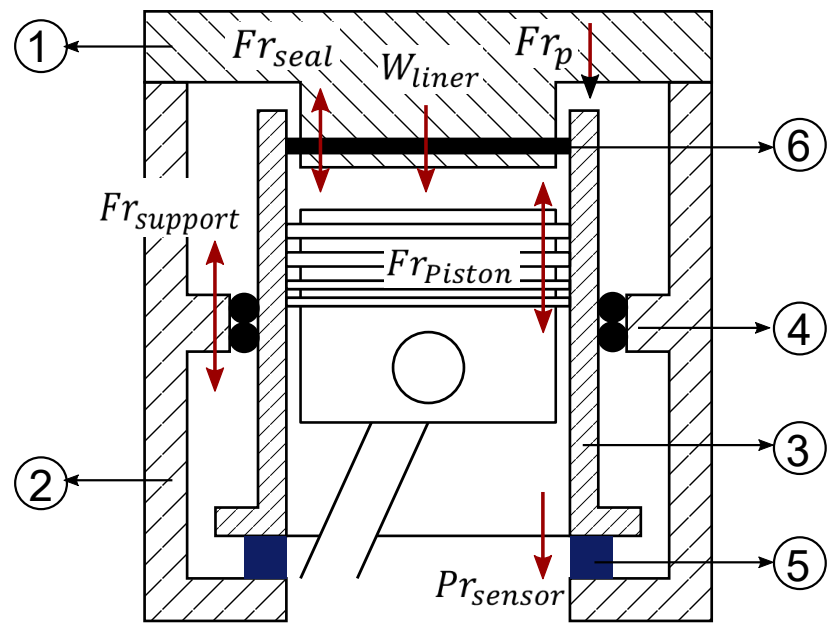

1. Cylinder head

2. External structure

3. Liner

4. Lateral support

5. Force sensors

6. Combustion chamber sealing

Figure 2.12. Floating liner components and forces in the axial direction.

From Figure 2.12, forces acting on the axial $(y)$ direction would be:

$$
\sum F_{y}=W_{\text {liner }}+F r_{\text {seal }}+F r_{p}+F r_{\text {support }}+F r_{\text {piston }}+P r_{\text {sensor }}
$$


Where $W_{\text {liner }}$ is the weight of the liner supported by the force sensors, $F r_{\text {seal }}$ is the friction force added by the sealing device of the combustion chamber, $F r_{p}$ is the additional force exerted by the in-cylinder pressure if there is any leakage from the combustion chamber, $F r_{\text {support }}$ is the friction force generated by the device used to constrain the lateral movement, $F r_{p i s t o n}$ is the actual friction force due to the contact between the piston and the liner wall, and $P r_{\text {sensor }}$ is the sensor's preload.

Floating liner test rigs have been developed and improved by many authors throughout the years with different designs and configurations attending to the aims of the investigation and own working conditions. Starting in 1980, with the work by Furuhama et al. [32], the designed test rig included piezoelectric force sensors to capture the friction force in the piston assembly of a singlecylinder ICE. Many design challenges arose regarding the sealing of the combustion chamber, for which different solutions were tested to balance the in-cylinder pressure, and avoid their interference with the true friction force reading of the sensors. For the final design of the floating liner, an O-ring was used to seal the combustion chamber. Given that the O-ring presented some inconveniences, such as the large space needed for its installation, and its useful life being reduced by the combustion pressure and temperature, a later work by Furuhama et al. [30, 31], addressed this issues by improving the sealing of the combustion chamber. Two designs were developed to balance the gas pressure by means of annular plates. The first design is shown schematically in Figure 2.13 A, and the second design in B. As it can be seen, the first design had the disadvantage of needing modifications in the piston head in order to take into account the upper protrusion of the liner. In the second design, this issue was solved adding drills to the liner and two annular plates to balance the gas pressure. Tests were developed in order to deeply understand the effect of engine speed and oil viscosity over the friction force curves. Furthermore, some test were developed with molybdenum (Mo) and boron (B) FMs, although no significant differences were found.

Takiguchi et al. [116], studied the friction force in two-ring packages based on the floating liner designs by Furuhama et al. [30]. The aim of the work was to be able to measure the friction force at higher speeds (up to $5000 \mathrm{rpm}$ ), and therefore expand the knowledge on piston ring lubrication conditions. In order to measure the friction share from the piston rings, the liner and piston were manufactured in such a way that only the rings would contact the liner. A guide was added to the piston and the cylinder head was replaced with a channel for the guide to slide. This setup allowed the piston rings to be studied as a package or separately, without any lateral movement. 
A

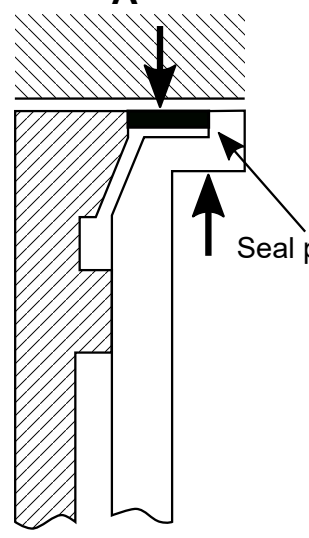

D

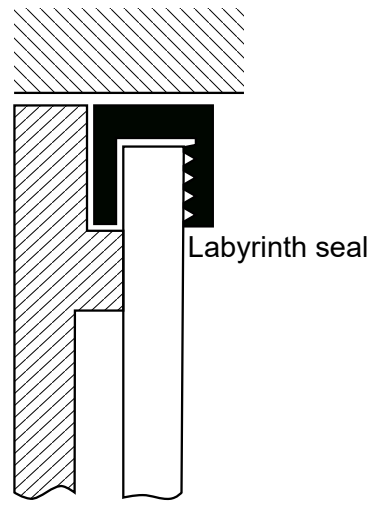

B

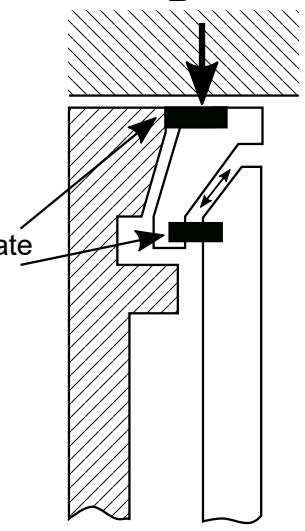

C

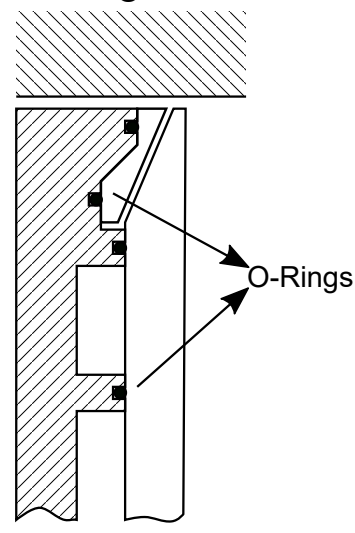

E

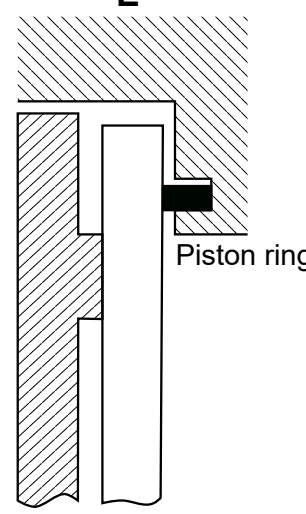

Figure 2.13. Solutions proposed by different authors to seal the combustion chamber of a floating liner test rig.

The floating liner test rig designed by Furuhama has been since employed and improved by many different authors [53, 54, 57, 65, 125, 132, 138, 139]. Contributions of some of these authors will be addressed in the following paragraphs.

Sherrington et al. [107] developed a floating liner rig based on an ICE and with four sensors located in the lower rim of the cylinder liner. This liner was modified with an extension to allocate a hydrostatic bearing used as lateral support along with the sensors. In order to maintain the compression ratio of the engine, the cylinder head was also extended in such a way that 
the protrusion would be inside the liner extension. The disadvantage of this set up was the oil flowing out from the hydrostatic bearing during tests, therefore allowing short periods of time for the tests' execution. Tests with this floating liner were carried out for both uncompressed and compressed conditions. Finally a modification to the rig was proposed to solve the issue with the oil leakage through the hydrostatic bearing by means of two O-rings. In a later work by Smith et al. [110], the previous floating liner design was improved with an annular seal plate to balance the in-cylinder pressure. This device was also used to add lateral support to the liner and therefore, the hydrostatic bearing was no longer necessary, along with the protrusion of the liner and cylinder head. The annular plate however, presented some issues to balance the pressure, distorting the friction force signal during the compression stroke. Corrections were then made to the friction signal to remove the effect of the in-cylinder pressure, using the reading of a pressure sensor.

Another solution to the radial support issue was implemented by Wakuri et al. $[140,141]$ in a new floating liner test rig. It consisted of eight hydrostatic bearings located around the cylinder liner to restrict the lateral movement, but allowing the liner to move freely in the axial direction. Furthermore, this test rig had the capability of developing tests under firing conditions. For the sealing of the combustion chamber, a thin rubber sheet was employed and proven to give good results for friction measurements, which were measured with one piezoelectric force sensor located in the base of the liner. Parametric tests carried out by the authors included different working conditions, oil formulations of different SAE grades and FMs. One of the main conclusion of the study was the reduction of the total friction loss with the use of low viscosity oils, although friction increased in the dead centers indicating more severe lubrication conditions.

The capabilities offered by the floating liner to study the lubrication conditions under motored and firing conditions, led this test rig to be used for the analysis of wear of the piston assembly components. Urabe et al. [132], by instance, studied the effect of exhaust gas recirculation (EGR) of diesel engines on wear. For this purpose a new piston ring package was used and wear levels were determined from weight comparisons. The floating liner developed by Furuhama was used to measure the friction force at different levels of EGR. It was found that EGR has an effect on wear due to the presence of soot. This combustion by-product highly increases wear acting as a third-body wear particle between the two sliding surfaces, and also exerting an extra load in the back face of the ring, if it enters the piston ring groove. 


\subsection{Experimental measurement of friction in the piston-cylinder liner}

assembly

Cho et al. [115] replaced the piezoelectric force sensors, commonly used by previous authors, with strain gauge loads cells. The floating liner was constructed in a four-cylinder ICE, and the lateral support design was based on the one described by Takiguchi et al. [116]; that is, by means of a guiding mechanism in the cylinder head, and a sliding guide attached to the piston head. For the tests, the piston-liner assembly was designed in such a way that the piston did not touch the liner wall, and only the friction share from the rings could be measured. Tests were developed with the aim of analyzing the lubrication conditions of the piston rings and classify them in five frictional modes for one engine cycle. These tests were developed under motored ambient pressure conditions.

In a research work developed by Ha et al. [38], a different solution to the combustion chamber sealing was proposed and tested. An schematic diagram of such solution is shown in Figure 2.13 C. It consisted of a modified cylinder liner with drills to allow the transfer of the in-cylinder pressure to a pressure chamber formed by the liner and the engine block. The upper part of the liner and the chamber were machined with the same area, hence, the gas pressure acting on these areas could be balanced. To seal the combustion and pressure chambers, three O-rings were employed and a cooling system was implemented to prevent their damage from high temperatures. An analysis of the sealing system showed that an uncertainty of less than $0.3 \%$ could be found in the friction force measurements. Among the tests developed by the authors, was the analysis of the effect of piston ring tension over friction. It was found that friction force increases proportionally with the tension for the whole engine cycle, and variations were more significant near the dead centers.

In a later work by Wakabayashi et al. [139], the floating liner by Furuhama et al., was employed with a series of modifications to study the effect of the different crank ratios over friction, For this purpose, the test rig was modified to allow the exchange of both crankshaft and connecting rod of different dimensions. Results showed that although a higher crank ratio helps to reduce the friction force, this correlation is not linear. In a subsequent research study, Wakabayashi et al. [138] studied the friction force differences between new and used components, after the break-in period. The same floating liner test rig was used, but this time the liner was able to be exchanged. The surface roughness of the piston rings and liner was measured at the beginning of the tests and after pre-determined periods of time. Results showed that surface roughness is reduced gradually with time and specially for the liner. FMEP was therefore also reduced with time however, after 4 hours of testing, reductions in FMEP were not longer observed. 
Employing the same floating liner design by Furuhama, Madden et al. [65] and Kim et al. [53, 54], developed a joint research study, divided in three parts, for the analysis of different piston skirt designs on the friction force generated in the piston-cylinder liner assembly. The study included the analysis of skirtliner cold clearance $(10,30$ and $50 \mu m)$, for which the skirt was instrumented with gap sensors to evaluate the clearance variations along the engine cycle. Significant reductions in friction force were found with the increase of the clearance; however, increasing the clearance further than $30 \mu \mathrm{m}$ increased the piston slap noise. For the second and third part of the study, a sapphire window was added to the floating liner test rig. The oil film formation and distribution throughout the cycle were studied using a high speed video camera, ultraviolet light and dye mixed in the oil. Six skirt designs were presented and tested by the authors; they consisted of skirt profiles with recessed areas in different patterns. Results showed that one of the skirt designs, with recessed areas at the top and bottom of the skirt, had lower friction force than the other designs. Given that the recessed areas act as oil reservoirs, oil was better retained and distributed for all the engine strokes.

Piezoelectric force sensors used by the previous authors to capture friction in the piston-cylinder assembly were unidirectional and installed at the bottom of the liner. O'Rourke et al. [76] on the other hand, developed a floating liner test rig with four tri-axial piezoelectric sensors, located on one side of the liner. The test rig consisted of a V-Twin ICE, where one of the cylinders was modified to accommodate the floating liner structure. This structure included two clamps around the liner and an external structure. The force sensors installed between the external structure and the clamps, allowed to capture the force components in the three axis without restricting the movement of the liner. Although the test rig is operated under motored conditions, the cylinder head, sealed with O-rings, allowed the generation of in-cylinder pressure. Some tests were developed with the test rig and oil formulations of different SAE grades, demonstrating that the test rig had enough sensitivity to evaluate the differences in friction force for parametric tests. Fiction force captured with the sensors required however, a correction from the in-cylinder pressure acting in the top rim of the liner. To solve this issue, a pressure sensor was installed in the combustion chamber to capture the pressure along the cycle. With this data and knowing the area of the liner rim, the friction force could be corrected during post-processing [75].

Another configuration for the force sensors was implemented by Gore et al. $[34,35]$ in their floating liner test rig, in this case for both motored and firing conditions. To accomplish the floating requirement, the engine block was replaced with a holding fixture manufactured with the same dimensions as the 


\subsection{Experimental measurement of friction in the piston-cylinder liner}

assembly

original engine block, but with the possibility of installing the sensors between the liner and the new block. For this purpose the liner was also manufactured with an external disc, at about half its length, to attach the sensors. Six piezoelectric force sensors were used and installed at $120^{\circ}$ spacing, three at the top of the liner disc, and three at the bottom, forming a sandwich. The sealing of the combustion chamber was made with a labyrinth seal, as shown in Figure 2.13 D, located between the liner and the cylinder head. This sealing device offers an intricate path for the in-cylinder pressure to leak, and leaves a gap between the cylinder head and the top rim of the liner, for it to move freely in the axial direction. To accommodate the labyrinth seal, the piston head was modified to avoid the interference with the seal during the upstrokes. Given that a proportion of the in-cylinder pressure would still leak through the seal, a correction to the friction force measurements was made, similar to to the method adopted by O'Rourke et al. [75], by installing a pressure sensor near the top rim of the liner.

Law et al. [56] proposed a floating liner design to be operated under motored conditions, but with the capability of achieving high in-cylinder pressures, similar to those found during normal engine combustion. The test rig was manufactured from components of an ICE engine, and consisted of an external structure, a liner, supported by flexible diaphragms in the upper and lower part, and a modified cylinder head to accommodate the air injection system and sealing. For the sealing of the combustion chamber, a labyrinth seal was employed, estimating that a maximum $35 \%$ of in-cylinder pressure would be lost through the sealing per engine revolution at 1000 rpm. In order to fill the combustion chamber with compressed air and refill the lost air, due to blow-by and through the sealing, a GDi injector was modified and installed in the cylinder head. The analysis of the friction force measurements, showed that under compressed conditions and mid-high engine speed, the labyrinth seal was interfering with the liner and therefore, causing erroneous measurements. Subsequent tests were carried out under uncompressed conditions and up to $1400 \mathrm{rpm}$. In a later work by Islam [48], the labyrinth seal was replaced with a piston compression ring to seal the combustion chamber, as shown in Figure 2.13 E. For this design, the cylinder head was modified to be inserted in the liner like a plug, allowing the ring to conform to the liner thanks to its own tension force and in-cylinder pressure. With this new sealing device, the air lost was reduced to $8 \%$ and tests could be developed under compressed conditions up to 80 bars. Given that the sealing ring added a friction force component to the reading of the force sensors, a calibration procedure was implemented to eliminate this force from the true friction force measurements. This calibration was carried out with the piston 
locked at the TDC and a constant air supply to rise the in-cylinder pressure; in this way, the pressure would push the ring up causing a force change captured by the sensors. This procedure was developed for multiple working conditions of temperature and pressure to obtain a calibration equation to be used in the data post-processing.

A floating liner test rig designed for HDD engine components was presented by Söderfjäll et al. [105], with the aim of being able to easily evaluate piston ring packs and liners under common working conditions of HDD engines. For this purpose, the test rig design was aimed to be as something in between a floating liner and a component test bench. A six cylinder ICE was used as base engine, using one of the cylinders for the floating liner structure. This structure consisted of a cylinder liner, located upside down, so the top rim would help to attach the force sensors, a steel rod attached to the piston head, and a piston ring holder to accommodate the rings to be tested. This additional weight was balanced by adding weights to the rest of the pistons. With this floating liner configuration, the friction force was measured in the axial direction only with three piezoelectric force sensors, and without the interference of the lateral force component. Tests were developed to evaluate the repeatability of the system, evaluating the friction power differences between assemblies and for different piston rings configurations; a difference below $1.5 \%$ was found for these tests, demonstrating the good repeatability of the test rig. In a later work, Söderfjäll et al. [106], studied the influence of some parameters on the friction force of oil control rings (OCR). It included different OCR designs,

cylinder surface roughness and two oil formulations of different SAE grades. Furthermore, experimental results with the floating liner were compared with results of a theoretical model developed by the authors.

\subsection{Use of low viscosity engine oils to reduce friction losses}

Reduction of the friction mechanical losses in ICEs can be tackled from two alternatives; one is through the improvement of the characteristics of the components' interface, such as materials, surface finishing and low friction coatings, new geometric designs. The other alternative is through the oil formulation, using low viscosity engine oils (LVEOs) in order to reduce the oil shear resistance during the hydrodynamic lubrication regime, and/or with the addition of additive packages to improve the tribological performance under boundary and mixed lubrication regimes. In this way, the first alternative includes big changes to the engine and vehicle design and operating conditions, 
which in turn represents a cost increase for manufacturers and consumers. The second alternative on the other hand, represents a good cost-effective solution, as it generally, may not require any changes to the engine hardware. However, reducing the viscosity of the oil formulation is critical for the appropriate lubrication of the engine; if the oil film thickness is not thick enough to separate the surfaces in relative motion, boundary and mixed lubrication can appear more easily with the consequent increase of associated wear.

\subsubsection{HTHS viscosity}

Previously in Section 2.2.3.3, it was mentioned the lubricant oil viscosity variation with temperature and shear rate. In order to characterize the engine oils according to its performance under representative working conditions of an engine, ASTM defined the High Temperature High Shear (HTHS) viscosity, measured at $150^{\circ} \mathrm{C}$ and $10^{6} \mathrm{~s}^{-1}$ of shear rate. This HTHS viscosity value can be found in the SAE J-300 standard [96] for the different engine oil categories. Given the correlation of the HTHS viscosity with the working conditions of ICE, this parameter has been used as an indicative of the fuel economy potential of the oil formulation; that is, with lower HTHS viscosity values, the reduction of fuel consumption is expected to be higher. Several authors have studied and confirmed this relationship between the HTHS viscosity and fuel economy results $[3,51,111,137]$. However, it has also been found that this HTHS viscosity reduction has a limit in terms of fuel consumption reduction, beyond which, friction losses increase and thus fuel consumption [51, 98].

On the other hand, in the research work developed by Taylor et al. [122] it was discussed that the HTHS viscosity (at $150^{\circ} \mathrm{C}$ and $10^{6} \mathrm{~s}^{-1}$ according to the SAE J-300 standard) may not be the appropriate parameter to evaluate the friction losses reduction and fuel economy potential of the engine oils, specially when evaluating these formulations under mild working conditions of the ICE and some engine components not working under high levels of shear rate. For this Thesis by instance, in the studies developed in the floating liner test rig, given that the engine speed was kept at low levels and the oil temperature at the crankcase up to $80^{\circ} \mathrm{C}$, the evaluation of the oil formulations on the reduction of the friction losses was referenced to the dynamic viscosity of the oil and its variation with the working temperature.

\subsubsection{Engine oil standards for fuel economy}

There are two main classification criteria for engine oils, one based on performance, and the other based on oil viscosity. For the former, the API in 
the United States and the European Automobile Manufacturers Association (ACEA), classify the engine oils in categories according to their performance and application. The Society of Automotive Engineers (SAE) on the other hand, classifies the engine oils under the SAE J-300 standard [96] based on the oil viscosity for both monograde and multigrade oils.

Following the path of fuel economy requirements and $\mathrm{CO}_{2}$ emissions regulations, API released in December 2016 the CK-4 and FA- 4 oil categories for diesel engines. The API CK-4 oils are compatible with previous categories like CJ-4 and CI-4, and its HTHS viscosity limit was maintained at CJ-4 levels. The FA-4 category gathers oil formulations with a reduced HTHS viscosity value to contribute to fuel economy and the reduction of GHG emissions. The reduction of the HTHS viscosity makes them incompatible with previous categories, therefore its use is only recommended for newer vehicles [86].

ACEA oil specifications are divided in three groups, two of them for passenger car engine oils, and the third one for Heavy-duty diesel (HDD) engine oils. Its requirements regarding LVEOs and HTHS viscosity have been more conservative than API, with HTHS viscosity limits of 2.6 and $2.9 \mathrm{cP}$ for passenger car oils and of $3.5 \mathrm{cP}$ for the Heavy-duty segment [1]. The release date for the next update of the ACEA sequences for Heavy-duty vehicles is still unknown; however, it is expected to include new categories for the HDD engine oils with HTHS viscosity limits of 2.9 to $3.2 \mathrm{cP}$ [47].

The SAE J-300 standard has also been updated in the past years. In 2013 the $\mathrm{SAE}$ grade 16 was included with an HTHS viscosity of $2.3 \mathrm{cP}$. The last update was in 2015, to include oils with lower viscosity in the SAE grades 12 and 8, with HTHS viscosity limits of 2 and $1.7 \mathrm{cP}$, respectively. The updated chart for SAE oil grades is presented in the following Table 2.3:

\subsubsection{Research on LVEOs}

As previously stated in Section2.3.4, LVEOs have been extensively studied for fuel economy and $\mathrm{CO}_{2}$ emissions reduction. These studies have been developed for both Light-duty and Heavy-duty vehicles, and the methodologies employed to test the oil formulations range from stationary test in an engine test bench or chassis dynamometer, under homologation cycles and fleet tests for real working conditions. Selection of the methodology to be employed depends on the aims of the work, but also on its associated cost.

For the Light-duty vehicle segment, the research work presented by Kaneko et al. [51] was driven by the need of meeting the European emissions standards of the moment regarding particulate matter $(\mathrm{PM})$ and $\mathrm{CO}_{2}$. It consisted 


\begin{tabular}{|c|c|c|c|c|c|}
\hline $\begin{array}{l}\text { SAE } \\
\text { Viscosity } \\
\text { Grade }\end{array}$ & $\begin{array}{l}\text { Low- } \\
\text { Temperature } \\
\left({ }^{\circ} \mathrm{C}\right) \\
\text { Cranking } \\
\text { Viscosity } \\
\text { mPas } \\
\text { max }\end{array}$ & $\begin{array}{l}\text { Low- } \\
\text { Temperature } \\
\left({ }^{\circ} \mathrm{C}\right) \\
\text { Pumping } \\
\text { Viscosity } \\
m P a s_{\max } \\
\end{array}$ & $\begin{array}{l}\text { Low-Shear- } \\
\text { Rate } \\
\text { Kinematic } \\
\text { Viscosity } \\
(\mathrm{mm} / \mathrm{s}) \text { at } \\
100^{\circ} \mathrm{C} \text { Min } \\
\end{array}$ & $\begin{array}{l}\text { Low-Shear- } \\
\text { Rate } \\
\text { Kinematic } \\
\text { Viscosity } \\
(\mathrm{mm} / \mathrm{s}) \text { at } \\
100^{\circ} \mathrm{C} \mathrm{Max} \\
\end{array}$ & $\begin{array}{l}\text { High-Shear } \\
\text { Rate- } \\
\text { Viscosity } \\
(m P a s) \text { at } \\
150^{\circ} \mathrm{C} \text { Min } \\
\text { and } 10^{6} s^{-1} \\
\end{array}$ \\
\hline $0 \mathrm{~W}$ & 6200 at -35 & 60000 at -40 & 3.8 & - & - \\
\hline $5 \mathrm{~W}$ & 6600 at -30 & 60000 at -35 & 3.8 & - & - \\
\hline $10 \mathrm{~W}$ & 7000 at -25 & 60000 at -30 & 4.1 & - & - \\
\hline $15 \mathrm{~W}$ & 7000 at -20 & 60000 at -25 & 5.6 & - & - \\
\hline $20 \mathrm{~W}$ & 9500 at -15 & 60000 at -20 & 5.6 & - & - \\
\hline $25 \mathrm{~W}$ & 13000 at -10 & 60000 at -15 & 9.3 & - & - \\
\hline 8 & - & - & 4.0 & ¡6.1 & 1.7 \\
\hline 12 & - & - & 5.0 & ¡7.1 & 2.0 \\
\hline 16 & - & - & 6.1 & ¡8.2 & 2.3 \\
\hline 20 & - & - & 6.9 & ¡9.3 & 2.6 \\
\hline 30 & - & - & 9.3 & ¡12.5 & 2.9 \\
\hline 40 & - & - & 12.5 & ¡16.3 & $3.5^{*}$ \\
\hline 40 & - & - & 12.5 & ¡16.3 & $3.7^{* *}$ \\
\hline 50 & - & - & 16.3 & ¡21.9 & 3.7 \\
\hline 60 & - & - & 21.9 & ¡26.1 & 3.7 \\
\hline
\end{tabular}

Table 2.3. SAE J-300 standard chart for engine lubricant oils. ${ }^{*} 0 W-40,5 W$-40, and $10 \mathrm{~W}-40$ grades. ${ }^{* *} 15 \mathrm{~W}-40,20 \mathrm{~W}-40,25 \mathrm{~W}-40,40$ grades [96].

of developing a new engine oil formulation to reduce fuel consumption, but keeping the protection of the engine against wear. Oil formulations were tested in an engine tests bench, and the final result was an oil formulation with a fuel consumption reduction of $2 \%$. Fontaras et al. [26], developed a research work with different oil formulations, including low viscosity oils 5W30 and 0W30, and combining two test methodologies. In the first one, tests were developed with two Light-duty diesel engines (Euro 3 and Euro 4) under the sequences of the NEDC and Artemis driving cycles. The second methodology was developed in an engine test bench under stationary working points, in order to compare the use of a mineral oil, against a low viscosity 
synthetic oil. Results of the NEDC and Artemis cycles showed good results of fuel economy and $\mathrm{CO}_{2}$ emissions reduction; however, results under the Artemis cycle (1-1.5\%) showed to be half of those found with the NEDC (3\%). Authors suggested that benefits of LVEOs should be lower under real driving conditions. Results obtained from the engine test bench showed that there exists zones in the engine working map with higher fuel consumption reduction potential, a $1 \%$ benefit was obtained when using the LVEO. In this study, regulated and non-regulated emission were also measured, such as PM, $\mathrm{CO}, \mathrm{HC}$ and NOx. Results showed no significant variations of these emissions with the use of LVEOs.

Later on, Souza de Carvalho et al. [111], studied the fuel consumption reduction with the use of multigrade oils instead of monograde formulations. For these studies a single-cylinder diesel engine in a test bench was employed and operated under different working conditions of load and speed. Results showed a linear correlation between the HTHS viscosity reduction and fuel economy. Some of the oils were also formulated with a viscosity improver additive, giving positive results for fuel consumption reduction. Finally, the Willans' line method was applied to investigate the effect of the oil viscosity reduction on friction power. Permude et al. [83], developed similar tests in an engine test bench and on a vehicle chassis dynamometer with different LVEOs. Some of the tested oils were further studied for wear resistance in an engine test bench and a predefined cycle. Results showed that 5W30 LVEOs had higher oil consumption than the reference oil $15 \mathrm{~W} 40$, and also presented abnormal wear in some components of the engine. These results highlight the importance of an appropriate matching between the oil formulation, the engine design and working conditions. In the work developed by Singh et al. [108], it was also found a higher oil consumption from the lubricant with lower HTHS viscosity. They were tested three oil formulations, including a SAE 0W20 with a HTHS viscosity of $2.55 \mathrm{cP}$. Although this formulation gave positive results for fuel economy, its oil consumption was bigger than the oils with higher HTHS viscosity. $\mathrm{HC}$ and NOx emissions were also evaluated, and results showed a significant emissions reduction with the LVEOs when compared to the reference oil SAE 20W40.

Macián et al. [61], carried out different tests to evaluate the fuel consumption reduction of a 5W20 engine oil in comparison with higher SAE grade oils. Tests were developed under three conditions: motored, fired and under the NEDC driving cycle. During the motored tests, oils were compared according to the torque required by the dynamometer to motor the ICE. In the fired tests, stationary points of the engine working map were selected in order to develop a screening of the working zones of the engine with more 
potential for fuel consumption reduction. Results presented by the authors showed fuel consumption reduction for the three tests, and specially when the engine was working under low loads. This situation was mainly observed during the NEDC cycle, where the engine is operated under low load and speed for most of the cycle. Stationary test also showed that if the load is increased beyond $50 \%$, the break specific fuel consumption (BSFC) begins to increase. Overall, it is stated by the authors that a maximum $2-3 \%$ fuel economy can be expected from the use of LVEOs under transient working conditions.

In a recent work developed by Sander et al. [98], ultralow viscosity engine oils were evaluated for a passenger car internal combustion engine. These formulations correspond to the latest SAE grades, 0W20, 0W16, 0W12 and 0W8. The oil with the first SAE grade was taken as reference oil for the analysis of results. To develop the study and evaluate the formulations, a simulation tool was developed with special attention to the engine bearings and piston skirt. The model included elastohydrodynamic lubrication for these tribo-pairs. Results from the simulations were related to the working points of the WLTC driving cycle, this in order to analyze the potential fuel consumption and emissions reduction required by the legislation. A fuel consumption reduction up to $20 \%$ was obtained with the SAE $0 \mathrm{~W} 8$ oil formulation, however, fuel consumption increased at low speed and mediumhigh loads where asperity contact began to appear, resulting in an overall fuel economy of about $14 \%$. Regarding wear of the engine components, the oil formulations were evaluated for different wear risk parameters, such as asperity friction power loss. All the risk parameters presented an increase with the low viscosity oils, and specially for the SAE 0W8 oil, where the wear risk appears in a big part of the engine working map covered by the WLTC driving cycle.

For the Heavy-duty vehicles segment, most of the test for LVEOs evaluation have been developed in engine test benches, however in the last years, there have been a couple of studies including bus fleets, adding the real working conditions of these buses to fuel economy analysis.

Van Dam et al. [136], carried out a series of tests, using a Heavy-duty diesel engine on a test bench, the methodology used was the Volvo D12D Fuel Economy engine test procedure. This test was based on the 13 mode European Stationary Cycle (ESC) and weighing factors to obtain a total fuel consumption estimation. The study included the analysis of the effect of different base oils over fuel economy, different HTHS viscosity levels (4.16 to $3.35 \mathrm{cP}$ ) and friction and viscosity modifiers. The main conclusions of the study are the good correlation between the HTHS viscosity reduction and fuel economy; furthermore, significant results of fuel consumption reduction 
were obtained with the uses of FM additives, although their characteristics or composition was not depicted. To include the effect of the use LVEOs in the driveline of the vehicle, Taylor et al. [120] developed a research study with different oil formulations for the engine, gearbox and axle. The tests consisted of two parts, one developed in an engine tests bench following the World Harmonized Transient Cycle (WHTC) and the World Harmonized Stationary Cycle (WHSC). This test bench consisted of a driveline facility with the capability of measuring the energy losses of each component independently by placing multiple torquimeters. The second part of the study consisted of a controlled field test with two trucks using the driveline oil formulations and following a predefined route, including city, highway and hill driving conditions. Results of the tests gave a fuel consumption reduction of about $1.8 \%$ for the WHTC cycle and up to $3.1 \%$ for the WHSC in the working conditions of low load and high speed. Finally, in the field tests, the trucks consumed $1.8 \%$ less fuel with the LVEOs.

Later on, Van Dam et al. [137] continued studying the effect of some oil properties on the engine oil potential for fuel economy. It was included the effect of the viscosity index improver (VII), base oil viscosity index and the use of some additives such as dispersants, detergents and antiwear. Negligible effects on fuel consumption were found with the use of these additives in the different oil formulations. In order to evaluate the effect of the HTHS viscosity reduction on wear of the engine components, Van Dam et al. [135] studied the cylinder liner wear of a Heavy-duty diesel engine, and for three candidate oil formulations, and one oil as reference. The HTHS viscosity of the candidate oils varied from 5.35 to $3.81 \mathrm{cP}$. Results demonstrated the close relationship between the HTHS viscosity and wear of the liner. in this way, wear was higher for the oil with the lowest HTHS viscosity; while the candidate oil with $3.5 \mathrm{cP}$ HTHS viscosity had a better wear protection than the reference oil. The same tendency was observed taking the oil viscosity at $100^{\circ} \mathrm{C}$.

Regarding fleet tests for the Heavy-duty segment, Brownie et al. [7], carried out a test with two buses, two oils formulations, $15 \mathrm{~W} 40$ (3.97 cP HTHS) and $5 \mathrm{~W} 30$ (3.55 cP HTHS), and a predefined test route of one hour duration. Both vehicles were used to evaluate the two oil formulations, and multiple repetitions were necessary to obtain results with statistical significance. For the data analysis, they were highlighted some external factors that added variability to the results, such as ambient temperature, wind, driving style and time of the day when the test was carried out. Around $85 \%$ of the data after post-processing was used for the final analysis. Results showed a fuel consumption reduction for the two buses, and specially for the urban part of the driving cycle, obtaining an overall $1.7 \%$ fuel economy. 
In a subsequent study developed by Van Dam et al. [134], different oil formulations were blended for fuel economy and tested by means of multiple methodologies. In one of them, 12 Heavy-duty vehicles were used and three candidate oil formulations of SAE grades 5W30 and 5W20; the reference oil was a $15 \mathrm{~W} 40$ with a conventional formulation. The entire test had a duration of two years and data of fuel consumption was recorded by means of the electronic data logging module in each vehicle. As expected, results of fuel economy improvements were directly correlated with the decrease of the HTHS viscosity.

A long term fleet test was also developed by Macian et al. [62-64] with the aim of evaluating the effect of HTHS viscosity over the fuel consumption of a group of public transport buses. An extensive oil analysis was also developed to monitor the engine wear and performance of the oils, by means of laboratory tests, including viscosity, TBN and TAN, oxidation, presence of wear metals, among others. The test included 39 buses with diesel and compressed natural gas (CNG) fuels, and three different bus models. Four engine oils were selected from commercial formulations, following the buses' OEMs recommendations, including the SAE grades $15 \mathrm{~W} 40$ (4.08 cP HTHS), $10 \mathrm{~W} 40(3.85 \mathrm{cP})$ and two $5 \mathrm{~W} 30$ oils (3.59 and $3.57 \mathrm{cP}$ HTHS). Due to the high variability imposed by external factors, such as ambient temperature, service route of the buses and load, the data analysis was developed by means of Analysis of Variance (ANOVA) and for each engine model. ANOVA is a statistical tool that allowed to determine the significance of the experimental variables over the fuel consumed by the vehicles, and therefore obtain the effect of the LVEOs on fuel economy. This test was carried out in two stages corresponding to two ODI periods of $30.000 \mathrm{~km}$ each. Results of the test showed fuel consumption reduction for all the bus models, and specially for the CNG buses with a $3.27 \%$ of fuel economy. Results for one of the groups with diesel fuel, although presented about $1 \%$ fuel reduction, they were not statistically significant. Regarding engine wear and oil analysis, samples of the different oil formulations were taken from the buses' crankcase at predefined periods between 3.000 and $5.000 \mathrm{~km}$. Results of the analysis showed no significant differences regarding engine wear with the use of LVEOs. Furthermore, candidate oils presented better performance characteristics than the reference oils, probably indicating that their formulation had been optimized for both fuel economy and wear protection.

Tormos et al. [128, 129] continued to develop the field tests in order to evaluate new engine oil formulations with ever-lower HTHS viscosities. They were included non-commercial engine oils, formulated specifically for the test. Candidate oils had an HTHS viscosity of $3.05 \mathrm{cP}$, a value lower than the one 
specified by ACEA for Heavy-duty vehicles. During this test stage, another bus model with diesel fuel was included to the test, accounting for a total of 49 public transport vehicles. Results of this stage were in line with those obtained in the previous two stages for both fuel consumption reduction and engine wear. Fuel consumption reduction was between 1.6 and $4.5 \%$ for the diesel and CNG buses, however for one of the bus models, fuel consumption increased significantly. This led to the conclusion that fuel economy highly depends on the engine design, fuel and service route.

\subsubsection{Use of friction modifiers}

Engine lubricant oils usually have FM additives in their formulation to reduce boundary friction. Their working mechanisms are multiple as well as their components and formulation. In this way, FMs can be classified in three different types: compounds that are absorbed by the surfaces, compounds that create a layer in the surfaces, and solid materials dispersed in the lubricant oil.

Regarding the second type of FMs, molybdenum (Mo) is the most used component in the additives packages. Once Mo comes into contact with the engine surfaces, it chemically reacts forming molybdenum disulfide $\left(\mathrm{MoS}_{2}\right)$. The structure of this compound consists of layers formed in the junctions of the asperities; in this way, when the asperities of the moving surfaces come into contact, the force required for one surface to slide over the other is reduced, resulting in lower friction. Although the exact mechanism of how these $\mathrm{MoS}_{2}$ layers are formed is still under study, it has been found that they only form in parts of the surface where rubbing takes place [85].

Mo FMs have been extensively used in lubricant oil formulations for gasoline engines, as their effect over friction reduction in the boundary/mixed lubrication regime, has been tested and proven in different studies [97, 109]. For diesel engines on the other hand, soot produced during combustion has been found to react with Mo, causing the additive to lose its properties and capability to reduce friction $[51,101]$. The use of Mo FM for diesel lubricant oils therefore, depends on the development and implementation of techniques to reduce soot in these engines, such as fuel post-injections $[22,90]$.

Given that soluble Mo FM requires a chemical reaction to effectively reduce friction, particles of $\mathrm{MoS}_{2}$ and/or graphite can also be added to the lubricant. When these particles are between two rubbing surfaces, they create a thirdbody barrier between the asperities reducing the force needed to slide the surfaces. The working mechanism of these particles however, depends on their 
appropriate dispersion in the oil, as they can agglomerate during engine shut down. In recent years, nanoparticles of different compounds, such as carbon, have been studied as they can reduce friction, as well as have better dispersion in the oil $[14,117]$.

\subsubsection{LVEOs current and future market share}

For diesel vehicles, including LDD and HDD, engine oil formulations have seen a gradual decrease of its HTHS viscosity through the years, thanks to the significant fuel consumption reduction obtained with these formulations. In the EU, and for the LDD vehicle segment, the inclusion of ever-lower viscosities is expected to continue, involving one of the latest SAE grade oil categories 0 W16. Predictions for the market share of LVEOs for this vehicles' segment have been developed by Ricardo [92] and are presented in the following Figure 2.14. As it can be seen, 0W20 and 0W16 oils are expected to account for a big part of the oil market for 2025 to 2030 .

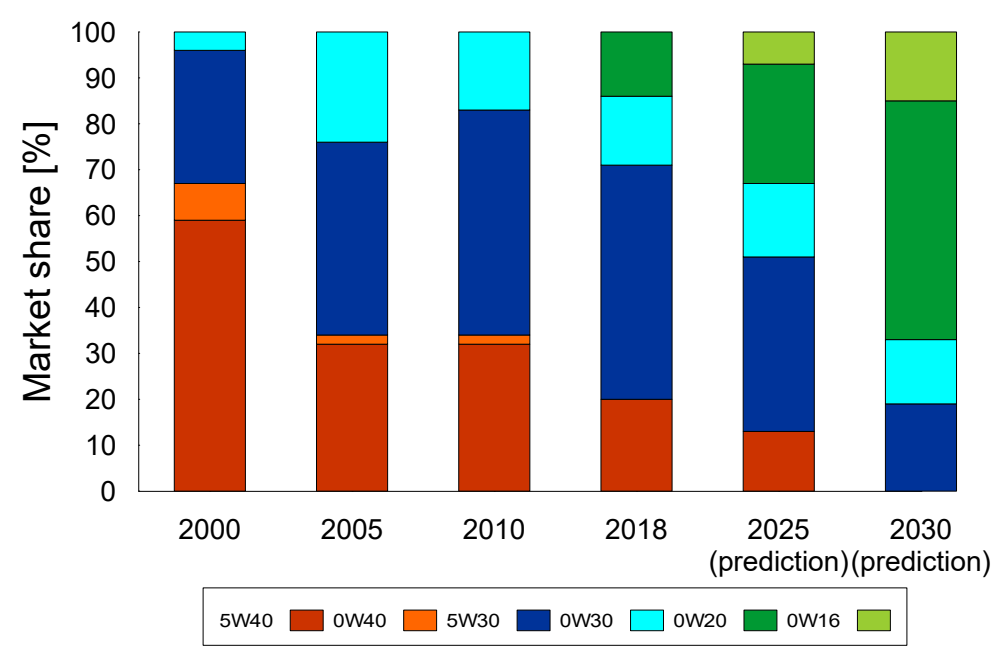

Figure 2.14. LVEOs market share for Light-duty diesel vehicles. Adapted from [92].

For the HDD vehicles, this change towards LVEOs has been slower than for LDD, specially due to the concern of maintaining the engine protection against wear and associated maintenance costs, a primary concern for manufactures and fleet owners. A market share study of LVEOs for the HDD segment in the EU has also been developed by Ricardo [92] and presented in Figure 2.15. 


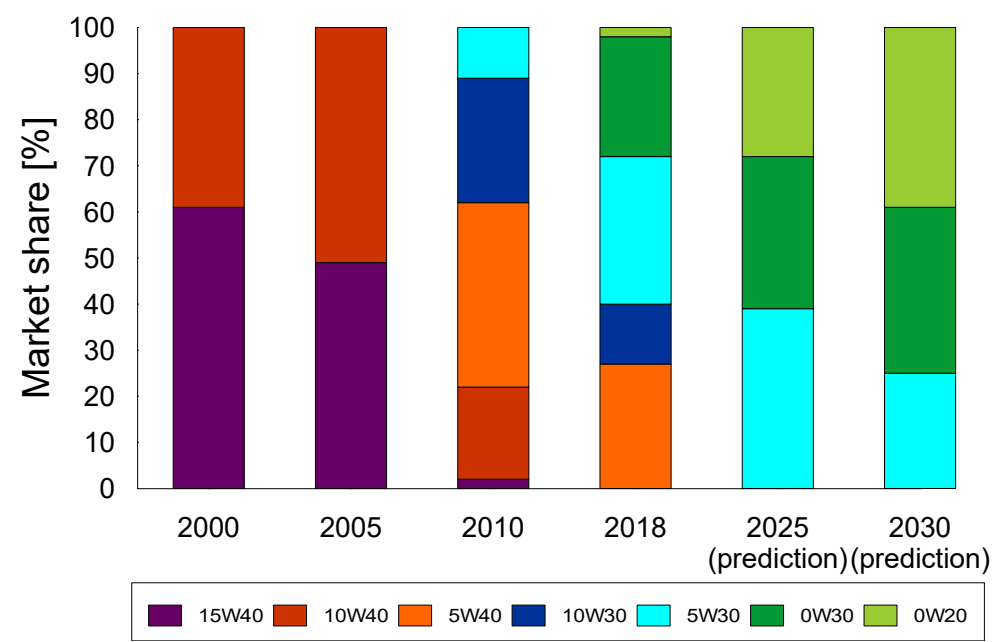

Figure 2.15. LVEOs market share for Hight-duty diesel vehicles. Adapted from [92].

\subsection{Discussion}

The literature review presented in this chapter along with the specific objectives presented in Chapter 1 defined the research approach at different stages of the Thesis development. Specifically, two main research gaps were drawn from this review. The first one related to the use of LVEO formulations and their contribution to fuel economy evaluated from the view point of the interaction between the oil and the driving conditions of the vehicle. As described in Section 2.6.3, different authors have acknowledged the link between the total fuel economy given by an oil and the working conditions of the vehicle, including research developed at CMT-Motores Térmicos. Up to this point, this joint effect had not been addressed directly and therefore, it represented an important field of research in order to advance and contribute to increase the fuel economy potential of these oils. The second gap, arose from the need of a dedicated experimental facility to measure and analyze the friction losses in the engine, specifically in the piston-cylinder liner tribopair. As described in Section 2.5.2, different floating liner test rigs have been developed, including some commercially available; however, for the research presented here and future works in the research line at CMT-Motores Térmicos, it was fundamental to develop a test rig from the scratch, adjusted to the requirements and limitations defined for this work, and specially without restrictions for future modifications and improvements. In line with this experimental work, the literature review showed that it was important to 
complement it with theoretical analysis; in this case, with the development of an own simulation model for the lubrication of the piston compression ring and representative of the working conditions of the floating liner developed here.

\section{Bibliography}

[1] ACEA. ACEA European oil sequences. European Union, 2016.

[2] M. Ahmed, H. Xianjun, R. Fiifi, and M. Ezzat. An analytical study of tribological parameters between piston ring and cylinder liner in internal combustion engines. Proceedings of the Institution of Mechanical Engineers, Part K: Journal of Multi-body Dynamics, 230(4):329-349, 2016. doi:10.1177/1464419315605922.

[3] K. Akiyama, F. Ueda, J. Miyake, K. Tasaka, and S. Sugiyama. Fuel economy performance of the highly efficient fuel economy oils using chassis dynamometer test. In International Fuels \& $\&$ Lubricants Meeting $\&$ Exposition. SAE International, oct 1993. doi: $10.4271 / 932690$.

[4] ASTM International. D341-17 Standard Practice for Viscosity-Temperature Charts for Liquid Petroleum Products. West Conshohocken, PA, 2017. doi:10.1520/D0341-17.

[5] ASTM International. D6278-17e1 Standard Test Method for Shear Stability of Polymer Containing Fluids Using a European Diesel Injector Apparatus. West Conshohocken, PA, 2017. doi:10.1520/D6278-17E01.

[6] P. Bergmann and F. Grun. Modeling wear of journal bearings. In COMSOL Conference Munich 2016. COMSOL, oct 2016.

[7] D. Browne, M. Dewey, S. Graham, M. Sutton, M. Munday, and et al. Novel fuel efficiency engine lubricants for urban transit applications. In SAE 2014 International Powertrain, Fuels $\&$ Lubricants Meeting. SAE International, oct 2014. doi:10.4271/ 2014-01-2793.

[8] A. Cameron. Basic Lubrication Theory, Third Edition. Ellis Horwood Limited, Sussex, 1981.

[9] P. Carden, D. Bell, M. Priest, and D. Barrell. Piston assembly friction losses: comparison of measured and predicted data. In SAE 2006 World Congress 83 Exhibition. SAE International, apr 2006. doi:10.4271/2006-01-0426.

[10] S. H. Cho, S. T. Ahn, and Y. H. Kim. A simple model to estimate the impact force induced by piston slap. Journal of Sound and Vibration, 255(2):229 - 242, 2002. doi:10.1006/jsvi.2001.4152.

[11] J. Cui, P. Yang, Z. M. Jin, and D. Dowson. Transient elastohydrodynamic analysis of elliptical contacts. Part 3: Non-Newtonian lubricant solution under isothermal and thermal conditions. Proceedings of the Institution of Mechanical Engineers, Part J: Journal of Engineering Tribology, 221(1):63-73, 2007. doi:10.1243/13506501JET165.

[12] V. D'Agostino, S. Della Valle, A. Ruggiero, and A. Senatore. A study on the piston top ring lubrication using the open-end boundary condition. In Aimeta International Tribology Conference, Italy, sep 2002. 
[13] V. D'Agostino and A. Senatore. 10 - fundamentals of lubrication and friction of piston ring contact. In H. Rahnejat, editor, Tribology and Dynamics of Engine and Powertrain, pages 343 - 386. Woodhead Publishing, 2010.

[14] W. Dai, B. Kheireddin, H. Gao, and H. Liang. Roles of nanoparticles in oil lubrication. Tribology International, 102:88 - 98, 2016. doi:10.1016/j.triboint.2016.05.020.

[15] C. Delprete, A. Razavykia, and P. Baldissera. Detailed analysis of piston secondary motion and tribological performance. International Journal of Engine Research, 0(0):1-15, 2019. doi:10.1177/1468087419833883.

[16] N. Dolatabadi, M. Forder, N. Morris, R. Rahmani, H. Rahnejat, and S. Howell-Smith. Influence of advanced cylinder coatings on vehicular fuel economy and emissions in piston compression ring conjunction. Applied Energy, 259:114129, 2020. doi:10. 1016/j . apenergy . 2019.114129.

[17] D Dowson. Piston assemblies; background and lubrication analysis. In C M Taylor, editor, Engine Tribology, volume 26, pages 213 - 240. Elsevier, 1993. doi:10.1016/ S0167-8922(08)70013-0.

[18] D. Dowson, P. N. Economou, B. L. Ruddy, P. J. Strachan, and A. J. S. Baker. Piston ring lubrication. Part II. Theoretical analysis of a single ring and a complete ring pack. Energy conservation through fluid film lubrication technology: frontiers in research and design, pages 23-52, 1979.

[19] D. Dowson and G. R. Higginson. Elasto-hydrodynamic Lubrication: The Fundamentals of Roller and Gear Lubrication. Pergamon Press, 1965.

[20] Z. Dursunkaya, R. Keribar, and V. Ganapathy. A model of piston secondary motion and elastohydrodynamic skirt lubrication. Journal of Tribology, 116(4):777-785, 1994. doi : 10.1115/1.2927332.

[21] H. G. Elrod. A cavitation algorithm. Journal of Tribology, 103(3):350-354, 1981. doi:10.1115/1.3251669.

[22] C. Fan, C. Song, G. Lv, J. Wei, X. Zhang, and et al. Impact of post-injection strategy on the physicochemical properties and reactivity of diesel in-cylinder soot. Proceedings of the Combustion Institute, 37(4):4821-4829, 2019. doi:10.1016/j.proci.2018.08. 001.

[23] G. Garcia-Atance Fatjo, E.H. Smith, and I. Sherrington. Piston-ring film thickness: Theory and experiment compared. Proceedings of the Institution of Mechanical Engineers, Part J: Journal of Engineering Tribology, 232(5):550-567, 2018. doi: 10.1177/1350650117722257.

[24] C. R. Ferguson and A. T. Kirkpatrick. Internal combustion engines: applied thermosciences. John Wiley \& Sons, New York [etc.], 2015.

[25] FEV. VIRTUAL ENGINE. Powertrain dynamics in your hands. URL: https:// virtualdynamics.fev.com/file/VIRTUALENGINE_Brochure_2020_web.pdf.

[26] G. Fontaras, E. Vouitsis, and Z. Samaras. Experimental evaluation of the fuel consumption and emissions reduction potential of low viscosity lubricants. In Powertrains, Fuels \& Lubricants Meeting. SAE International, jun 2009. doi:10.4271/ 2009-01-1803.

[27] I. E. Fox. Numerical evaluation of the potential for fuel economy improvement due to boundary friction reduction within heavy-duty diesel engines. Tribology International, 38(3):265-275, 2005. doi:10.1016/j.triboint.2004.08.010. 
[28] E. Fuentes and K. Kanase. Friction and wear in engine bearings. In P.A. Lakshminarayanan and N.S. Nayak, editors, Critical Component Wear in Heavy Duty Engines, pages 197-252. John Wiley \& Sons, Ltd, 2011. doi:10.1002/9780470828847. ch12.

[29] S. Furuhama. A dynamic theory of piston ring lubrication. Bull. JSME, 3:291-297, 01 1960. doi:10.1299/jsme1958.2.423.

[30] S. Furuhama and S. Sasaki. New device for the measurement of piston frictional forces in small engines. In 1983 SAE International Off-Highway and Powerplant Congress and Exposition. SAE International, sep 1983. doi:https://doi.org/10.4271/831284.

[31] S. Furuhama and S. Sasaki. Effect of oil properties on piston frictional forces. International Journal of vehicle design, 7(1-2):133-150, 1986.

[32] S. Furuhama and M. Takiguchi. Measurement of piston frictional force in actual operating diesel engine. SAE Transactions, pages 2896-2914, 1979.

[33] D. W. Gebretsadik, J. Hardell, and B. Prakash. Tribological performance of tin-based overlay plated engine bearing materials. Tribology International, 92:281- 289, 2015. doi:10.1016/j.triboint.2015.06.014.

[34] M Gore, R Rahmani, H Rahnejat, and P D King. Assessment of friction from compression ring conjunction of a high-performance internal combustion engine: A combined numerical and experimental study. Proceedings of the Institution of Mechanical Engineers, Part C: Journal of Mechanical Engineering Science, 230(12):2073-2085, 2016. doi:10.1177/0954406215588480.

[35] M. Gore, M. Theaker, S. Howell-Smith, H. Rahnejat, and P. D. King. Direct measurement of piston friction of internal-combustion engines using the floating-liner principle. Proceedings of the Institution of Mechanical Engineers, Part D: Journal of Automobile Engineering, 228(3):344-354, 2014. doi:10.1177/0954407013511795.

[36] D.A. Green, K. Selby, R. Mainwaring, and R. Herrera. The effect of engine, axle and transmission lubricant, and operating conditions on heavy duty diesel fuel economy: Part 1: Measurements. SAE Int. J. Fuels Lubr., 5(1):480-487, 2012. doi:10.4271/ 2011-01-2129.

[37] J A Greenwood and J H Tripp. The contact of two nominally flat rough surfaces. Proceedings of the Institution of Mechanical Engineers, 185(1):625-633, 1970. doi: 10.1243/PIME_PROC_1970_185_069_02.

[38] K. P. Ha, J. S. Kim, M. R. Cho, and D. Y. Oh. Development of piston friction force measurement system. In SAE Powertrain 83 Fluid Systems Conference 83 Exhibition. SAE International, oct 2002. doi: https://doi.org/10.4271/2002-01-2902.

[39] G. M. Hamilton and S. L. Moore. Second paper: Comparison between measured and calculated thicknesses of the oil-film lubricating piston rings. Proceedings of the Institution of Mechanical Engineers, 188(1):262-268, 1974. doi:10.1243/PIME\_PROC \ _1974\_188\_029\_02.

[40] J. B. Heywood. Internal combustion engine fundamentals. McGraw-Hill, 1988.

[41] K. Holmberg, P. Andersson, and A. Erdemir. Global energy consumption due to friction in passenger cars. Tribology International, 47:221-234, 2012. doi:10.1016/j . triboint.2011.11.022.

[42] K. Holmberg, P. Andersson, N. O. Nylund, K. Makela, and A. Erdemir. Global energy consumption due to friction in trucks and buses. Tribology International, 78:94 - 114, 2014. doi:10.1016/j.triboint.2014.05.004. 
[43] M. Hoshi. Reducing friction losses in automobile engines. Tribology International, 17(4):185 - 189, 1984. doi:10.1016/0301-679X (84)90017-3.

[44] L. Houpert. New results of traction force calculations in elastohydrodynamic contacts. Journal of Tribology, 107(2):241-245, 1985. doi:10.1115/1.3261033.

[45] C. S. Hsu and P. R. Robinson. Springer handbook of petroleum technology. Springer, Cham, 2017.

[46] I. Hutchings and P. Shipway. 4 - lubricants and lubrication. In Ian Hutchings and Philip Shipway, editors, Tribology (Second Edition), pages 79-105. Butterworth-Heinemann, 2017. doi:10.1016/B978-0-08-100910-9.00004-0.

[47] INSIGHT. ACEA revisions coming soon. Accessed: 25/02/2021. URL: https://www.infineuminsight.com/en-gb/articles/specification-updates/ acea-revisions-coming-soon/?utm_campaign=Inf ineum+Insight+Feb21+email\& utm_medium=email\&utm_source=Inf ineum+Insight.

[48] M. R Islam. A floating liner facility and studies of friction at a reciprocating pistoncylinder wall interface. PhD thesis, The University of Nottingham, 2016.

[49] C. J. James. Analysis of parasitic losses in heavy duty diesel engines. PhD thesis, Massachusetts Institute of Technology, 2012.

[50] J. Y. Jang and M. M. Khonsari. Lubrication with a non-newtonian fluid. In Q. J. Wang and Y. W. Chung, editors, Encyclopedia of Tribology, pages 2146-2151. Springer US, 2013. doi:10.1007/978-0-387-92897-5_151.

[51] T. Kaneko, M. Yamashita, M. Ohori, and M. Murakami. Development of low sulfated ash and fuel economy diesel engine oil. In Powertrains, Fuels 85 Lubricants Meeting. SAE International, jun 2009. doi:10.4271/2009-01-1845.

[52] R. Keribar, Z. Dursunkaya, and M.F. Flemming. An integrated model of ring pack performance. ASME. J. Eng. Gas Turbines Power, 113(3):382-389, 1991. doi:10. $1115 / 1.2906242$.

[53] K. S. Kim, T. Godward, M. Takiguchi, and S. Aoki. Part 2: The effects of lubricating oil film thickness distribution on gasoline engine piston friction. In $S A E$ World Congress ES Exhibition. SAE International, apr 2007. doi:10.4271/2007-01-1247.

[54] K. S. Kim, P. Shah, M. Takiguchi, and S. Aoki. Part 3: A study of friction and lubrication behavior for gasoline piston skirt profile concepts. In SAE World Congress \& Exhibition. SAE International, apr 2009. doi:10.4271/2009-01-0193.

[55] M. Kushwaha and H. Rahnejat. Transient elastohydrodynamic lubrication of finite line conjunction of cam to follower concentrated contact. Journal of Physics D: Applied Physics, 35(21):2872-2890, 2002. doi:10.1088/0022-3727/35/21/327.

[56] T. Law, D. MacMillan, P. J. Shayler, G. Kirk, I. Pegg, and R. Stark. A new floating-liner test rig design to investigate factors influencing piston-liner friction. In SAE 2012 World Congress \& Exhibition. SAE International, apr 2012. doi: 10.4271/2012-01-1328.

[57] K. Liao, Y. Liu, D. Kim, P. Urzua, and T. Tian. Practical challenges in determining piston ring friction. Proceedings of the Institution of Mechanical Engineers, Part J: Journal of Engineering Tribology, 227(2):112-125, 2013. doi: 10.1177/1350650112465364.

[58] K. Liu, Y. B. Xie, and C. L. Gui. Two-dimensional lubrication study of the piston ring pack. Proceedings of the Institution of Mechanical Engineers, Part J: Journal of Engineering Tribology, 212(3):215-220, 1998. doi:10.1243/1350650981542029. 
[59] L. Liu and T. Tian. Implementation and improvements of a flow continuity algorithm in modeling ring/liner lubrication. SAE Transactions, 114:1165-1173, 2005.

[60] M. T. Ma, I. Sherrington, and E. H. Smith. Implementation of an algorithm to model the starved lubrication of a piston ring in distorted bores: prediction of oil flow and onset of gas blow-by. Proceedings of the Institution of Mechanical Engineers, Part J: Journal of Engineering Tribology, 210(1):29-44, 1996. doi:10.1243/PIME\_PROC \ _1996\_210\_475\_02.

[61] V. Macián, B. Tormos, V. Bermúdez, and L. Ramírez. Assessment of the effect of low viscosity oils usage on a light duty diesel engine fuel consumption in stationary and transient conditions. Tribology International, 79:132-139, 2014. doi:10.1016/j . triboint.2014.06.003.

[62] V. Macián, B. Tormos, G. Miró, and T. Pérez. Assessment of low-viscosity oil performance and degradation in a heavy duty engine real-world fleet test. Proceedings of the Institution of Mechanical Engineers, Part J: Journal of Engineering Tribology, 230(6):729-743, 2016. doi:10.1177/1350650115619612.

[63] V. Macián, B. Tormos, S. Ruiz, and G. Miró. Low viscosity engine oils: Study of wear effects and oil key parameters in a heavy duty engine fleet test. Tribology International, 94:240-248, 2016. doi:10.1016/j.triboint.2015.08.028.

[64] V. Macián, B. Tormos, S. Ruíz, and L. Ramírez. Potential of low viscosity oils to reduce $\mathrm{CO}_{2}$ emissions and fuel consumption of urban buses fleets. Transportation Research Part D: Transport and Environment, 39:76-88, 2015. doi:10.1016/j.trd. 2015.06 .006$.

[65] D. Madden, K. Kim, and M. Takiguchi. Part 1: Piston friction and noise study of three different piston architectures for an automotive gasoline engine. In SAE 2006 World Congress \& Exhibition. SAE International, apr 2006. doi:10.4271/2006-01-0427.

[66] M. A. Malik, B. Rashid, S. A. Qasim, and S. Khushnood. Modeling and simulation of elastohydrodynamic lubrication of piston skirts considering elastic deformation in the initial engine start-up. In ASME/STLE 2004 International Joint Tribology Conference, Parts $A$ and B. ASME, 10 2004. doi:10.1115/TRIB2004-64101.

[67] S. H. Mansouri and V. W. Wong. Effects of piston design parameters on piston secondary motion and skirt - liner friction. Proceedings of the Institution of Mechanical Engineers, Part J: Journal of Engineering Tribology, 219(6):435-449, 2005. doi: 10.1243/135065005X34026.

[68] G. K. Miltsios, D. J. Patterson, and T. C. Papanastasiou. Solution of the lubrication problem and calculation of the friction force on the piston rings. Journal of Tribology, 111(4):635-641, 1989. doi:10.1115/1.3261988.

[69] N. Morris, M. Mohammadpour, R. Rahmani, and H. Rahnejat. Optimisation of the piston compression ring for improved energy efficiency of high performance race engines. Proceedings of the Institution of Mechanical Engineers, Part D: Journal of Automobile Engineering, 231(13):1806-1817, 2017. doi:10.1177/0954407016686249.

[70] N. Morris, R. Rahmani, H. Rahnejat, P. D. King, and B. Fitzsimons. The influence of piston ring geometry and topography on friction. Proceedings of the Institution of Mechanical Engineers, Part J: Journal of Engineering Tribology, 227(2):141-153, 2013. doi:10.1177/1350650112463534.

[71] N. Morris, R. Rahmani, H. Rahnejat, P. D. King, and B. Fitzsimons. Tribology of piston compression ring conjunction under transient thermal mixed regime of 
lubrication. Tribology International, 59:248-258, 2014. doi:10.1016/j.triboint. 2012.09 .002 .

[72] L. Moughon. Effects of piston design and lubricant selection on reciprocating engine friction. PhD thesis, Massachusetts Institute of Technology, 2006.

[73] R. A. Mufti, M. Priest, and R. J. Chittenden. Analysis of piston assembly friction using the indicated mean effective pressure experimental method to validate mathematical models. Proceedings of the Institution of Mechanical Engineers, Part D: Journal of Automobile Engineering, 222(8):1441-1457, 2008. doi:10.1243/09544070JAUT0469.

[74] Li C. H. Oh, K. P. and P. K. Goenka. Elastohydrodynamic lubrication of piston skirts. ASME. J. Tribol., 109(2):356 - 362, 1987. doi:10.1115/1.3261366.

[75] B. O'Rourke, D. Radford, and R. Stanglmaier. Tri-Axial force measurements on the cylinder of a motored SI engine operated on lubricants of differing viscosity. Journal of Engineering for Gas Turbines and Power, 132(9), 2010. doi:10.1115/1.4000608.

[76] B. O'Rourke, R. Stanglmaier, and D. Radford. Development of a floating-liner engine for improving the mechanical efficiency of high performance engines. In Motorsports Engineering Conference \& Exposition. SAE International, dec 2006. doi:10.4271/ 2006-01-3636.

[77] H. Overgaard, P. Klit, and A. Vølund. Investigation of different piston ring curvatures on lubricant transport along cylinder liner in large two-stroke marine diesel engines. Proceedings of the Institution of Mechanical Engineers, Part J: Journal of Engineering Tribology, 232(1):85-93, 2018. doi:10.1177/1350650117744100.

[78] N. Patir and H. S. Cheng. An average flow model for determining effects of threedimensional roughness on partial hydrodynamic lubrication. Journal of Tribology, 100:12-17, 1978. doi:10.1115/1.3453103.

[79] A. Paydas and E. H. Smith. A flow-continuity approach to the analysis of hydrodynamic journal bearings. Proceedings of the Institution of Mechanical Engineers, Part C: Mechanical Engineering Science, 206(1):57-69, 1992. doi:10.1243/ PIME \_PROC\_1992\_206\_095\_02.

[80] F. Payri González and J.M ${ }^{\mathrm{a}}$ Desantes Fernández. Motores de combustión interna alternativos. Reverté: Universitat Politècnica de València, Barcelona [etc.], 2011.

[81] M. S. M. Perera, S. Theodossiades, and H. Rahnejat. A multi-physics multi-scale approach in engine design analysis. Proceedings of the Institution of Mechanical Engineers, Part K: Journal of Multi-body Dynamics, 221(3):335-348, 2007. doi: 10.1243/14644193JMBD78.

[82] M. S. M. Perera, S. Theodossiades, and H. Rahnejat. Elasto-multi-body dynamics of internal combustion engines with tribological conjunctions. Proceedings of the Institution of Mechanical Engineers, Part K: Journal of Multi-body Dynamics, 224(3):261-277, 2010. doi:10.1243/14644193JMBD242.

[83] A. Permude, M. Pathak, V. Kumar, and S. Singh. Influence of low viscosity lubricating oils on fuel economy and durability of passenger car diesel engine. SAE Int. J. Fuels Lubr., 5(3):1426-1435, 2012. doi:10.4271/2012-28-0010.

[84] Y. Piao and S.D. Gulwadi. Numerical investigation of the effects of axial cylinder bore profiles on piston ring radial dynamics. ASME. J. Eng. Gas Turbines Power, 125(4):1081-1089, 2003. doi:10.1115/1.1610016.

[85] D. M. Pirro, M. Webster, and E. Daschner. Lubrication fundamentals, revised and expanded. CRC Press, Boca Raton, 2017. 
[86] R. Porter. New API certified CK-4 and FA-4 diesel engine oils are available beginning December $1 . \quad$ Accessed: 06/12/2019. URL: http://www.api.org/news-policy-and-issues/news/2016/11/18/ new-api-certified-diesel-engine-oils-are.

[87] W. W. Pulkrabek. Engineering fundamentals of the internal combustion engine. Prentice hall, New Jersey, 2000.

[88] R. Rahmani, H. Rahnejat, B. Fitzsimons, and D. Dowson. The effect of cylinder liner operating temperature on frictional loss and engine emissions in piston ring conjunction. Applied Energy, 191:568-581, 2017. doi:10.1016/j.apenergy. 2017. 01.098.

[89] H. Rahnejat. Tribology and dynamics of engine and powertrain: fundamentals, applications and future trends. Woodhead Publishing, Oxford [etc.], 2010.

[90] L. Rao, Y. Zhang, S. Kook, K. S. Kim, and C. B. Kweon. Understanding in-cylinder soot reduction in the use of high pressure fuel injection in a small-bore diesel engine. Proceedings of the Combustion Institute, 37(4):4839 - 4846, 2019. doi:10.1016/j. proci.2018.09.013.

[91] E. D. Rejowski, P. Mordente Sr, M. F. Pillis, and T. Casserly. Application of dlc coating in cylinder liners for friction reduction. In SAE 2012 World Congress 8 Exhibition. SAE International, apr 2012. doi:10.4271/2012-01-1329.

[92] Ricardo Energy and Environment. Lubricant's contribution to fuel economy. United Kingdom, 2019.

[93] C. J. A. Roelands. Correlation aspects of the viscosity-temperature-pressure relationships of lubricant oils. PhD thesis, Technische Universiteit Delft, 1966.

[94] B. L. Ruddy, D. Dowson, P. N. Economou, and A. J. S. Baker. Piston-ring lubrication. part iii. the influence of ring dynamics and ring twist. Energy conservation through fluid film lubrication technology: frontiers in research and design, pages 191-215, 1979.

[95] L. R. Rudnick. Lubricant additives: chemistry and applications. CRC press, Boca Raton, 2017.

[96] SAE International. SAE J300 Engine oil viscosity classification. United States, 2015.

[97] T. Sagawa, T. Ueno, K. Nakamura, T. Ishikawa, T. Ando, and M. Ishikawa. Development of 0W-20 ILSAC GF-3 gasoline engine oil. In Spring Fuels \& Lubricants Meeting $\&$ Exhibition. SAE International, may 2002. doi:10.4271/2002-01-1636.

[98] D. E. Sander, H. Allmaier, C. Knauder, and F Strömstedt. Potentials and risks of reducing friction with future ultra-low-viscosity engine oils. MTZ worldwide, 79(12):20-27, 2018. doi:10.1007/s38313-018-0124-3.

[99] D. E. Sander, H. Allmaier, and H. H. Priebsch. Friction and wear in automotive journal bearings operating in todays severe conditions. In Pranav $\mathrm{H}$ Darji, editor, Advances in Tribology, pages 143-172. InTech, 2016. doi:10.5772/61873.

[100] D.E. Sander, H. Allmaier, H.H. Priebsch, F.M. Reich, M. Witt, and et al. Impact of high pressure and shear thinning on journal bearing friction. Tribology International, 81:29-37, 2015. doi:10.1016/j.triboint.2014.07.021.

[101] M. Sasaki, Y. Kishi, T. Hyuga, H. Omata, S. Takeshima, I. Kurihara, and et al. Development of high performance heavy-duty diesel engine oil to extend oil drain intervals: 5W30 fully synthetic oil containing MoDTC. In CEC/SAE Spring Fuels $\&$ Lubricants Meeting \& Exposition. SAE International, 2000. doi:10.4271/ 2000-01-1992. 
[102] O. Sato, M. Takiguchi, A. Takayuki, Y. Seki, K. Fujimura, and Y. Tateishi. Improvement of piston lubrication in a diesel engine by means of cylinder surface roughness. In SAE 2004 World Congress 83 Exhibition. SAE International, mar 2004. doi: 10.4271/2004-01-0604.

[103] J. T. Sawicki and B. Yu. Analytical solution of piston ring lubrication using mass conserving cavitation algorithm. Tribology Transactions, 43(4):587-594, 2000. doi: $10.1080 / 10402000008982382$.

[104] H. Schwarze. Lubricants and the lubrication system. In Tschöke H Mollenhauer K., editor, Handbook of Diesel Engines, pages 359-376. Springer, 2010. doi:10.1007/ 978-3-540-89083-6_11.

[105] M. Söderfjäll, A. Almqvist, and R. Larsson. Component test for simulation of piston ring-cylinder liner friction at realistic speeds. Tribology International, 104:57 - 63, 2016. doi:10.1016/j.triboint.2016.08.021.

[106] M. Söderfjäll, H. M. Herbst, R. Larsson, and A. Almqvist. Influence on friction from piston ring design, cylinder liner roughness and lubricant properties. Tribology International, 116:272 - 284, 2017. doi:10.1016/j.triboint.2017.07.015.

[107] I. Sherrington and E. H. Smith. The measurement of piston-ring friction by the "floating-liner" method. SAE paper, (884707), 1988.

[108] S. K. Singh, S. Singh, and A. K. Sehgal. Impact of low viscosity engine oil on performance, fuel economy and emissions of light duty diesel engine. In SAE 2016 International Powertrains, Fuels \& Lubricants Meeting. SAE International, oct 2016. doi: 10.4271/2016-01-2316.

[109] M. Skjoedt, R. Butts, D. N. Assanis, and S. V. Bohac. Effects of oil properties on spark-ignition gasoline engine friction. Tribology International, 41(6):556-563, 2008. doi:10.1016/j.triboint.2007.12.001.

[110] E. H. Smith, C. A. Clark, and I. Sherrington. The measurement of piston assembly friction in a motored engine. In IMechE Conference on Universal and Poly Research on IC Engines, pages 185-190, 1991.

[111] M. J. Souza De Carvalho, P. Seidl, C. Rodriguez Pereira Belchior, and J. R. Sodre. Lubricant viscosity and viscosity improver additive effects on diesel fuel economy. Tribology international, 43(12):2298-2302, 2010. doi:10.1016/j.triboint.2010.07. 014.

[112] H. Spikes. Friction modifier additives. Tribology Letters, 60(1):5, 2015. doi:10.1007/ s11249-015-0589-z.

[113] Gwidon W. Stachowiak and Andrew W. Batchelor. Engineering Tribology. Butterworth-Heinemann, Boston, 2014.

[114] R. Stanley, D. Taraza, N. Henein, and W. Bryzik. A simplified friction model of the piston ring assembly. In International Congress 83 Exposition. SAE International, 1999. doi:10.4271/1999-01-0974.

[115] C. Sung-Woo, C. Sang-Min, and B. Choong-Sik. Frictional modes of barrel shaped piston rings under flooded lubrication. Tribology International, 33(8):545 - 551, 2000. doi:10.1016/S0301-679X (00)00103-1.

[116] M Takiguchi, K Machida, and S Furuhama. Piston friction force of a small high speed gasoline engine. Journal of Tribology, 110(1):112-118, 1988. doi:10.1115/1.3261548. 
[117] Z. Tang and S. Li. A review of recent developments of friction modifiers for liquid lubricants (2007-present). Current Opinion in Solid State and Materials Science, 18(3):119 - 139, 2014. doi:10.1016/j.cossms.2014.02.002.

[118] D. Taraza, N. Henein, and W. Bryzik. Friction losses in multi-cylinder diesel engines. In SAE 2000 World Congress. SAE International, mar 2000. doi:10.4271/ 2000-01-0921.

[119] C.M. Taylor. Lubrication regimes and the internal combustion engine. In C.M. Taylor, editor, Engine Tribology, volume 26, pages 75-87. Elsevier, 1993.

[120] R. Taylor, K. Selby, R. Herrera, and D. A. Green. The effect of engine, axle and transmission lubricant, and operating conditions on heavy duty diesel fuel economy: Part 2: Predictions. In SAE International Powertrains, Fuels and Lubricants Meeting. SAE International, aug 2011. doi:10.4271/2011-01-2130.

[121] R. I. Taylor. Squeeze film lubrication in piston rings and reciprocating contacts. Proceedings of the Institution of Mechanical Engineers, Part J: Journal of Engineering Tribology, 229(8):977-988, 2015. doi:10.1177/1350650114564234.

[122] R.I. Taylor and B.R. de Kraker. Shear rates in engines and implications for lubricant design. Proceedings of the Institution of Mechanical Engineers, Part J: Journal of Engineering Tribology, 231(9):1106-1116, 2017. doi:10.1177/1350650117696181.

[123] M. Teodorescu, M. Kushwaha, H. Rahnejat, and S. J. Rothberg. Multi-physics analysis of valve train systems: From system level to microscale interactions. Proceedings of the Institution of Mechanical Engineers, Part K: Journal of Multi-body Dynamics, 221(3):349-361, 2007. doi:10.1243/14644193JMBD77.

[124] M. Teodorescu, D. Taraza, N.. Henein, and W. Bryzik. Simplified elasto-hydrodynamic friction model of the cam-tappet contact. In SAE 2003 World Congress \& Exhibition. SAE International, mar 2003. doi:10.4271/2003-01-0985.

[125] S. Teraguchi, W. Suzuki, M. Takiguchi, and D. Sato. Effects of lubricating oil supply on reductions of piston slap vibration and piston friction. In SAE 2001 World Congress. SAE International, mar 2001. doi:10.4271/2001-01-0566.

[126] E. Tomanik, F. Profito, B. Sheets, and R. Souza. Combined lubricant-surface

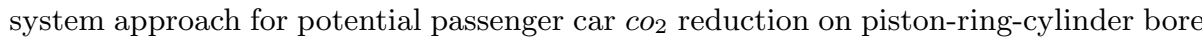
assembly. Tribology International, 149:105514, 2020. doi:10.1016/j.triboint. 2018. 12.014 .

[127] B. Tormos, J. Martín, D. Blanco-Cavero, and A.J. Jiménez-Reyes. One-dimensional modeling of mechanical and friction losses distribution in a four-stroke internal combustion engine. ASME. J. of Tribology, 142(1):011703, 2020. doi:10.1115/1. 4044856 .

[128] B Tormos, G. Miró, L. Ramirez, and T. Pérez. Real world fleet test to determine the impact of low viscosity engine oils from heavy-duty CNG and diesel buses - Part II: Oil performance. In International Powertrains, Fuels \& Lubricants Meeting. SAE International, oct 2017. doi:10.4271/2017-01-2351.

[129] B. Tormos, L. Ramirez, G. Miró, and T. Pérez. Real world fleet test to determine the impact of low viscosity engine oils from heavy-duty CNG and diesel buses - Part I: Fuel consumption. In International Powertrains, Fuels \& Lubricants Meeting. SAE International, oct 2017. doi:10.4271/2017-01-2353.

[130] B. Tormos, L. Ramírez, J. Johansson, M. Björling, and R. Larsson. Fuel consumption and friction benefits of low viscosity engine oils for heavy duty applications. Tribology International, 110:23-34, 2017. doi:10.1016/j.triboint.2017.02.007. 
[131] S. C. Tung and M. L. McMillan. Automotive tribology overview of current advances and challenges for the future. Tribology International, 37(7):517 - 536, 2004. doi: 10.1016/j.triboint.2004.01.013.

[132] M. Urabe, T. Tomomatsu, K. Ishiki, M. Takiguchi, and T. Someya. Variation of piston friction force and ring lubricating condition in a diesel engine with egr. In International Fall Fuels and Lubricants Meeting and Exposition. SAE International, oct 1998. doi: 10.4271/982660.

[133] H. M. Uras and D. J.. Patterson. Measurement of piston and ring assembly friction instantaneous IMEP method. In SAE International Congress and Exposition. SAE International, feb 1983. doi:10.4271/830416.

[134] W. Van Dam, J. Booth, and G. Parsons. Taking heavy duty diesel engine oil performance to the next level, part 1: Optimizing for improved fuel economy. In SAE 2014 International Powertrain, Fuels $\&$ Lubricants Meeting. SAE International, oct 2014. doi: 10.4271/2014-01-2792.

[135] W. Van Dam, M. W. Cooper, K. Oxorn, and S. Richards. Observations from cylinder liner wear studies in heavy duty diesel engines and the evolution towards lower viscosity heavy duty engine lubricants. In SAE 2011 World Congress \&6 Exhibition. SAE International, apr 2011. doi:10.4271/2011-01-1207.

[136] W. Van Dam, P. Kleijwegt, M. Torreman, and G. Parsons. The lubricant contribution to improved fuel economy in heavy duty diesel engines. In SAE 2009 Commercial Vehicle Engineering Congress $\& 5$ Exhibition. SAE International, oct 2009. doi:10. 4271/2009-01-2856.

[137] W.. Van Dam, T. Miller, G. M. Parsons, and Y. Takeuchi. The impact of lubricant viscosity and additive chemistry on fuel economy in heavy duty diesel engines. In Powertrains, Fuels \& Lubricants Meeting. SAE International, aug 2011. doi:10.4271/ 2011-01-2124.

[138] R. Wakabayashi, M. Kawanishi, H. Yoshida, and Y. Ozaki. The effects of piston rings and liner break-in on lubricating condition. In SAE World Congress $\mathcal{E}$ Exhibition. SAE International, apr 2007. doi:10.4271/2007-01-1250.

[139] R. Wakabayashi, M. Takiguchi, T. Shimada, Y. Mizuno, and T. Yamauchi. The effects of crank ratio and crankshaft offset on piston friction losses. In SAE 2003 World Congress \& Exhibition. SAE International, mar 2003. doi:10.4271/2003-01-0983.

[140] Y. Wakuri, T. Hamatake, M. Soejima, and T. Kitahara. Piston ring friction in internal combustion engines. Tribology International, 25(5):299-308, 1992 . doi: 10.1016/0301-679X (92) 90027-K.

[141] Y. Wakuri, M. Soejima, T. Kitahara, M. Nunotani, and Y. Kabe. Characteristics of piston ring friction: influences of lubricating oil properties. JSME international journal. Ser. C, Dynamics, control, robotics, design and manufacturing, 38(3):593600, 1995. doi:10.1299/jsmec1993.38.593.

[142] Q Jane Wang and Yip-Wah Chung. Encyclopedia of Tribology. Springer, 2013.

[143] K. Wannatong, S. Chanchaona, and S. Sanitjai. Simulation algorithm for piston ring dynamics. Simulation Modelling Practice and Theory, 16(1):127-146, 2008. doi: 10.1016/j.simpat.2007.11.004.

[144] V. W. Wong, T. Tian, H. Lang, J. P. Ryan, Y. Sekiya, and et al. A numerical model of piston secondary motion and piston slap in partially flooded elastohydrodynamic skirt lubrication. In International Congress 86 Exposition. SAE International, mar 1994. doi: $10.4271 / 940696$. 
[145] A. Zavos and P. G. Nikolakopoulos. Tribology of new thin compression ring of fired engine under controlled conditions-a combined experimental and numerical study. Tribology International, 128:214 - 230, 2018. doi:10.1016/j.triboint.2018.07.034. 



\section{Chapter 3}

\section{Low viscosity engine oils evaluation for fuel economy}

Contents

3.1 Introduction ................... 77

3.2 Experimental setup $\ldots \ldots \ldots \ldots \ldots \ldots \ldots \ldots \ldots \ldots$

3.3 Methodology for the engine bench tests ...... 79

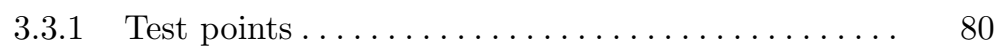

3.3 .2 Oil formulations $\ldots \ldots \ldots \ldots \ldots \ldots \ldots \ldots \ldots$

3.4 Vehicle model ................... 81

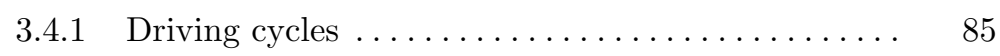

3.5 Results under stationary conditions ......... 89

3.6 Results for real driving conditions........... 93

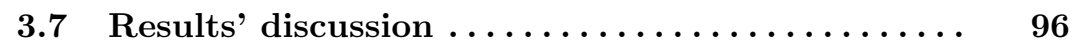

Bibliography $\ldots \ldots \ldots \ldots \ldots \ldots \ldots \ldots \ldots \ldots \ldots \ldots$ 



\subsection{Introduction}

Extensive research on LVEOs have demonstrated the potential of the lubricant oil to contribute to the reduction of the friction mechanical losses, the increase of the engine efficiency and therefore, the reduction of fuel consumption. This oil capability for fuel economy is closely linked to the engine characteristics and the working conditions of the vehicle. The assessment and quantification of this relationship has not been previously reported in literature; however it can be of great importance for the achievement of targets related to the reduction of fuel consumption and emissions. In this chapter, this joint interaction between the oil formulation and the driving conditions of a freight transport vehicle was evaluated for fuel economy through experimental tests and simulations. Six oil formulations were chosen for the study with different HTHS viscosity and two formulations with molybdenum-based FM.

\subsection{Experimental setup}

In order to evaluate the effect of a lower HTHS viscosity and Mo FM additive over fuel consumption, stationary fired tests were developed in a medium-duty diesel engine following the bracketing technique described in Section 3.3. The engine test bench was located in a climate chamber to control the ambient temperature and pressure for the tests. These values were set to $18^{\circ} \mathrm{C}$ and $1003 \mathrm{hPa}$. The internal combustion engine was a 3 liters diesel engine, its main characteristics are summarized in Table 3.1, coupled to a dynamometer to absorb and dissipate the energy delivered by the engine during operation. The instrumentation and data acquisition of the test bench consisted primarily of piezoelectric pressure sensors located in the combustion chamber of each cylinder and an angular position sensor (encoder). The instantaneous reading of the pressure sensors was recorded with a Yokogawa DL850V data acquisition system, along with the encoder, used to trigger the data acquisition. The sampling frequency of the in-cylinder pressure was set to one crankshaft degree. Pressure sensors were installed in the lubrication system, and at the intake and exhaust manifolds. Temperature of the manifolds was also measured by means of K-type thermocouples. An in-house software SAMARUC was implemented in the data acquisition of the test rig to record and display the sensors' data. To control the oil temperature during tests, an external system was adapted to the engine test bench; it consisted of a heat exchanger, a PID (proportional-integral-derivative) controller, a K-type 
thermocouple, located in the engine crankcase, cooler fluid and a water supplydrainage network. Data of the fuel consumed by the engine was recorded by the ECU, along with the engine working parameters, and extracted by means of the ETAS INCA software. Figure 3.1, shows a schematic diagram of the experimental setup described above.

\begin{tabular}{|r|c|}
\hline Engine characteristics & Value \\
\hline \hline Cylinder bore & $102[\mathrm{~mm}]$ \\
Stroke & $96[\mathrm{~mm}]$ \\
Engine displacement & $3[\mathrm{l}]$ \\
Cylinders & 4 \\
Valves & 2 per cylinder \\
Max. effective power $[\mathrm{kW}]$ & $111.3 @ 3600[\mathrm{rev} / \mathrm{min}]$ \\
Max. effective torque $[\mathrm{Nm}]$ & $350 @ 2000[\mathrm{rev} / \mathrm{min}]$ \\
Emissions control & EGR \\
Turbocharger & Variable geometry $(\mathrm{VGT})$ \\
Emissions standard & Euro VI \\
\hline
\end{tabular}

Table 3.1. Main characteristics of the medium-duty diesel engine.

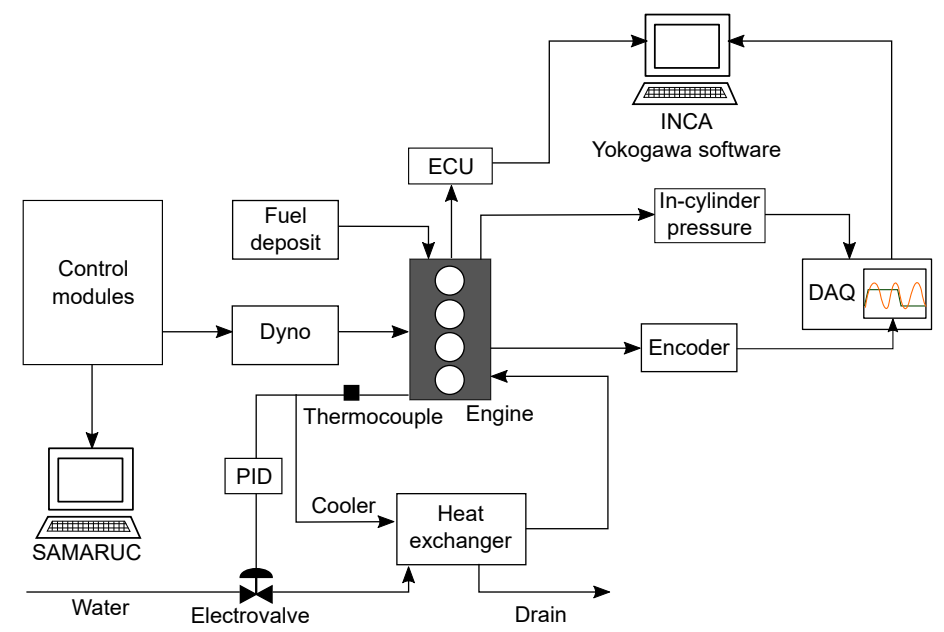

Figure 3.1. Schematic diagram of the experimental setup for the engine bench tests. 


\subsection{Methodology for the engine bench tests}

The methodology employed for the tests is based on the bracketing technique, which consists of selecting one oil formulation as reference, and the other formulations as candidate oils. The reference oil is always tested before and after the candidate oil. Results of fuel consumption with the reference oil, used for the data analysis, are the average of the two measurements. This bracketing technique helps to minimize possible drifts in the measurements with the reference oil due to any small changes in the engine operation or ambient conditions. In the bracketing technique were also included flushing and oil conditioning procedures; the first one consisted in draining the used oil from the engine, and filled it with fresh reference oil. The engine was then operated at four different speed and load conditions for two hours, as presented in Table 3.2. After this step, the oil was drained from the engine with the aim of removing any remaining of the previous oil. For the oil conditioning procedure, the engine was filled again with fresh oil, of the same reference formulation, and run at a pre-defined speed and torque for one hour (see Table 3.2). In this step, the oil is subjected to shear conditions causing the oil polymers to reach their final properties $[1,2,6]$. During the oil conditioning step, the working conditions of the engine were checked by looking at performance variables, such as torque, throttle position and EGR. After this step, the reference oil was tested under the conditions of selected points of the engine working map, described in the following Section 3.3.1, by adjusting the engine speed and torque values; the throttle position was variable. After completing the engine map with the reference oil, it was allowed to drain, usually overnight, and replaced with the candidate oil formulation. The oil flushing and conditioning procedures described above were repeated for the candidate oil and then once again for the reference oil, in order to complete the bracketing methodology. Figure 3.2 presents a diagram of the testing methodology described here.

Tests with each oil formulation, started by reaching the working conditions of the testing points, followed by a stabilization time. Each testing point was executed for a period of 30 seconds, where different performance parameters of the engine were recorded, including the ambient conditions of the climate chamber. The in-cylinder pressure was also recorded and averaged for fifty engine cycles. Furthermore, all the testing points comprised three repetitions.

Regarding the oil temperature measured at the crankcase, it was allowed to increase during the stabilization period and then it was controlled through the PID controller (Section 3.2) during the execution of the tests points, it varied 


\begin{tabular}{|c|c|c|c|}
\hline \multicolumn{4}{|c|}{ Oil flushing points } \\
\hline Point & Engine speed $[\mathrm{rpm}]$ & Torque $[\mathrm{Nm}]$ & Time $[\mathrm{min}]$ \\
\hline 1 & 1500 & 211 & 30 \\
\hline 2 & 2000 & 141 & 30 \\
\hline 3 & 2500 & 70 & 30 \\
\hline 4 & 3400 & 94 & 30 \\
\hline \multicolumn{4}{|c|}{ Oil conditioning points } \\
\hline 1 & 2400 & 188 & 60 \\
\hline
\end{tabular}

Table 3.2. Testing points for the oil flushing and conditioning procedures.

according to the demand of the test point. These oil temperature values were referenced and controlled for the testing of the different oil formulations. In this way, potential variations of the oil temperature between oil formulations were kept minimum as much as possible and therefore, no corrections were applied in the vehicle model.

\subsubsection{Test points}

In order to obtain the engine fuel consumption map with each oil formulation, 18 stationary points were selected to cover different working conditions of the engine, from low to high load, and medium to high speed; idle conditions were also included in the test points. The following Figure 3.3, presents the test points defined by engine speed and torque.

\subsubsection{Oil formulations}

For the engine bench tests, six oil formulations of different SAE grade and HTHS viscosity were selected. These formulations are representative of the latest API oil categories CK-4 and FA-4 for diesel engines (See Section 2.6.2). One of these formulations was selected as reference oil and was designated with the letter R, the other six formulations correspond to the candidate oils, and were identified with the letter $\mathrm{C}$. The main characteristics of the oil formulations are presented in Table 3.3. As it can be seen, candidate oil C5 was formulated with a HTHS viscosity of $2.7 \mathrm{cP}$, a value lower than the specified by API for the FA-4 category. Candidate oils $\mathrm{C} 3$ and $\mathrm{C} 4$ on the 


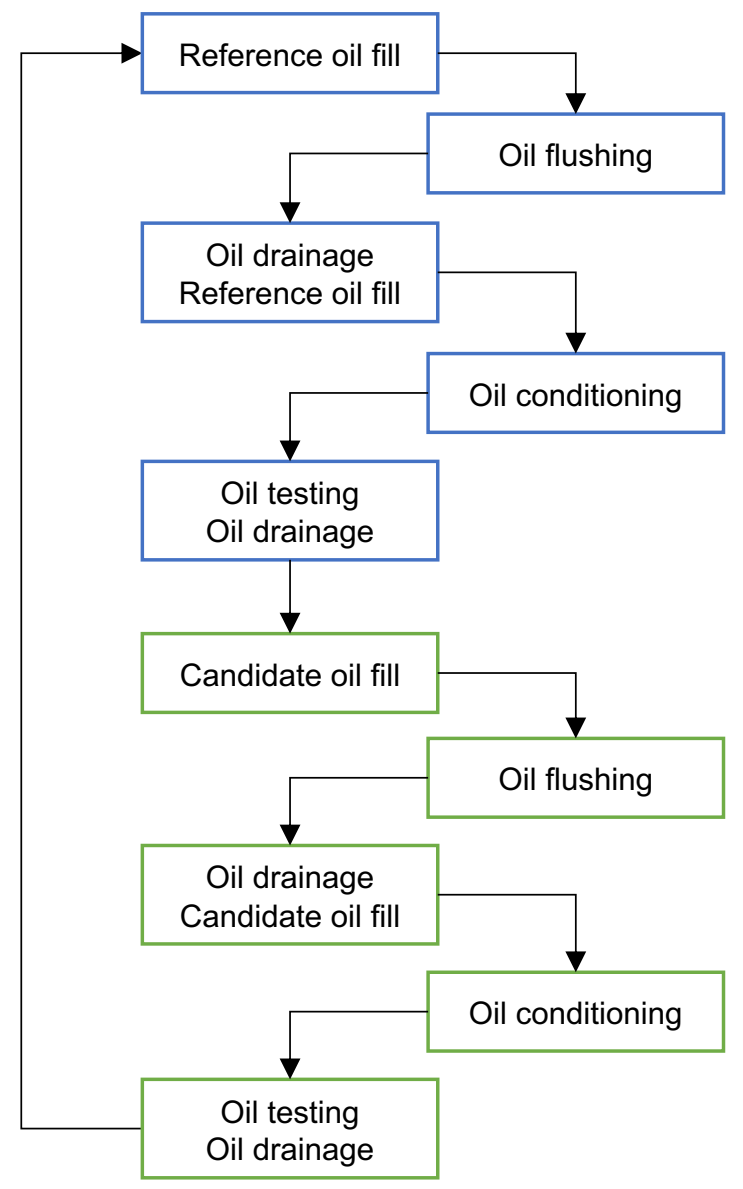

Figure 3.2. Diagram of the testing methodology for the engine bench tests.

other hand, were formulated with a Mo based friction modifier with the aim of evaluating its potential to reduce the fuel consumed by the engine under severe lubrication conditions. The oil formulations used in this chapter of the thesis were formulated for the tests presented here, except for the candidate oil $\mathrm{C} 1$, which is commercially available.

\subsection{Vehicle model}

As it was previously mentioned in Section 3.1, the main objective of this chapter of the thesis was to extend the current knowledge on LVEOs and 


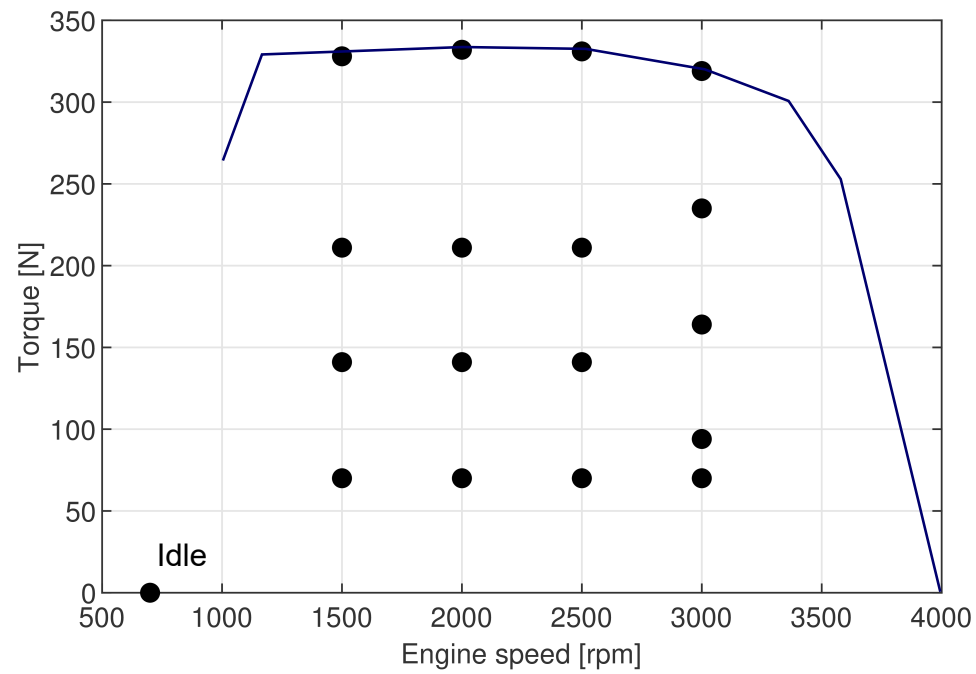

Figure 3.3. Stationary points for the engine bench tests.

\begin{tabular}{|l|c|c|c|c|c|c|}
\hline Oil designation & $\mathrm{R}$ & $\mathrm{C} 1$ & $\mathrm{C} 2$ & $\mathrm{C} 3$ & $\mathrm{C} 4$ & $\mathrm{C} 5$ \\
\hline \hline SAE grade & $10 \mathrm{~W} 30$ & $10 \mathrm{~W} 40$ & $10 \mathrm{~W} 30$ & $5 \mathrm{~W} 30$ & $5 \mathrm{~W} 30$ & $5 \mathrm{~W} 20$ \\
KV@40ㄷ $[\mathrm{cSt}]$ & 75.23 & 86.71 & 56.45 & 70.60 & 70.15 & 43.72 \\
KV@ $100^{\circ} \mathrm{C}[\mathrm{cSt}]$ & 12.05 & 13.34 & 9.607 & 11.85 & 12.08 & 7.992 \\
HTHS@150 ${ }^{\circ} \mathrm{C}[\mathrm{cP}]$ & 3.67 & 3.85 & 3.17 & 3.61 & 3.61 & 2.7 \\
SAPS level & Medium & Medium & Medium & Low & Medium & Medium \\
API base oil group & III & III & III & III + IV & III & III \\
API category & CK-4 & CI-4 & FA-4 & CJ-4 & CK-4 & - \\
Friction modifier & {$[-]$} & {$[-]$} & {$[-]$} & Mo & Mo & {$[-]$} \\
\hline
\end{tabular}

Table 3.3. Main characteristics of the oil formulations for the engine bench tests.

their potential to reduce fuel consumption, by evaluating the joint effect of the oil formulation and the vehicle driving conditions. To this end, a simplified vehicle model was adapted from a previous work developed at CMT-Motores Térmicos by Luján et al. [5]. Three driving cycles were employed in the model, representative of urban and rural driving conditions, and described in the following Section 3.4.1. Finally, A freight transport vehicle, powered by an engine model equal to that used in the stationary tests, was selected for the 


\begin{tabular}{|r|c|c|}
\hline \multicolumn{2}{|c|}{ Parameter } & Value \\
\hline \hline Mass & $\mathrm{m}$ & $2465 \mathrm{~kg}$ \\
Wheel size & {$[-]$} & $195 / 80 \mathrm{R} 15 \mathrm{LT}$ \\
Frontal area & $\mathrm{A}$ & $4.30 \mathrm{~m}^{2}$ \\
Drag coefficient & $C_{d}$ & 0.3 \\
Road friction coefficient & $C_{r}$ & 0.01 \\
Air density & $\rho$ & $1.225 \mathrm{~kg} / \mathrm{m}^{3}$ \\
& $1 \mathrm{st}$ & 4.225 \\
& $2 \mathrm{nd}$ & 2.341 \\
Gear ratios & $3 \mathrm{rd}$ & 1.458 \\
& $4 \mathrm{th}$ & 1.000 \\
& $5 \mathrm{th}$ & 0.796 \\
\hline
\end{tabular}

Table 3.4. Vehicle main specifications.

analysis. The vehicle specifications used in the model are summarized in Table 3.4.

The vehicle model was implemented in mathematical software Matlab, it consists of a series of equations to describe the vehicle dynamics and the performance of the powertrain, the speed and elevation profiles of the driving cycles, and the fuel consumption maps obtained experimentally in the engine bench tests. To model the vehicle longitudinal dynamics, forces acting on the vehicle were taken into account, as presented in the following equation 3.1; these are the aerodynamic drag, rolling resistance, gravitational forces, driving and braking force, and the vehicle inertia [7]. The vehicle model was solved using a backward quasi-static approach [9], starting from the speed and elevation profiles of the driving cycles' routes, and then computing the forces acting on the vehicle. The torque and speed required from the engine were calculated afterwards, as well as the associated fuel consumption.

$$
F_{i}=F_{a}-F_{r}-F_{g}-F_{t}-F_{b}
$$

$F_{i}$ is the vehicle inertia and was calculated from the vehicle mass (Table 3.4) and acceleration $\dot{v}$, as shown in equation 3.2. The vehicle acceleration was calculated from the derivative of the velocity profile (Figure 3.4), for each driving cycle. 


$$
F_{i}=m \dot{v}
$$

Regarding the aerodynamic drag, it was calculated from the following equation 3.3, the frontal area of the vehicle $A$, the air density $\rho$, the vehicle speed $v$ and the drag coefficient $C_{d}$, assumed to be equal to $0.3[7]$.

$$
F_{a}=\frac{1}{2} A \rho v^{2} C_{d}
$$

The rolling resistance, opposed to the vehicle motion, was calculated from the road friction coefficient $C_{r}$ (between 0.01 and 0.015 [8]), the mass of the vehicle $m$ and the road gradient $\beta$, with the following equation 3.4. The road gradient was obtained from the elevation profile of the driving cycles' route, shown in Figure 3.5, and represents the slope of the road.

$$
F_{r}=C_{r} m g \cos \beta
$$

The gravitational force component was obtained in a similar way as the rolling resistance, from equation 3.5:

$$
F_{g}=m g \sin \beta
$$

The effect of the brakes force $F_{b}$ was estimated using the maximum breaking force $\widehat{F}_{b}$ and a coefficient $u_{b}$ to represent the brakes' actuation; 1 for fully breaking and 0 for released position.

$$
F_{b}=u_{b} \widehat{F}_{b}
$$

From equation 3.1, the only unknown in the model was the driving force $F_{t}$, which describes the force developed in the wheels:

$$
F_{t}=\frac{T_{w}}{r_{w}}
$$

The torque developed at the wheels $T_{w}$, obtained from the previous equation 3.7, was then employed to calculate the torque required from the engine $T$, as well as the speed $N$, from the following expressions 3.8 and 3.9, respectively. Furthermore, the transmission of the vehicle was model as an ideal set of gears [4]. $R_{g b}$ is the transmission ratio, as function of the selected gear (Table 3.4). 


$$
\begin{gathered}
T_{w}=R_{g b} T \\
N=\frac{30 R_{g b} v}{\pi r_{w}}
\end{gathered}
$$

Finally, to complete the model and obtain the fuel consumption of the vehicle in each driving cycle, the engine was represented by its equivalent operating map [3], that is, the fuel consumption map obtained experimentally in the engine bench tests and for every oil formulation. In this way, the engine speed and torque obtained from the vehicle model, were evaluated over the fuel consumption maps.

\subsubsection{Driving cycles}

In order to evaluate the fuel economy potential of the LVEO formulations under real driving conditions, three driving cycles were selected for the vehicle simulation, representative of the working conditions of a freight transport vehicle. From these driving cycles, the vehicle speed profile and elevation of the route were employed as input data in the vehicle model, described in the previous Section 3.4. With the aim of evaluating the performance of the lubricant formulations under both urban and rural conditions, two of the driving cycles covered urban routes, one in the city of Valencia in Spain, and the other in Romsey, a market town located in the United Kingdom. The third route on the other hand, covered a rural route between two municipalities in the Valencian community in Spain, Quesa and Canals. Regarding the duration of the driving cycles, the urban cycle in Spain had a duration of 2039 seconds and $10.4 \mathrm{~km}$ covered. The urban cycle in the UK covered a distance of 2.1 $\mathrm{km}$ with a duration of 596 seconds. The rural route in Spain had a longer distance, covering $26.6 \mathrm{~km}$ in 1763 seconds.

The speed profiles of the three driving cycles are shown in Figure 3.4. As it can be seen, the differences between the urban and rural conditions are significant in terms of the velocity reached by the vehicle. In the rural cycle, the vehicle velocity exceeded $100 \mathrm{~km} / \mathrm{h}$ at some points, while in the urban cycles, the velocity was maintained up to $50 \mathrm{~km} / \mathrm{h}$.

In the following Figure 3.5, are plotted the elevation profiles of the routes of the three driving cycles. The urban cycle in Valencia, Spain was completely flat and was measured at sea level. The urban profile in the UK on the other hand, presented some slopes and flat areas, and was measured at about 30 


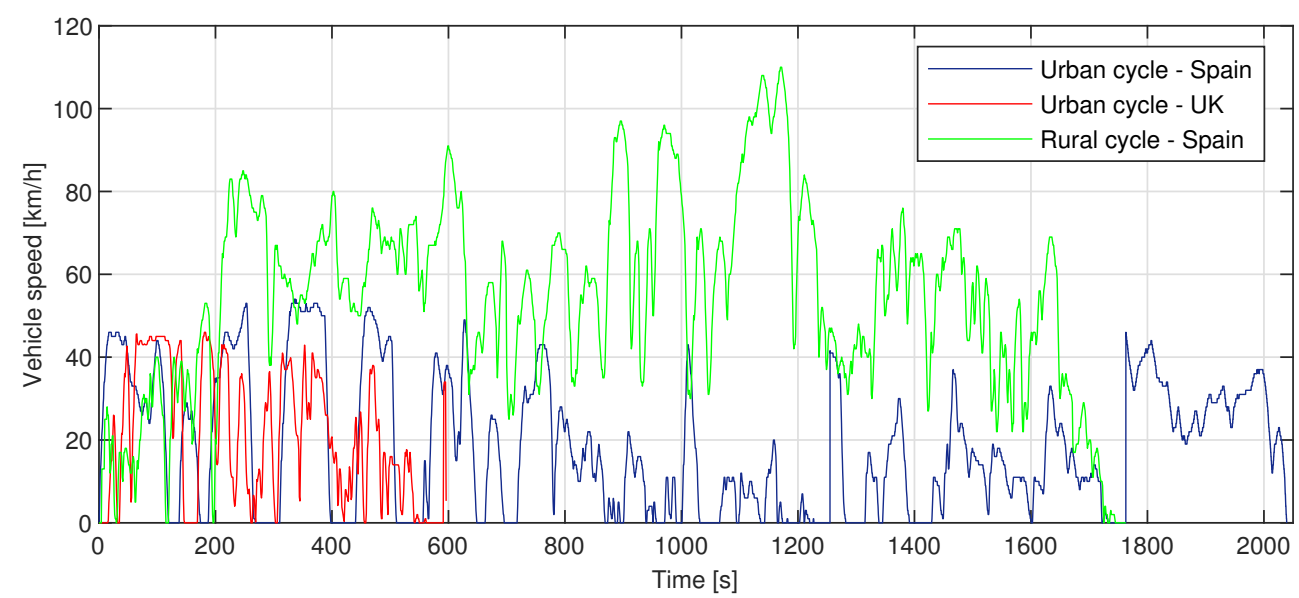

Figure 3.4. Vehicle speed profile for the three driving cycles.

m.a.s.l. The rural profile in Spain, presented a more diverse typography than the other two cycles. These differences among the driving conditions of the cycles had an impact on the power required from the engine and therefore, on fuel consumption.

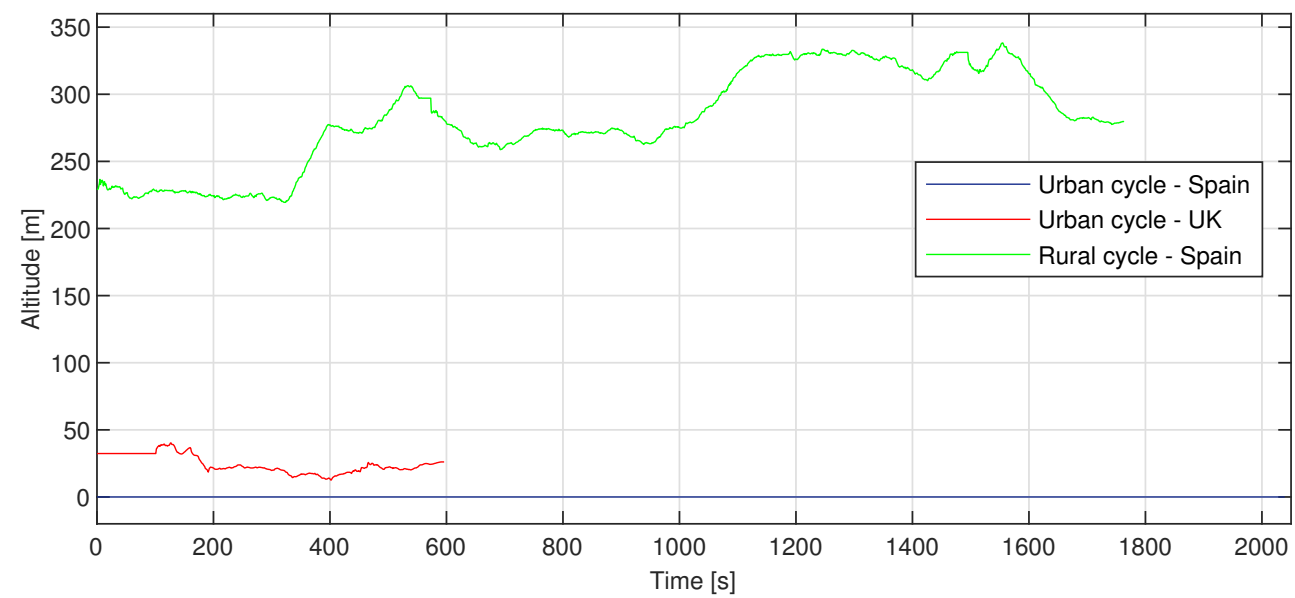

Figure 3.5. Altitude profile for the three driving cycles. 
A more detailed view of the working conditions of the driving cycles, and more specifically under which conditions the vehicle worked longer, was obtained with the use of bivariate histograms to represent the points' distribution measured in each cycle. Figure 3.6, 3.7 and 3.8, are bivariate histograms of the urban cycle in Spain, in the UK, and the rural cycle in Spain, respectively. These histograms were plotted from the equivalent engine speed and torque, calculated from the vehicle model in Section 3.4. In these Figures, the color scale corresponds to the amount of points measured at the specified working condition and therefore, shows the regions where the vehicle worked more often.

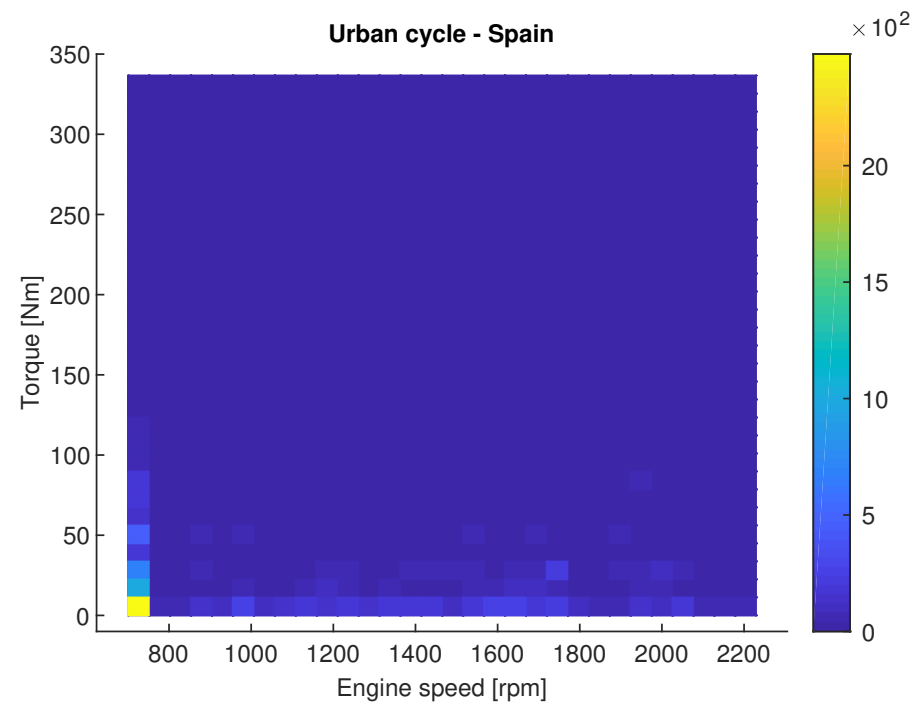

Figure 3.6. Bivariate histogram of the urban cycle in Spain.

For the urban cycle in Spain, it is clear from Figure 3.6, that the vehicle worked mainly under low load conditions, with multiple idle periods, reflected also in the velocity profile in the previous Figure 3.4. These idle periods correspond to vehicle stops due to the urban traffic. The urban cycle in the UK, shown in Figure 3.7, presents a more scattered distribution throughout the load range, with some points measured at maximum load. The highest concentration of points however, appeared again at idle and at medium speed and low load working conditions.

For the rural cycle in Spain, the bivariate histogram of Figure 3.8 shows that the vehicle worked mainly at medium speed and at low-medium load. Although the driving cycle covered all the speed range, the points 


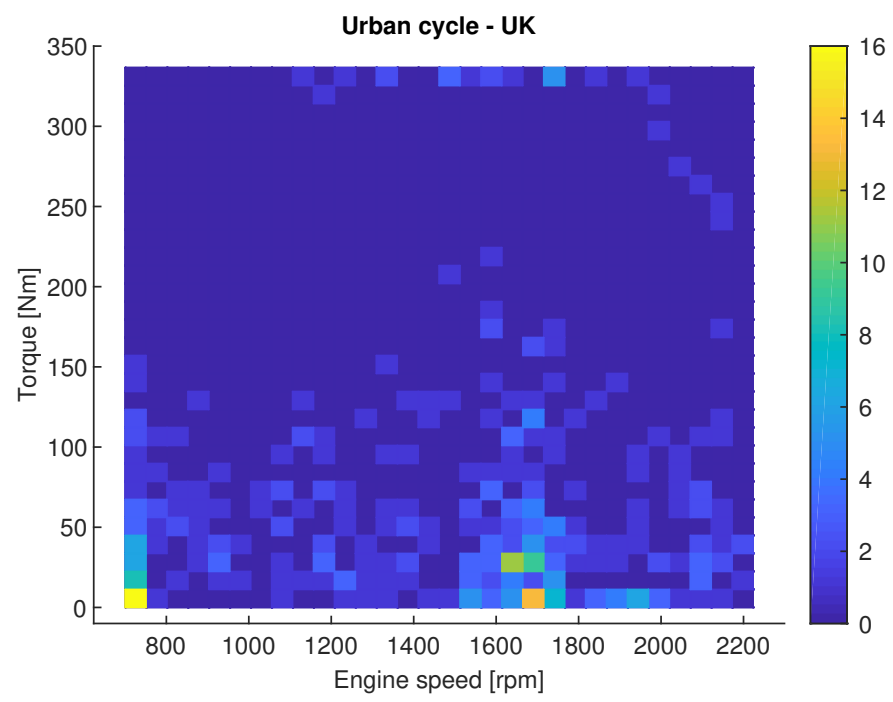

Figure 3.7. Bivariate histogram of the urban cycle in the UK.

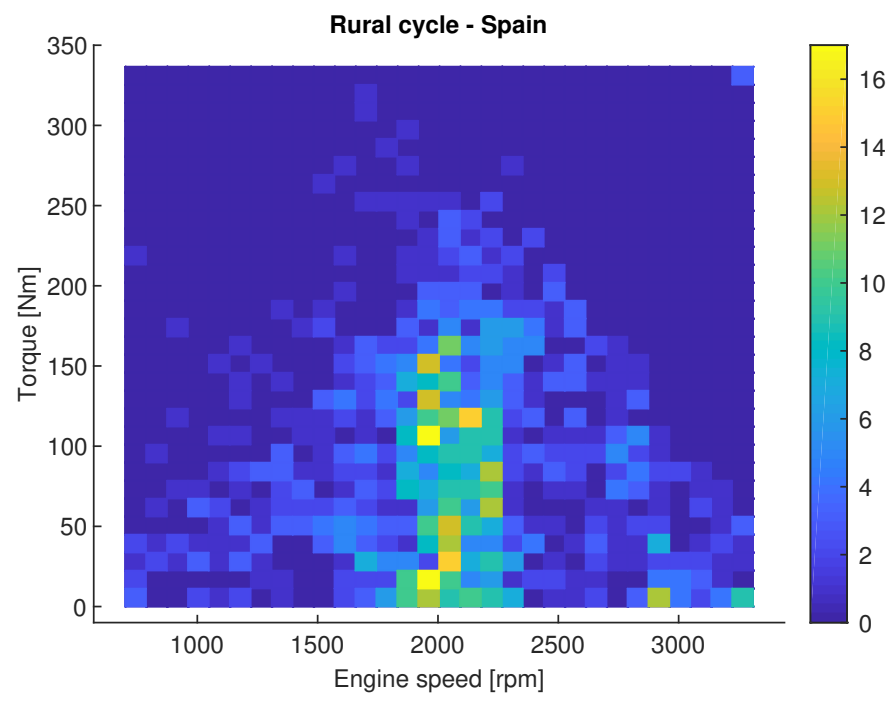

Figure 3.8. Bivariate histogram of the rural cycle in Spain.

concentration was higher between 1500 and $2500 \mathrm{rpm}$, which represents common working conditions in a rural route. The concentration of points was also significant at low load and high engine speed, at about $2900 \mathrm{rpm}$. 


\subsection{Results under stationary conditions}

For the analysis of the fuel consumption reduction due to the use of LVEOs and Mo FM, the fuel consumption maps of the candidate oils, obtained under stationary conditions in the engine test bench (Section 3.3), were compared with the reference oil R. For this comparison, the fuel consumption in each stationary point with the candidate oil was compared with the corresponding point measured with the reference oil. The difference obtained was then presented in percentage and plotted in fuel consumption difference maps. In this way, a negative percentage represents a decrease in the fuel consumed by the engine with the candidate oil, while a positive value indicates an increase in fuel consumption.

For the candidate oil $\mathrm{C} 1$, the fuel consumption difference map is presented in Figure 3.9. This lubricant oil was formulated with a HTHS viscosity higher than the reference oil, $3.85 \mathrm{cP}$ and $3.67 \mathrm{cP}$ respectively, which resulted in fuel consumption increase for the most part of the engine map. This increase however, was more pronounced at high engine speed and medium load $(0.8 \%$ increase), working conditions that promote the appearance of hydrodynamic lubrication in tribo-pairs such as the piston-cylinder liner and the journal bearings. If these engine components were already working under hydrodynamic conditions, a higher HTHS viscosity would have led to an increase in the viscous friction and consequent fuel consumption increase.

Fuel consumption reduction was found with the candidate oil $\mathrm{C} 2$ for most of the engine map, shown in Figure 3.10, and specially for low-medium load conditions. The reference oil and C2 shared the same 10W30 SAE grade; however, the candidate oil $\mathrm{C} 2$ had a lower HTHS viscosity of 3.17 $\mathrm{cP}$; furthermore, its formulation was developed to contribute to fuel economy complying with the new API FA-4 category. From Figure 3.10, it can also be seen the effect of the load over the potential of LVEOs to reduce fuel consumption. Once the engine enters the high load region, the oil film thickness gets thinner; therefore, with a formulation of lower HTHS viscosity, this oil thinning can lead to the transition of lubrication regime towards mixed and boundary conditions, where the friction losses do no longer depend solely on the oil formulation, but on the surface characteristics of the engine components.

Candidate oils C3 and C4 were formulated with Mo FM with the aim of evaluating its contribution to reduce friction between the engine components during boundary and mixed lubrication. As it was previously mentioned in Section 2.6.3.1, Mo FM additives have been found to have a negative 


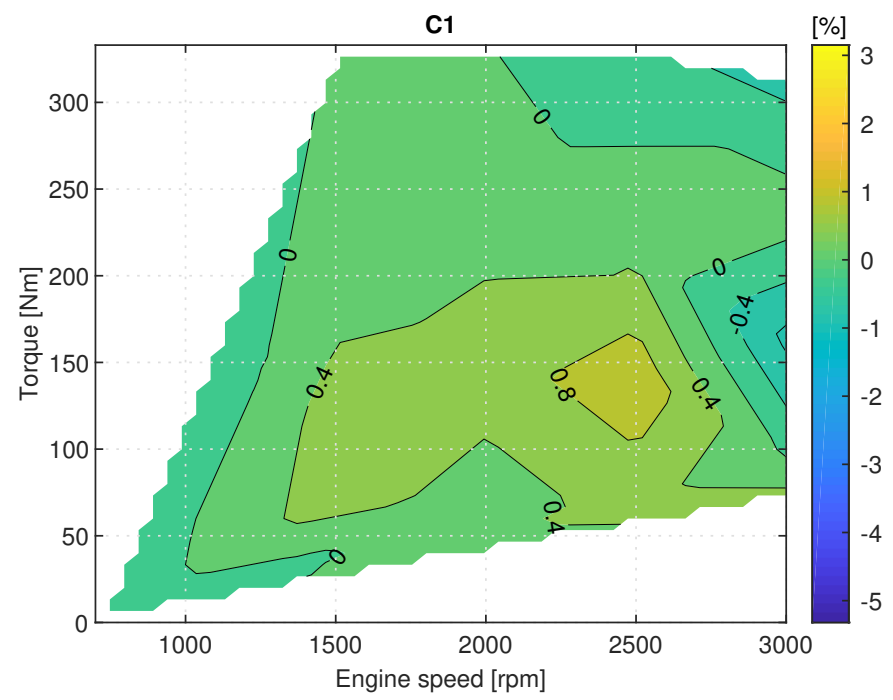

Figure 3.9. Fuel consumption difference between the candidate oil C1 and the reference oil.

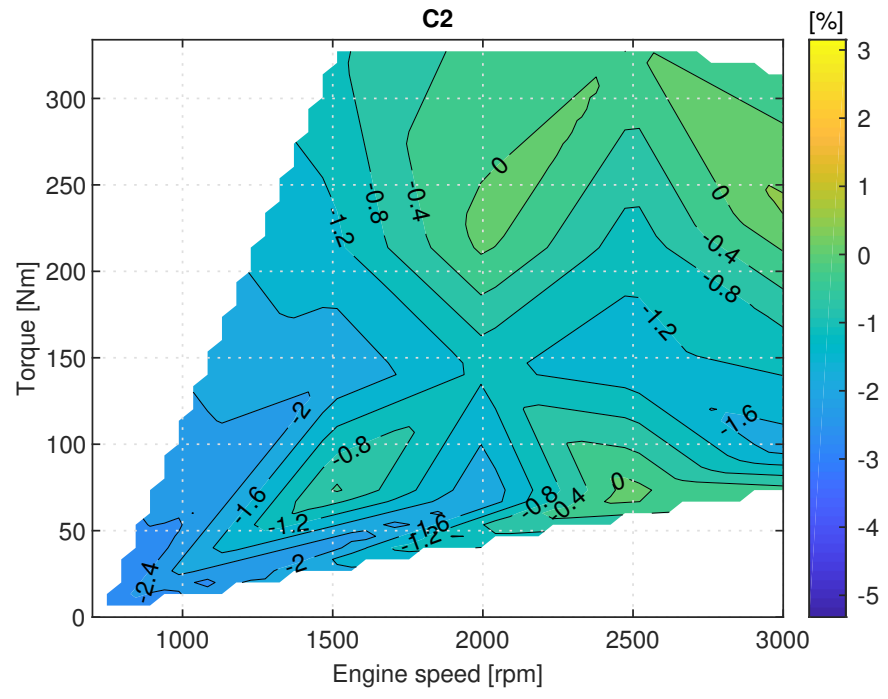

Figure 3.10. Fuel consumption difference between the candidate oil C2 and the reference oil.

reaction with soot, loosing their properties to reduce friction; nonetheless, the implementation of new engine technologies to reduce soot, could allow 
the use of this FM and therefore, increase the fuel economy potential of LVEOs. These two candidate oil formulations shared the same SAE grade and HTHS viscosity; their main difference consisted on the API base oil group used for their formulation, group III + IV for C3 and group III for C4. Results of fuel consumption difference with the candidate oil C3 are shown in Figure 3.11. Compared with the reference oil, C3 showed a significant increase of fuel consumption for the major part of the engine map, except for idle conditions, and specially at $2500 \mathrm{rpm}$ and low load. According to the Stribeck curve, the working conditions of this point should promote the appearance of hydrodynamic lubrication in the tribo-contacts of the ICE; however, the friction reduction effect of $\mathrm{C} 3$, with a lower HTHS viscosity than the reference oil, was completely masked. On the other hand, under idle conditions and up to $1200 \mathrm{rpm}$, where the engine was likely working under boundary and mixed lubrication, the effect of the Mo FM seemed to have an effect on the reduction of friction losses.

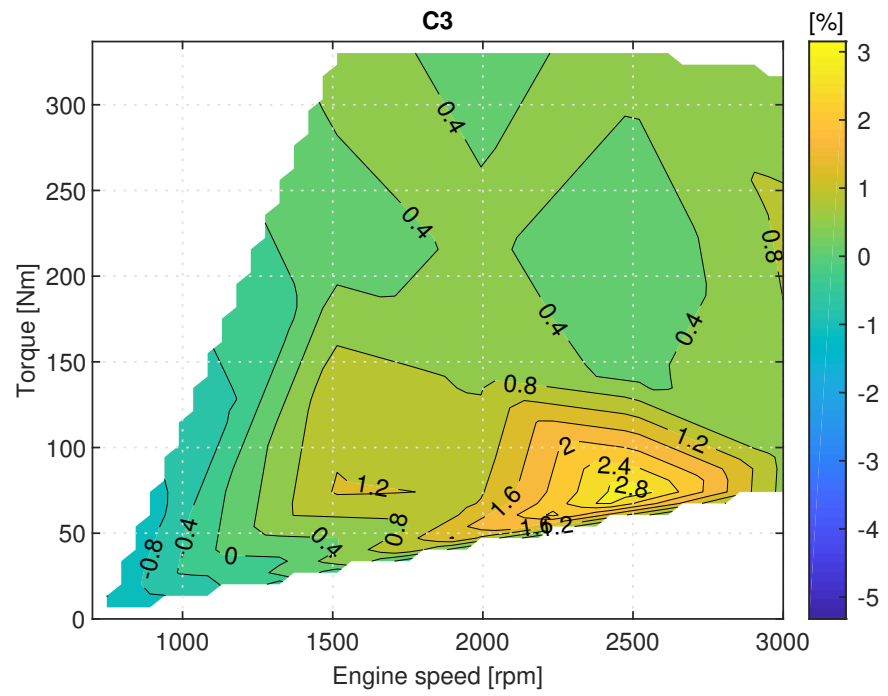

Figure 3.11. Fuel consumption difference between the candidate oil C3 and the reference oil.

For the candidate oil C4 shown in Figure 3.12, the results of fuel consumption compared to the reference oil, were opposed to that of C3. Fuel consumption decreased for most of the engine map, with a maximum $1.6 \%$ during idle, and a $0.4 \%$ of fuel economy at high load working conditions. These results showed the positive effect of reducing the HTHS viscosity over fuel consumption, during working conditions that favor hydrodynamic lubrication; 
but also showed the potential of the Mo FM to reduce the friction losses in conditions typical of mixed/boundary lubrication. Moreover, if the results obtained with the candidate oils $\mathrm{C} 2$ and $\mathrm{C} 4$ are compared, the effect of the Mo FM stand out. Overall, these two formulations presented similar results of fuel economy, due to their lower HTHS viscosity values; however, the addition of Mo FM to C4, helped to extend the fuel economy from low to high load conditions.

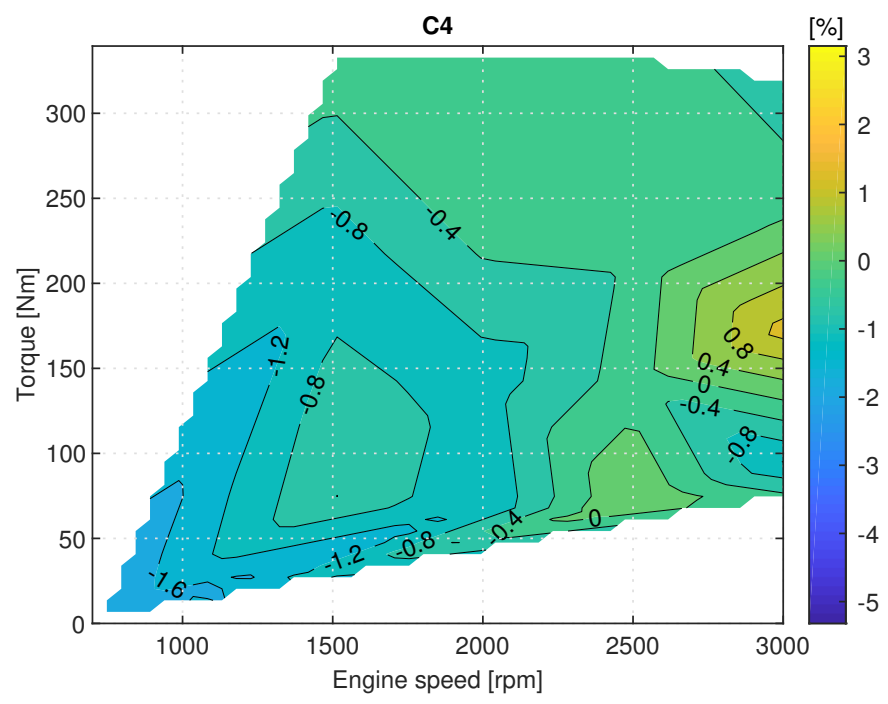

Figure 3.12. Fuel consumption difference between the candidate oil C4 and the reference oil.

Comparing the results of candidate oils $\mathrm{C} 3$ and $\mathrm{C} 4$, and taking into account that their formulation is fairly similar with the same HTHS viscosity, the use of Mo FM seems to be closely related with the base oil group used in the formulation. For the candidate oil C3, this synergy between the additive and base oil was poor, resulting in a significant fuel consumption increase. Van Dam et al. [10] on the other hand, found positive results of fuel economy with the use of different FM additives in four oil formulations for HDD applications. The compound of the FMs were not depicted, but the oils were blended to the same 5W30 SAE grade and with similar viscosity values. The study demonstrated the friction reduction effect of the FMs under conditions of boundary lubrication, as expected; however, authors also concluded that some results suggested that one of the FMs contributed to reduce the viscous friction under hydrodynamic lubrication, in addition to reducing friction in boundary conditions. 
Figure 3.13 shows the fuel consumption difference map for the candidate oil C5, this formulation had the lowest HTHS viscosity value of the six oils, 2.7 $\mathrm{cP}$, resulting in a significant fuel consumption decrease for the whole engine map, and specially under low load conditions and medium-high engine speed. It stands out the $5.3 \%$ of fuel economy obtained at $2000 \mathrm{rpm}$, and the extension of this friction reduction effect to all the speed range, and even at high load conditions. The performance of this formulation demonstrated the potential of a lower HTHS viscosity and probably the appropriate synergy of the additives employed in the formulation.

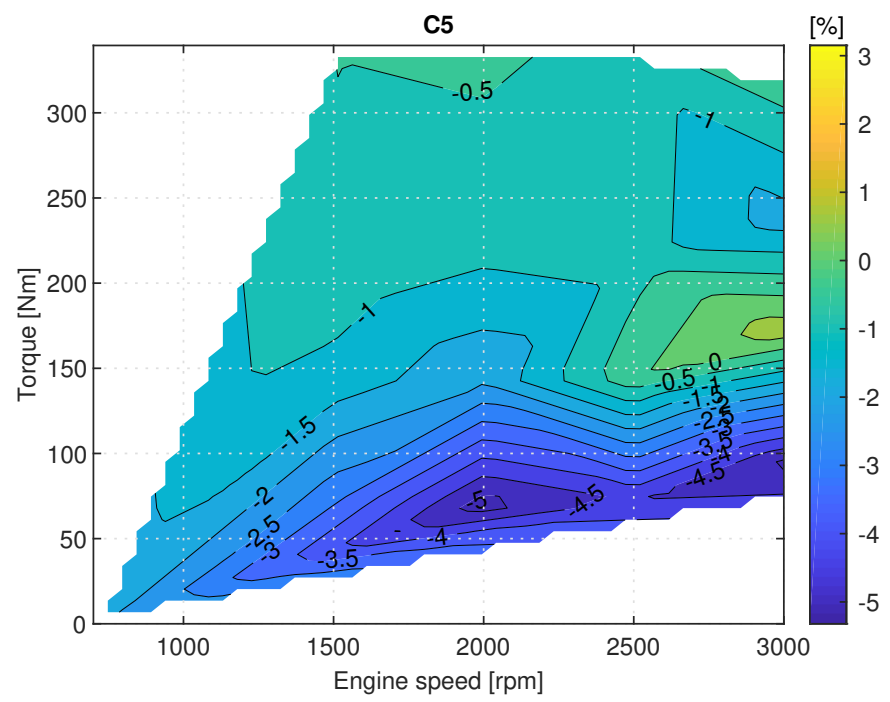

Figure 3.13. Fuel consumption difference between the candidate oil C5 and the reference oil.

\subsection{Results for real driving conditions}

In order to compare the results of fuel consumption between the candidate and reference oils under the working conditions of each driving cycle, the accumulated fuel consumption was plotted in the following Figures 3.14, 3.15 and 3.16 for the urban cycle in Spain, the urban cycle in the UK, and the rural cycle, respectively. Boxes inside each figure are zoom-in plots of the end of the cycle, where differences between oils are more visible. The accumulated fuel consumption at the end of the cycle with the candidate oil was then compared 
to that obtained with the reference oil. These results are summarized in Table 3.5 in terms of absolute and percentage difference.

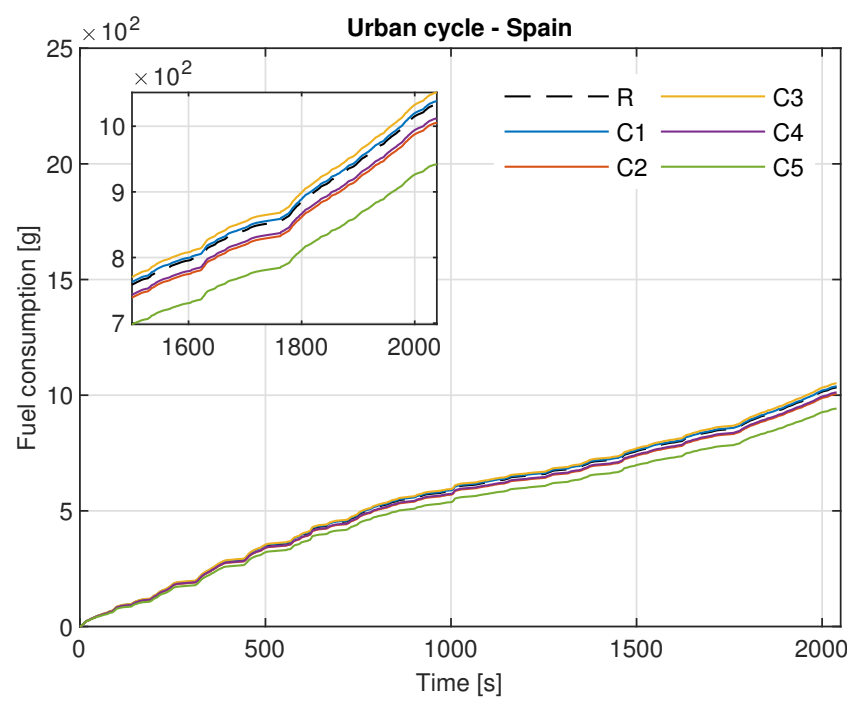

Figure 3.14. Accumulated fuel consumption for the urban cycle in Spain and the six oil formulations.

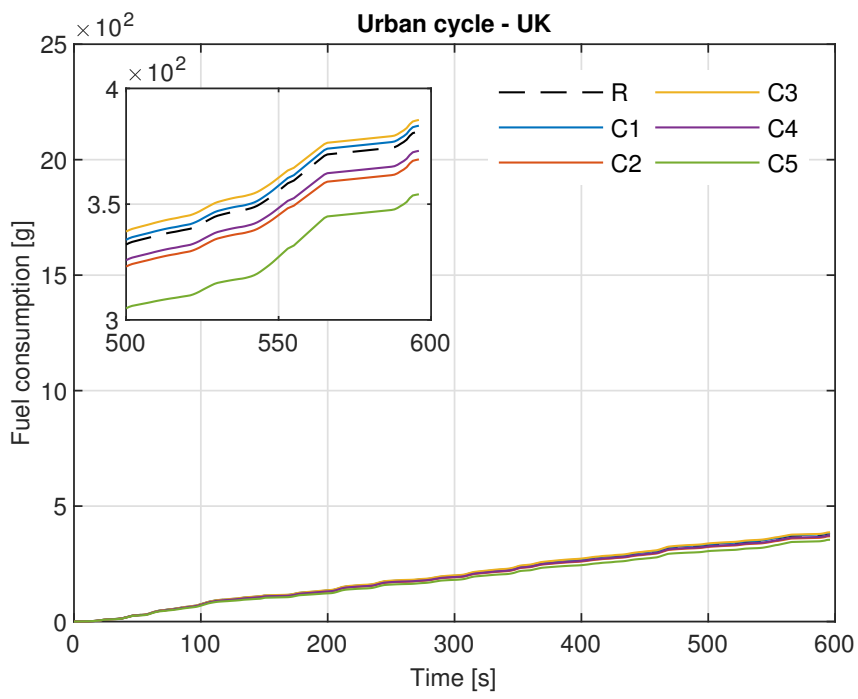

Figure 3.15. Accumulated fuel consumption for the urban cycle in the UK and the six oil formulations. 


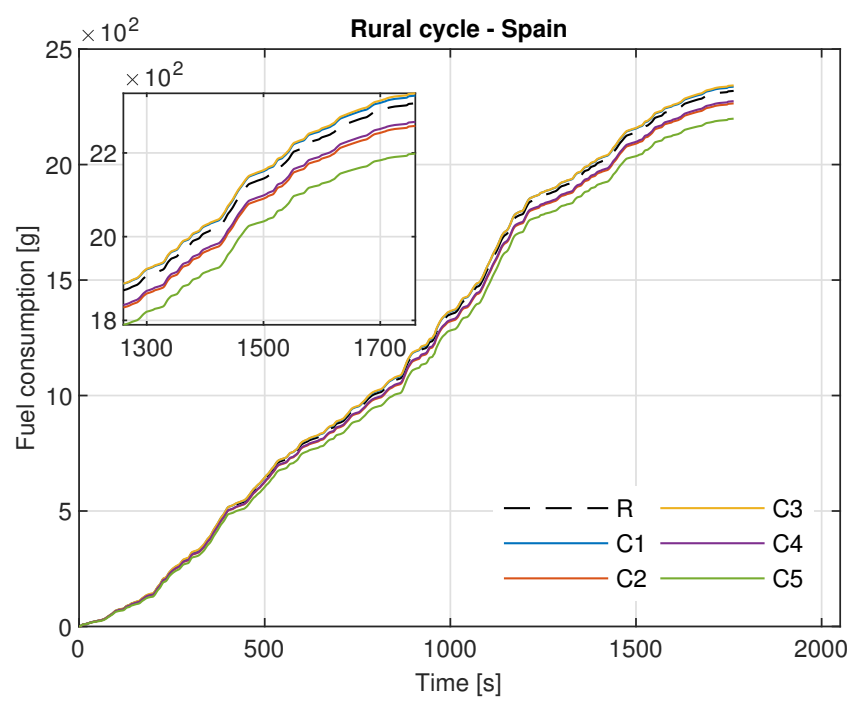

Figure 3.16. Accumulated fuel consumption for the rural cycle in Spain and the six oil formulations.

The driving conditions of the urban cycles in Spain and in the UK, low speed and low-medium load, are reflected in the accumulated fuel consumption in Figure 3.14 and 3.15, the slope of the lines are significantly smaller than for the rural cycle, shown in Figure 3.16. The topography of the route in the rural cycle, and the higher vehicle speed and load conditions, led to higher power demands from the engine, and therefore to higher fuel consumption. It stands out the performance of the candidate oil C5 for the three driving cycles, with the lowest fuel consumption. The opposite can be observed for C3, with the highest fuel consumption for the three cycles. In the rural cycle, however, the accumulated fuel consumption of candidate oils $\mathrm{C} 1$ and $\mathrm{C} 3$, is very similar. For the former formulation, this increase is the result of a higher HTHS viscosity than the reference oil, while for $\mathrm{C} 3$ is the result of the negative effect of the Mo FM. Looking at the points' distribution of Figure 3.8, it is clear that most of the rural cycle occurred at medium-speed and low-high load, which are conditions that correspond to regions of higher fuel consumption with these oil formulations.

From Table 3.5 and taking into account that the fuel consumption maps, obtained experimentally under stationary conditions in the engine bench tests, were employed as input parameters in the vehicle model, results of fuel consumption differences are in accordance with those described in Section 3.5, as expected. From these results, it is remarkable the fuel consumption decrease 


\begin{tabular}{|c|c|c|c|c|c|c|c|}
\hline \multicolumn{2}{|c|}{ Oils } & \multicolumn{3}{c|}{ Absolute difference $[\mathrm{g}]$} & \multicolumn{3}{c|}{ Percentage difference [\%] } \\
\hline \multirow{2}{*}{} & & $\begin{array}{c}\text { Urban cycle } \\
\text { Spain }\end{array}$ & $\begin{array}{c}\text { Urban cycle } \\
\text { UK }\end{array}$ & $\begin{array}{c}\text { Rural cycle } \\
\text { Spain }\end{array}$ & $\begin{array}{c}\text { Urban cycle } \\
\text { Spain }\end{array}$ & $\begin{array}{c}\text { Urban cycle } \\
\text { UK }\end{array}$ & $\begin{array}{c}\text { Rural cycle } \\
\text { Spain }\end{array}$ \\
\hline \multirow{4}{*}{$\mathrm{R}$} & $\mathrm{C} 1$ & 4.77 & 2.56 & 18.26 & 0.46 & 0.67 & 0.79 \\
\cline { 2 - 8 } & $\mathrm{C} 2$ & -28.12 & -12.00 & -54.06 & -2.72 & -3.15 & -2.33 \\
\cline { 2 - 8 } & C3 & 18.03 & 5.05 & 23.80 & 1.75 & 1.32 & 1.03 \\
\cline { 2 - 8 } & C4 & -21.43 & -8.30 & -44.44 & -2.07 & -2.18 & -1.92 \\
\cline { 2 - 8 } & C5 & -91.32 & -27.07 & -120.25 & -8.84 & -7.10 & -5.19 \\
\hline
\end{tabular}

Table 3.5. Results of fuel consumption under real driving conditions..

obtained with candidate oil C5 for the urban cycle in Spain, with an $8.8 \%$ of fuel economy compared to the reference oil. This decrease was also present in the other driving cycles; however, the topographic characteristics of the urban route in Valencia provided better working conditions to take advantage of the fuel economy potential of a lower HTHS viscosity. It is also important to highlight the fuel economy provided by the oil formulations $\mathrm{C} 2$ and C4; although their fuel consumption reduction results are similar, it is notable the higher fuel economy obtained using an oil formulation of lower HTHS viscosity, rather than employing a Mo FM additive.

\subsection{Results' discussion}

With the study presented in this chapter of the thesis, the well known potential of LVEOs to reduce fuel consumption in ICE has been evaluated as a joint effect with the driving conditions of a freight transport vehicle under the conditions of three driving cycles. This analysis under real working conditions was developed using a vehicle model, reducing testing time and expenses associated to field tests. Results for both stationary conditions and for the driving cycles, showed significant fuel consumption reductions for the oil formulations with lower HTHS viscosity, in accordance with the lubrication theory. Results with the formulations including Mo FM however, presented opposite results, leading to the conclusion that the base oil group has a determining joint effect with the FM additive over the fuel consumption increase or reduction.

From the fuel consumption maps shown in Section 3.5, it was possible to determine the working conditions of the engine where a lower HTHS viscosity is likely to contribute to the reduction of the viscous friction; in 
the same way, it was possible to identify the contribution of the Mo FM to reduce friction under more severe lubrication regimes. These results however, provided an overall view of the total fuel consumption reduction in the engine, without the possibility of drawing details of the lubrication conditions of the main tribological pairs, and more importantly, the cyclic variations of these lubrication conditions as function of the working parameters of the engine, the oil viscosity and the additives of the formulations.

In this way, with the aim of developing a more focused research on the lubrication of ICE, and specifically for the piston-cylinder liner assembly, it was acknowledged the need of an experimental set up that allowed to analyze the lubrication of the assembly components, and to evaluate the effect of different parameters on friction losses. To this end, a floating liner test rig was developed in this thesis and is presented in the following Chapter 4.

\section{Bibliography}

[1] ASTM International. D6278-17e1 Standard Test Method for Shear Stability of Polymer Containing Fluids Using a European Diesel Injector Apparatus. West Conshohocken, PA, 2017. doi:10.1520/D6278-17E01.

[2] J. Cui, S. Oberoi, I. Goldmints, and S. Briggs. Field and bench study of shear stability of heavy duty diesel lubricants. SAE Int. J. Fuels Lubr., 7(3):882-889, 2014. doi: 10.4271/2014-01-2791.

[3] L. Guzzella and C. Onder. Introduction to modeling and control of internal combustion engine systems. Springer-Verlag Berlin Heidelberg, 2009.

[4] L. Guzzella and A. Sciarretta. Vehicle propulsion systems. Introduction to modeling and optimization. Springer-Verlag Berlin Heidelberg, 2013.

[5] J. M. Luján, C. Guardiola, B. Pla, and A. Reig. Fuel and pollutant efficient vehicle speed optimization in real driving conditions. IFAC-PapersOnLine, 51(31):225 - 232, 2018. doi:10.1016/j.ifacol.2018.10.041.

[6] N. Marx, A. Ponjavic, R. I. Taylor, and H. A. Spikes. Study of permanent shear thinning of VM polymer solutions. Tribology Letters, 65(3):106, 2017. doi:10.1007/ s11249-017-0888-7.

[7] W. F. Milliken, D. L. Milliken, and et al. Race car vehicle dynamics. Society of Automotive Engineers, Warrendale, PA, 1995.

[8] Rajesh Rajamani. Vehicle dynamics and control. Springer US, 2011.

[9] G. Rizzoni, L. Guzzella, and B. M. Baumann. Unified modeling of hybrid electric vehicle drivetrains. IEEE/ASME Transactions on Mechatronics, 4(3):246 - 257, 1999.

[10] W. Van Dam, P. Kleijwegt, M. Torreman, and G. Parsons. The lubricant contribution to improved fuel economy in heavy duty diesel engines. In SAE 2009 Commercial Vehicle Engineering Congress \& Exhibition. SAE International, oct 2009. doi : 10.4271/ 2009-01-2856. 



\section{Chapter 4}

\section{Development of a Floating Liner test rig}

\section{Contents}

4.1 Introduction .................... 101

4.2 Description of the floating liner measurement principle ..................... 101

4.3 Design of the test $\operatorname{rig} \ldots \ldots \ldots \ldots \ldots \ldots \ldots \ldots \ldots$

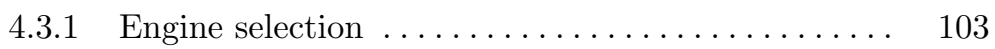

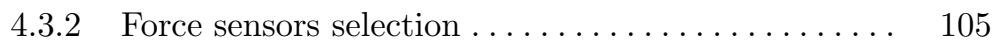

4.3.3 Designed and modified components.......... 107

4.3.3.1 Considerations for the structural analysis 109

4.3.3.2 Upper locking system ............ 111

4.3.3.3 Radial support ............... 114

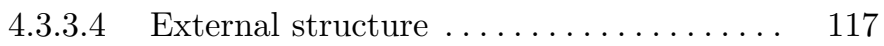

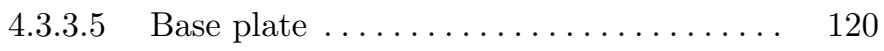

4.4 Auxiliary systems . . . . . . . . . . . . 122

4.4 .1 Lubrication system ................. 123

4.4 .2 Transmission system $\ldots \ldots \ldots \ldots \ldots \ldots \ldots \ldots \ldots$

4.4.3 Data acquisition system ............. 125

4.5 Friction force measurement analysis ......... 128

4.6 Performance assessment of the floating liner test

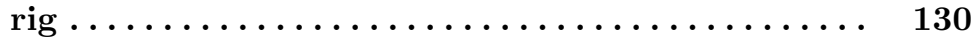

4.6 .1 Tests reproducibility $\ldots \ldots \ldots \ldots \ldots \ldots \ldots \ldots \ldots$

4.6 .2 Tests repeatability $\ldots \ldots \ldots \ldots \ldots \ldots \ldots \ldots \ldots \ldots$ 
4.7 Experimental results . . . . . . . . . . . 133

4.7.1 Engine speed and oil temperature .......... 134

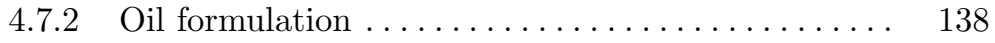

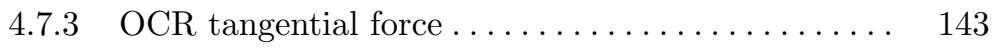

4.8 Discussion ....................... 151

4.A Appendix: Kinematics and dynamics of the floating liner engine .............. 153

4.A. 1 Kinematics ........................ 153

4.A. 1.1 Kinematics of the point A . . . . . . . 154

4.A. 1.2 Kinematics of the point B . . . . . . 155

4.A. 1.3 Kinematics of the point $\mathrm{G} \ldots \ldots \ldots \ldots$

4.A. 2 Dynamics .......................... 157

4.A. 2.1 Dynamics of the connecting rod ...... 158

4.A. 2.2 Dynamics of the piston . . . . . . . . . 159

Bibliography ........................ 160 


\subsection{Introduction}

Experimental measurement of the friction force generated in the pistoncylinder assembly of ICEs was previously addressed in Section 2.5, where the two main methodologies employed to measure the in situ friction force were explained, the IMEP and the floating liner method. Friction force measurements with the IMEP method rely on the measurement of the incylinder pressure and calculation of other forces acting in the connecting rod, which can make this method inaccurate. The floating liner test rig on the other hand, provides a direct measurement of the friction force, although the modifications required on the base engine are significant. For this thesis, the development of a floating liner test rig was of great interest in order to understand the fundamentals of friction generation in the piston-cylinder liner assembly, the factors and working conditions involved in this phenomenon and, as the ultimate goal, be able to develop studies to further understand the contribution of different parameters to the increase or decrease of the friction losses in this assembly. In this way, this chapter of the thesis presents the development of a floating liner test rig, including the design of mechanical components, structural analysis, definition of auxiliary systems for the rig operation, the performance assessment of the test rig and finally, some parametric studies.

\subsection{Description of the floating liner measurement principle}

The measuring principle of a floating liner was previously described in Section 2.5.2, including some of the most common components used in this type of rigs, and the forces acting on the system along the axial direction. The floating liner test rig developed in this thesis was designed to work under ambient pressure conditions, leaving the combustion chamber open to the atmosphere. It was however, one of the requirements for the floating liner design, to be able to add a cylinder head in future improvements of the rig, allowing its operation under high pressure conditions. Without the cylinder head, some of the force components acting in the axial direction, as described in expression 2.16, are no longer present: $F r_{\text {seal }}$ and $F r_{p}$. The force components are then reduced to:

$$
\sum F_{y}=W_{\text {liner }}+F r_{\text {support }}+F r_{\text {piston }}+P r_{\text {sensor }}
$$


Piezoelectric force sensors were selected to measure the friction force in the test rig, as will be described in Section 4.3.2. These sensors were preloaded and calibrated by the manufacturer, so the force sensors could measure the dynamic changes of the applied force both under compression and tension. This preload is a constant force, its corresponding charge output is eliminated or tared by resetting the amplifier. Furthermore, due to the measurement characteristics of the piezoelectric sensors, the static load of the liner weight is also eliminated before tests; therefore, only the friction force changes are measured. $P r_{\text {sensor }}$ and $W_{\text {liner }}$ are therefore, removed form expression 4.1. In order to restrict the lateral motion of the piston, a radial support was added to the test rig, explained in more detail in Section 4.3.3.3. It consists primarily of four ball transfer units, with a working principle similar to a bearing, and low friction multi-directional movement. In this way, given that the friction share from the radial support can be neglected, the actual friction force in the piston assembly can be measured directly with the piezoelectric force sensors.

\subsection{Design of the test rig}

The floating liner test rig was entirely developed in this thesis, its basic design arose from the definition of basic requirements and goals. The test rig was designed in software CAD, including structural analysis of its main components, redesigns when needed and finally manufactured and assembled. The main requirements proposed for the floating liner design were the following:

- The test rig must be operated under motored conditions, without combustion. Taking into account the lack of experience on designing and mounting a floating liner test rig, it was deemed convenient to start with a less complex design than a rig involving combustion and intake/exhaust processes. The test rig would therefore include an electric motor to operate the ICE under ambient pressure conditions.

- Initially the test rig would be operated under ambient pressure conditions, without the cylinder head; however, the design of the floating liner structure should include previsions to seal the combustion chamber in future improvements of the test rig.

- The design of the test rig should be simple enough to facilitate the assembly and disassembly of components for the parametric tests. 
- Given that the oil viscosity is a parameter that determines the lubrication conditions of the components in the piston-cylinder liner assembly, the working temperature of the oil must be properly set, measured and controlled during test.

- The floating liner design should be based on common dimensions of engine components commercially available. This with the aim of facilitating the exchange of components for parametric tests.

- The floating liner test rig should allow tests under speeds common of ICE, up to $3000 \mathrm{rpm}$.

With the proposed requirements and attending the literature review done on floating liner test rigs developed by different authors (Section 2.5.2), it was decided to base the floating liner design in a commercial ICE, and perform the modifications necessary to isolate the liner from the engine block and install the components and sensors to measure the friction force. The selection of an ICE as base for the test rig allowed to take advantage of most of the transmission components, including the connecting rod and lubrication components, such as the oil pump and jets that lubricate the piston from below.

\subsubsection{Engine selection}

In this step of the floating liner design, additional requirements and technical aspects were proposed for the selection of the ICE to be used as base for the test rig. The ICEs evaluated in this step ranged from automotive to multipurpose application engines, with different number of cylinders and configurations. Next, are described the aspects that were taken into account to select the ICE.

- The engine block must be big enough to allow modifications. If the engine is multi-cylinder, there must be enough space between cylinders to install the force sensors and the structure required to isolate the liner.

- The specifications and working conditions of the engine should be representative in the automotive industry.

- Costs and number of modifications needed in the engine.

- It is preferable to have the lowest amount of mechanical components, as it is translated to lower overall friction, less components to be properly lubricated, and also less possibilities of mechanical failures. 
- Space and infrastructure needed to mount and operate the test rig.

- Given that the test rig does not have combustion, the engine can be air cooled, which also facilitates modifications in the engine block.

Based on the above requirements, a single-cylinder motorcycle ICE was considered to be the most suitable engine type for the floating liner test rig. With a multi-cylinder engine, different issues must be addressed: since the friction force is only measured in one cylinder, and the rig is operated under motored conditions, modifications are necessary in the rest of the cylinders to account for force changes that unbalance the engine, causing undesired vibration. On the other hand, in a single cylinder engine there is sufficient space to make modifications without being disturbed by another cylinders; furthermore, the number of mechanical components is lower, which facilitates the lubrication and maintenance of the rig. The selected motorcycle engine is shown in the following Figure 4.1, and its main specifications are summarized in Table 4.1.

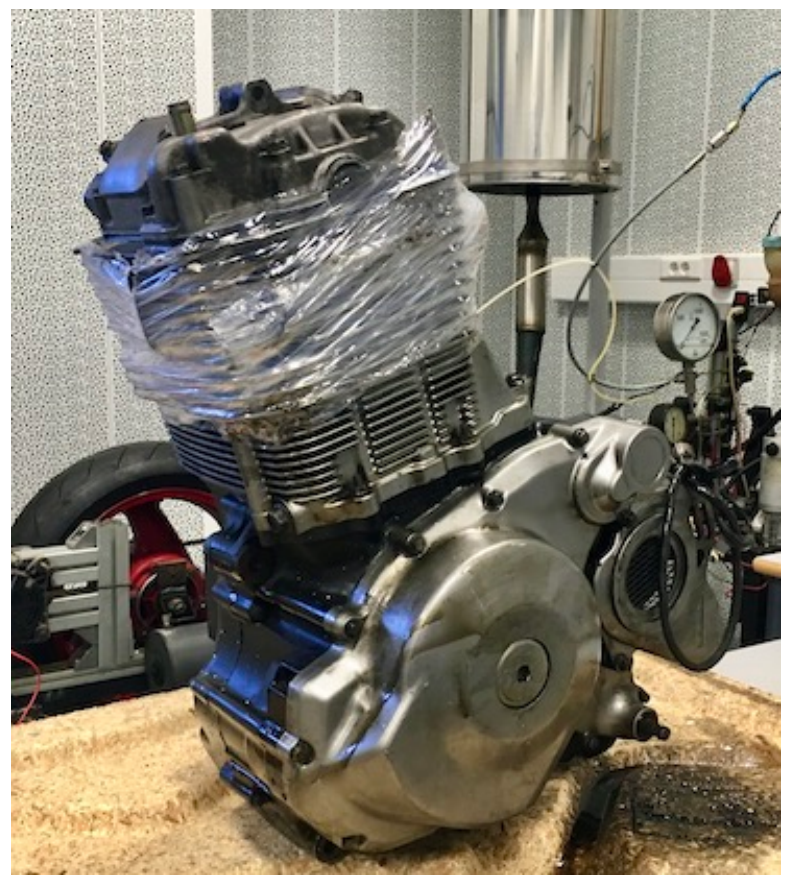

Figure 4.1. ICE selected for the floating liner test rig. 


\begin{tabular}{|r|c|}
\hline Parameter & Value \\
\hline \hline Engine reference & Suzuki DR800 \\
Displaced volume & $799 \mathrm{cc}$ \\
Bore & $105 \mathrm{~mm}$ \\
Stroke & $90 \mathrm{~mm}$ \\
Compression ratio & $9.5: 1$ \\
Connecting rod length & $148 \mathrm{~mm}$ \\
Max power & $39.1 \mathrm{~kW} @ 7000 \mathrm{rpm}$ \\
Max torque & $58.8 \mathrm{Nm} @ 5500 \mathrm{rpm}$ \\
\hline
\end{tabular}

Table 4.1. Main specifications of the ICE selected for the floating liner.

\subsubsection{Force sensors selection}

From the literature review on previously developed floating liner test rigs, piezoelectric force sensors were selected to measure the friction force, which are based on the piezoelectric effect of quartz. This characteristic consists in producing an electric charge output proportional to the force applied to the material. Piezoelectric sensors are mechanically preloaded by setting a constant static load, which is necessary to keep the quartz crystals in close contact, and to allow a tension measuring range in the sensor. In this way, when a tension force is applied, the corresponding preload is released causing a proportional charge output [6]. Given that this preload is constant, it can be tared before tests so the output of the sensors corresponds to the applied force. Piezoelectric force sensors are also active sensing elements, they do not need any power supply to operate. They can be manufactured to measure the force in one direction, but also in three directions. For the unidirectional sensors, their installation depends on the direction of the force to be measured, as they must be mounted in line with the force path to measure it directly [3]. In order to select the unidirectional piezoelectric force sensors, commercial options were evaluated based on the following aspects: measuring range, dimensions, ease of installation, preloading and calibration and working conditions. Some of the force sensors evaluated in this step of the floating liner design are summarized in the following Table 4.2.

From Table 4.2 and the analysis of available piezoelectric force sensors, it was determined that the best option would be the third: a 9301B Kistler force sensor. The main reason for this decision was that this sensor is preloaded 


\begin{tabular}{|c|c|c|c|}
\hline \multirow[b]{2}{*}{$\begin{array}{l}\text { Kistler } \\
\text { piezoelectric } \\
\text { force sensors }\end{array}$} & $9130 \mathrm{~B}$ & 9173B & 9301B \\
\hline & & & 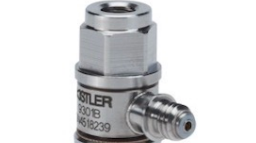 \\
\hline $\begin{array}{r}\text { Measurement } \\
\text { range }[\mathrm{kN}]\end{array}$ & $\begin{array}{c}\text { Compression: } \\
0 \ldots 3\end{array}$ & $-3 \ldots 12$ & $-2.5 \ldots 2.5$ \\
\hline $\begin{array}{r}\text { Sensitivity } \\
{[\mathrm{pC} / \mathrm{N}]}\end{array}$ & -3.5 & -3.5 & -3.2 \\
\hline $\begin{array}{r}\text { Temperature } \\
\text { range }\left[{ }^{\circ} \mathrm{C}\right]\end{array}$ & $-20 \ldots 120$ & $-20 \ldots 80$ & $-40 \ldots 120$ \\
\hline $\begin{array}{r}\text { Outside } \\
\text { diameter }[\mathrm{mm}]\end{array}$ & 8 & 18 & 11 \\
\hline $\begin{array}{r}\text { Internal } \\
\text { diameter }[\mathrm{mm}]\end{array}$ & 2.7 & 8 & 8.5 \\
\hline Height $[\mathrm{mm}]$ & 3 & 22 & 25 \\
\hline \multirow[t]{2}{*}{ Adventages } & Lower height & $\begin{array}{l}\text { Preloaded in } \\
\text { factory }\end{array}$ & $\begin{array}{l}\text { Preloaded and } \\
\text { calibrated in } \\
\text { factory }\end{array}$ \\
\hline & Lower price & $\begin{array}{l}\text { No calibration } \\
\text { needed after } \\
\text { installation }\end{array}$ & $\begin{array}{l}\text { No calibration } \\
\text { needed after } \\
\text { installation }\end{array}$ \\
\hline \multirow{3}{*}{ Disadventages } & $\begin{array}{c}\text { Complex } \\
\text { installation }\end{array}$ & \multirow{3}{*}{ Mounting space } & \multirow{3}{*}{ Mounting space } \\
\hline & Preload required & & \\
\hline & $\begin{array}{c}\text { Calibration } \\
\text { needed after } \\
\text { installation }\end{array}$ & & \\
\hline
\end{tabular}

Table 4.2. Decision aid matrix to select the piezoelectric force sensor for friction measurement in the floating liner. 
and calibrated in factory; therefore, its installation is comparatively easier than the other references. This preload also offers a measuring range suitable for the friction force measurements in the floating liner under both compression and tension forces. The height of this sensor however, was one of the main restrictions to take into account when designing the floating liner.

\subsubsection{Designed and modified components}

In this section is described the design process of the floating liner test rig and its mechanical and structural components, including modifications made to the ICE. Attending that the next step on the improvement of the test rig is the sealing of the combustion chamber to operate under high pressure conditions, some of the structural components were analyzed for structural performance under these conditions.

The design of the floating liner started with the definition of the method or solution to isolate the liner from the engine block, allowing it to float restricted only by the piezoelectric force sensors, selected in the previous Section 4.3.2. To accomplish this step, the geometric dimensions of the sensors were taken into account, as well as the dimensions and characteristics of the ICE. The configuration of the motorcycle engine did not include a removable liner, instead it was cast in the engine block; for this reason, the engine block and cylinder head were completely removed from the ICE, keeping only the bottom part of the engine, as shown in Figure 4.2. The engine block was replaced by a custom liner with smaller diameter of $91.64 \mathrm{~mm}$, the original was $105 \mathrm{~mm}$ (Table 4.1). This diameter was selected as it is more representative of the automotive industry and therefore, it would facilitate the exchange of the liner and piston rings. The floating liner structure was finally assembled to the crankcase of the ICE, taking advantage of the crankshaft, connecting rod, oil pump, oil lubrication passages and jets, etc.

The mechanical solution proposed to isolate the liner and measure the friction force is shown in Figure 4.3. It consists of a customized cylinder liner with an external disc around is outer diameter, and three piezoelectric force sensors installed between this external disc and a base plate, that serves as link between the ICE and the floating liner structure. The sensors were located at $120^{\circ}$ spacing, with one of them located in the anti-thrust side of the piston. With this configuration, the micrometrical displacement of the liner in the axial direction, due to the reciprocating motion of the piston, is only restricted by the force sensors; which in turn, capture the dynamic friction force changes in the piston-liner contact. 

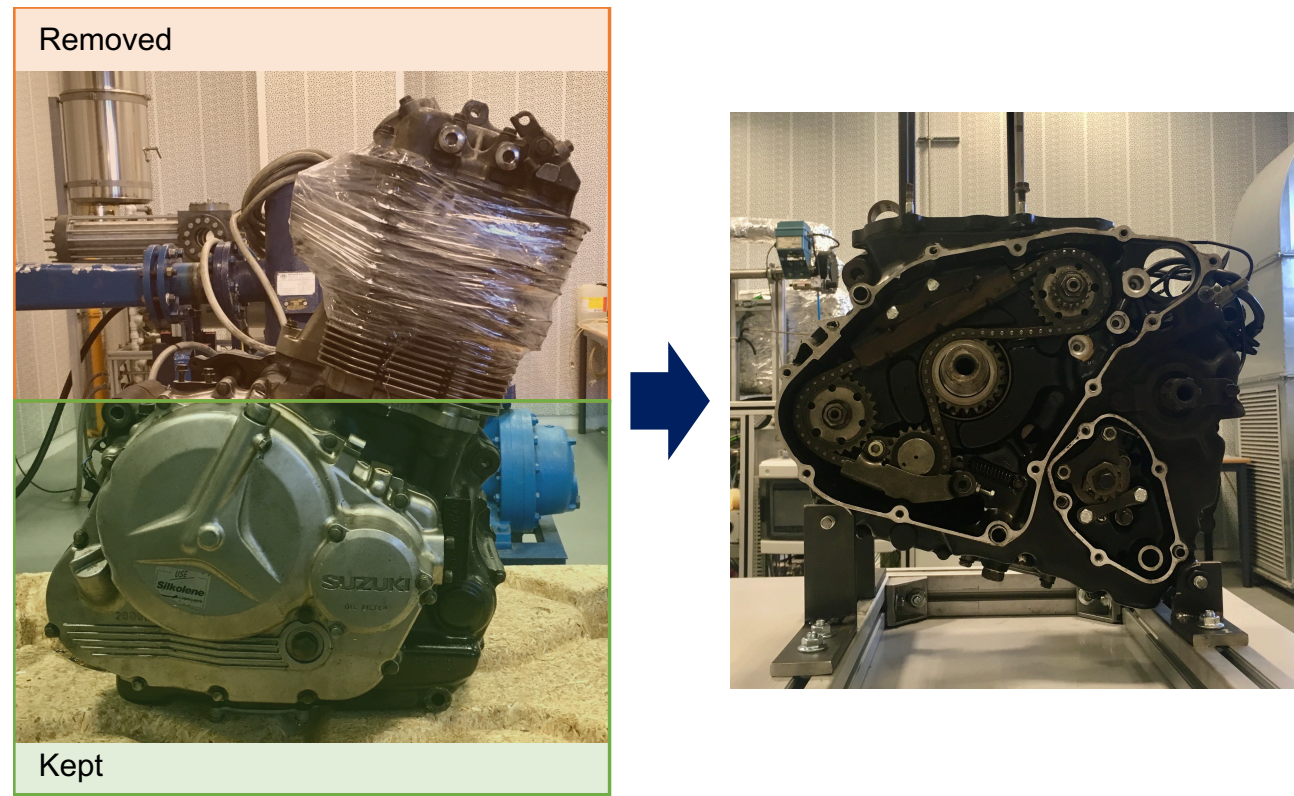

Figure 4.2. ICE with sections to be removed and kept for the floating liner assembly.

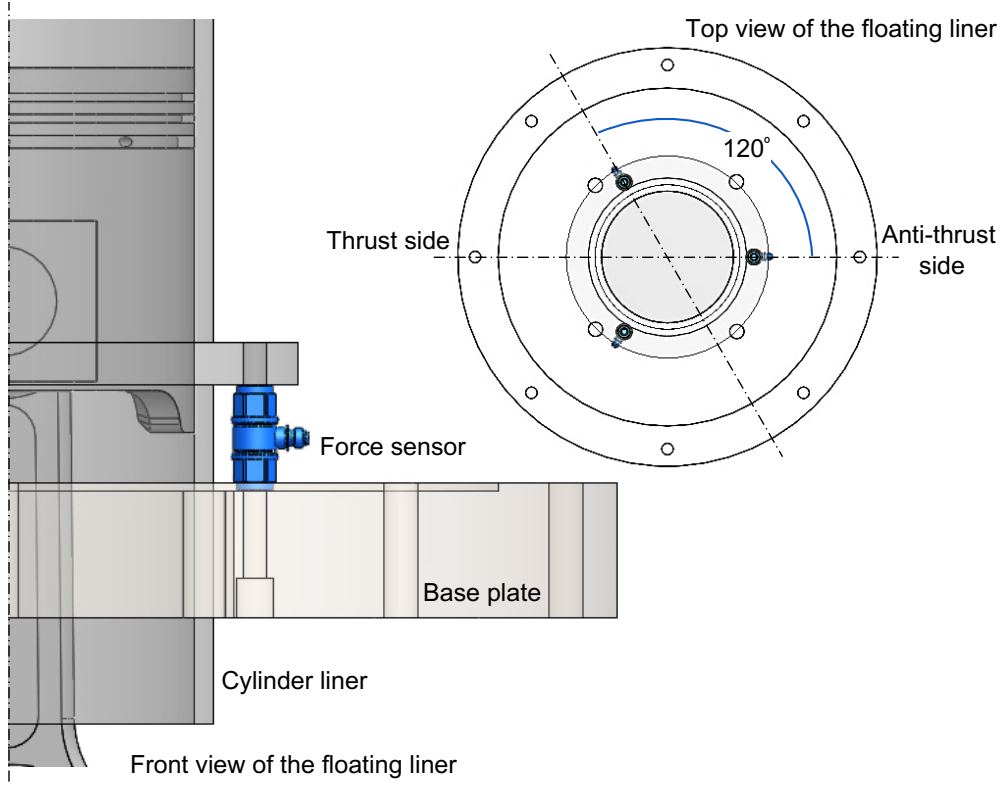

Figure 4.3. Mechanical solution to measure the friction force in the floating liner. 
The final design of the floating liner test rig is presented in the following Figure 4.4, as it can be seen, the design includes the sealing of the combustion chamber with a preliminary design that helped to develop the structural analysis. In this way, the test rig comprises a custom cylinder liner, a base plate that serves as link between the floating liner structure and the crankcase, and is also used to install the sensors, a radial support, an external structure composed by three hollow cylinders of the same dimensions, and the upper locking system to seal the combustion chamber. These components are further described in the following sections.

\subsubsection{Considerations for the structural analysis}

This study consisted of a linear structural analysis of the main components of the floating liner developed by finite element analysis (FEA) using Ansys Mechanical. Some overall considerations were taken into account during the analysis of each component, such as mesh convergence, Von Mises stress results, identification of zones with high stress concentration, and over engineered designs. To help with the mesh convergence analysis, the NAFEMS 4-point convergence curve, shown in Figure 4.5, was employed as guideline. This method consists of plotting the result of a critical parameter against a measure of the mesh density for at least three runs of the structural analysis with different mesh refinements. The plotted curve indicates if convergence has been achieved when the latest results are very similar. It can occur however, that two runs of the analysis are sufficient for the mesh convergence [4]. For the mesh convergence analysis developed to some components of the floating liner, the Von Mises stress was selected as the critical parameter, and the number of nodes as the indicator of the mesh density.

The initial conditions for the analysis were:

- Applied force: according to the design of the floating liner, as presented in Figure 4.4, the force applied to the structure of the test rig comes from the in-cylinder pressure, when the sealing of the combustion chamber is in place. In order to evaluate the design of the floating liner under the worst case scenario, it was assumed that air at 4 bar was supplied to the combustion chamber when the piston was at the BDC, reaching a pressure of about 90 bar during compression. The resultant force of this maximum in-cylinder pressure, applied to the area of the sealing of the combustion chamber, was used as applied force in the structural analysis of the test rig components. 


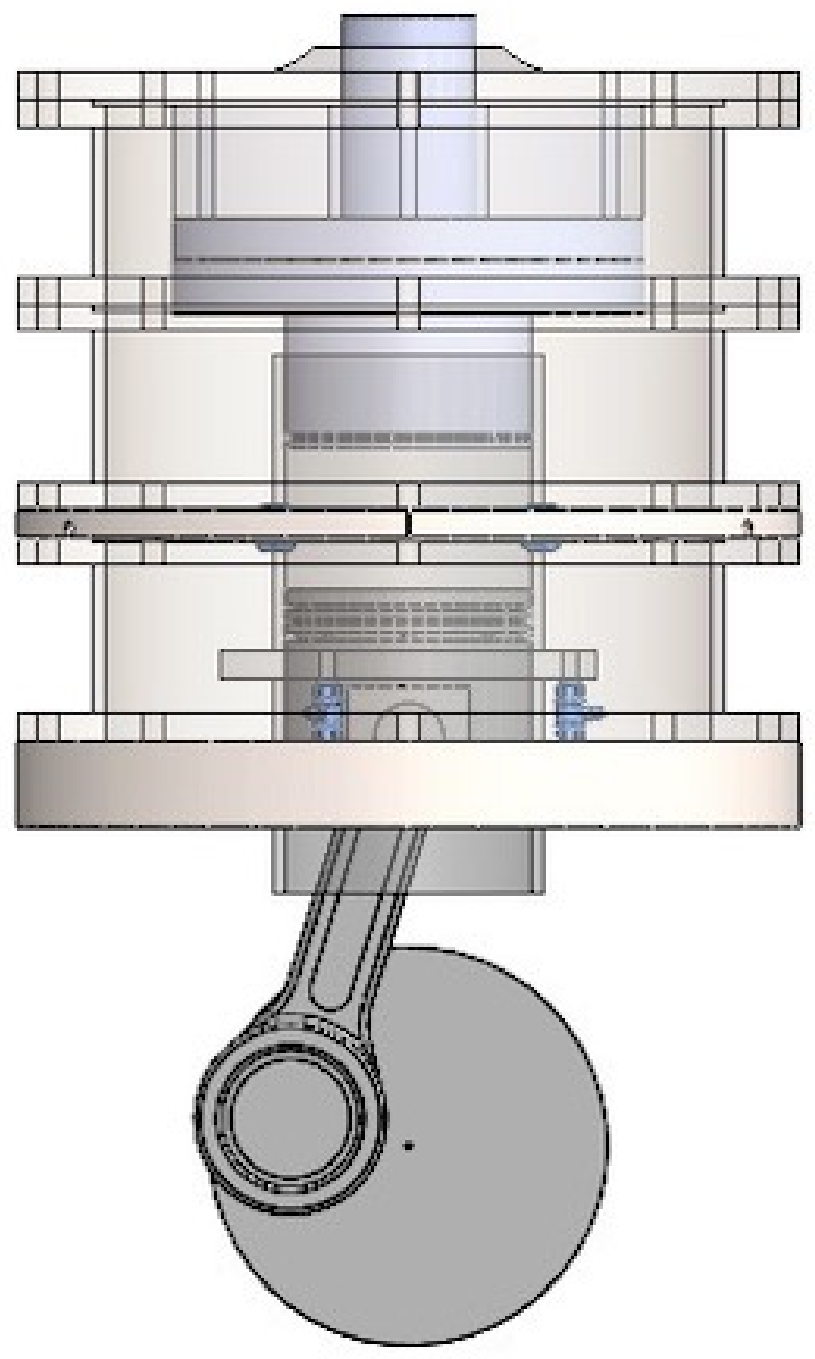

Figure 4.4. CAD of the floating liner test rig.

- Material properties: structural steel was selected for the manufacture of the floating liner components. The mechanical characteristics of this material are summarized in Table 4.3; they were obtained from the Ansys Mechanical materials database. 


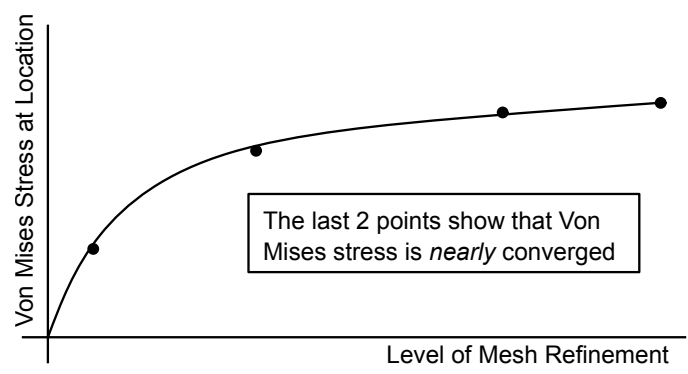

Figure 4.5. NAFEMS 4-point convergence curve. Adapted from [4].

\begin{tabular}{|r|c|}
\hline \multicolumn{2}{|c|}{ Structural steel } \\
\hline Density & $7850 \mathrm{~kg} / \mathrm{m}^{3}$ \\
Poisson's ratio & 0.3 \\
Young's modulus & $200 \mathrm{GPa}$ \\
Tensile yield strength & $250 \mathrm{MPa}$ \\
Tensile ultimate strength & $460 \mathrm{MPa}$ \\
\hline
\end{tabular}

Table 4.3. Mechanical properties of structural steel.

\subsubsection{Upper locking system}

As it was mentioned in Section 4.3.3, the sealing of the combustion chamber has been proposed as a future improvement of the floating liner test rig; therefore, it was important that its design had previsions for the sealing of the combustion chamber. With this in mind, a preliminary design of an upper locking system was proposed consisting of three components: a plug, an attachment plate and a spacer plate. This assembly is shown in Figure 4.6. The plug is fitted inside the liner to seal the combustion chamber by means of an O-ring, allowing the free displacement of the liner in the axial direction. This component will also accommodate a pressure sensor and the device to supply the compressed air. The space and holes required for these components were included in the design of the plug. In order to help to the concentric location of the plug inside the liner, and to reduce erroneous friction force measurements from the combustion chamber sealing, an attachment plate was added to the upper locking system. This component was designed with a boss feature thought to be assembled with a high tolerance to the external top plate 
(Section 4.3.3.4), as shown in Figure 4.4. Between the attachment plate and the external top plate, a spacer plate was added composed by annular discs of the desired thickness; in this way, with the addition or removal of one or more discs it would be possible to adjust the location of the plug relative to the piston and therefore, modify the compression ratio of the engine. This spacer plate also provides a greater area for the transmission of the high in-cylinder pressure to the external structure of the floating liner. The final assembly of the upper locking system was jointed using four threaded studs.

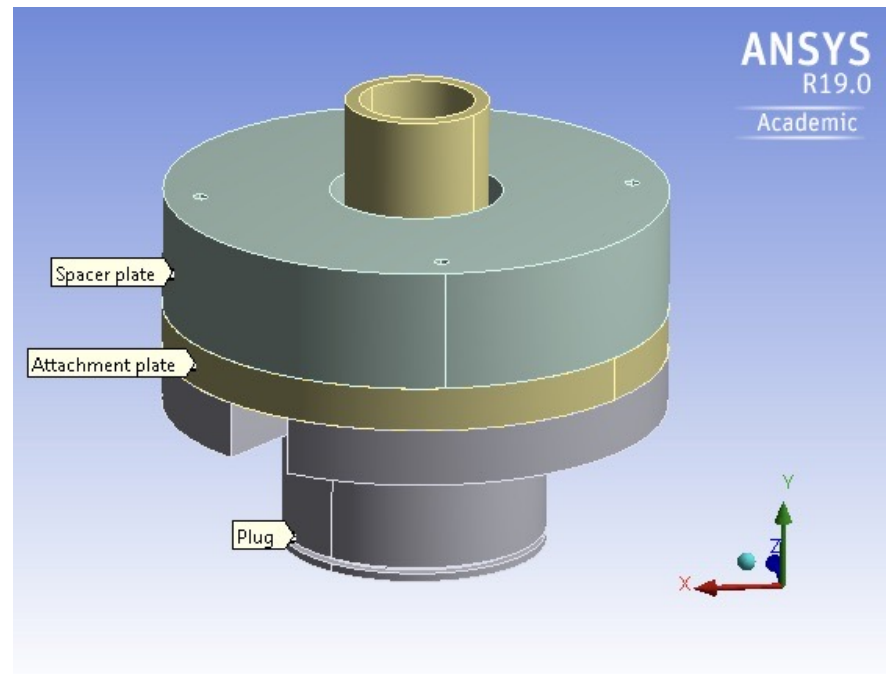

Figure 4.6. Upper locking system assembly for the structural analysis.

For the structural analysis of the upper locking system, its components were analyzed as an assembly in order to simulate the connections between them: the contact between the three components was set to rough so the assembly is not analyzed as a single body. Regarding the boundary conditions applied to the FEA analysis, they comprise: a displacement in the top face of the spacer plate to restrict its movement in the $y$ direction and allow the deformation in $x$ and $z$, and the resultant force applied to the lower face of the plug, due to the in-cylinder pressure. This force was selected for the worst case scenario with an in-cylinder pressure of 90 bar when the piston is at the TDC.

The mesh applied to the assembly was a tetrahedron based mesh; however, each component was refined according to their specific stress results in order to increase the accuracy and to reduce the structural error. Results of the mesh 
convergence studies are presented for the plug as they showed improvements when refining the mesh.

The mesh refinements added to the plug consisted of: a body sizing for the whole component, a refinement applied to the edges of the holes, destined to the pressure sensor and the device to supply the compressed air, and a face sizing for the lower face of the plug, where the force is applied, and for the its internal hole. The mesh convergence results are presented in the following Figure 4.7. As it can be seen from this plot, the mesh convergence curve follows the trend of the NAFEMS 4-point convergence curve (Figure 4.5), and it can be said that convergence has been achieved with the latest runs of the analysis. It can also be noted that the second point in the Von Mises stress curve differs slightly from the trend line, this is because the body sizing was added in this iteration.

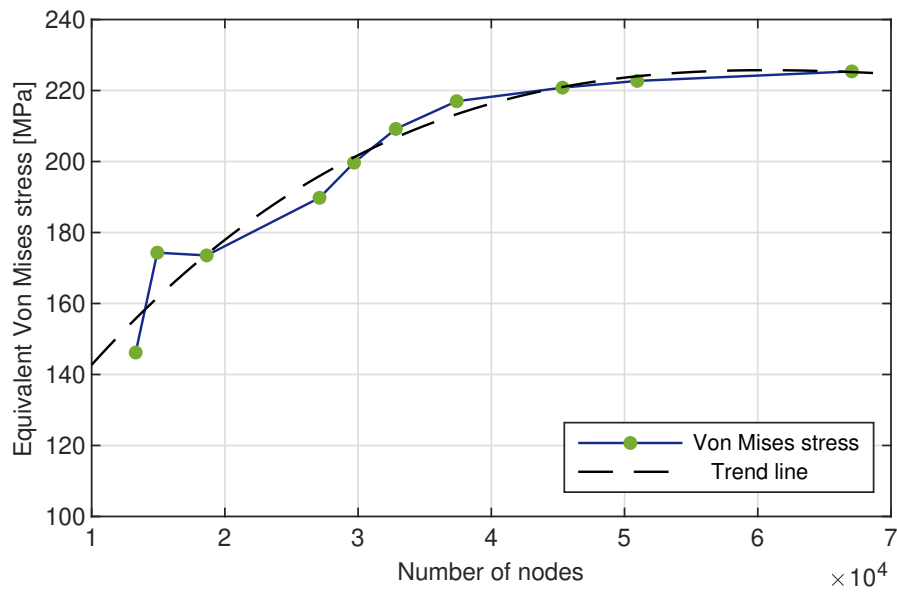

Figure 4.7. Mesh convergence curve for the plug structural study.

For the attachment plate and spacer plate components, a body sizing was applied along with a refinement in the lower edge of the spacer plate hole, where these two components come into contact and high stress concentration occurs. These mesh refinements showed a small reduction of the structural error, as well as a small variation in the Von Mises stress results. The final mesh applied to the upper locking system is shown in Figure 4.8.

The structural analysis results for the upper locking system are presented in Figure 4.9, for the whole assembly and for each of the three components. These results show a high stress concentration area in the plug of about 223 $\mathrm{MPa}$, in the holes for the device to supply the compressed air and the pressure 


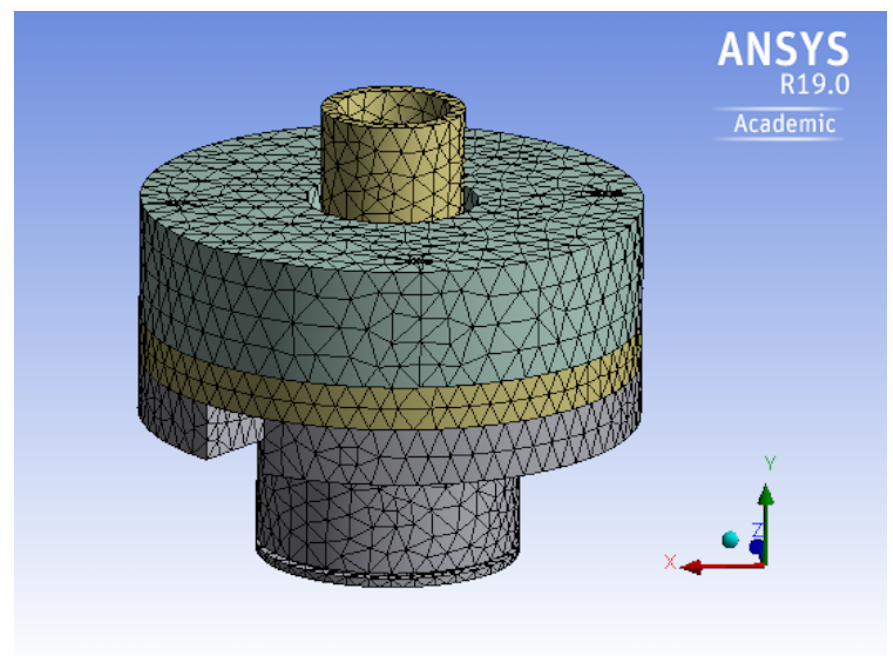

Figure 4.8. Upper locking system mesh.

sensor (Figure 4.9a). Since this is a preliminary design of the plug, a further structural analysis of this component is needed based on the device selected to supply the air to the combustion chamber. Regarding the spacer and attachment plate components (Figure $4.9 \mathrm{~b}$ and c), areas of stress concentration appeared in the zone where they come into contact, emphasized by the sharp edges of the gap in the top cylinder of the plug.

\subsubsection{Radial support}

The function of this component in the floating liner is to provide a restriction to the lateral movement of the piston, and to reduce the effect of the side force on the friction force measurement, while allowing the free motion of the liner in the axial direction. The radial support comprises two components: two half-moons with a thickness of $10 \mathrm{~mm}$ attached to the external structure of the test rig using bolts, and four ball transfer units. These transfer units are load bearings composed by a ball with omnidirectional motion supported by small balls and a holding fixture. The ball transfer units are mounted on the internal diameter of the half-moons, as shown in Figure 4.10, providing radial support to the liner, while allowing its vertical motion with a negligible friction contribution.

For the structural analysis of the radial support, the dynamics of the connecting rod-crank mechanism was calculated to obtain the lateral force 


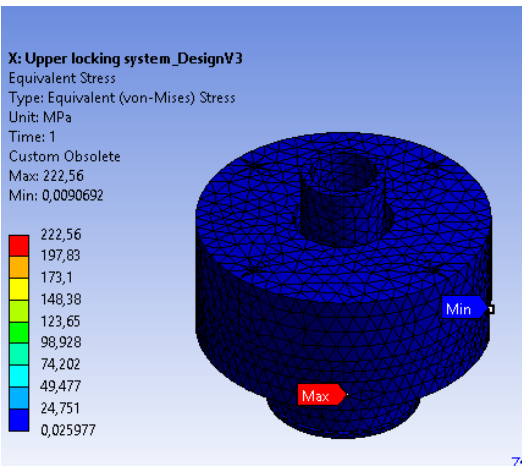

a. Assembly-ISO view

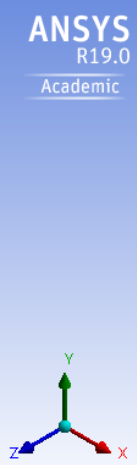

ANSYS

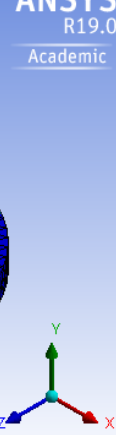

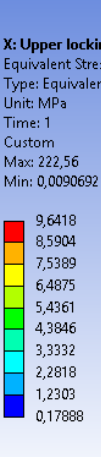

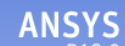

R19.0

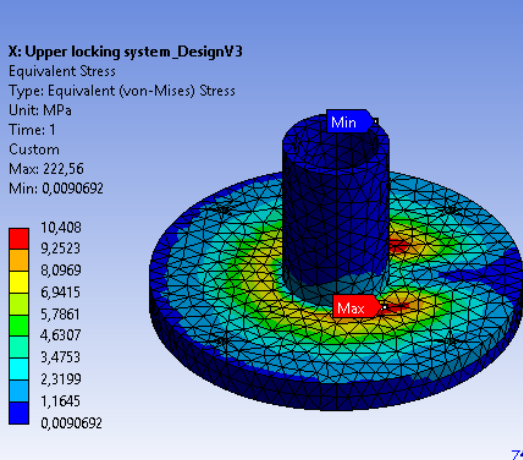

c. Attachment plate-ISO view

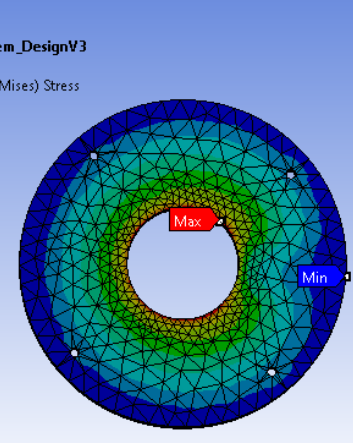

b. Spacer plate-bottom view

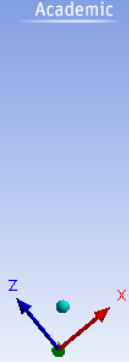

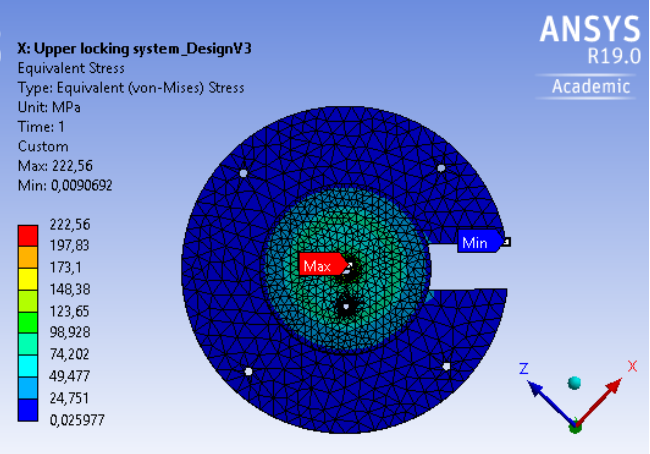

d. Plug-bottom view

Figure 4.9. Upper locking system Von Mises stress results.

between the piston and the liner; this study is presented in the Appendix 4.A. As it can be seen from Figure 4.44 and 4.45, the lateral force varies significantly with the working conditions of the test rig. With the floating liner working under ambient pressure conditions, the lateral force depends only on the inertia of the moving mass, and increases with the engine speed, reaching $1 \mathrm{kN}$ under $3000 \mathrm{rpm}$. Under compressed conditions, this lateral force is highly affected by the in-cylinder pressure; and although the inertia compensates the load [5], the lateral force reaches more than $4 \mathrm{kN}$ with and engine speed of $500 \mathrm{rpm}$ and a compression pressure of about 90 bar.

A half of one of the half-moons was selected for the structural analysis, the mesh applied consisted of a multizone mesh and edge sizings, applied specially to the holes of the component . Regarding the boundary conditions, they included: the maximum lateral force applied as a bearing load to the 


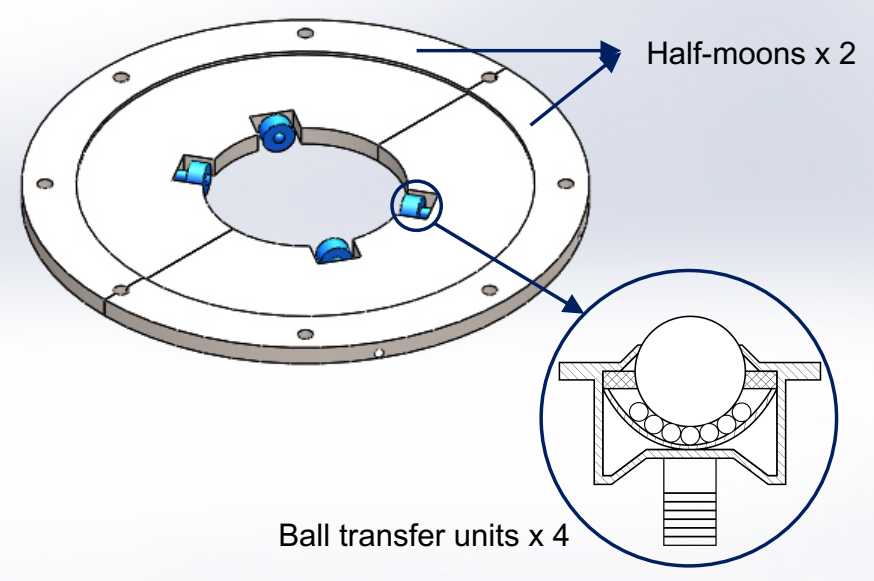

Figure 4.10. Radial support components.

internal diameter of the half-moon, frictionless supports to mimic the rest of the component and fixed support to represent the bolts that join the radial support to the external structure of the floating liner. Figure 4.11 shows the final mesh applied to the half-moon.

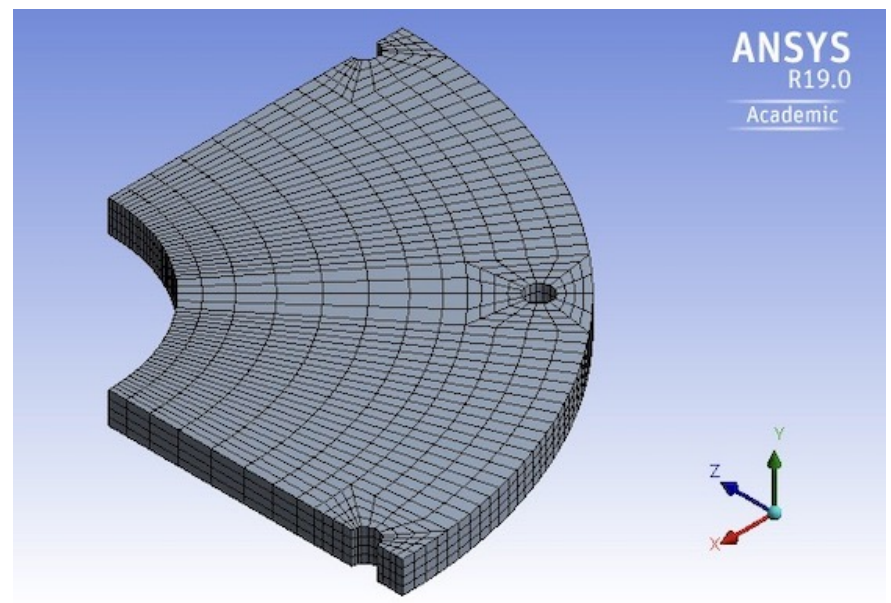

Figure 4.11. Radial support mesh.

The results of the structural analysis are presented in Figure 4.12; it can be seen that the bearing load applied to the internal face of the half-moon resulted in high stress contours along the $Z$ direction, as expected, due to the 
secondary motion of the piston and the resultant force applied to the liner. A region of high stress concentration appeared in one hole, where it is stretched.

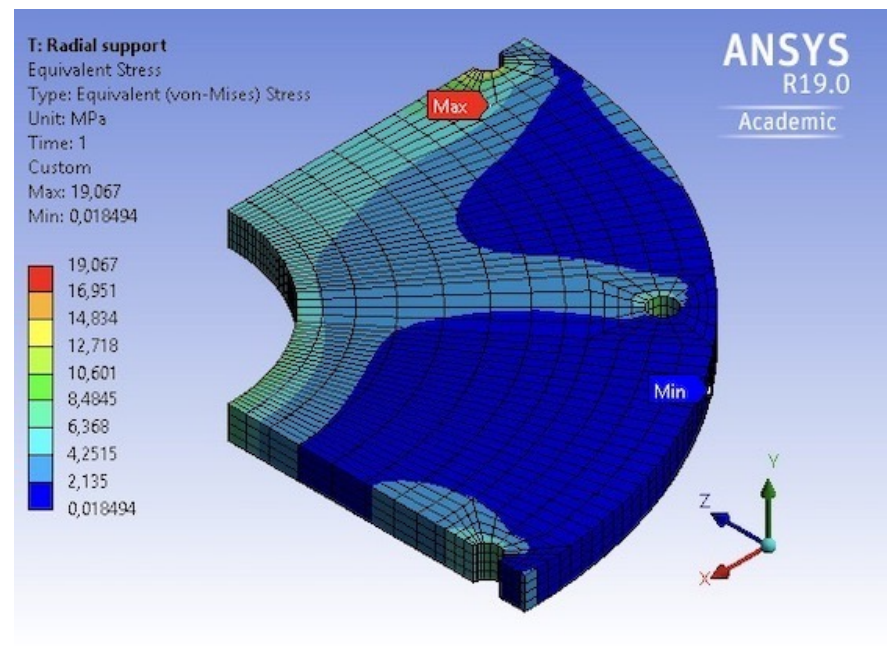

Figure 4.12. Radial support Von Mises stress results.

\subsubsection{External structure}

The external structure of the floating liner test rig consists of a top plate and three hollow cylinders of the same dimensions to transmit the force from the in-cylinder pressure to the base plate. These components are shown in the previous Figure 4.4. For the design of the external structure some considerations were taken into account, such as the need of sufficient space to install the force sensors and the radial support, and also to have a modularlike design that allows testing under both ambient pressure and compressed conditions. The structural analysis of the external structure components is presented below:

\section{External cylinder}

As it was mentioned above, this component consists of three hollow cylinders with a wall thickness of $5 \mathrm{~mm}$ and two flanges at the top and bottom faces. The size of the flange was determined by the space required by the bolts and washers used to assemble the structure. For the structural analysis, one eight of the external cylinder was used and two washers were added to the 
bolt holes, as they were found to improve the mesh and reduce the structural error. Figure 4.13 shows the final mesh applied to the geometry, it consisted of a multizone mesh, different edge sizings and a face meshing for the washers.

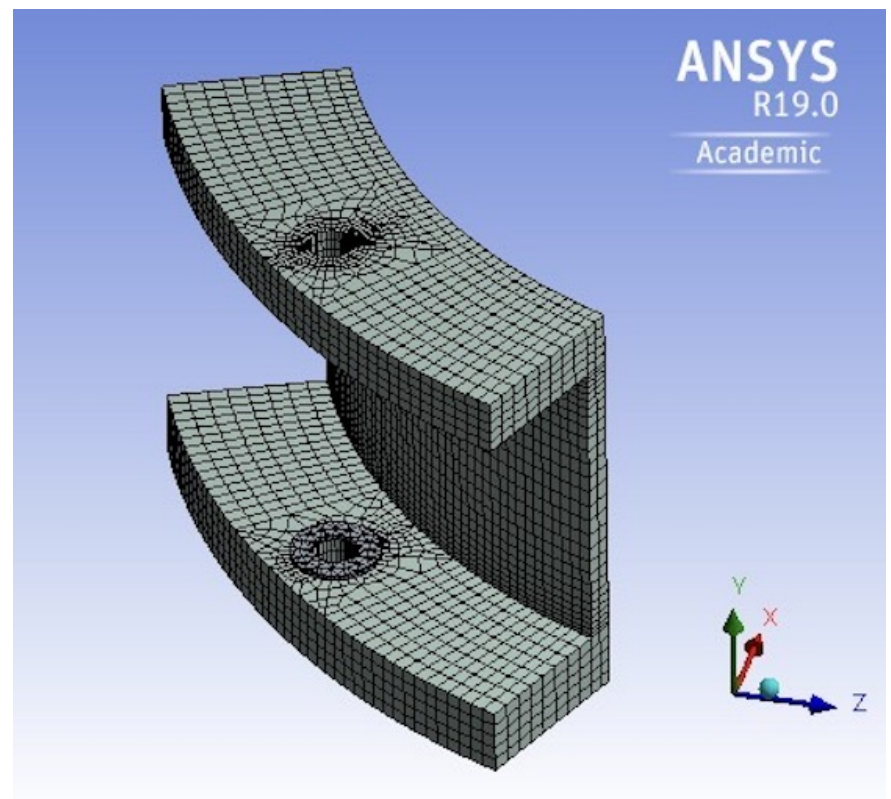

Figure 4.13. External cylinder mesh.

The boundary conditions applied to the component consisted on the resultant force, from the in-cylinder pressure, a fixed support on the lower washer to simulate the connection between the external cylinder and the rest of the structure, a frictionless support to mimic the rest of the solid, and a remote displacement applied to the top and bottom faces of the external cylinder to constrain the displacement in the $Y$ direction, and simulate its bond with the rest of the external structure, with the base plate and the radial support, in the case of the third cylinder (Figure 4.4).

The results of the structural analysis are presented in Figure 4.14; it can be seen that the force applied to the cylinder, resulted in a bending effect on the component, which can be observed in the different stress contours in the center of the cylinder, and in a zone of high stress concentration at the top washer. The resultant Von Mises stress however, is well below the yield strength of the material. 


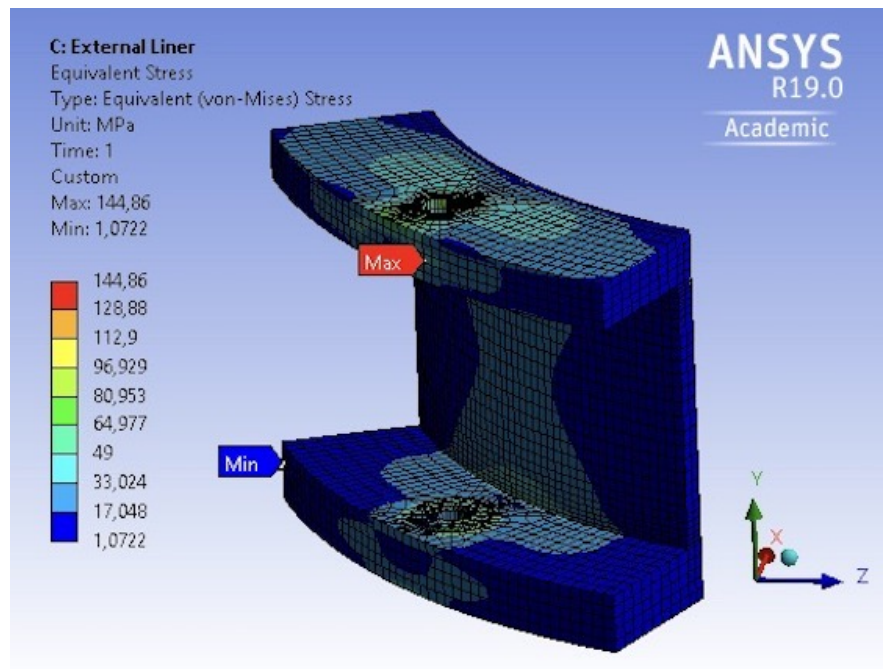

Figure 4.14. External cylinder Von Mises stress results.

\section{Top plate}

This component is the cover of the floating liner structure as shown in Figure 4.4, and serves to multiple purposes: it keeps the plug (upper locking system) in place and at the required distance from the TDC, the hole in the top plate forms an assembly of high tolerance with the boss feature of the attachment plate helping to the concentric location of the plug inside the liner (Section 4.3.3.2), and finally, this component transmits the resultant force from the in-cylinder pressure to the rest of the external structure of the test rig.

The final design of the top plate consists of a circular plate with bolt holes in its outer diameter, and a circular boss feature in the center of the plate. This circular feature, which allows the assembly of this component with the attachment plate, was designed with a blended radius of $40 \mathrm{~mm}$ to reduce the stress concentration in this area, as described in the structural analysis below.

For the structural analysis, one sixteenth of the top plate was taken and a multizone mesh and some edge sizings were applied to the component. The final mesh is show in Figure 4.15. The boundary conditions include: a fixed support for the bolt hole, a displacement constrain in the lower outer region of the plate, where it meets the external liner, and at the center hole, where it meets the attachment plate, the force form the in-cylinder pressure, and a 
frictionless support applied to the edges of the solid to mimic the rest of the top plate.

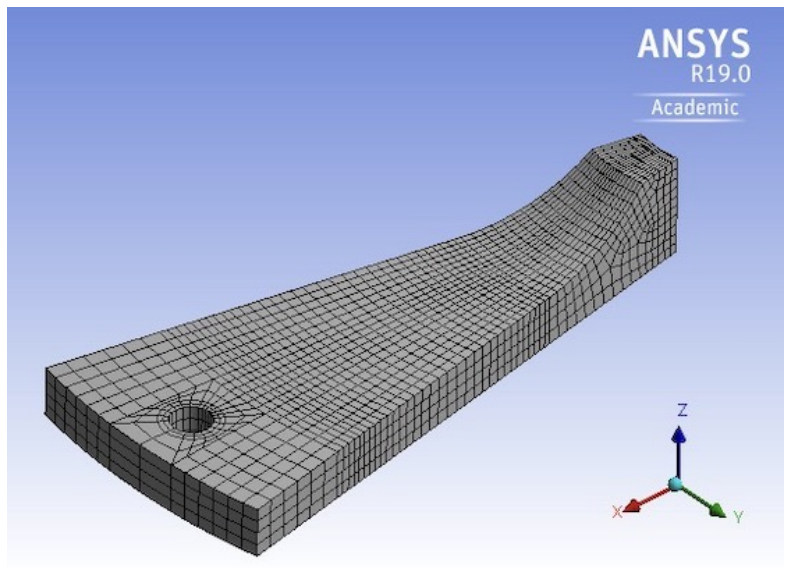

Figure 4.15. Top plate mesh.

As it was mentioned before, a blended radius was added, in the intersection of the boss feature and the top plate, to decrease the stress concentration in this area. In order to select the appropriate blended radius, the structural study was developed for a range of radius, from $5 \mathrm{~mm}$ to $40 \mathrm{~mm}$. The results showed a maximum Von Mises stress of $492.56 \mathrm{MPa}$ with a radius of $5 \mathrm{~mm}$; while the result with $40 \mathrm{~mm}$ was of $197.12 \mathrm{MPa}$. Figure 4.16 shows the Von Mises stress results for some of the blended radius: 5, 20 and $40 \mathrm{~mm}$.

From the results shown in previous Figure 4.16, it was clear that the addition of a blended radius was critical for the reduction of the localized stress; going beyond $40 \mathrm{~mm}$ however, did not show a significant change in the Von Mises stress; therefore, this value was selected for the final design of the component.

\subsubsection{Base plate}

The base plate component consists of a circular plate with a center hole and four bolt holes located around it to attach the base plate to the engine block. Three bolt holes were also machined in the base plate to attach the force sensors. Finally, in order to assemble this component to the external structure of the test rig, bolt holes were created in the external diameter of the plate. 


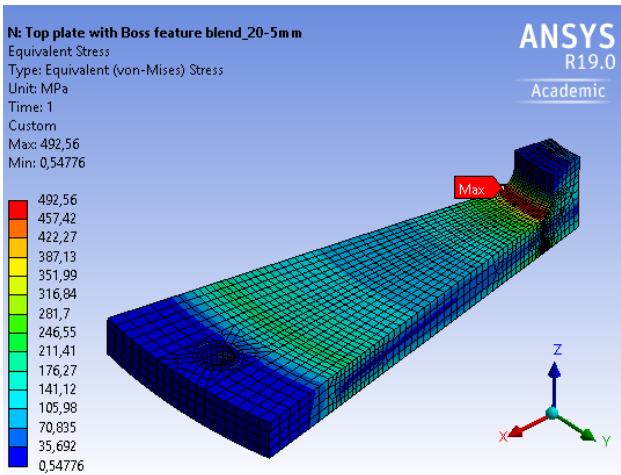

a. Blended radius $=5 \mathrm{~mm}$

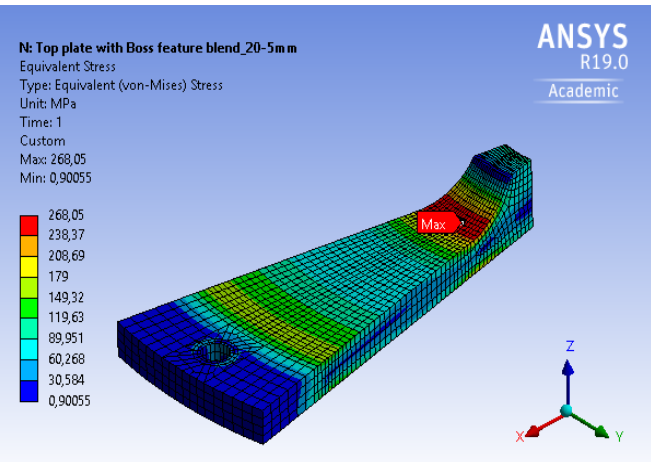

b. Blended radius $=20 \mathrm{~mm}$

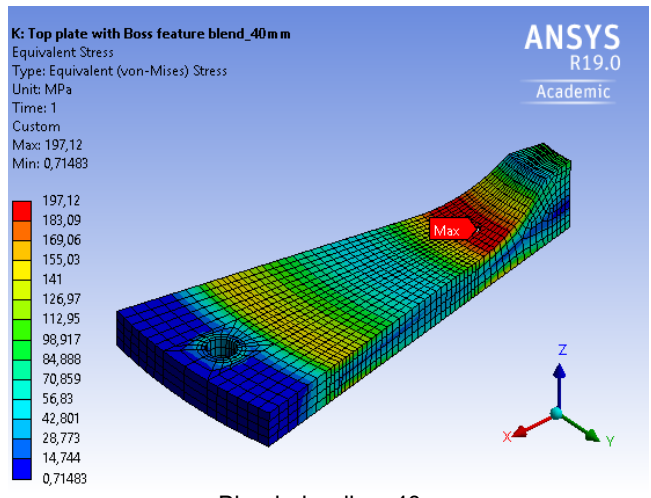

c. Blended radius $=40 \mathrm{~mm}$

Figure 4.16. Top plate Von Mises stress results.

Besides of serving as link between the floating liner structure and the ICE, the design of the base plate showed to be critical for the structural integrity of the test rig, as it adsorbs the resultant force from the in-cylinder pressure. For the structural analysis in Ansys Mechanical, a quarter of the base plate was used and the analysis was performed for different thicknesses of the plate. The final mesh applied to the component consisted of a tetrahedrons patch conforming mesh and refinements added to the areas of interest, such as the bolt holes, this is shown in Figure 4.17.

The applied boundary conditions were the resultant force from the incylinder pressure, frictionless supports to simulate the rest of the base plate, a displacement in the outer bolt holes, that attach the base plate to the external structure, and in the hole that attaches the base plate to the engine block, to restrict the movement in the $x$ and $z$ directions, and finally a displacement 


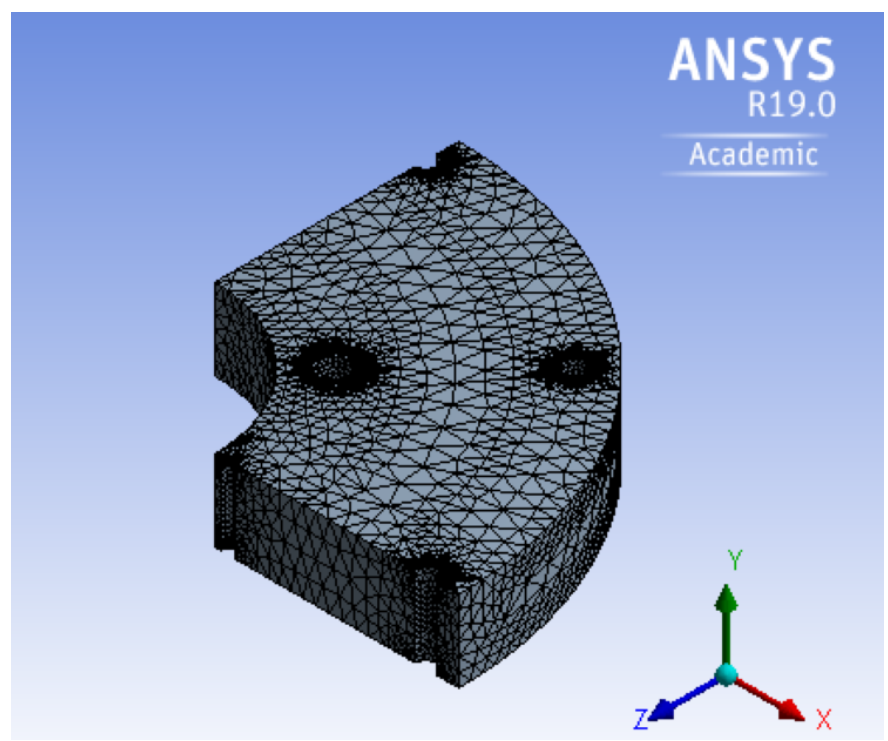

Figure 4.17. Base plate mesh.

restriction in the $y$ direction applied to upper face of the bolt hole that attaches the base plate to the ICE.

The results of the parametric study, with different thicknesses of the base plate ranging from 5 to $40 \mathrm{~mm}$, are presented in Figure 4.18. The initial design of the base plate with a thickness of $5 \mathrm{~mm}$ showed stresses of almost $5000 \mathrm{MPa}$ localized in one of the outer bolt holes (shown in Figure 4.19a); this is the due to the upward bending effect generated on the outer edge of the base plate by the applied force, which is supported only by the bolt holes that attach the base plate to the ICE.

From the results of Figure 4.18, a thickness of $30 \mathrm{~mm}$ was selected for the base plate, as it results in a stress of about $180 \mathrm{MPa}$ (Figure 4.19b), well below the tensile yield strength of steel; going beyond this value, does not change significantly the stress results instead, it adds material and weight to the component.

\subsection{Auxiliary systems}

The floating liner test rig comprises three auxiliary systems for its operation and the development of tests under ambient pressure conditions. 


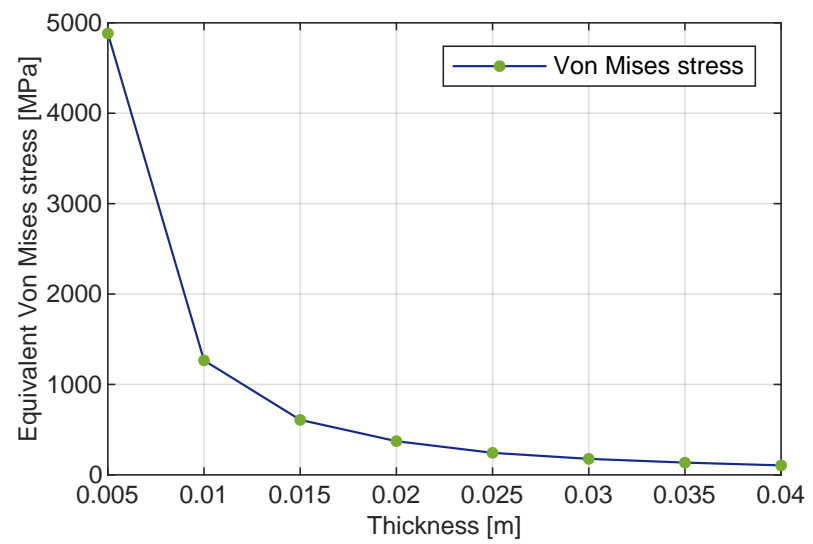

Figure 4.18. Von Mises stress results for the base plate with different thicknesses.

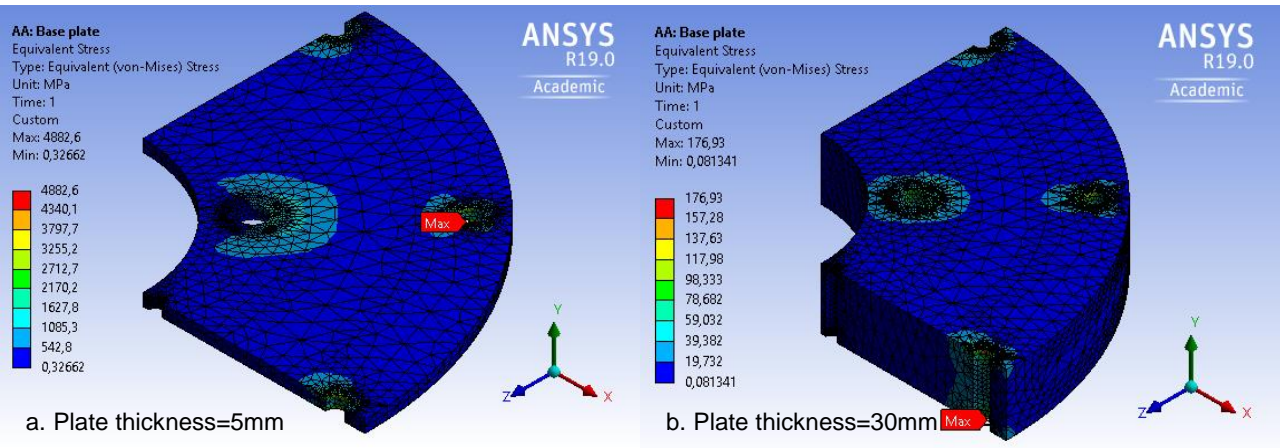

Figure 4.19. Von Mises stress results for the base plate.

These are the lubrication, transmission and data acquisition systems; a schematic diagram of the configuration of these systems in the test rig is presented in Figure 4.20.

\subsubsection{Lubrication system}

Friction force in the piston-cylinder liner assembly is highly affected by the working conditions of the oil, specifically the temperature, as it determines the oil viscosity and therefore, the lubrication condition of the engine components. In this way, the main objectives of this system are the appropriate lubrication of the test rig, and the control of the oil temperature for the parametric tests. 


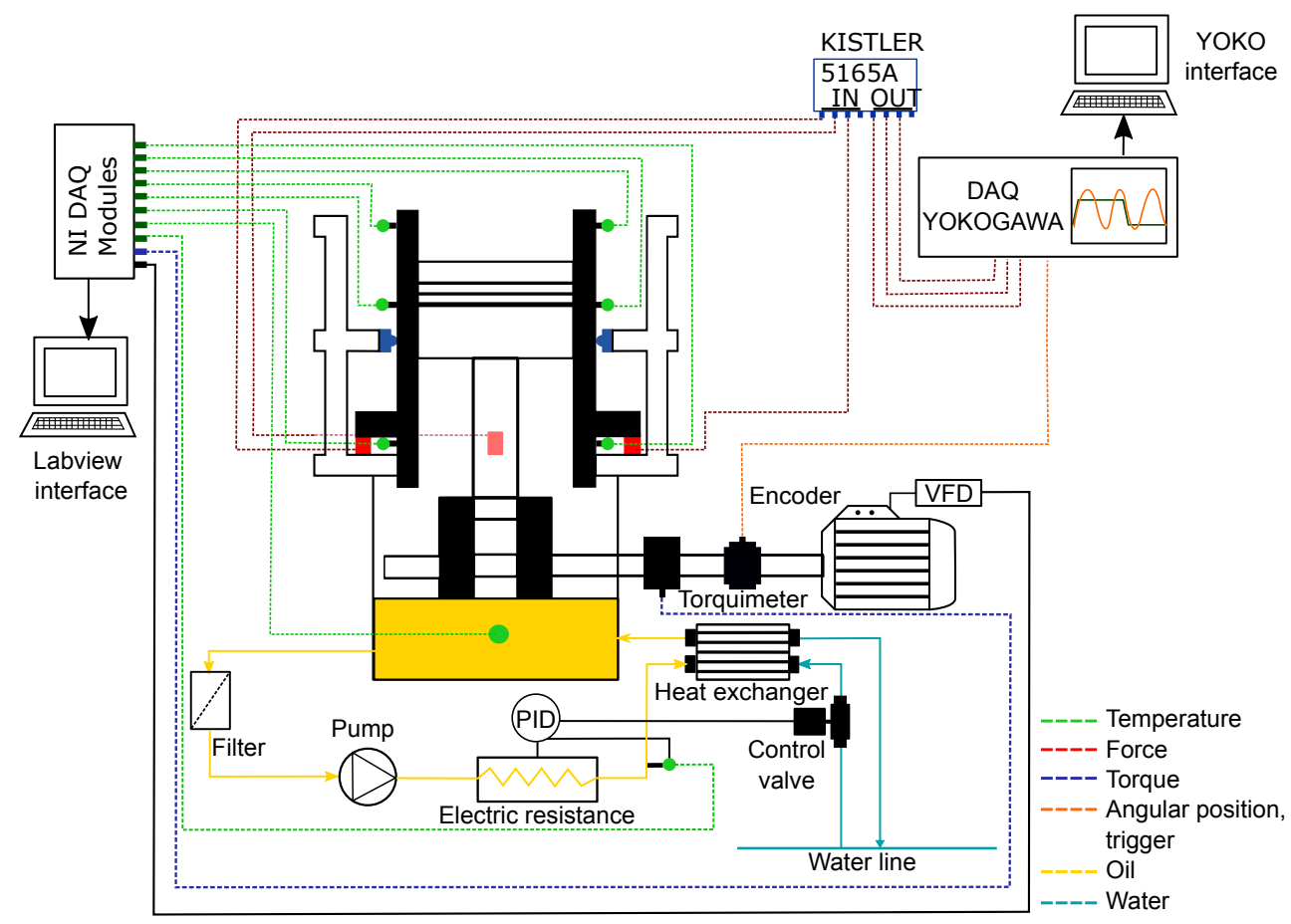

Figure 4.20. Auxiliary systems of the floating liner test rig.

To accomplish these objectives, the lubrication of the test rig was made taking advantage of the wet sump lubrication system of the engine; that is, using the oil pump, lubrication passages and the oil jet that lubricates the piston and liner from below. In addition, an external system was adapted to the test rig, as shown in Figure 4.20. It is mainly composed by an electric resistance to heat the oil entering the engine, a heat exchanger to cool the oil if needed, and an oil pump to recirculate the oil from and back to the crankcase. In order to control de temperature of the oil supplied to the engine, a PID controller was installed in the circuit; it compares the temperature set for the test with the temperature of the oil entering the crankcase, measured with a K-type thermocouple; the electric resistance and the control valve act accordingly, either to heat the oil, or to allow the flow of water to the heat exchanger. Finally, the temperature of the oil at the crankcase was controlled and registered with a K-type thermocouple; other six thermocouples were 
installed in the outer wall of the liner, in the anti-thrust and thrust side of the engine, in order to have an indirect measurement of the oil temperature along the stroke.

\subsubsection{Transmission system}

This system comprises the components needed to motor the ICE under ambient pressure conditions. It consists of an electric motor with a variable frequency drive (VFD), and the coupling between the motor and ICE. In order to make this coupling, some mechanical components were designed and manufactured, which also allowed the installation of a torque sensor and an encoder. The CAD assembly of this auxiliary system is presented in Figure 4.21. Starting from the ICE, the right-hand side cover of the crankcase was replaced with a custom made cover, of a smaller thickness than the original, to allow the crankshaft to protrude. Right after the ICE, a Kistler $4550 \mathrm{~A}$ torque sensor was installed, consisting of a rotating part installed in the shaft, and a stator installed in the structure of the test rig. Next, a hollow shaft encoder was installed to measure the angular position of the crankshaft during tests, with a resolution of 0.36 crank angle degrees. Finally, the electric motor was installed in the test rig using a flexible coupling, as it helps to absorb the sudden load during the start up of the motor, as well as any misalignment of the shafts.

\subsubsection{Data acquisition system}

This auxiliary system, shown in Figure 4.20, gathers all the measuring components, data acquisition devices and software employed in the floating liner to record the measuring parameters and to operate the test rig. Regarding the measuring components, they include: $8 \mathrm{~K}$-type thermocouples to measure the oil temperature in the lubrication system and in the cylinder wall. One of these thermocouples also served as feedback for the PDI controlling the temperature of the oil entering the engine. A torque sensor, installed in the transmission system, to register and control the torque delivered to the ICE and also, as a double-check of the motor speed. A hollow-shaft encoder to measure the angular position of the crankshaft, and to trigger the measurement of the force sensors; and finally, three piezoelectric force sensors for the direct measurement of the friction force in the piston-cylinder liner assembly.

For the data acquisition, specific devices were employed for the conditioning and recording of the sensors' signals. For the piezoelectric force 


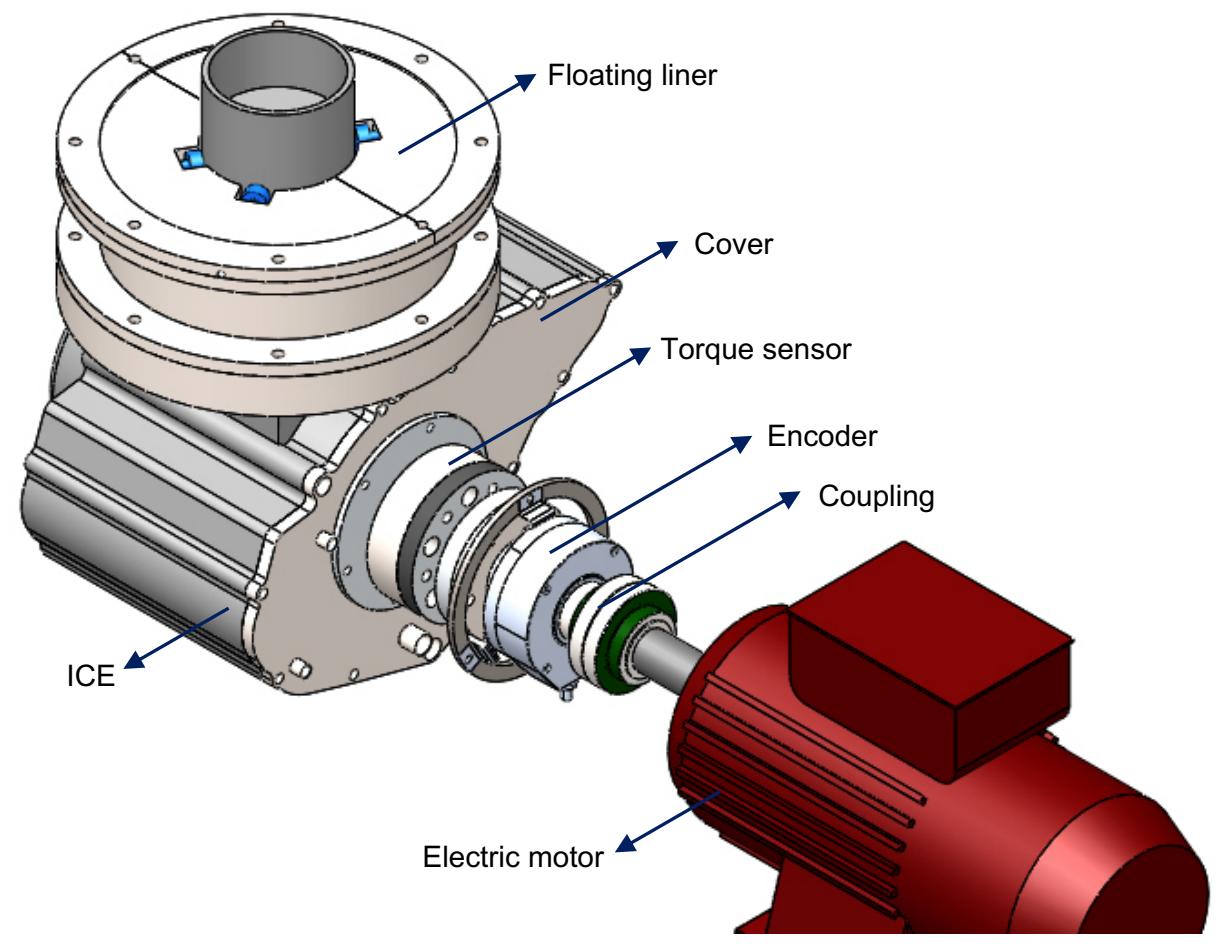

Figure 4.21. Transmission system assembly.

sensors, a Kistler LabAmp amplifier was integrated in the system in order to convert the charge output of the sensors to voltage. The analog output of the amplifier was then transmitted, through coaxial cable, to a Yokogawa data acquisition system (DAQ), where it was finally converted to force. In order to relate the friction force measurement with the angular position of the piston, the signal from the encoder was also acquired by the Yokogawa. Measurements of the thermocouples and the torque sensor were acquired by National Instruments (NI) DAQ modules.

A custom LabVIEW code was written for the floating liner which, in conjunction with the NI DAQ modules, allowed the acquisition, processing, display and recording of the performance parameters of the test rig, and the reading of the thermocouples and torque sensor. The operation of the electric motor was also implemented in the code through the VFD to adjust the speed for the tests. For the recording of the friction force and the angular position of the crankshaft, the software provided by the Yokogawa DAQ system was employed; which was also used to trigger the measurement of the force sensors. 
References and specifications of the measuring components in the data acquisition system are summarized in Table 4.4:

\begin{tabular}{|r|c|c|c|}
\hline \multicolumn{1}{|c|}{ Component } & Reference & Measuring range & Uncertainty \\
\hline \hline Thermocouples & K-type & Max $135^{\circ} \mathrm{C}$ & $\pm 2.5^{\circ} \mathrm{C}$ \\
Torque sensor & Kistler 4550A200... & $200 \mathrm{Nm}$ & $\pm 0.05 \% \mathrm{FS}^{*}$ \\
Encoder & Hohner 80-242111-1000 & $1000 \mathrm{pulse} / \mathrm{rev}$ & - \\
Force sensors & Kistler 9301B & $\pm 2.5 \mathrm{kN}$ & $2 \% \mathrm{FS}$ \\
\hline
\end{tabular}

Table 4.4. Specifications of the measuring components of the data acquisition system. ${ }^{*}$ FS: Full scale.

A picture of the final assembly of the floating liner test rig with the auxiliary systems is shown in Figure 4.22. For the piston-liner assembly specifically, an schematic diagram of the ring pack is shown in Figure 4.23; while Table 4.5 summarizes the main dimensions and specifications of the piston, ring pack and cylinder liner.

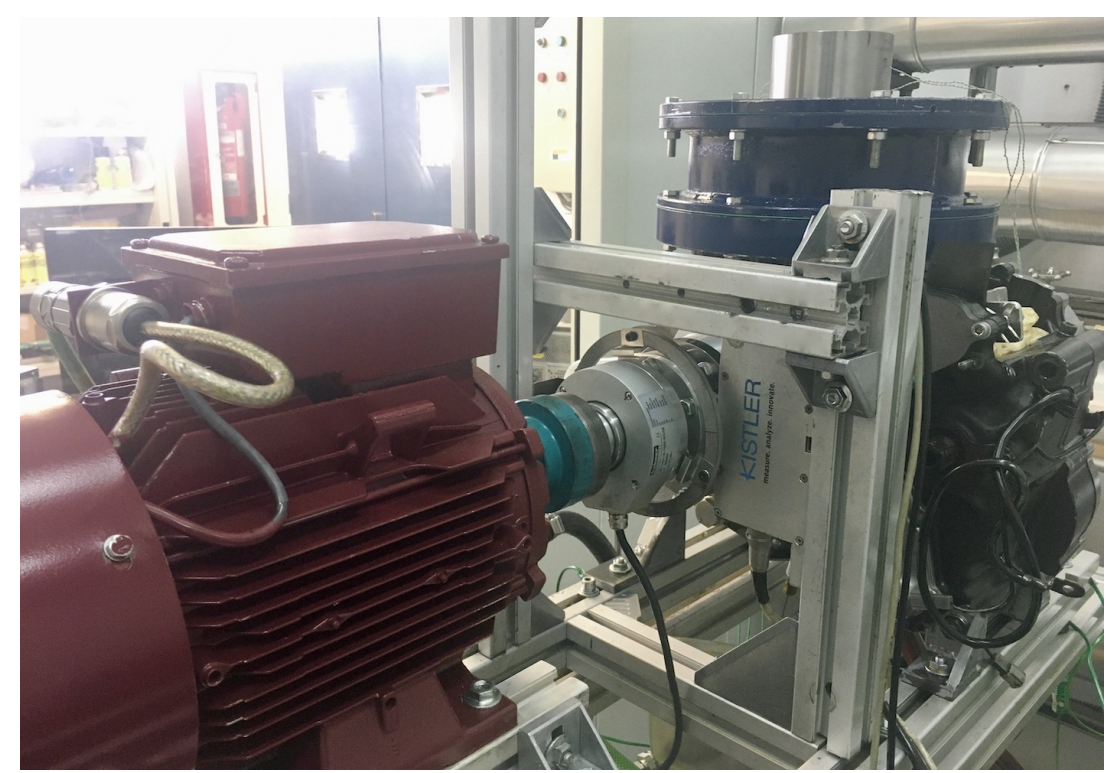

Figure 4.22. Final assembly of the floating liner test rig. 


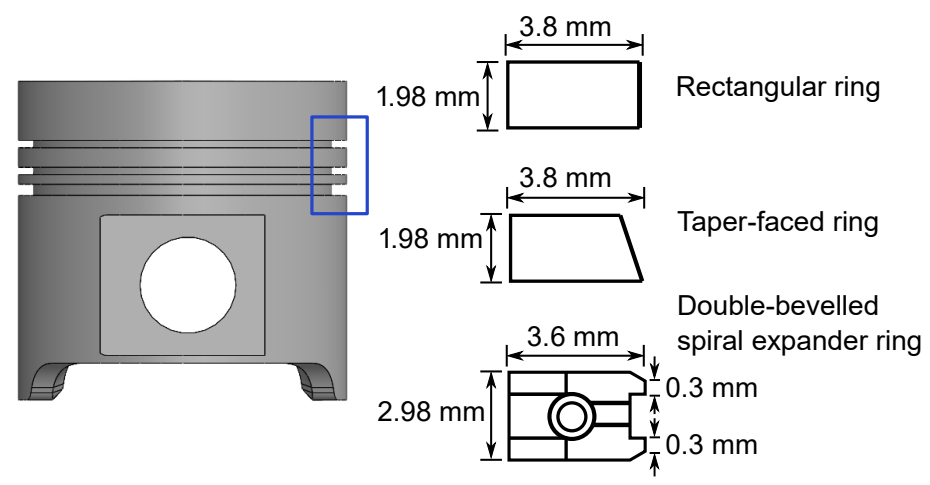

Figure 4.23. Ring pack characteristics in the floating liner test rig.

\begin{tabular}{|c|c|}
\hline Parameter & Value \\
\hline \hline Cylinder liner diameter & $91.64 \mathrm{~mm}$ \\
\hline Piston diameter & $91.42 \mathrm{~mm}$ \\
\hline Stroke & $90 \mathrm{~mm}$ \\
\hline Compression ring $F t_{1}$ & $17.3 \mathrm{~N}$ \\
\hline Scraper ring $\mathrm{Ft}_{2}$ & $17.8 \mathrm{~N}$ \\
\hline OCR ring $\mathrm{Ft}_{3}$ & $38.4 \mathrm{~N}$ \\
\hline
\end{tabular}

Table 4.5. Specifications of the piston-cylinder liner assembly in the floating liner.

\subsection{Friction force measurement analysis}

As previously described in Section 4.2, the friction force in the pistoncylinder liner assembly can be directly measured in the floating liner with the three piezoelectric force sensors located at the bottom of the liner. In this way, the friction force generated in the piston-liner interface is the result of the shearing of the oil film and the asperity interactions, due to the reciprocating motion of the piston. When the engine begins to operate and the piston moves from the TDC to the BDC in the intake stroke, the piston (ring pack and skirt) encounters the oil available at the liner, which enters the piston-liner interface at the given crank angle. At this instant of time, the displacement of the piston drags the liner downwards; however, given that the liner is attached to the force sensors, this sliding motion results in shearing of the oil film and 
finally, in a resultant friction force which is opposite to the direction of motion of the piston. This instantaneous friction force is captured by the force sensors as a compression force applied to the piezoelectric material and therefore, as a change in the charge output of the sensors. This output is later converted to voltage by the amplifier and finally to the corresponding force in Newtons. During the upstrokes, on the other hand, the friction force captured by the sensors corresponds to tensile forces due to the upward motion of the piston from the BDC to the TDC.

Figure 4.24 shows a characteristic friction force curve in the left $y$ axis, and the piston speed in the right $y$ axis measured in the floating liner at 100 $\mathrm{rpm}$ and $40^{\circ} \mathrm{C}$ of oil temperature in the crankcase. The piston configuration for this measurement is presented in Table 4.5, and the lubricant oil was a commercial formulation SAE 5W30. Due to the performance characteristics of the force sensors and the charge-voltage conversion performed by the amplifier, compression forces appear as a positive friction force, while tensile forces give a negative output. This signs convention is employed for all the friction force results presented in this Thesis, and is depicted in Figure 4.24: the intake and expansion strokes present positive friction forces due to the compression forces applied by the downward motion of the piston; in the compression and exhaust strokes, tensile forces are applied to the sensors. The intake, compression, expansion and exhaust stroke annotations in this figure are only for referencing purposes, as the floating liner is operated without combustion and with the combustion chamber open to ambient pressure conditions. Furthermore, for the instantaneous friction force results presented in this chapter and later in Chapter 6, a moving average filter was applied to the raw friction measurement in order to provide a clearer view of the friction force variation along the cycle and for comparison in the parametric tests.

The friction force curve in Figure 4.24 shows the lubrication characteristics of the piston-cylinder liner assembly throughout an engine cycle. The different lubrication regimes that experiments this tribological pair are reflected in the form of the friction curve: during hydrodynamic lubrication, friction is determined by the shearing of the oil film, composed by the Couette term, due to the relative velocity of the surfaces, and the Poiseuille term, resultant from the oil film pressure gradient. For the working conditions of the floating liner, without in-cylinder pressure, the Couette term has a major contribution to friction than the pressure term; this condition is reflected in the mid-stroke regions, where the form and peaks of the friction curve corresponds to the maximum speed values. Once the piston approximates the dead centers, the friction force diminishes during a few crank angles, presenting a mixed lubrication regime, to then increase at the dead centers and the reversals. In 


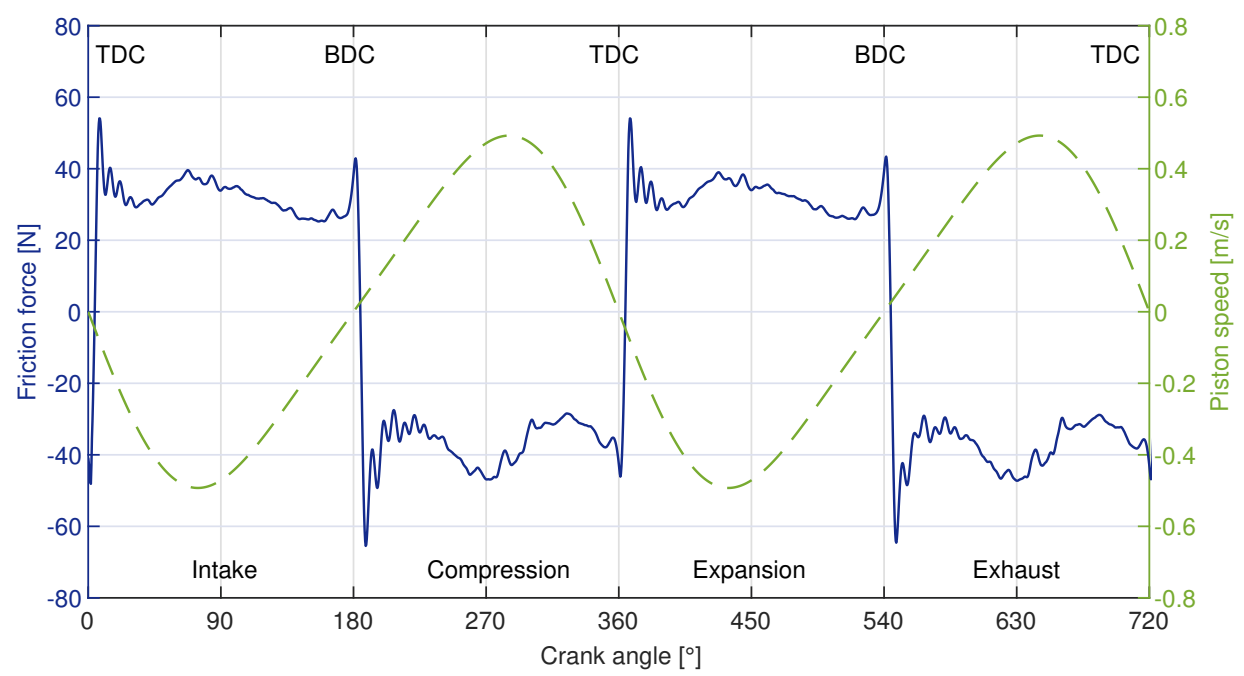

Figure 4.24. Friction force measured in the floating liner test rig and corresponding piston speed. *Intake, compression, expansion and exhaust stroke annotations are only for reference.

these regions, the piston decelerates up to zero in the dead centers reducing the oil film thickness which in turn, results in boundary lubrication. At the piston reversals, this boundary/mixed friction is maintained until the piston speed increases again and there is sufficient oil film thickness to completely separate the surfaces.

\subsection{Performance assessment of the floating liner test rig}

This section presents a selection of tests developed in the floating liner to evaluate the capability of the test rig to measure the friction force in a reliable way. This ensures that the friction measurement is the result of deliberate changes in the working conditions or setup of the test rig for the tests, and is not the result of undesired variations, during the mounting procedure, by instance. For this purpose, reproducibility and repeatability of tests were evaluated under the working conditions of the test points shown in Table 4.6.

For the first part of the analysis, the reproducibility of tests was evaluated comparing the friction force measurements before and after a disassemblyassembly procedure: starting with a first friction force measurement (assembly 
1) then, the disassembly of the external cylinders, the two half-moons and the ball transfer units, followed by the assembly of these components (assembly 2 ) and finally, the respective friction force measurement. The friction force was recorded for an engine cycle of $720^{\circ}$ and then converted to FMEP for the comparison of results. The following Section 4.6.1 presents the results of this analysis.

\begin{tabular}{|c|c|c|c|}
\hline Test point & $\begin{array}{c}\text { Engine speed } \\
{[\mathrm{rpm}]}\end{array}$ & $\begin{array}{c}\text { Oil temperature } \\
{\left[{ }^{\circ} \mathrm{C}\right]}\end{array}$ & Assembly \\
\hline \hline 1 & 500 & 40 & 1 \\
2 & 500 & 40 & 2 \\
3 & 2500 & 40 & 1 \\
4 & 2500 & 40 & 2 \\
5 & 500 & 60 & 1 \\
6 & 500 & 60 & 2 \\
7 & 2500 & 60 & 1 \\
8 & 2500 & 60 & 2 \\
\hline
\end{tabular}

Table 4.6. Test points for the performance assessment of the floating liner test rig.

In the second part of the analysis, the cycle-to-cycle repeatability was evaluated comparing the results of different measurement repetitions. Friction force was measured for a complete engine cycle $\left(720^{\circ}\right)$ and four repetitions under the same assembly of the test rig. The comparison of results was also developed with the resultant FMEP, and is presented in Section 4.6.2.

\subsubsection{Tests reproducibility}

The friction force measurements obtained with the assemblies 1 and 2 are presented in the following Figure 4.25 a and b, respectively; they correspond to the working condition of $500 \mathrm{rpm}$ and $60^{\circ} \mathrm{C}$. The plots also include the four measurement repetitions used to evaluate the cycle-to-cycle repeatability.

Table 4.7 summarizes the FMEP obtained with the assemblies 1 and 2 for the rest of the working conditions in Table 4.6, and the comparison of results in percentage difference.

From the results presented in Table 4.7, it can be concluded that the disassembly-assembly procedure, required in the floating liner for future tests, 

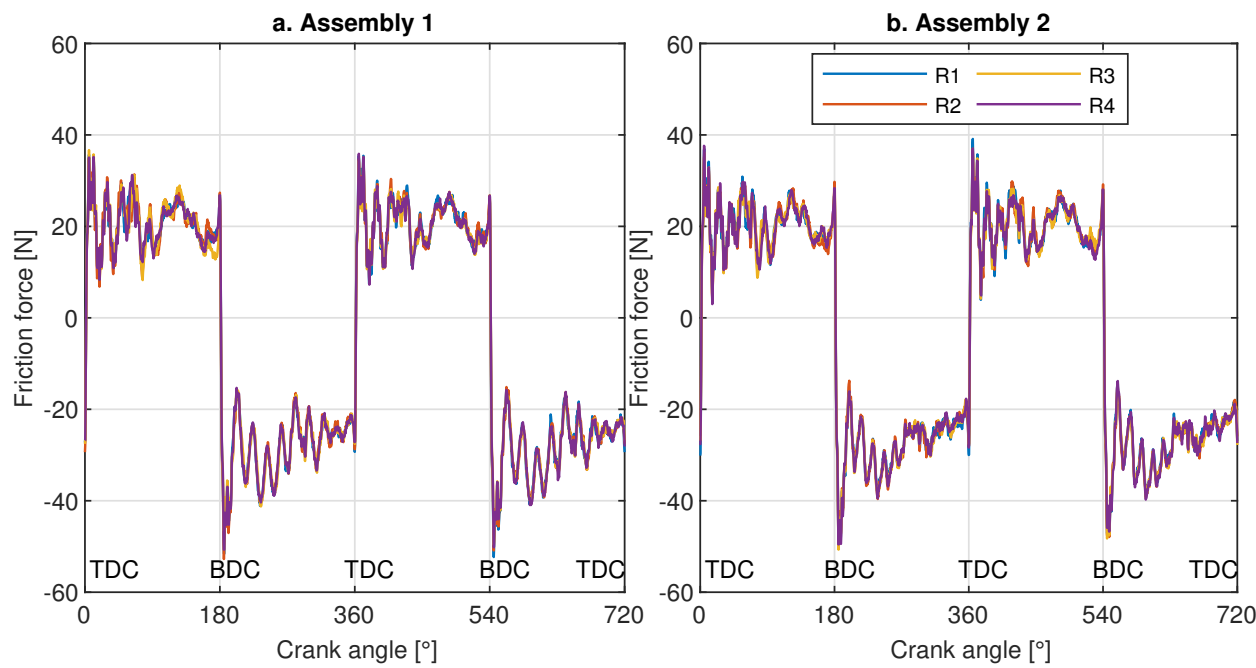

Figure 4.25. Reproducibility and repeatability assessment of tests developed in the floating liner test rig. ${ }^{*} R$ : repetition.

\begin{tabular}{|c|c|c|c|}
\hline Working conditions & $\begin{array}{c}\text { FMEP [KPa] } \\
\text { Assembly 1 }\end{array}$ & $\begin{array}{c}\text { FMEP [KPa] } \\
\text { Assembly 2 }\end{array}$ & Difference [\%] \\
\hline \hline $40^{\circ} @ 500 \mathrm{rpm}$ & 19.77 & 19.85 & 0.42 \\
$60^{\circ} @ 500 \mathrm{rpm}$ & 14.86 & 14.64 & 1.48 \\
$40^{\circ} @ 2500 \mathrm{rpm}$ & 61.61 & 61.58 & 0.04 \\
$60^{\circ} @ 2500 \mathrm{rpm}$ & 61.91 & 61.31 & 0.97 \\
\hline
\end{tabular}

Table 4.7. Results of the reproducibility analysis.

does not affect the friction force measurement and the reliability of the results. The difference in FMEP between assemblies 1 and 2 was less than $1 \%$ for most of the test points, while under higher oil temperature, this difference increased to about $1.5 \%$.

\subsubsection{Tests repeatability}

Results of the tests' repeatability are presented in Table 4.8; they include the mean FMEP for the four repetitions, the standard deviation (STD) and the relative STD of the measurement. These tests were developed for the two 


\begin{tabular}{|c|c|c|c|c|}
\hline $\begin{array}{c}\text { Working } \\
\text { conditions }\end{array}$ & Assembly & $\begin{array}{c}\text { Mean } \\
\text { FMEP }[\mathrm{kPa}]\end{array}$ & STD [kPa] & $\begin{array}{c}\text { Relative } \\
\text { STD [\%] }\end{array}$ \\
\hline \hline $40^{\circ} @ 500 \mathrm{rpm}$ & 1 & 19.77 & 0.03 & 0.13 \\
$40^{\circ} @ 500 \mathrm{rpm}$ & 2 & 19.85 & 0.04 & 0.18 \\
$60^{\circ} @ 500 \mathrm{rpm}$ & 1 & 14.86 & 0.03 & 0.23 \\
$60^{\circ} @ 500 \mathrm{rpm}$ & 2 & 14.64 & 0.04 & 0.30 \\
$40^{\circ} @ 2500 \mathrm{rpm}$ & 1 & 61.61 & 0.15 & 0.24 \\
$40^{\circ} @ 2500 \mathrm{rpm}$ & 2 & 61.58 & 0.13 & 0.22 \\
$60^{\circ} @ 2500 \mathrm{rpm}$ & 1 & 61.91 & 0.12 & 0.20 \\
$60^{\circ} @ 2500 \mathrm{rpm}$ & 2 & 61.31 & 0.05 & 0.09 \\
\hline
\end{tabular}

Table 4.8. Results of the repeatability analysis.

assemblies used in the reproducibility analysis, and are included in Figure 4.25 $a$ and $b$.

Results of the repeatability analysis showed a good response of the cyclic friction force measurement; all the results presented a relative STD below $0.40 \%$. Given that the floating liner test rig is operated under ambient pressure conditions without the cylinder head, it can be observed from Figure 4.7 that the intake-compression strokes and the expansion-exhaust strokes are fairly similar due to the lack of combustion.

\subsection{Experimental results}

Once the performance assessment of the floating liner test rig was completed, as presented in Section 4.6, some parametric tests were proposed under working conditions that have a direct impact over the friction losses in the piston-cylinder liner assembly. The chosen parameters were the engine speed and oil temperature, oil formulations of different SAE grades and the OCR tangential force. For the first part, eight engine speed levels were chosen (from 100 to $800 \mathrm{rpm}$ ) with the aim of covering the speed range of the test rig and avoid noise and vibration at higher speeds. The oil temperature levels $\left(40\right.$ to $80^{\circ} \mathrm{C}$ in steps of $10^{\circ} \mathrm{C}$ ) were chosen with the same objective of covering a temperature range that allowed to investigate the effect of the oil viscosity on friction within the limitations of the test rig. The oil formulations, 
SAE 5W30, 0W20 and 0W16 for the second parametric tests, were chosen as they represent the current and future trend on LVEOs for the LDD vehicle segment (Section 2.6.4). Finally, the OCR tangential force was studied for two levels, $38.4 \mathrm{~N}$ which is the commercial version of the ring and a lower level for a direct comparison on the friction losses. The corresponding results and analysis of these parametric tests are presented in Section 4.7.1, 4.7.2 and 4.7.3, respectively.

For the development of the parametric tests, a common procedure was followed to operate the test rig and set the working conditions required for each test; however, a specific procedure was also defined for the parametric tests involving different oil formulations and the OCRs of various tangential force levels, they are further described in their corresponding section. Regarding the overall procedure to develop the tests in the floating liner, the first step consisted of preparing the test rig with the required components of the piston assembly and the oil formulation defined for the tests. The oil was supplied to the engine through the fill hole in the crankcase. The oil deposit with the electric resistance (Figure 4.20) was filled through the pipes that connects this component to the bottom of the crankcase. Then, the oil was heated in the deposit to the required temperature using the PID controller; which also controls the supply of water to the heat exchanger if necessary. For the operation of the floating liner, the desired speed in the electric motor was set through the VFD. With the ICE running, the oil temperature in the crankcase was allowed to reach the level defined for the test.

The properties of the oil formulations, dynamic viscosity, kinematic viscosity and density, employed in the different parametric tests were measured using the viscometer Anton Paar SVM 3001 available at the Fuels and Lubricants laboratory at CMT-Motores Térmicos for temperatures ranging from 20 to $100^{\circ} \mathrm{C}$ in intervals of $5^{\circ} \mathrm{C}$. These results are shown in Figure 4.26.

\subsubsection{Engine speed and oil temperature}

In order to evaluate the effect of the engine speed and oil temperature on the lubrication performance of the piston-cylinder liner assembly, specifically the friction losses, the test points in Table 4.9 were proposed. They consist of eight engine speed levels and five oil temperature levels combined to form a test matrix of 40 points. For the development of the tests, the oil formulation SAE 0W20 was used in the floating liner along with the cylinder liner, piston and ring pack with the characteristics in Table 4.5. 


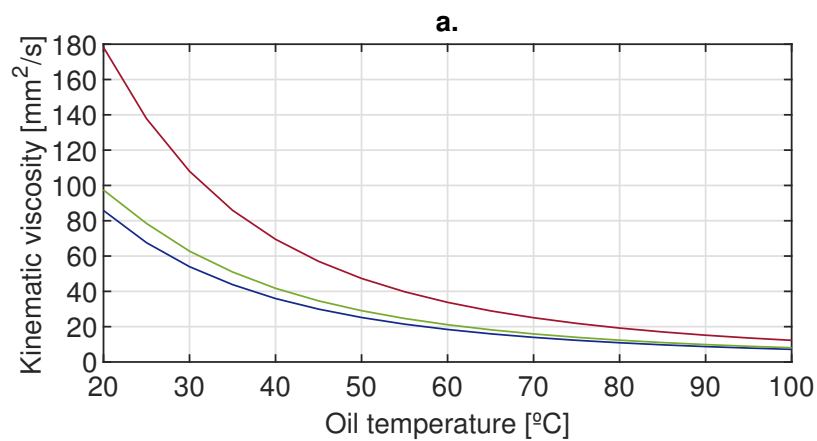

b.

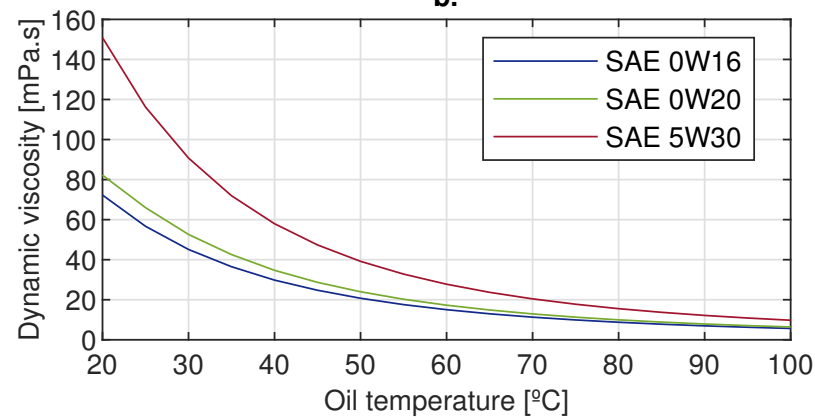

c.

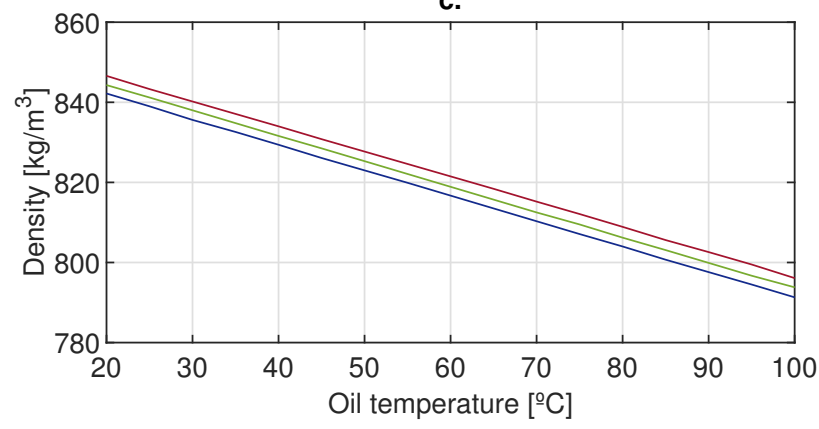

Figure 4.26. Properties of the oil formulations used in the parametric tests. a. Kinematic viscosity, b. dynamic viscosity, c. density.

The results of this study are presented in Figure 4.27 where the instantaneous friction force measured in the floating liner is shown comparing the effect of the oil temperature for each engine speed level. From this figure it can be observed that the effect of the oil working temperature on the friction losses is present throughout the engine cycle; however, its effect is highly related to the engine speed. Looking at Figure 4.27a. for $100 \mathrm{rpm}$ it is clear that a higher oil temperature, lower viscosity, resulted in an overall increase of the friction losses, both in the dead centers and in the mid-stroke regions. 


\begin{tabular}{|c|c|}
\hline $\begin{array}{c}\text { Engine speed levels } \\
{[\mathrm{rpm}]}\end{array}$ & $\begin{array}{c}\text { Oil temperature levels } \\
{\left[{ }^{\circ} \mathrm{C}\right]}\end{array}$ \\
\hline \hline 100 & 40 \\
200 & 50 \\
300 & 60 \\
400 & 70 \\
500 & 80 \\
600 & \\
700 & \\
800 & \\
\hline
\end{tabular}

Table 4.9. Test points for the engine speed and oil temperature parametric tests.

This trend changes with the increase of the engine speed; from $300 \mathrm{rpm}$ in Figure $4.27 \mathrm{c}$. a higher oil viscosity increases the friction force in the mid-stroke, specially during the intake stroke (from 0 to 180 crank angle degrees). In this region of maximum piston speed, hydrodynamic lubrication is expected to occur; therefore, higher viscosity promotes a thicker oil film and higher viscous friction, which is reduced with the increase of the oil temperature. Moving towards the dead centers, mixed lubrication conditions start to appear, where the oil film is not longer thick enough to completely separate the asperity contact and thus, friction is more prominent for $80^{\circ} \mathrm{C}$ with lower oil viscosity. With the deceleration of the piston, boundary lubrication appeared markedly at the dead centers, where the effect of a higher oil temperature is directly reflected in the friction increase.

Regarding the engine speed solely, its effect can be observed both at the dead centers and mid-stroke regions. The wedge effect, favored by the increase of the engine speed, results in thicker oil films at the mid-stroke and resultant viscous friction, while the squeeze effect contributes to the friction reduction at the dead centers. In these tests it is also important to highlight the effect of the inertia forces that increase with the engine speed as well as the piston secondary motion that are reflected in the form of noise impulses in the friction measurements, specially from $600 \mathrm{rpm}$.

In order to have a clearer view of the effect that the engine speed and oil temperature have on the friction losses, the FMEP was obtained from the instantaneous friction force measurements and plotted in Figure 4.28 for all 
a. $100 \mathrm{rpm}$

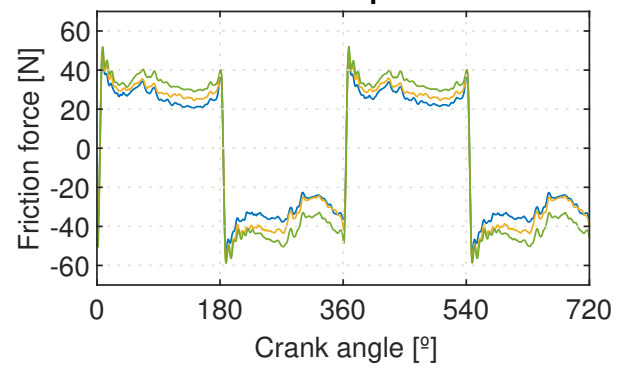

c. $300 \mathrm{rpm}$

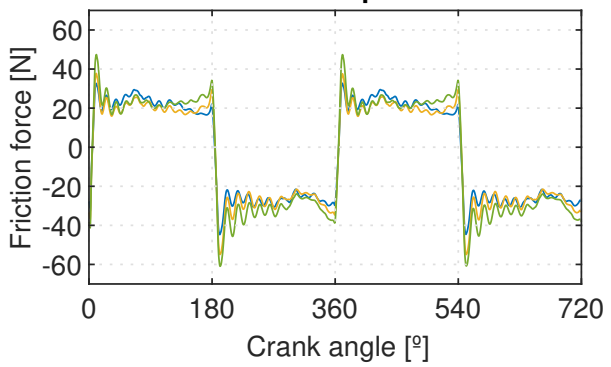

e. $500 \mathrm{rpm}$

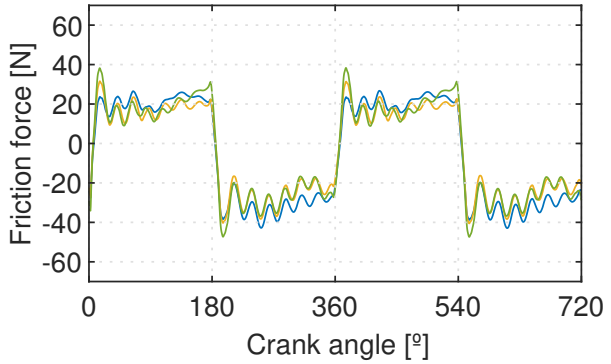

g. $700 \mathrm{rpm}$

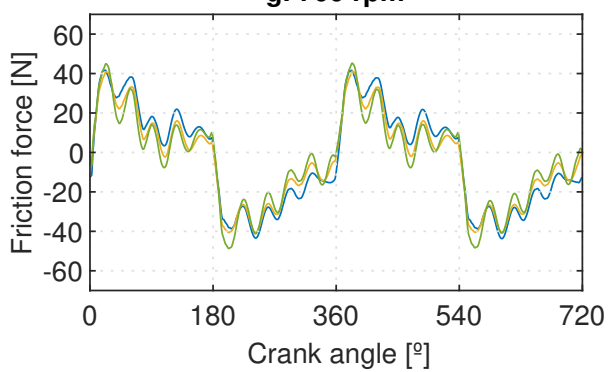

b. $200 \mathrm{rpm}$

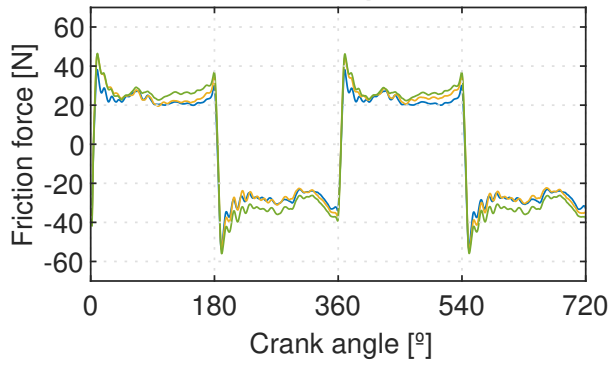

d. $400 \mathrm{rpm}$

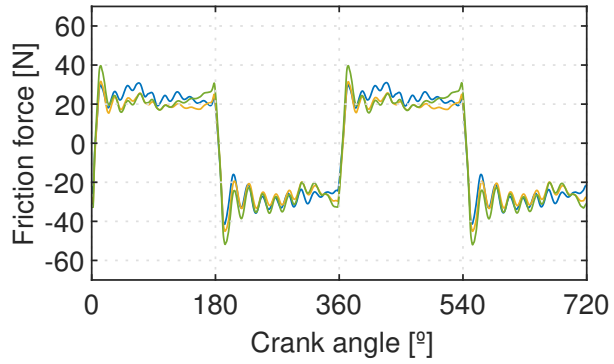

f. $600 \mathrm{rpm}$

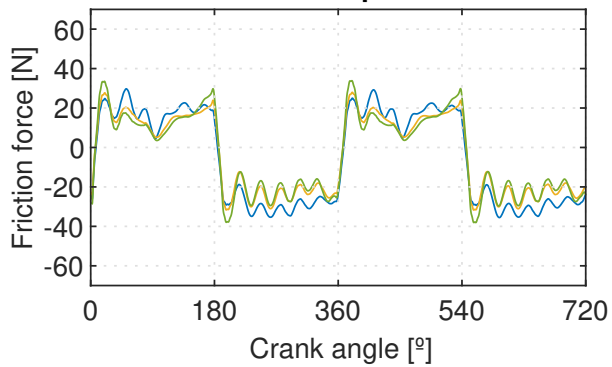

h. $800 \mathrm{rpm}$

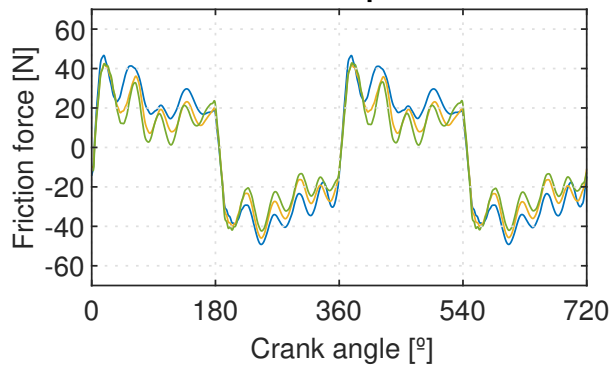

Oil temp $=60^{\circ} \mathrm{C}-$ Oil temp $=80^{\circ} \mathrm{C}$

Figure 4.27. Friction force variation with the oil temperature under engine speeds of 100 to $800 \mathrm{rpm}$. 
the test points. This plot is a modified form of the Stribeck curve and thus, it allows to have an idea of the lubrication regime that experiences the piston assembly and its progression with the two variables being studied. In this way, it can be seen in the left side of the plot, that mixed and boundary lubrication prevailed due to the low engine speeds and the FMEP increased with the oil temperature. This effect can be clearly observed at $100 \mathrm{rpm}$, where the lowest FMEP was measured for $40^{\circ} \mathrm{C}$, and increased progressively with the oil temperature. Between 200 and $300 \mathrm{rpm}$, the Stribeck curve trend for 40 and $50^{\circ} \mathrm{C}$ began to shift towards hydrodynamic lubrication. Instead, for the oil temperature levels, 60,70 and $80^{\circ} \mathrm{C}$, the change of lubrication regime was more marked and only from $700 \mathrm{rpm}$ hydrodynamic lubrication appeared. Looking at the right side of this figure, the variation of the FMEP with temperature also gives and indicative of the prevalence of hydrodynamic lubrication conditions. As mentioned previously in this section and shown in Figure 4.27, a lower oil temperature resulted in increased viscous friction at the mid-stroke, sufficient to increase the FMEP.

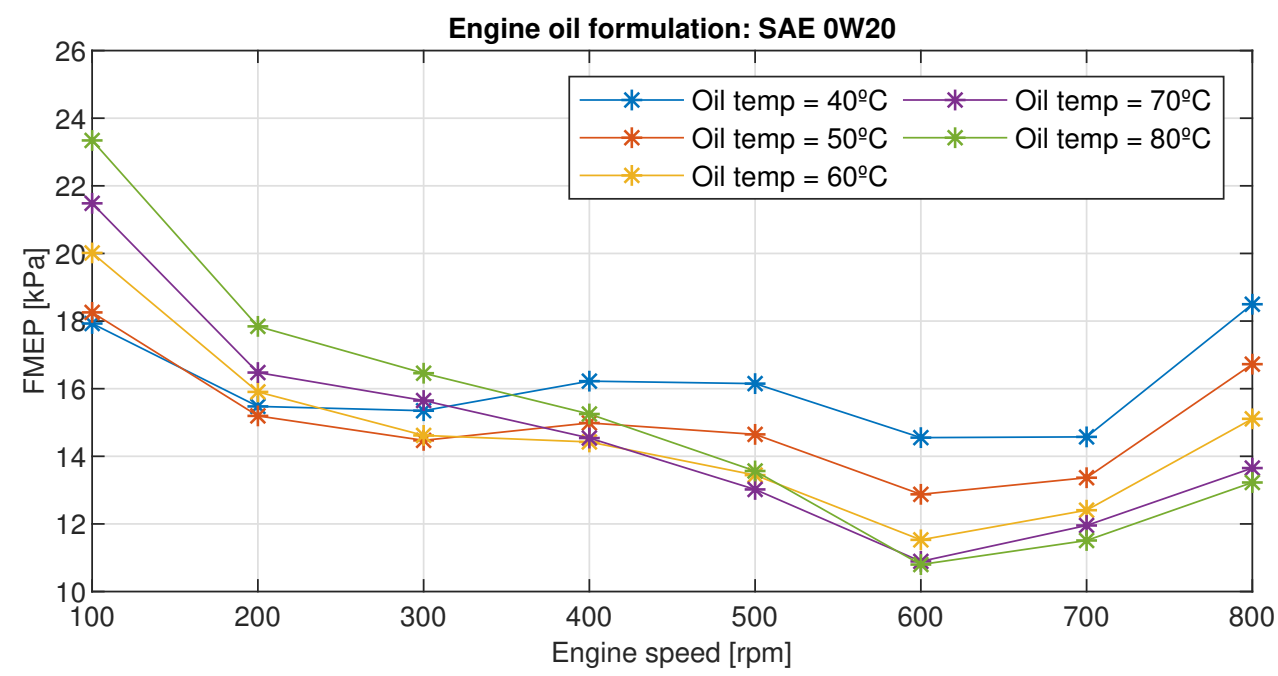

Figure 4.28. FMEP variation with the oil temperature and engine speed.

\subsubsection{Oil formulation}

This section presents a study developed in the floating liner with the aim of evaluating the lubricating performance of the piston assembly as function of the oil formulation, specifically due to the viscosity property and its impact 
on the friction losses generated in the assembly. To accomplish this purpose, three oils were proposed: a commercial SAE 5W30, which is commonly used in LDVs, and two LVEOs of the latest SAE grades 0W20 and 0W16 developed for fuel economy. The main properties of these oils were presented previously in Figure 4.26. The configuration of the piston assembly for the tests was that presented in Table 4.5 .

In addition to the methodology for the tests described in Section 4.7, a bracketing technique was followed, similar to that described in Section 3.3 for the engine bench tests and depicted in Figure 3.2. For these tests, the SAE 0W20 oil was selected as reference, and the other formulations as candidate. The oil conditioning task consisted of running the test rig for two hours with the oil to be tested under $500 \mathrm{rpm}$ and $60^{\circ} \mathrm{C}$. Then, tests were run under the pre-defined conditions for the study. Once tests were completed with one oil formulation, it was drained overnight from the engine and the auxiliary lubrication system.

The oil formulations were evaluated under two engine speeds, 500 and $800 \mathrm{rpm}$, and five oil temperature levels, 40, 50, 60, 70 and $80^{\circ} \mathrm{C}$, forming a matrix of 10 test points for each oil formulation. Each test point consisted of six repetitions of the measurement. Given that the objective of the study presented in this section was to evaluate the performance of the oils determined by their viscosity, it was important to maintain the temperature of the oil at a pre-defined value during the tests. As described in Section 4.4.1, the oil was heated to the desired temperature with a heat resistance to be supplied to the crankcase; there, the oil was distributed to the piston assembly by means of an oil jet located at the bottom of the liner. The ring pack and specially the OCR would then transport the oil to the upper part of the liner. In the floating liner test rig, the cylinder liner was open to the ambient temperature conditions; therefore, the only heat source came from the oil and the friction generated in the conjunction. With these conditions, prior to start each test, the oil temperature was allowed to stabilize at the desired value in the crankcase, the same for the temperature along the liner. The measurement of these temperature values was done with thermocouples located in the crankcase and along the liner external wall, as shown in Figure 4.29. They were recorder at the same time as the friction force and were averaged for a period of five seconds.

The following Figure 4.30 and 4.31 present the oil temperature measured at the crankcase and liner for the two engine speed conditions, 500 and $800 \mathrm{rpm}$, respectively. Each figure gathers the measurements of all the temperature levels defined for the tests, including the standard deviation of the measure 


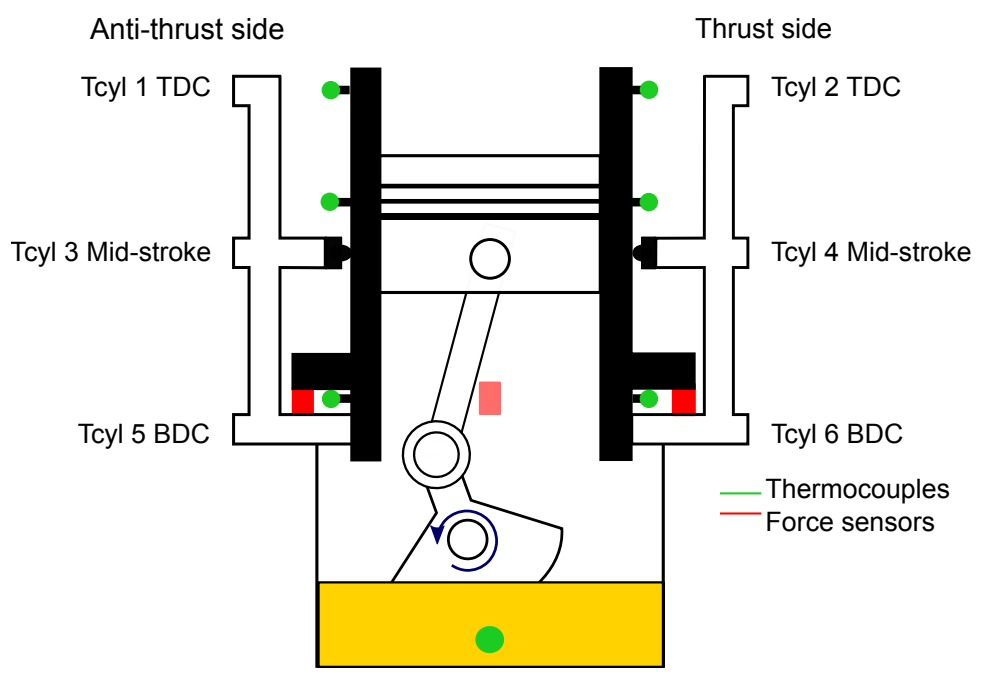

Figure 4.29. Location of the thermocouples in the floating liner test rig.

(STD) and in the $y$ right axis, the relative STD. During tests it was realized that one of the thermocouples located at the mid-stroke in the thrust side was not measuring correctly for all the tests; hence, it was decided to not include this measurement in the consequent analyses.

As it can be seen in Figure 4.30 and 4.31, although the oil temperature at the crankcase reached the defined values for the tests, the temperature at the liner was lower, being colder at the TDC and hotter at the BDC given that this section of the liner was closer to the crankcase and to the oil jet. At $500 \mathrm{rpm}$ and $40^{\circ} \mathrm{C}$ by instance, the temperature reached at the mid-stroke was of about $35^{\circ} \mathrm{C}$, giving a difference of $5^{\circ} \mathrm{C}$ compared to that in the crankcase; however, for $80^{\circ} \mathrm{C}$ this difference was increased significantly to about $25^{\circ} \mathrm{C}$ for the same locations. Overall, it can also be observed that the oil temperature at the liner was well stabilized during the tests, with slightly greater deviations with the increase of the oil temperature, and there were no significant differences between the two engine speed levels.

The friction force measured under these conditions is shown in Figure 4.32 for $500 \mathrm{rpm}$ and in Figure 4.33 for $800 \mathrm{rpm}$, comparing the three oil formulations for all the temperature levels. According to the viscosity of the oils, it was expected that the biggest differences in friction losses were observed at the mid-stroke regions for the lower oil temperature values, and at the dead centers with the increase of temperature. This performance can be observed 

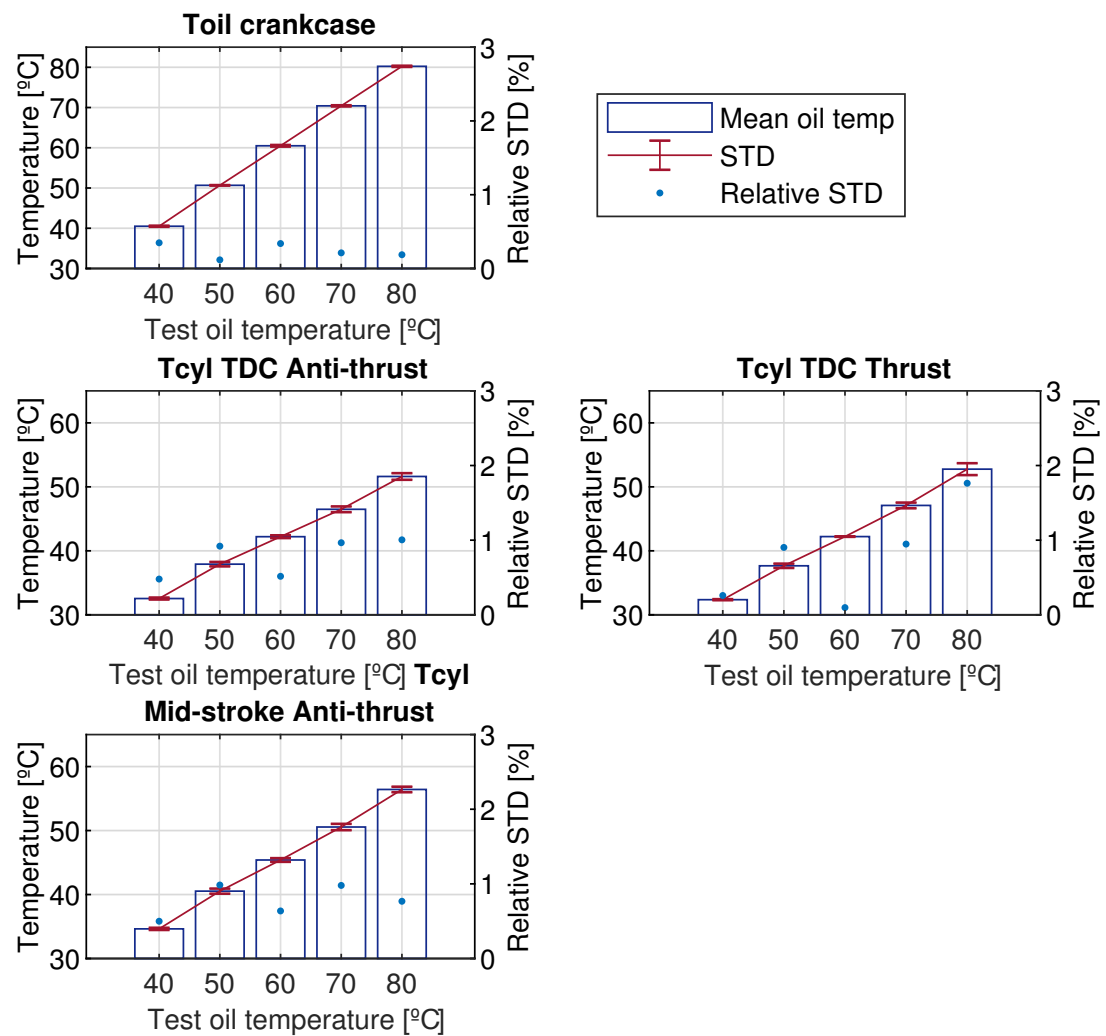

Tcyl BDC Anti-thrust
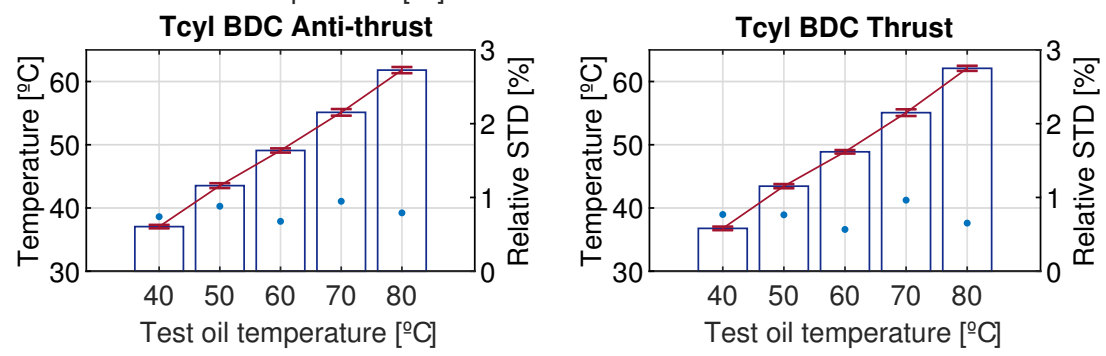

Figure 4.30. Oil temperature at the crankcase and liner at constant engine speed of 500 rpm. ${ }^{*}$ Tcyl: temperature at the cylinder liner.

for $500 \mathrm{rpm}$, the oil of higher viscosity SAE 5W30 showed higher friction losses at the mid-stroke for all the temperature levels; however, it can be observed that the difference between oils is reduced with the oil temperature increase. At the dead centers and specially for the higher temperatures, the candidate oils of lower viscosity presented higher boundary friction than the reference, as a consequence of thinner oil films and associated asperity contact. From 

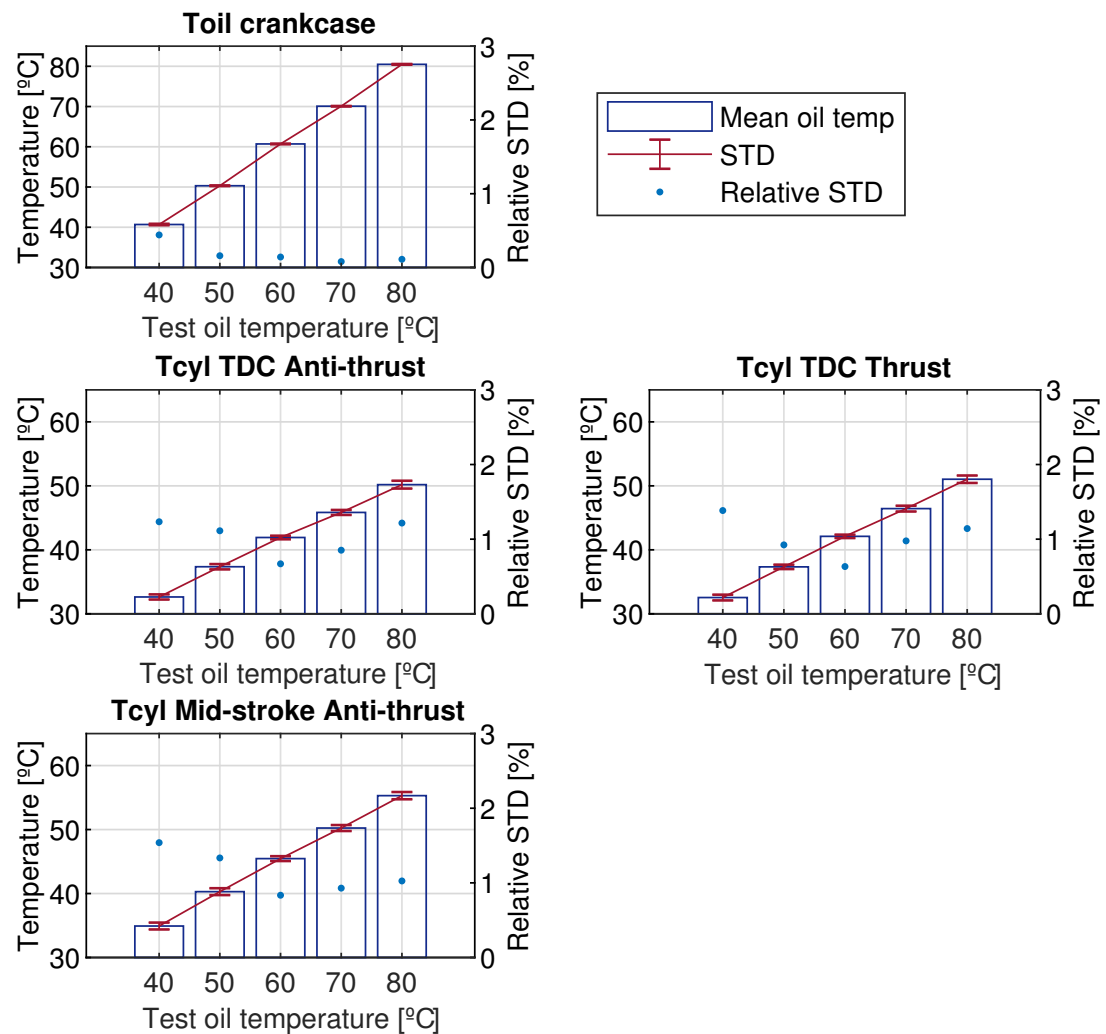

Tcyl BDC Anti-thrust
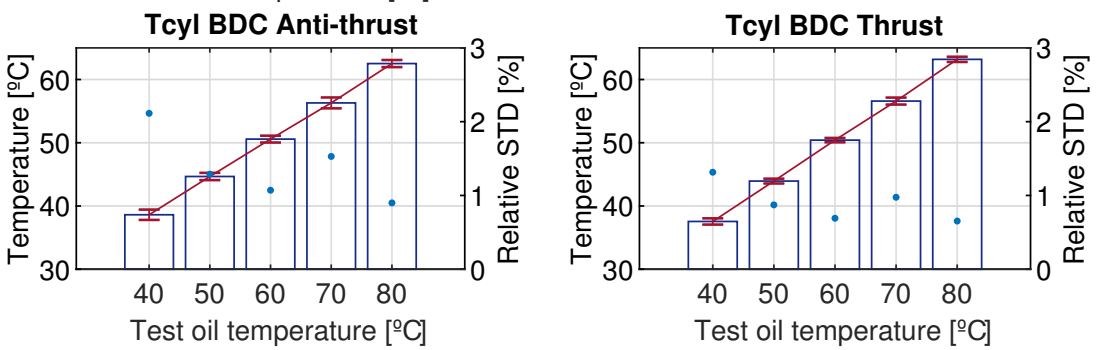

Figure 4.31. Oil temperature at the crankcase and liner at constant engine speed of 800 rpm. ${ }^{*}$ Tcyl: temperature at the cylinder liner.

Figure 4.32 it can also be noted that the friction force differences between candidate oils SAE 0W20 and 0W16 did not present the same behavior at the dead centers. At the TDC, the increased boundary friction with the 0W16 oil was higher than that of the 0W20 oil, as expected; nevertheless, this difference between oils was not as noticeable at the BDC. This situation can be explained looking at Figure 4.30 for the oil temperature measured in the liner at the 
dead centers; for $80^{\circ} \mathrm{C}$ at the crankcase, the TDC temperature was of about $52^{\circ} \mathrm{C}$, while the temperature at the $\mathrm{BDC}$ was $10^{\circ} \mathrm{C}$ higher, which gives a smaller difference in viscosity for these oils and therefore, smaller differences in friction.

For $800 \mathrm{rpm}$ in Figure 4.33, the same oil performance was observed as for $500 \mathrm{rpm}$. One thing to note in these results is the friction force curve obtained at $80^{\circ} \mathrm{C}$ for the candidate oil SAE 0W16; although under this engine speed the secondary motion of the piston can be observed for all the oils and temperature levels, as the high amplitude oscillations of the curve, it is specially marked in this test condition. This situation can be the result of thinner oil film along the liner that could accentuate the effect of the piston slap on the friction measurement.

The instantaneous friction force results were summarized in the following Figure 4.34 and 4.35 in terms of FMEP and oil temperature measured at the crankcase. These plots give an overall view of the lubrication regimes that experience the piston assembly. The left side of the plot shows an increase of the FMEP with the reduction of the oil temperature, indicating the prevalence of hydrodynamic lubrication conditions, specially under $800 \mathrm{rpm}$. It is also in this region where there are more differences between the candidate and reference oil. This difference is narrowed with the increase of the oil temperature, specially under $500 \mathrm{rpm}$, where the presence of mixed/boundary lubrication is more pronounced and it is reflected in the slight increase of the FMEP at $80^{\circ} \mathrm{C}$.

\subsubsection{OCR tangential force}

Another parameter that was interesting to test in the floating liner is the OCR tangential force $F t$ as it highly affects the lubrication conditions of the ring pack. Specifically, the tangential force determines the scrapping capacity of the OCR and therefore, determines the oil quantity that is available for the other piston rings [8]. Consequently, this restriction on the oil flow will affect the creation of the oil film and resultant friction force in the piston-liner conjunction.

For this study, two OCR tangential force levels were tested, $38.4 \mathrm{~N}$ and 18.7 N. The brand new ring packs were supplied by an engine components manufacturer therefore, a breaking-in procedure was applied before running the tests. The breaking-in consisted of wearing out the piston ring pack in the floating liner for a period of time until the measured FMEP reached stability in the last measurements. For the cylinder liner, given that this component had 

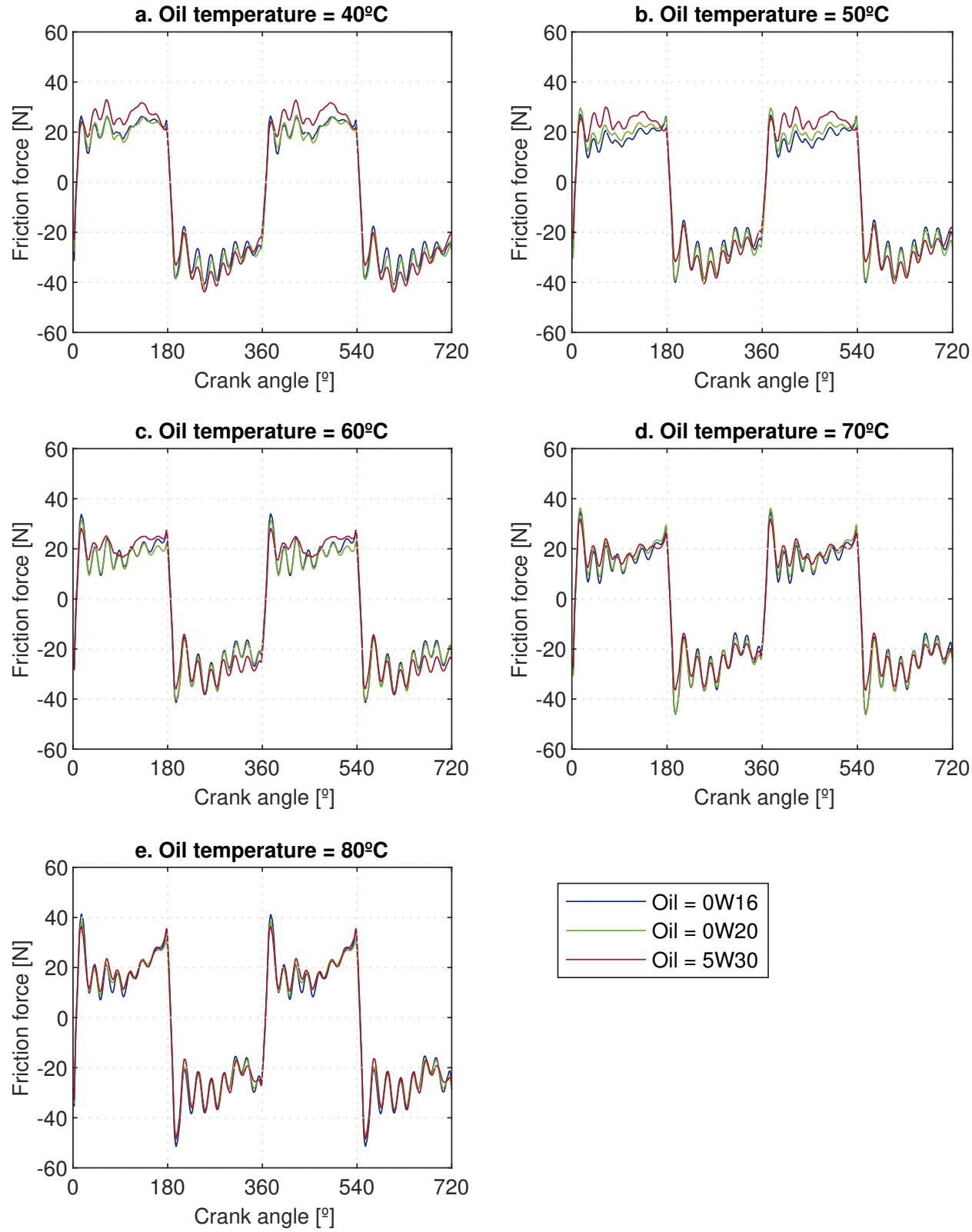

Figure 4.32. Friction force variation with different oil formulations and oil temperatures at constant engine speed of $500 \mathrm{rpm}$. 

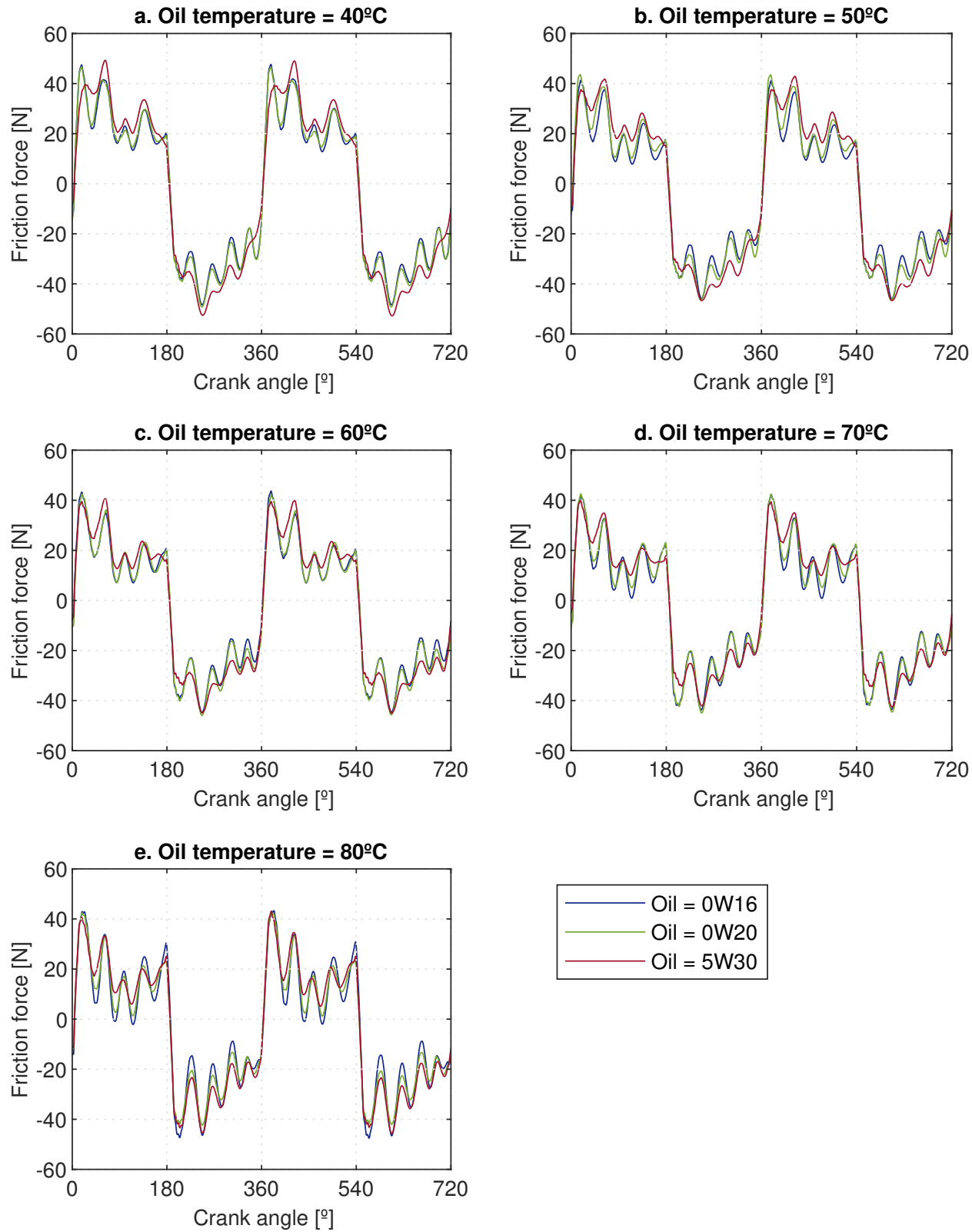

Figure 4.33. Friction force variation with different oil formulations and oil temperatures at constant engine speed of $800 \mathrm{rpm}$. 


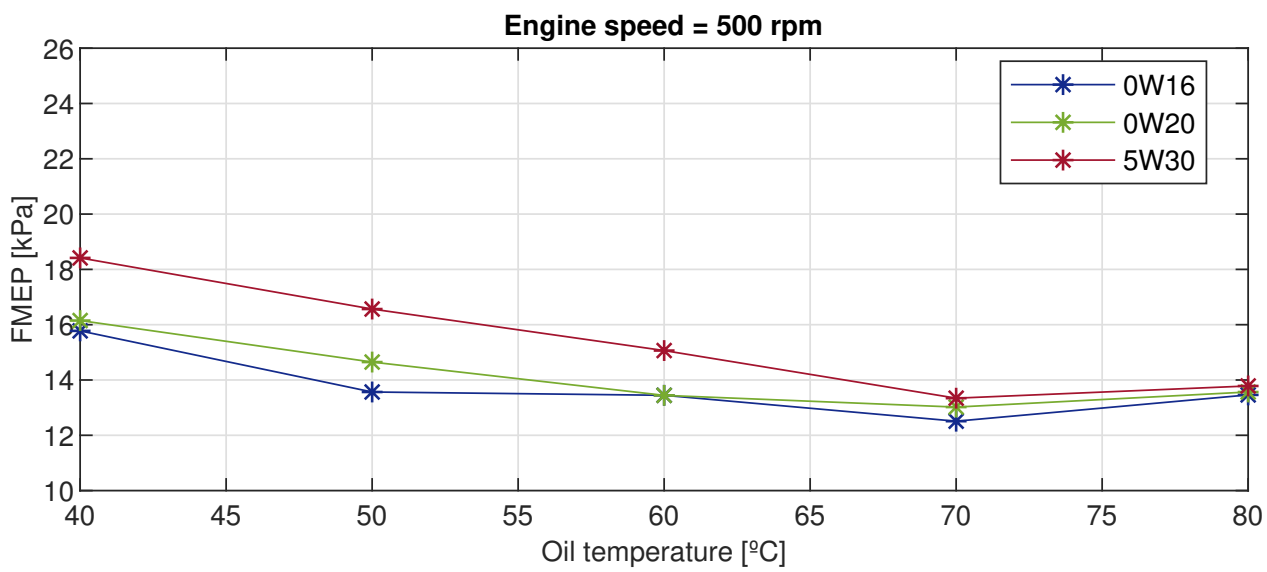

Figure 4.34. FMEP variation with the oil formulation and temperature at 500 rpm.

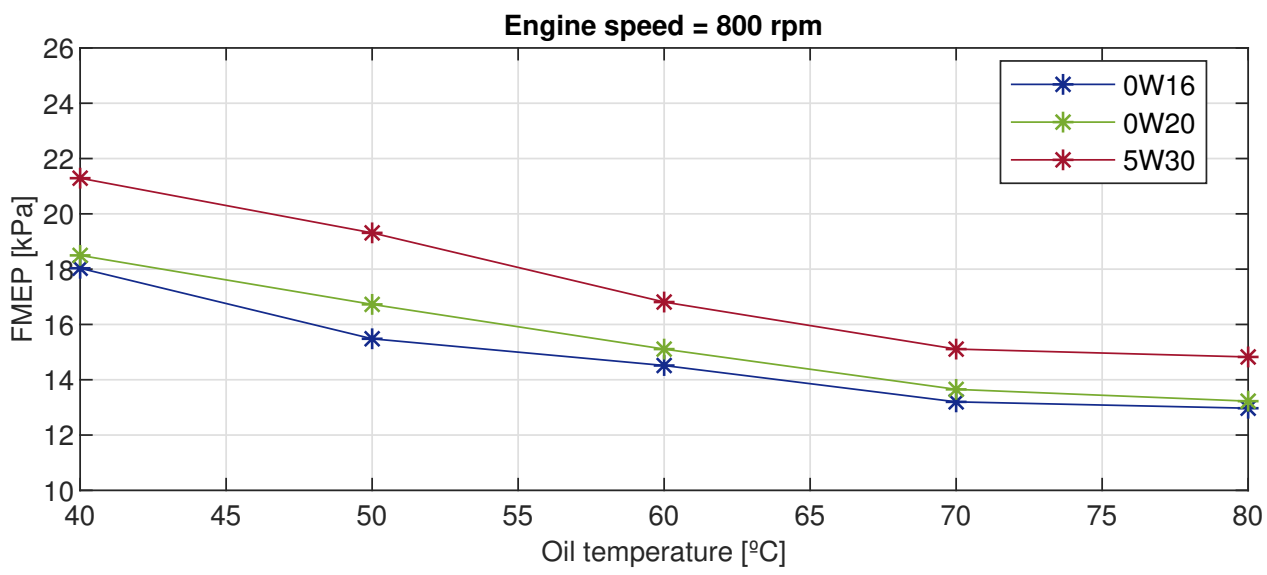

Figure 4.35. FMEP variation with the oil formulation and temperature at 800 rpm.

already been employed for different tests in the floating liner, it was assumed to be wore out to its final surface roughness.

The methodology followed for the breaking-in of the rings started with the mounting of the corresponding piston ring pack in the floating liner. Then, the oil SAE $5 \mathrm{~W} 30$ was heated to $55^{\circ} \mathrm{C}$ in the crankcase and the engine was set to $500 \mathrm{rpm}$. Friction force measurements were registered every half hour to obtain the FMEP, in this way, the new measurement was compared with the previous one. This comparison was done until the FMEP difference of the last points was very small, indicating that the friction losses had stabilized and 
the piston rings were wore out. The results of this analysis are presented in Figure 4.36, it shows the FMEP obtained from the friction measurements for a period of time for the two piston ring packs of high and low OCR tangential force. In the right $y$ axis of the figure was plotted the oil temperature measured at the crankcase throughout the breaking-in procedure of the two ring packs.

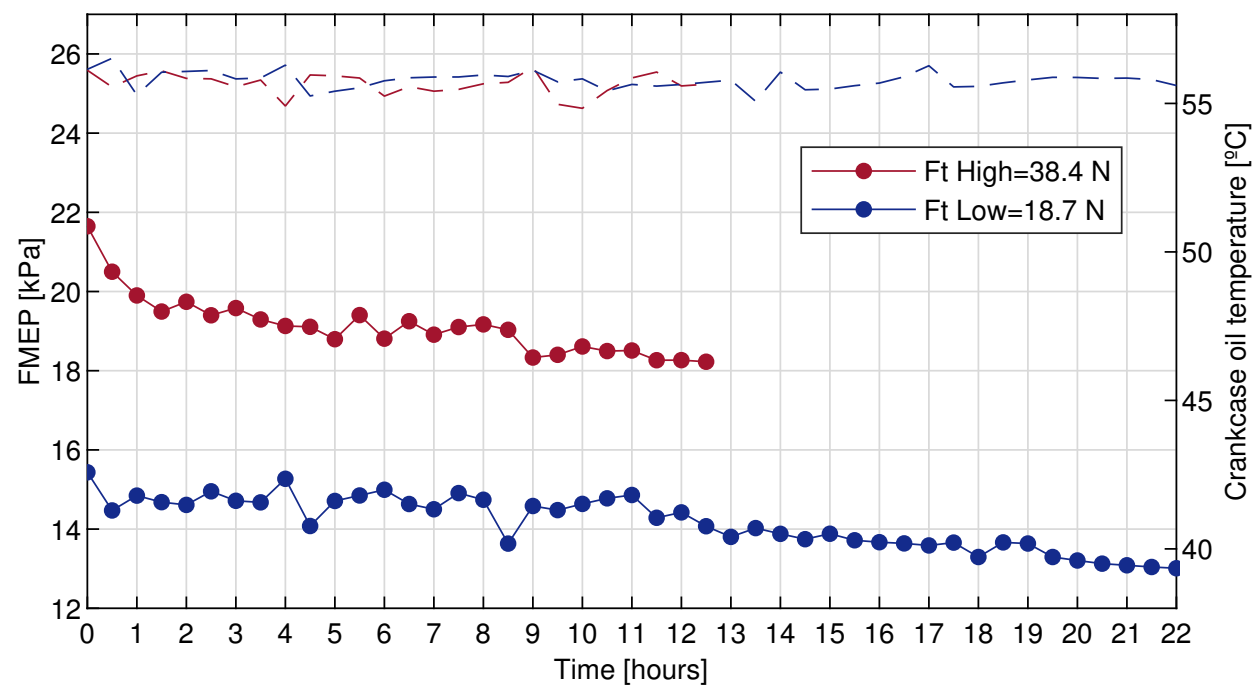

Figure 4.36. FMEP variation during the breaking-in of the piston ring packs.

For the OCR of higher $F t$, the time employed to wear out the ring pack was of twelve and a half hours; the percentage difference for the last two points was of $0.22 \%$. For the OCR of lower $F t$, this breaking-in period was significantly increased, taking 22 hours to be completely wore out; the percentage difference for the last two points was of $0.24 \%$. The increase in the breaking-in period for the ring pack of lower $F t$, can be explained from the smaller radial pressure that the rings are exerting against the liner wall and that therefore, resulted in lower rates of wear.

In order to evaluate the effect of the OCR tangential force on the friction losses of the piston assembly, a test matrix of 24 points was completed for each piston ring pack. It consisted of eight engine speed levels, from 100 to 800 $\mathrm{rpm}$, and three oil temperature levels measured at the crankcase of 40,60 and $80^{\circ} \mathrm{C}$. Some results of these tests were plotted in Figure 4.37, they correspond to the instantaneous friction force measured at $60^{\circ} \mathrm{C}$ for all the engine speed levels. 
a. $100 \mathrm{rpm}$

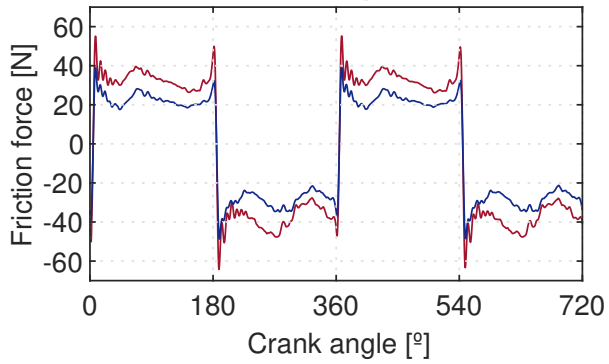

c. $300 \mathrm{rpm}$

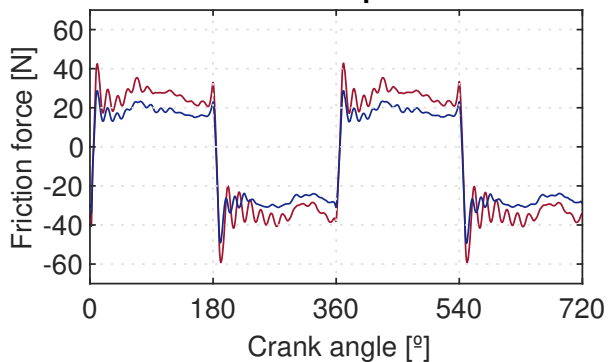

e. $500 \mathrm{rpm}$

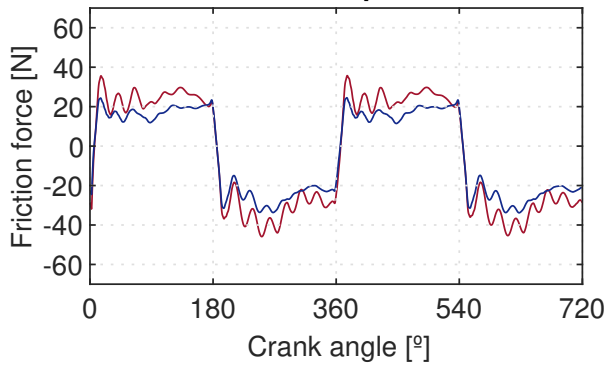

g. $700 \mathrm{rpm}$

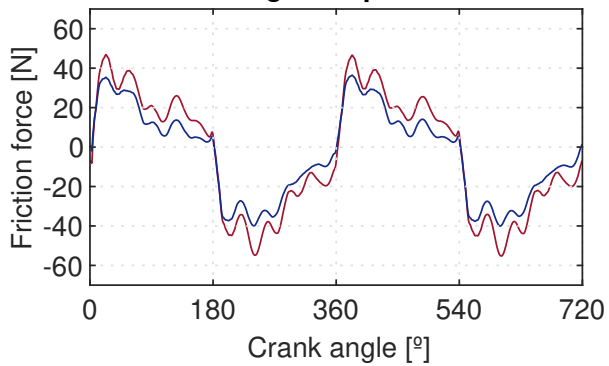

b. $200 \mathrm{rpm}$

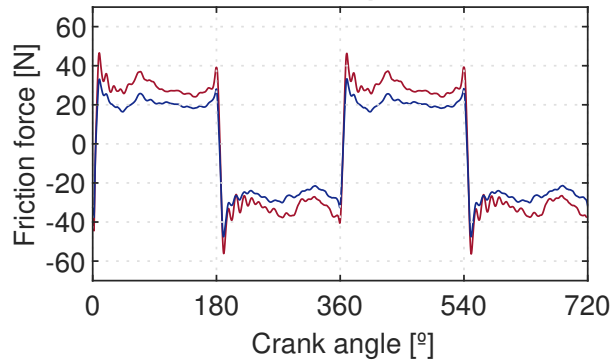

d. $400 \mathrm{rpm}$

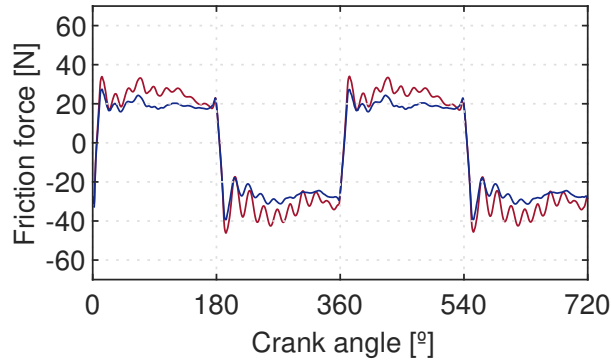

f. $600 \mathrm{rpm}$

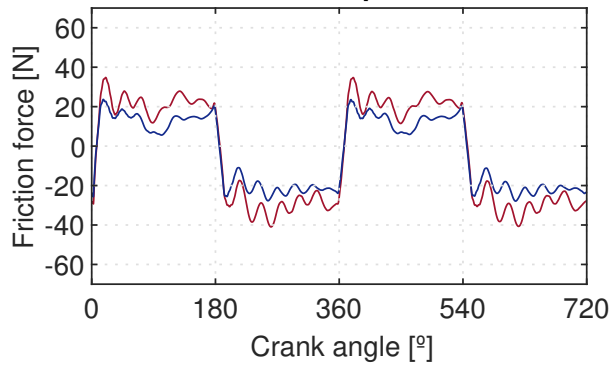

h. $800 \mathrm{rpm}$

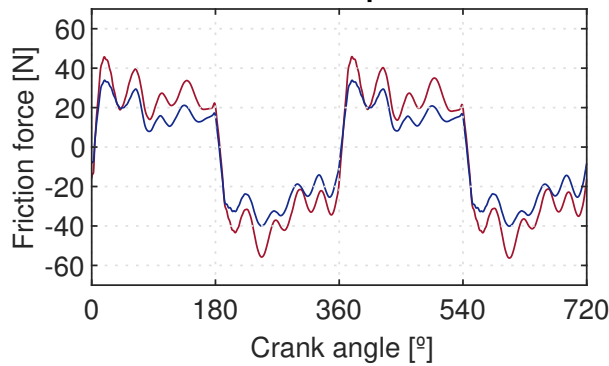

$\mathrm{Ft}=38.4 \mathrm{~N}$ $\mathrm{Ft}=18.7 \mathrm{~N}$

Figure 4.37. Friction force variation with the OCR tangential force at constant oil temperature of $60^{\circ} \mathrm{C}$. 
Figure 4.37 shows that increasing the tangential force of the OCR had a significant effect on the friction force generated in the piston-liner contact throughout the engine cycle, as the friction force increased at the dead centers as well as at the mid-stroke region. Based on the lubrication theory, and the Stribeck curve of Figure 2.1, a higher load, in this case the ring tension, moves the lubrication conditions of the piston towards the left side of the curve; the high applied load results in a thinner oil film to increase its load carrying capacity. As it was previously mentioned at the beginning of this section, a higher OCR tension means that a lower quantity of oil is left behind in the liner wall available for the other rings, leading to a major probability of asperity contact around the dead centers. This effect can be clearly seen in Figure 4.37 for all the engine speed levels; the ring pack with the OCR of higher $F t$ showed greater friction force values at the dead center locations.

Greater friction force values with higher OCR $F t$ were also observed for all the engine cycle. Around the mid-stroke regions, although the piston speed contributes to the creation of the oil film, the load applied by the OCR tension needs to be counteracted and equilibrated by the hydrodynamic reaction of the oil film and any possible asperity interaction of the surfaces, resulting in a thinner oil film and the consequent increase of the friction losses. To compare these experimental results, the research work developed by Westerfield et al. [8] was referenced. In their work, experimental tests were developed in a floating liner test rig both under motored and combustion conditions, using three ring packs with OCRs of different tangential force levels (10.5, 19.5 and 29.5 N). The results presented in this section (Figure 4.37) are in accordance with their findings, showing the same trend of increased friction force throughout the engine cycle with the increase of the OCR tension.

The following Figure 4.38 is a Stribeck-like curve that gathers all the test points measured in this parametric study, allowing to observe and analyze the joint effect of the engine speed, oil temperature and OCR Ft over the friction losses of the piston assembly. The $y$ axis of the plot is the FMEP obtained from the instantaneous friction force measurements and the $x$ axis is an equivalent Sommerfeld parameter calculated from equation 4.2.

$$
\text { Sommer feld }_{\text {equivalent }}=\frac{\mu U}{\sum F t_{\text {rings }} / L_{\text {rings }}}
$$

Where $\mu$ is the dynamic viscosity of the oil corresponding to the temperature measured in the crankcase and $U$ is the average piston speed. The denominator is the quotient of the total tangential force of the piston ring pack, calculated from equation 4.3 as described by Taraza et al. [7], and 
the total axial length of the rings $\left(L_{\text {rings }}\right)$ that come in contact with the liner wall, these dimensions can be seen in Figure 4.23. In equation 4.3, $F t_{1}, F t_{2}$ and $\mathrm{Ft}_{3}$ correspond to the tangential force of the compression ring, scrapper ring and OCR, respectively. These values can be found in Table 4.5.

$$
\sum F t_{\text {rings }}=2\left(F t_{1}+F t_{2}+F t_{3}\right)
$$

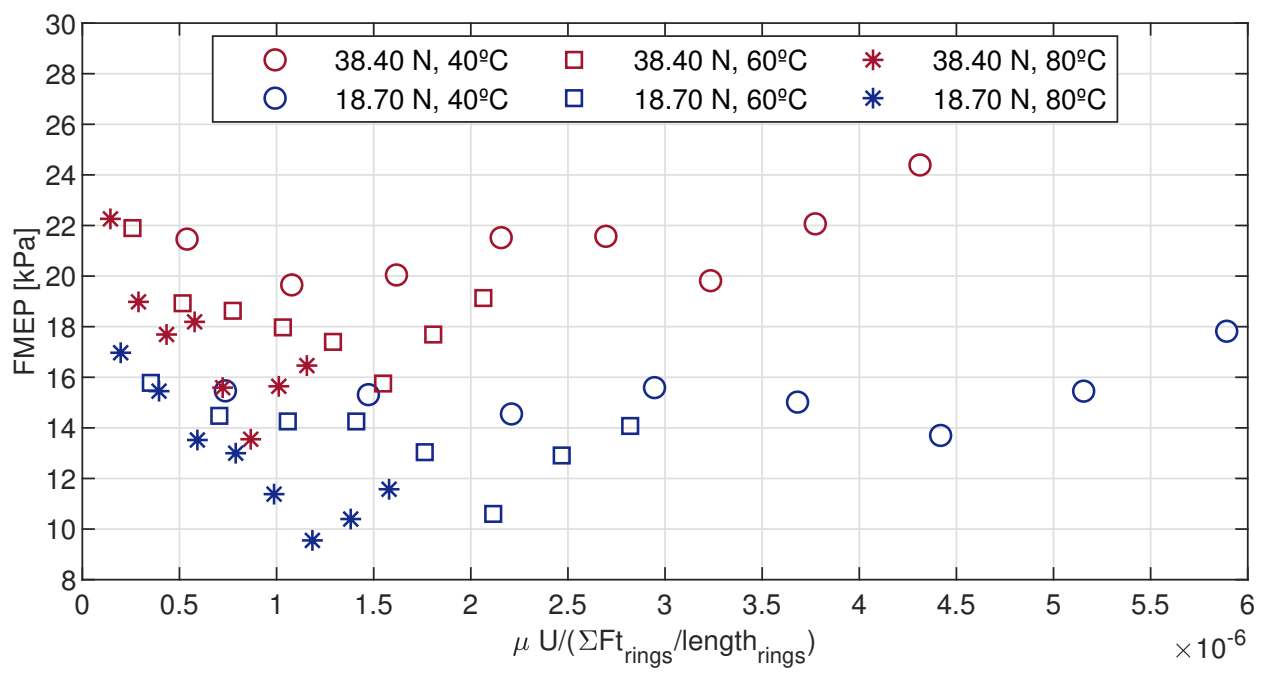

Figure 4.38. Stribeck-like curve for the FMEP variation with speed and oil temperature comparing two OCR Ft levels.

Overall, Figure 4.38 showed again the direct effect that a higher OCR tangential force had over the increase of the friction losses for all the tested points. Following the trend of the scattered points for one of the OCR Ft, it can be observed that the left side of the plot indicates the prevalence of boundary and mixed lubrication conditions, with most of the points of 60 and $80^{\circ} \mathrm{C}$ gathered in this region. For the OCR of higher Ft, just a few points measured under $60^{\circ} \mathrm{C}$ moved to the right side of the plot, provably with a major presence of hydrodynamic lubrication. Instead, for the OCR of lower $F t$ the change of trend towards more favorable lubrication conditions started with some points at $80^{\circ} \mathrm{C}$. On the hand, the right side of the plot gathers the majority of test points measured at $40^{\circ} \mathrm{C}$ for the two OCR Ft levels, that correspond to hydrodynamic lubrication conditions caused by the high oil viscosity and engine speed. Some of these points however, also appeared at the left side of the modified Stribeck curve, corresponding to the lower engine speed 
levels as the piston speed is low enough to promote higher boundary/mixed friction.

From the results presented in this section, decreasing the OCR tension showed to contribute significantly to the reduction of the friction losses in the piston assembly; however, this could lead to an increased oil transport to the combustion chamber where the lubricant is burnt during combustion, increasing the oil consumption and harmful emissions. These opposing effects of varying the OCR Ft were tested by Frommer et al. [2] in a diesel and a gasoline engine, demonstrating the importance of evaluating both the friction losses and oil emissions due to changes in the ring tension, specially during the design this engine component.

\subsection{Discussion}

The floating liner designed and developed in this Thesis, along with the three auxiliary systems implemented for its operation, showed to measure and register the instantaneous friction force in the piston-cylinder liner assembly with repetitive and reproducible results. Furthermore, the design and configuration of the test rig allowed to perform multiple parametric tests with an appropriate and expected response to these variations. These experimental tests also showed that at higher engine speeds (above $800 \mathrm{rpm}$ ), vibration and the piston secondary motion started to interfere with the friction force measurement. In this way, future modifications to the floating liner should include improvements to the structure that help to reduce the noise from vibration, in order to obtain a cleaner friction force measurement at higher engine speed regimes, more representative of the automotive industry.

This limitation on the engine speed range covered by the floating liner is one of the main limitations of the test rig; higher engine speeds would allow to investigate the lubrication of the piston assembly under more favorable conditions for hydrodynamic lubrication and therefore for the study on LVEOs. Other limitation of the test rig is the lack of combustion, which has a direct impact on the lubrication conditions of the piston assembly, the applied load, temperature of the components and the oil and consequently, on the measured friction force, specially during the combustion stroke. As it was mentioned in Section 4.3, for the work developed in this Thesis, a motored floating liner was deemed to be the best option to start with the advantage of not needing complex installations and equipment for the engine operation with combustion and for the intake/exhaust processes. This limitation on the lack of similitude with the actual operation of an ICE is expected to be addressed in a future 
work with the sealing of the combustion chamber and implementation of a compressed air injection system that would allow to obtain high in-cylinder pressure, representative of combustion conditions.

Regarding the experimental results in the floating liner, these initial tests allowed to investigate the correct performance of the test rig, delivering expected friction force measurements. These tests allowed a fundamental analysis of the friction force phenomenon occurring in the piston-cylinder liner assembly and the effect that varying different parameters have on the friction losses. Of these parametric tests, the oil formulations selected for the study, SAE 5W30, 0W20 and 0W16 are representative of the current and future oil usage trend for LDD; while for the OCR tangential force, one of the two tested levels corresponded to the commercial version of this ring. 


\section{A Appendix: Kinematics and dynamics of the floating liner engine}

In this appendix are presented the equations that describe the kinematics and dynamics of the connecting rod-crank mechanism of the floating liner test rig developed in this thesis.

\section{A. 1 Kinematics}

The kinematics of the connecting rod-crank mechanism determine the position, speed and acceleration of the different reference points located in this assembly. This mechanism is presented in the following Figure 4.39; where the piston is represented by the point $B ; \overline{A B}$ is the connecting rod and $\overline{O A}$ is the crank of length $R$. $O$ and $A$ are the bearings in the crank pin end and crankshaft, respectively. The point $G$ represents the center of mass of the connecting rod. According to the signs criterion of Figure 4.39 and the operation of the engine, the direction of rotation of the crank mechanism is counterclockwise, therefore the crank angle $\alpha$ is positive in this direction.

From the previous Figure 4.39 and the geometric relations formed by the mechanism, the following expression can be stablished:

$$
L \sin \beta=R \sin \alpha
$$

From where the connecting rod angle $\beta$ can be obtained as function of the crank angle $\alpha$ :

$$
\beta=\sin ^{-1}\left(\frac{R}{L} \sin \alpha\right)
$$

Equation 4.4 can be derived twice to obtain the angular speed and acceleration of the connecting rod. Therefore, for the angular speed:

$$
L \frac{d \beta}{d t} \cos \beta=R \frac{d \alpha}{d t} \cos \alpha
$$

And for the acceleration:

$$
L \frac{d^{2} \beta}{d t^{2}} \cos \beta-L\left(\frac{d \beta}{d t}\right)^{2} \sin \beta=R \frac{d^{2} \alpha}{d t^{2}} \cos \alpha-R\left(\frac{d \alpha}{d t}\right)^{2} \sin \alpha
$$




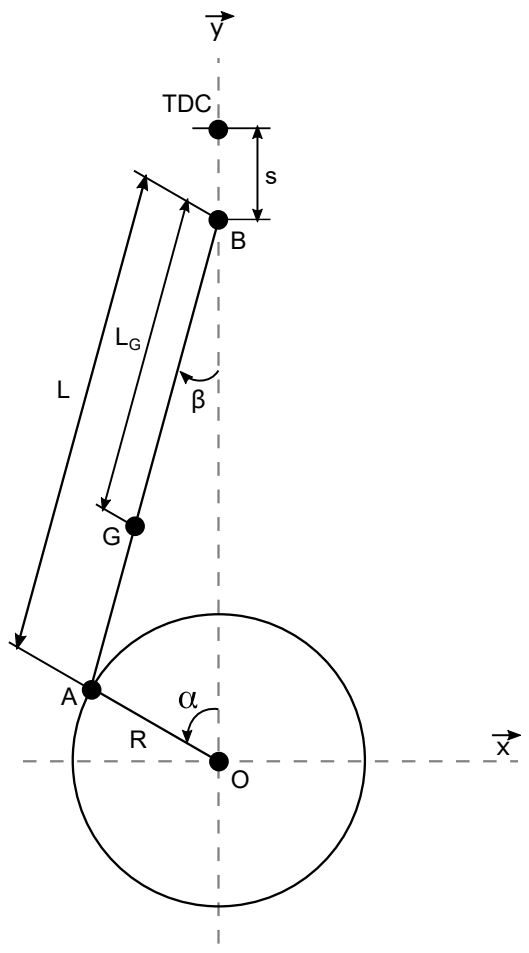

Figure 4.39. Kinematics of the connecting rod-crank mechanism.

Given that the angular speed of the crankshaft is assumed as constant [5], $d \alpha / d t=w, d^{2} \alpha / d t^{2}=0$, the previous equations 4.6 and 4.7 , can be rewritten as follows:

$$
\begin{gathered}
\frac{d \beta}{d t}=\frac{R}{L} \frac{\cos \alpha}{\cos \beta} w \\
\frac{d^{2} \beta}{d t^{2}}=\left[\left(\frac{d \beta}{d t}\right)^{2}-w^{2}\right] \tan \beta
\end{gathered}
$$

\section{A. 1.1 Kinematics of the point $\mathrm{A}$}

In the connecting rod-crank mechanism of Figure 4.39, the point $\mathrm{A}$ is used to describe the position, speed and acceleration of the crankshaft, both in 
the axial and lateral directions $(\vec{x}, \vec{y})$. In this way, the position, speed and acceleration of the point A can be calculated from the following equation 4.10.

$$
\begin{aligned}
& x_{A}=-R \sin \alpha \quad ; \quad y_{A}=R \cos \alpha \\
& v_{x, A}=-R w \cos \alpha \quad ; \quad v_{y, A}=-R w \sin \alpha \\
& a_{x, A}=R w^{2} \sin \alpha \quad ; \quad a_{y, A}=-R w^{2} \cos \alpha
\end{aligned}
$$

\section{A. 1.2 Kinematics of the point $B$}

The point $\mathrm{B}$ represents the piston in the connecting rod-crank mechanism; its position, speed and acceleration can be determined from equation 4.11:

$$
\begin{aligned}
x_{B}=0 & ; & y_{B}=R \cos \alpha+L \cos \beta \\
v_{x, A}=0 & ; & v_{y, B}=-R w \frac{\sin (\alpha+\beta)}{\cos \beta} \\
a_{x, A}=0 & ; & a_{y, B}=-R w^{2}\left[\frac{\cos (\alpha+\beta)}{\cos \beta}+\frac{R \cos ^{2} \alpha}{L \cos ^{3} \beta}\right]
\end{aligned}
$$

The position of the piston can also be referenced to the TDC; in this way, the distance $s$ between the point $B$ and the TDC is the engine displacement:

$$
s=R+L-(R \cos \alpha+L \cos \beta)
$$

The position, speed and acceleration of the piston, calculated with the previous equations, are presented in Figure 4.40, 4.41 and 4.42, respectively:

\section{A. 1.3 Kinematics of the point $G$}

The point G in Figure 4.39 is the center of mass of the connecting rod. During the operation of the engine, the motion of the connecting rod comprises a translation and a pendular rotation around the piston pin. The position, speed and acceleration of the point $G$ are determined by: 


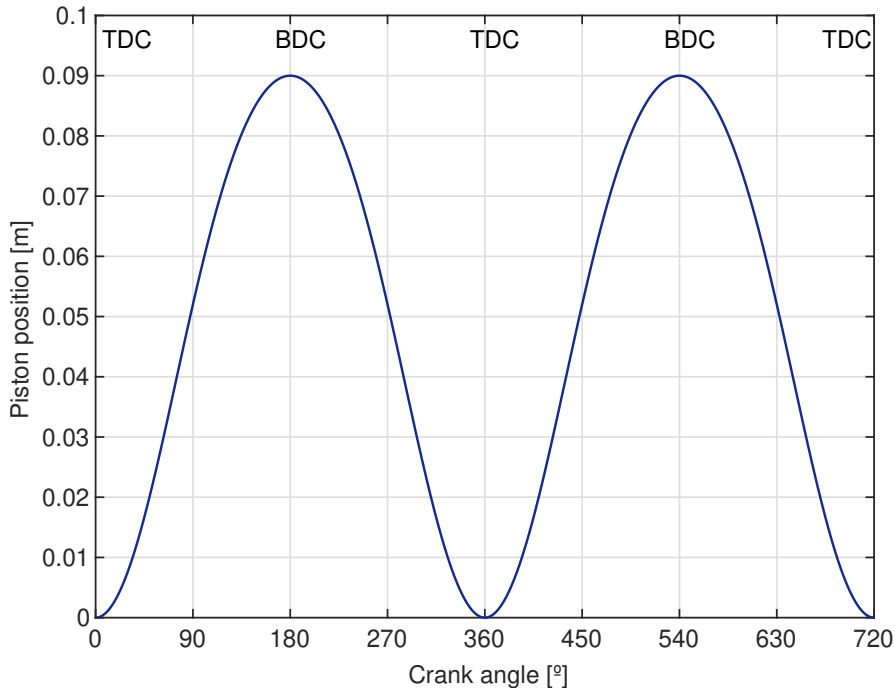

Figure 4.40. Piston position.

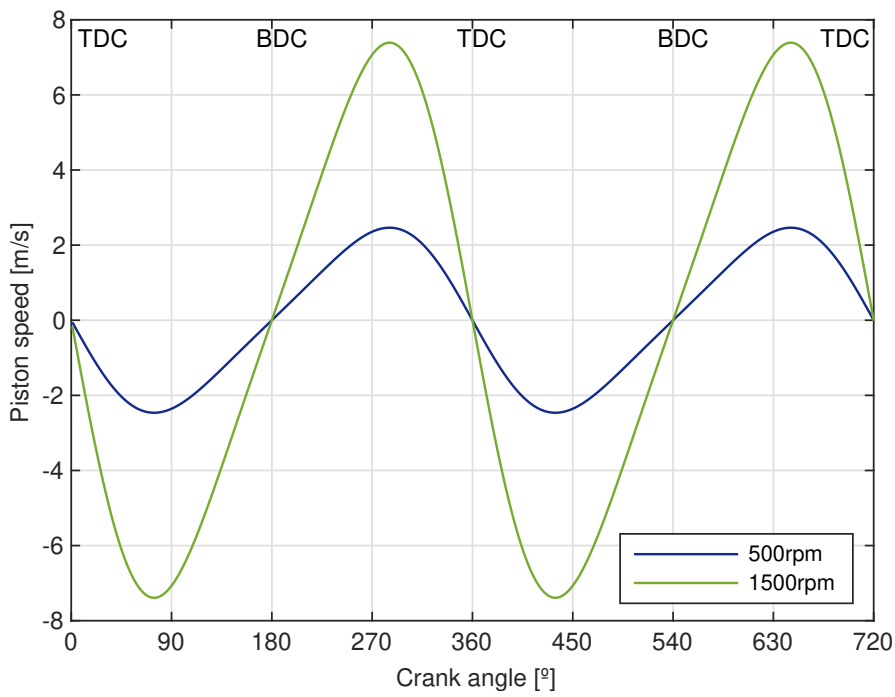

Figure 4.41. Piston speed at 500 and $1500 \mathrm{rpm}$. 


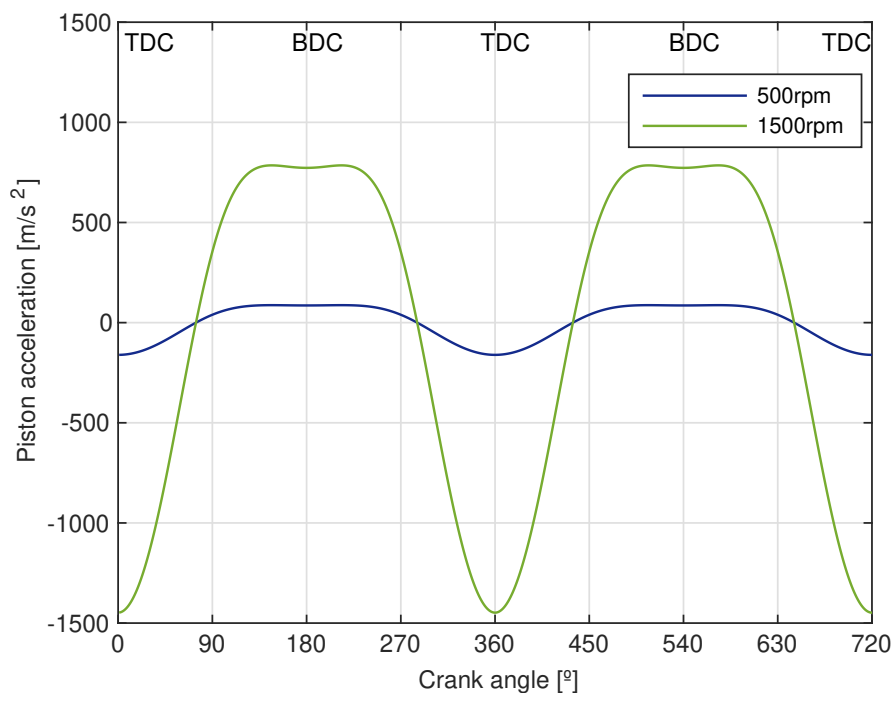

Figure 4.42. Piston acceleration at 500 and 1500 rpm.

$$
\begin{aligned}
x_{G} & =-L_{G} \sin \beta \quad ; y_{G}=R \cos \alpha+\left(L-L_{G}\right) \cos \beta \\
v_{x, G} & =-L_{G} \frac{R}{L} w \cos \alpha ; v_{y, G}=-R w \sin \alpha\left(1+\frac{L-L_{G}}{L} \frac{\tan \beta}{\tan \alpha}\right) \\
a_{x, G} & =L_{G} \frac{R}{L} w^{2} \sin \alpha ; a_{y, G}=-R w^{2}\left[\cos \alpha+\frac{L-L_{G}}{L}\left(\frac{R \cos ^{2} \alpha}{L \cos ^{3} \beta}\right)\right]
\end{aligned}
$$

\section{A. 2 Dynamics}

The dynamics of the connecting rod-crank mechanism describes the forces acting on its components, these are the force due to the in-cylinder pressure applied to the piston, the moment of inertia, the mass of the components and the friction force generated in the contacts. For this analysis however, the mass of the components and the friction force are not included, as their contribution is negligible compared to the other forces [5]. The dynamic analysis of the connecting rod-crank mechanism is presented in Figure 4.43. 

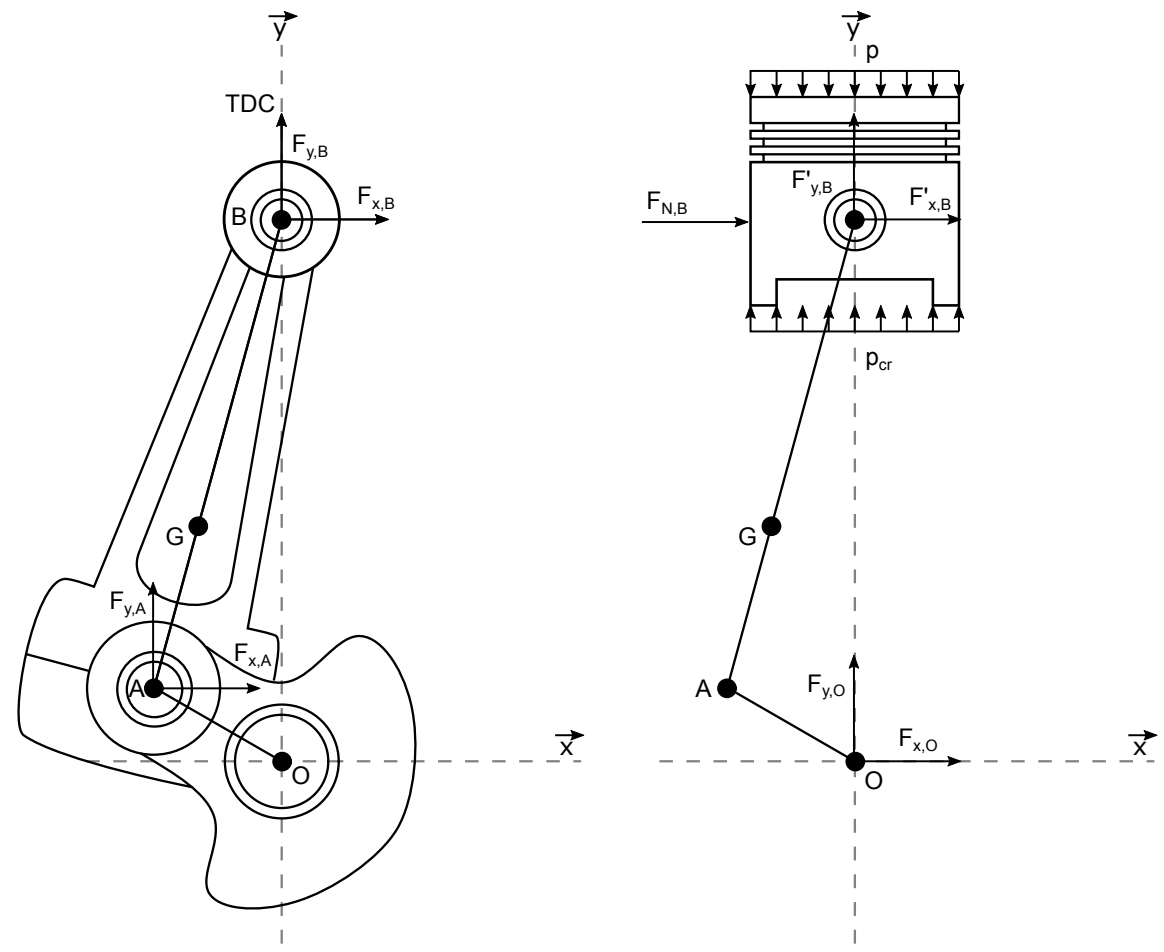

Figure 4.43. Dynamics of the connecting rod-crank mechanism.

\section{A. 2.1 Dynamics of the connecting rod}

The forces acting on the connecting rod comprise: the force applied by the crank on the point $\mathrm{A}$, and the force from the piston pin on the point B. According to the coordinate system $(\vec{x}, \vec{y})$ of Figure 4.43 , these forces can be written as follows:

$$
\begin{aligned}
& F_{x, A}+F_{x, B}=m_{c} a_{x, G} \\
& F_{y, A}+F_{y, B}=m_{c} a_{y, G}
\end{aligned}
$$

$m_{c}$ is the mass of the connecting rod, which can be decomposed in the three reference points of the mechanism, A, B and G. The mass of the point G $\left(m_{G}\right)$ however, is normally neglected as it is very small compared to the other 
masses, $m_{A}$ and $m_{B}$. From this decomposition, the moment of inertia of the connecting rod can be determined from the following expression:

$$
I_{c}=m_{A}\left(L-L_{G}\right)^{2}+m_{B} L_{G}^{2}
$$

The location of the center of mass of the connecting rod is not normally known; therefore, a good approximation for $G$ is to locate it at $L / 3$ from the point A [1]. Additionally, the sum of moments in the point $\mathrm{G}$ can be determined from:

$I_{c} \frac{d^{2} \beta}{d t^{2}}=-\left(L-L_{G}\right) \cos \beta F_{x, A}+L_{G} \cos \beta F_{x, A}+\left(L-L_{G}\right) \sin \beta F_{y, B}-L_{G} \sin \beta F_{y, B}$

\section{A. 2.2 Dynamics of the piston}

The forces acting on the piston are from the in-cylinder pressure applied to its upper and lower faces, $p$ and $p_{c} r$ which is the pressure in the crankcase, the force exerted by the connecting rod on the point $\mathrm{B}\left(F_{x, B}^{\prime}\right)$, which is opposite to that exerted by the piston on the connecting $\operatorname{rod}\left(F_{x, B}\right)$, and the lateral force between the piston and the liner $\left(F_{N, B}\right)$.

The forces applied on the piston in the $x$ direction are:

$$
F_{N, B}+F^{\prime} x, B=0 \quad \text { or } \quad F x, B-F_{N \cdot B}=0
$$

And in the $y$ direction:

$$
F_{y, B}=-m_{p} a_{y, B}-\left[\frac{\pi D^{2}}{4}\left(p-p_{c r}\right)\right]
$$

Equations 4.14, 4.15, 4.174 .18 and 4.19 form a system of equations to solve the dynamics of the connecting rod-crank mechanism at every crank angle position: 


$$
\left.\begin{array}{c}
{\left[\begin{array}{ccccc}
1 & 0 & 1 & 0 & 0 \\
0 & 1 & 0 & 1 & 0 \\
0 & 0 & 1 & 0 & -1 \\
0 & 0 & 0 & 1 & 0 \\
-\left(L-L_{G}\right) \cos \beta & \left(L-L_{G}\right) \sin \beta & L_{G} \cos \beta & -L_{G} \sin \beta & 0
\end{array}\right]\left[\begin{array}{c}
F_{x, A} \\
F_{y, A} \\
F_{x, B} \\
F_{y, B} \\
F_{N, B}
\end{array}\right]=} \\
{\left[\begin{array}{c}
m_{c} a_{x, G} \\
m_{c} a_{y, G} \\
0 \\
-m_{p} a_{y, B}-\left[\frac{\pi D^{2}}{4}\left(p-p_{c r}\right)\right.
\end{array}\right]} \\
I_{c} \frac{d^{2} \beta}{d t^{2}}
\end{array}\right]
$$

From the solution of the previous equation 4.20, the normal force between the piston and the liner $F_{N, B}$ is the most important in the analysis of the friction in this tribological assembly. For the floating liner developed in this thesis, this lateral force is also employed in the structural analysis of the test rig components, specifically the radial support depicted in Section 4.3.3.3.

Figure 4.44 presents the lateral force developed in the piston-liner interface for an engine speed of $500 \mathrm{rpm}$. The green line shows the lateral force under compressed conditions, that is, with an in-cylinder pressure of about 90 bar in TDC, plotted with the red dashed line. The blue line on the other hand, shows the lateral force under ambient pressure conditions, which therefore, only depends on the inertia of the moving parts.

The same analysis is presented for an engine speed of $3000 \mathrm{rpm}$ in Figure 4.45 .

\section{Bibliography}

[1] R. Carreño Arango. A comprehensive methodology to analyse the global energy balance in reciprocating internal combustion engines. $\mathrm{PhD}$ thesis, Universitat Politècnica de València, 2016.

[2] A. Frommer, T. Deub, H. Ehnis, and R. Künzel. Design of the tangential force of the oil control ring - oil emission versus friction. MTZ worldwide, 77:48-53, 2016. doi: $10.1007 / \mathrm{s} 38313-015-0077-8$. 


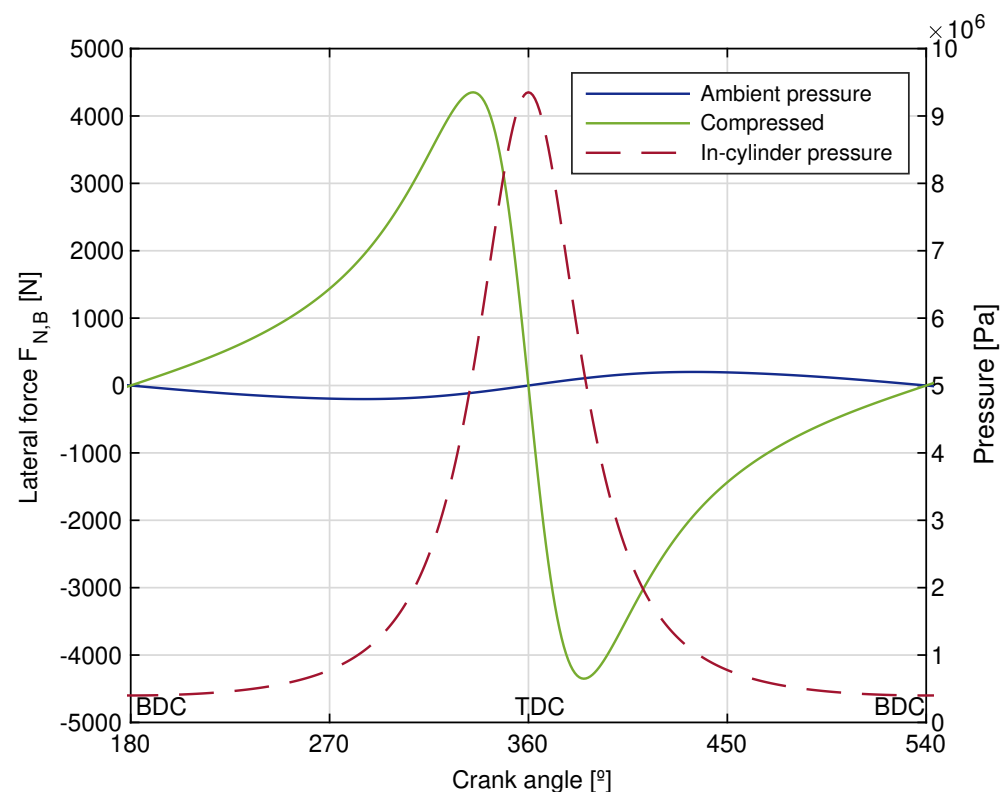

Figure 4.44. Piston lateral force under ambient pressure and compressed conditions for $500 \mathrm{rpm}$.

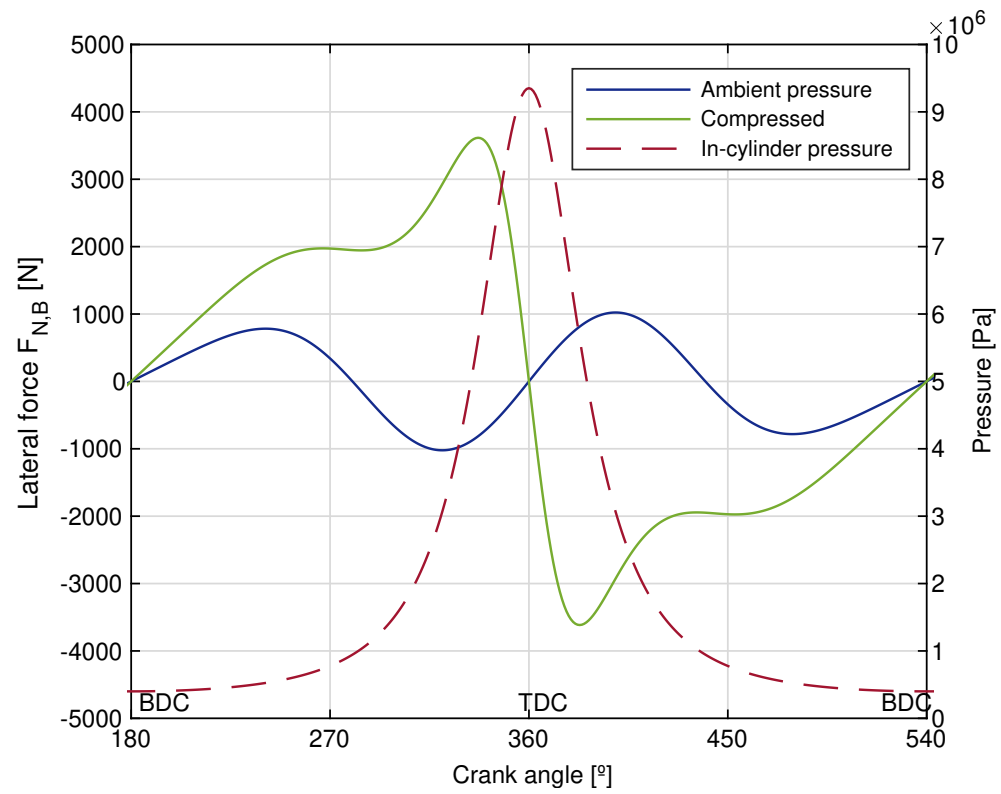

Figure 4.45. Piston lateral force under ambient pressure and compressed conditions for $3000 \mathrm{rpm}$. 
[3] Kistler. Force sensors. Switzerland, 2019.

[4] NAFEMS. The importance of mesh convergence - Part 1. URL: https://www.nafems.org/publications/knowledge-base/ the-importance-of-mesh-convergence-part-1/.

[5] F. Payri González and J.M ${ }^{\mathrm{a}}$ Desantes Fernández. Motores de combustión interna alternativos. Reverté: Universitat Politècnica de València, Barcelona [etc.], 2011.

[6] D. M. Stefanescu. Handbook of force transducers: principles and components. SpringerVerlag Berlin Heidelberg, 2011.

[7] D. Taraza, N. Henein, and W. Bryzik. Friction losses in multi-cylinder diesel engines. In SAE 2000 World Congress. SAE International, mar 2000. doi:10.4271/2000-01-0921.

[8] Z. Westerfield, Y. Liu, D. Kim, and T. Tian. A study of the friction of oil control rings using the floating liner engine. In SAE 2016 World Congress $\mathcal{E}$ Exhibition. SAE International, 04 2016. doi:10.4271/2016-01-1048. 


\section{Chapter 5}

\section{Theoretical model to estimate the friction losses in the piston compression ring and cylinder liner interface}

\section{Contents}

$5.1 \quad$ Introduction $\ldots \ldots \ldots \ldots \ldots \ldots \ldots \ldots \ldots \ldots \ldots, 165$

5.2 One-dimensional model description ......... 165

5.2.1 Non-dimensional Reynolds equation ........... 168

5.2 .2 Pressure distribution $\ldots \ldots \ldots \ldots \ldots \ldots \ldots \ldots$

5.2.2.1 Finite differences method ........... 169

$5.2 .3 \quad$ Load carrying capacity $\ldots \ldots \ldots \ldots \ldots \ldots \ldots . \ldots \ldots . \ldots \ldots$

5.2 .4 Oil flow rate........................ 174

$5.2 .5 \quad$ Lubricant oil starvation .................. 176

5.2 .6 Friction force $\ldots \ldots \ldots \ldots \ldots \ldots \ldots \ldots \ldots \ldots, 177$

$5.2 .7 \quad$ Engine oil rheology ...................... 181

5.2.8 Piston compression ring and liner surface topography 181

5.2.8.1 Piston compression ring ........... 182

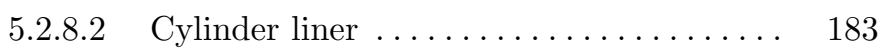

$\mathbf{5 . 3}$ Results......................... 184

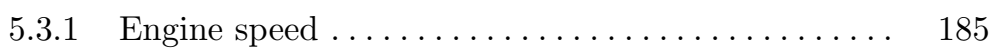

5.3 .2 Oil temperature $\ldots \ldots \ldots \ldots \ldots \ldots \ldots \ldots \ldots \ldots, 188$

5.3 .3 Oil formulation $\ldots \ldots \ldots \ldots \ldots \ldots \ldots \ldots \ldots \ldots, 191$ 
5. Theoretical model to estimate the friction losses in the piston compression ring and cylinder liner interface

5.3.4 Piston ring radius of curvature . . . . . . . . . . . 193

5.3.5 Piston ring tangential force................ 197

5.4 Discussion ....................... 198

5.A Verification of the oil pressure distribution on an inclined pad ...................... 201

Bibliography $\ldots \ldots \ldots \ldots \ldots \ldots \ldots \ldots \ldots \ldots \ldots . \quad 203$ 


\subsection{Introduction}

In order to support the experimental friction force measurements in the floating test rig and complement the research study on the piston-liner friction losses carried out in this thesis, a lubrication model for the piston compression ring was developed and described in this chapter. This theoretical model aims to estimate the lubrication performance, and specifically the friction force generated in the piston compression ring and cylinder liner interface of an ICE. This chapter comprises the model approach, description of equations and input data, methodology followed to implement the model in the mathematical software Matlab and finally, some parametric studies involving working conditions of the engine and design characteristics of the compression ring.

\subsection{One-dimensional model description}

Lubrication of the piston compression ring is modeled as a one-dimensional problem where the piston ring remains static, and the cylinder liner moves in the axial direction dragging the lubricant oil into the ring-liner domain, defined by the axial coordinates $x_{1}$ and $x_{4}$, which represent the oil film inlet and outlet locations, respectively. A diagram of the compression ring lubrication is presented in Figure 5.1. Here, if the piston ring is fully flooded with oil, the inlet position $x_{1}$ corresponds to the leading edge of the ring; however, if the oil film thickness available at the liner is not sufficient, the oil film inlet moves inwards the ring domain to the coordinate $x_{1}^{\prime}$; therefore, it is said that the ring works under starved lubrication conditions partially filled with oil. The oil film rupture is located at $x_{2}$, being also the starting point of cavitation, which extends to the location $x_{3}$. Finally, $x_{4}$ represents the outlet of the oil film from the ring-liner domain.

To model the lubrication of the piston compression ring, the onedimensional Reynolds equation was used as presented in expression 5.1; this is a simplified form of the full Reynolds equation applying the assumptions listed below.

$$
\frac{\partial}{\partial x}\left(h^{3} \frac{\partial p}{\partial x}\right)=6 \eta U \frac{\partial h}{\partial x}+12 \eta \frac{\partial h}{\partial t}
$$

- The lubricant oil follows a Newtonian behavior therefore, the shear stress is proportional to the shear strain rate. 


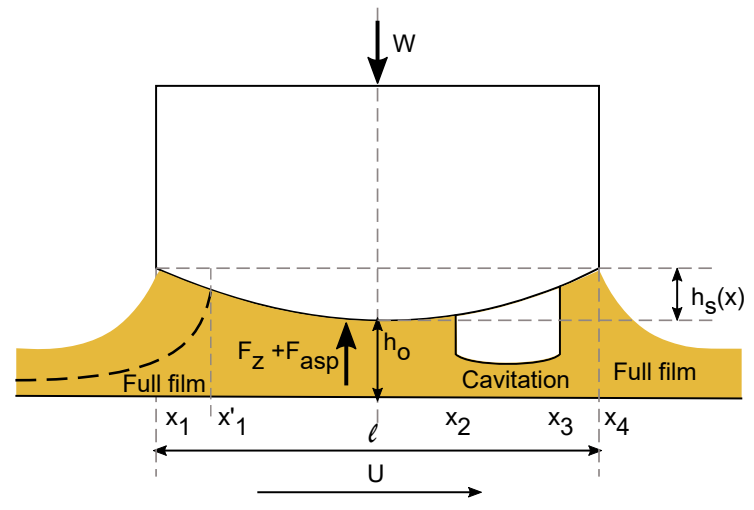

Figure 5.1. Piston compression ring lubrication.

- The oil is considered as iso-viscous throughout the film thickness, but its value varies with the oil temperature.

- There is no side leakage of oil therefore, the lubrication analysis is kept in one dimension, along the ring axial height.

- The oil density is constant with pressure.

- There is good piston ring-liner bore conformance.

- Piston ring dynamics, twist and tilting are not considered in the analysis. Inertia effects are neglected.

Equation 5.1 describes the flow of lubricant oil and the pressure generated in the piston-liner interface. The term in the left-hand side of this equation, known as the Poiseuille term, describes the flow of lubricant due to the oil pressure gradient. The first term in the right-hand side, is the Couette term, which describes the flow of lubricant due to shearing of the oil film. Finally, the last term in Reynolds equation is the squeeze term, which describes the change of the oil film thickness with time. This oil squeeze effect can specially be seen at the dead centers, due to the deceleration of the piston and the approach of the surfaces, the oil film is squeezed between the ring and the liner reducing its thickness, which can lead to mixed and boundary lubrication [16, 24].

In equation 5.1, the movement of the liner occurs in the axial coordinate $x, p$ is the oil pressure generated in the interface, $\eta$ is the oil dynamic viscosity, $U$ is the relative velocity between the surfaces, which is taken as the piston speed calculated from equation $4.11 \mathrm{~b}, t$ is the time, and $h$ is the 
oil film thickness defined by the profile of the compression ring $h_{s}$ and the minimum oil film thickness $h_{o}$. In this model, the profile of the compression ring was simulated as a parabola, as shown in Figure 5.2; in this way, $h$ can be found with equation 5.2 and the radius of curvature of the ring $R_{f 1}$. Dimensions, coefficients and other parameters used in the model are summarized in Table 5.1.

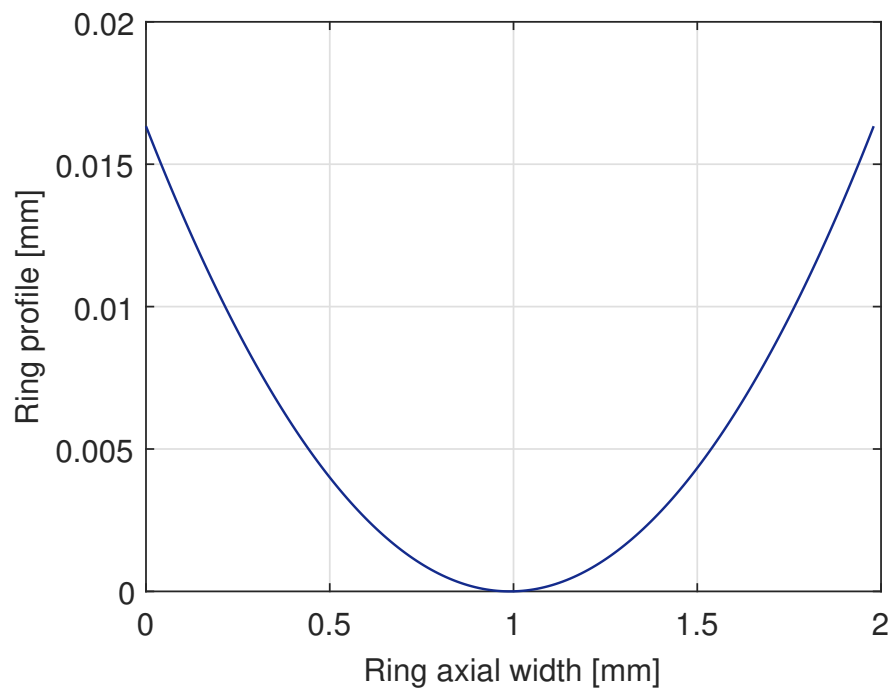

Figure 5.2. Parabolic profile of the compression ring used in the lubrication model.

$$
h=h_{s}+h_{o}=\frac{x^{2}}{2 R_{f 1}}+h_{o}
$$

Referring to the lubrication conditions of the compression ring in Figure 5.1, given that the floating liner is operated under ambient pressure conditions, the force applied to the internal face of the ring is the result of the ring tension force $W$, which opposes to the load carrying capacity developed by the oil $F_{z}$ and the force from the asperity interactions $F_{a s p}$. As mentioned at the beginning of this Section 5.2, lubrication of the piston ring can be assumed as fully flooded; however, experimental research conducted by authors $[17,22,23]$ has shown that the piston compression ring works under starved lubrication conditions for the most part of the engine cycle. Considering the piston ring pack, starved lubrication of the piston rings is the result of the lubrication conditions of each ring and the oil left behind them, available to the next ring. In ICEs with splash lubrication and/or oil jets 
5. Theoretical model to estimate the friction losses in the piston

\begin{tabular}{|r|c|c|}
\hline Parameter & Nomenclature & Value \\
\hline \hline Piston bore & - & $91.42 \mathrm{~mm}$ \\
\hline Piston length & - & $86.27 \mathrm{~mm}$ \\
\hline Clearance & - & $0.220 \mathrm{~mm}$ \\
\hline Compression ring (rectangular) axial height & $l$ & $1.98 \mathrm{~mm}$ \\
\hline Combined modulus of elasticity & $E$ & $1.08 \times 10^{11} \mathrm{~Pa}$ \\
\hline Coefficient of asperity shear strength & $\zeta$ & 0.1 \\
\hline Pressure tolerance & $\epsilon_{P}$ & $5 \times 10^{-5}$ \\
\hline Load tolerance & $\epsilon_{W}$ & $1 \times 10^{-3}$ \\
\hline Flow rate tolerance & $\epsilon_{Q}$ & $1.5 \times 10^{-2}$ \\
\hline MOFT tolerance & $\epsilon_{h}$ & $5 \times 10^{-3}$ \\
\hline Number of nodes & $n$ & 200 \\
\hline Ring radius of curvature & $R_{f 1}$ & $30 \mathrm{~mm}$ \\
\hline Composed $\sigma \beta \eta_{s}$ & {$[-]$} & 0.0398 \\
\hline Compression ring tangential force & $F t$ & $17.3 \mathrm{~N}$ \\
\hline Lil dynamic viscosity at $40^{\circ} \mathrm{C}$ & - & $56.20 \mathrm{mPa} . \mathrm{S}$ \\
\hline Oil dynamic viscosity at $60^{\circ} \mathrm{C}$ & - & $26.70 \mathrm{mPa} . \mathrm{s}$ \\
\hline Oil dynamic viscosity at $80^{\circ} \mathrm{C}$ & - & $14.62 \mathrm{mPa} . \mathrm{s}$ \\
\hline
\end{tabular}

Table 5.1. Data used in the piston compression ring lubrication model.

located at the bottom of the liner, lubrication of the oil control ring can be assumed as fully flooded during the downstroke, due to the constant supply of oil. This assumption however, is not very likely to occur in the compression ring, as the oil availability relies on the oil film smeared by the preceding rings during the downstroke, and the upward oil transport during the upstroke.

\subsubsection{Non-dimensional Reynolds equation}

Non-dimensional terms were defined for the solution of the Reynolds equation 5.1 with the aim of reducing the amount of variables involved in 
the analysis, and to eliminate their physical dimensions. This substitution of variables allows to simplify the problem and avoid mistakes when using different units. The following non-dimensional terms were defined:

$$
H=\frac{h}{h_{o}} \quad X=\frac{x}{l} \quad P=\frac{p h_{o}^{2}}{\eta U l} \quad K_{t}=\frac{l \omega}{U}
$$

Furthermore, for the squeeze term, the time term $t$ was replaced for the crank angle: $t=\alpha / \omega$; where $\omega$ is the angular velocity of the engine. After the appropriate substitution of variables in equation 5.1, the Reynolds equation can be re-written in non-dimensional terms as follows:

$$
\frac{\partial}{\partial X}\left(H^{3} \frac{\partial P}{\partial X}\right)=6 \frac{\partial H}{\partial X}+12 K_{t} \frac{\partial H}{\partial \alpha}
$$

\subsubsection{Pressure distribution}

In order to obtain the oil pressure distribution from Reynolds equation 5.3, the following boundary conditions were defined, including the Reynolds cavitation condition:

- Inlet: $p=$ ambient gauge pressure at $x=x_{1}$

- Cavitation: $p=0 ; d p / d x=0$ at $x=x_{2}$

- Outlet: $p=$ ambient gauge pressure at $x=x_{4}$

\subsubsection{Finite differences method}

To solve the Reynolds equation 5.3, defined as a second-order differential equation, the finite differences method was employed. It consists of dividing the domain in small sections or nodes and approximate the first and second derivatives by solving the equation in each node. In this way, the first derivative is approximated as the slope between adjacent points either by backward, forward or central differences. Here, a central difference was selected for the left hand side term and the first term in the right hand side, as it can be more accurate. However, for the squeeze term, second term in the right hand side of equation 5.3, a backward time finite difference method was used. The second derivative was approximated dividing the difference 
of two adjacent first derivatives over the distance between the two nodes. A schematic diagram of the first and second derivatives in finite differences is presented in Figure 5.3, and the overall definition of the backward, forward and central differences is presented in equation 5.4.

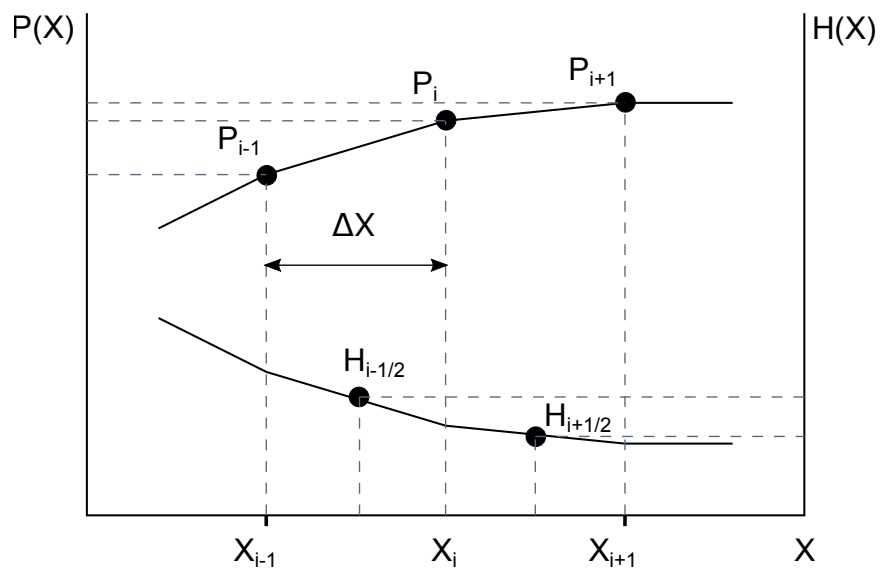

Figure 5.3. Firsts and second derivatives for the finite differences method.

$$
\begin{array}{lr}
\left(\frac{\partial P}{\partial X}\right)_{i} \approx \frac{P_{i+1}-P_{i}}{\Delta X} & \text { Forward difference } \\
\left(\frac{\partial P}{\partial X}\right)_{i} \approx \frac{P_{i}-P_{i-1}}{\Delta X} & \text { Backward difference } \\
\left(\frac{\partial P}{\partial X}\right)_{i} \approx \frac{P_{i+1}-P_{i-1}}{2 \Delta X} & \text { Central difference }
\end{array}
$$

The second derivative is approximated with the expression 5.5:

$$
\frac{\partial}{\partial X}\left(\frac{\partial P}{\partial X}\right)_{i} \approx \frac{\frac{P_{i+1}-P_{i}}{\Delta X}-\frac{P_{i}-P_{i-1}}{\Delta X}}{\Delta X}
$$

Re-writing equation 5.3 in finite differences, the following expression is obtained:

$$
\frac{\left(H_{i+1 / 2}^{3} \frac{P_{i+1}-P_{i}}{\partial X}\right)-\left(H_{i-1 / 2}^{3} \frac{P_{i}-P_{i-1}}{\partial X}\right)}{\partial X}=6 \frac{H_{i+1 / 2}-H_{i-1 / 2}}{\partial X}+12 K_{t} \frac{H_{j}-H_{j-1}}{\partial \alpha}
$$


Where,

$$
H_{i+1 / 2}=\frac{H_{i+1}+H_{i}}{2} \quad H_{i-1 / 2}=\frac{H_{i}+H_{i-1}}{2}
$$

Finally, equation 5.6 can be rearranged to find the pressure at node i:

$$
P_{i}=\frac{H_{i+1 / 2}^{3} P_{i+1}+H_{i-1 / 2}^{3} P_{i-1}-6 \delta X\left(H_{i+1 / 2}-H_{i-1 / 2}\right)-12 K_{t} \delta X^{2}\left(\frac{H_{j}-H_{j-1}}{\delta \alpha}\right)}{\left(H_{i+1 / 2}^{3}+H_{i-1 / 2}^{3}\right)}
$$

Once the pressure distribution was obtained for all the nodes in the domain at the specific crank angle, convergence was sought with expression 5.9 and a tolerance $\epsilon_{P} . \quad n$ is the number of nodes in the axial domain and $m$ is the iteration.

$$
\sum_{i=1}^{n} \frac{\left|P_{i, j}^{m}-P_{i, j}^{m-1}\right|}{P_{i, j}^{m}} \leqslant \epsilon_{P}
$$

In order to verify that the Reynolds equation is correctly expressed in finite differences and that its implementation in Matlab allows to obtain the correct oil pressure distribution, a comparison of results with data found in literature was developed and presented in Appendix 5.A.

\subsubsection{Load carrying capacity}

The load carrying capacity per unit width developed by the lubricant oil at each crankcangle is obtained as the integral of the pressure curve along the piston ring axial domain with equation 5.10. This force and that from the asperities' interaction $F_{\text {asp }}$ oppose to the force exerted by the ring tension $W$.

$$
F_{z}=\int_{0}^{l} p d x
$$

The force due to the interaction of the asperities between the piston compression ring and the liner, $F_{a s p}$, was obtained applying the Greenwood and Tripp model [9], through equation 5.11, assuming that the distribution of the asperities in both surfaces, liner and ring, follow a Gaussian distribution. This assumption has been implemented by different authors [11, 15, 26, 29, 32]. 
5. Theoretical model to estimate the friction losses in the piston compression ring and cylinder liner interface

$$
F_{a s p}=\frac{16 \sqrt{2}}{15} \pi\left(\sigma \beta \eta_{s}\right)^{2} E \sqrt{\frac{\sigma}{\beta}} A F_{5 / 2}(\lambda)
$$

Coefficients $\sigma, \beta$ and $\eta_{s}$, that describe the surfaces of the liner and the piston ring, are summarized in Table 5.1; their calculation is described in Section 5.2.8. $A$ is the contact area of the ring, and the statistical function $F_{5 / 2}$ was obtained from expression 5.12 proposed in [9].

$$
F_{5 / 2}(\lambda)=\frac{1}{\sqrt{2 \pi}} \int_{\lambda}^{\infty}(s-\lambda)^{5 / 2} e^{-s^{2} / 2} d s
$$

As it can be seen in equation $5.12, F_{5 / 2}$ is function of the Stribeck oil film parameter $\lambda$, which is the ratio of the minimum oil film thickness $h_{o}$ and the combined roughness of the surfaces $\sigma$. Values of $\lambda$ equal or greater than 4 indicate that there is no asperity interaction and therefore, lubrication is purely hydrodynamic with $F_{5 / 2}=0$. This $\lambda$ value equal to 4 was selected from literature, as it commonly ranges between 2 and 5 , as presented in the summary of Table 5.2.

\begin{tabular}{|r|c|}
\hline Author & $\lambda$ limit for hydrodynamic lubrication \\
\hline \hline Hu et al., 1994 [1]] & $\lambda i 4$ \\
\hline Arcoumanis et al., 1997[2] & $\lambda \geqslant 4$ \\
\hline Tian T. et al., 1998 [26] & $\lambda i 4$ \\
\hline Mishra, 2013 [15] & $\lambda i 4$ \\
\hline Ahmed Ali et al., 2016 [1] & $\lambda \succsim 4$ \\
\hline Bewsher et al., 2019 [3] & $\lambda i 4.8$ \\
\hline Turnbull et al., 2020 [29] & $\lambda i 2.22$ for $F_{5 / 2}$ \\
\cline { 2 - 2 } & $\lambda i 2.29$ for $F_{2}$ \\
\hline
\end{tabular}

Table 5.2. Limit for the oil film parameter $(\lambda)$ defined by different authors for purely hydrodynamic lubrication.

Equation 5.12 can be solved by numerical integration; however, it can also be approximated with a polynomial of ninth oder to reduce the model execution time. The statistical function $F_{5 / 2}$ for $\lambda$ values in the range 0 to 4 has been plotted in Figure 5.4, along with the ninth order polynomial fit. This Figure 5.4 also includes the statistical function $F_{2}$ of the Greenwood and 
Tripp model and its fit used to calculate the area covered with asperities $A_{a s p}$. Calculation of $F_{2}$ and $A_{a s p}$ is described in more detail in Section 5.2.6.

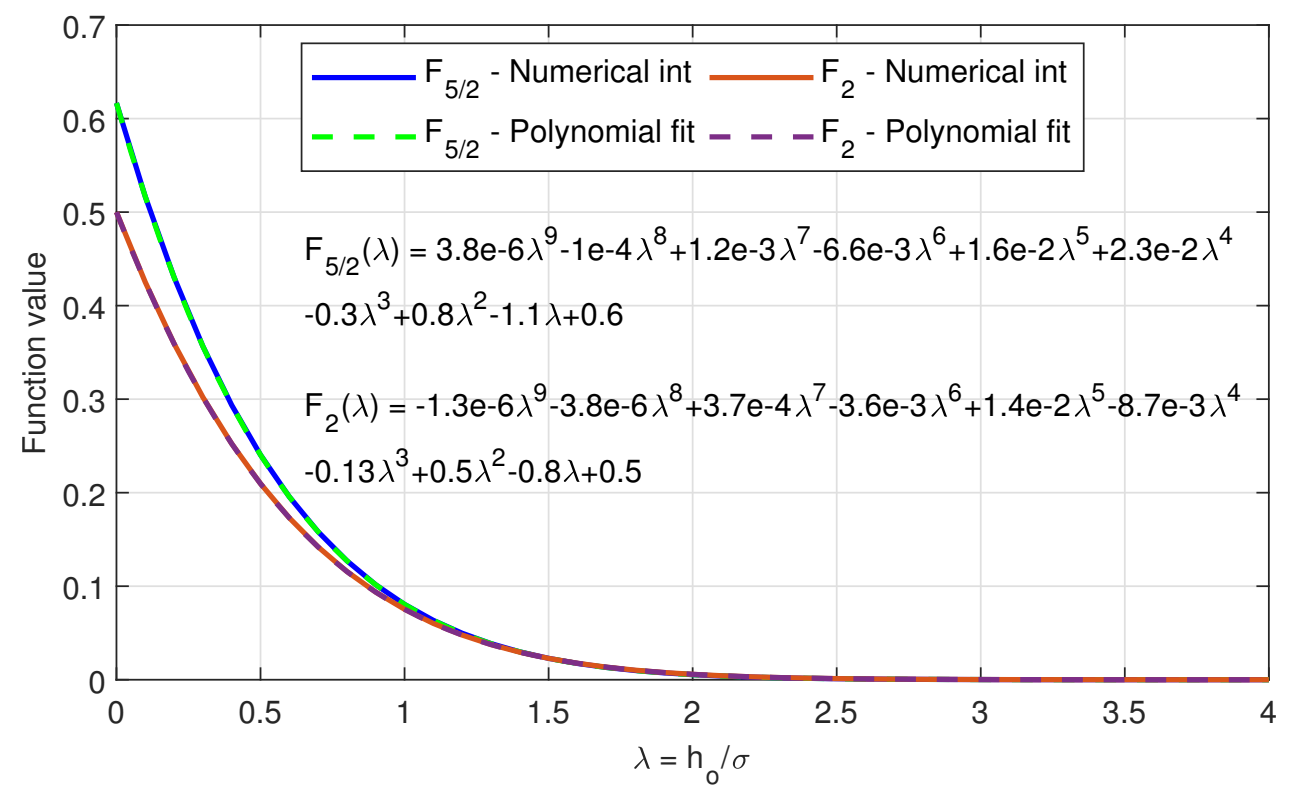

Figure 5.4. $F_{5 / 2}$ and $F_{2}$ statistical functions and their polynomial fit.

The total contact reaction $W_{t}$ per unit width from the lubricant oil and the asperities is therefore the sum of both terms in equation 5.13. It is important to note that in this equation, $F_{a s p}$ needs to be converted to force per unit width using the ring circumferential length $b$.

$$
W_{t}=F_{z}+F_{a s p}
$$

Equation 5.13 was then compared to the ring tension force $W$ obtained from equation 5.14 for the piston compression ring.

$$
W=\frac{P_{c} A}{b}
$$

$P_{c}$ is the contact pressure exerted by the piston ring due to its tangential force $F t$, and can be obtained from equation 5.15 [14, 18].

$$
P_{c}=\frac{2 F t}{D l}
$$



compression ring and cylinder liner interface

Given that the ring tension force $W$ and the total contact reaction $W_{t}$ are opposed to each other, they must be in equilibrium. In this way, these two forces are compared for equality with the following equation 5.16 and the tolerance $\epsilon_{W}$.

$$
\frac{\left|W-W_{t}\right|}{W} \leqslant \epsilon_{W}
$$

If convergence was not achieved, and iterative procedure was started to update the minimum oil film thickness $h_{o}$ using equation 5.17. If the total contact reaction was lower than the force applied by the ring tension, the minimum film thickness is reduced increasing the load carrying capacity of the oil. This procedure continues until the convergence criterion is met.

$$
h_{o, \text { new }}=h_{o, \text { old }}+\gamma_{1}\left(\frac{W_{t}-W}{W}\right)
$$

In equation $5.17, h_{o, n e w}$ is the new film thickness to be used in the following iteration, $h_{o, \text { old }}$ is the minimum film thickness obtained in the current iteration, and $\gamma_{1}$ is a coefficient used for the update, defined between 0.02 and 0.075. Once the load equilibrium was achieved, the model continued with the calculation of the oil flow rate (Section 5.2.4) and then to the next crank angle if lubrication of the piston compression ring is considered to be fully flooded; instead, if starvation is included, flow continuity needs to be evaluated before proceeding to the next crank angle, as explained in Section 5.2.5.

\subsubsection{Oil flow rate}

As previously mentioned in Section 5.2, for the simulation of the piston compression ring lubrication, it is assumed that the cylinder liner moves in the axial direction $x$ with velocity $U$, while the piston ring remains static with zero velocity. As the oil is dragged into the piston-liner interface, the pressure of the oil begins to increase, due to the height decrease of the parabolic profile of the ring, as shown in Figure 5.5. At this inlet position $h^{*}$, the flow rate of the oil is determined by two components: the velocity of the moving surface that drags the oil (Couette term), and the effect of the oil pressure gradient (Poiseuille term). In this way, the oil flow rate $q^{*}$ can be found with equation 5.18.

$$
q^{*}=-\frac{h^{* 3}}{12 \eta} \frac{d p}{d x}+U \frac{h^{*}}{2}
$$




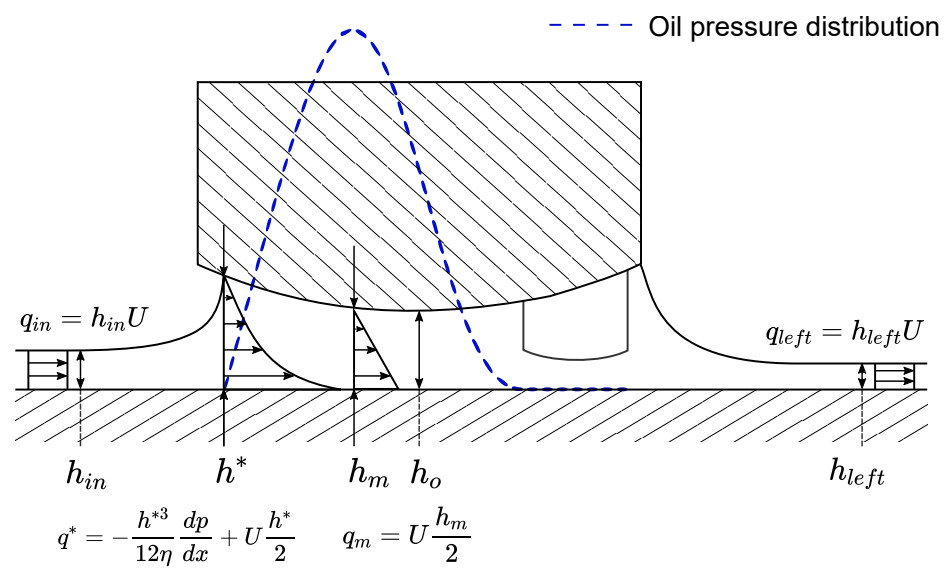

Figure 5.5. Volume flow on the piston ring-liner interface.

At the point of maximum oil pressure, $d p / d x=0$; therefore, the oil flow rate only depends on the Couette flow, and can be determined with equation 5.19 and the oil film thickness $h_{m}$ at this location. At the cylinder liner wall, before the leading edge of the ring, the volume of oil flows with uniform velocity and film thickness $h_{i n}$; the oil flow rate per unit width is therefore determined with equation 5.20. The same condition applies to the oil left by the ring in the liner, available to the following ring or to the same ring during the next stroke, as shown in equation 5.21. Figure 5.5 summarizes the oil flow rate at the different locations of the piston ring-liner domain.

$$
\begin{gathered}
q_{m}=U \frac{h_{m}}{2} \\
q_{i n}=h_{i n} U \\
q_{l e f t}=h_{\text {left }} U
\end{gathered}
$$

For fully flooded conditions, lubricant oil can accumulate in front of the ring, if this situation occurs at any crank angle, the accumulated oil is added to the oil film thickness available at the cylinder wall for the next crank angle [13]. 

compression ring and cylinder liner interface

\subsubsection{Lubricant oil starvation}

The next step in the lubrication model of the piston compression ring was the inclusion of the mass conservation principle; that is, the oil entering the ring at any crank angle, must be equal to the oil left by the ring in the liner in the previous stroke after its passage. For the implementation in Matlab, it is assumed that an oil film of constant thickness is available at the liner wall to start the execution of the model. Once the piston ring starts to move towards the $\mathrm{BDC}$ in the downstroke, it encounters the oil film thickness at the liner; if this thickness is more than enough to fill the ring at the leading edge, oil accumulation occurs. However, if the available film thickness is not sufficient, the oil inlet moves inwards the ring domain to the location $x_{1}^{\prime}$, as shown in the dotted line of Figure 5.1. The ring therefore, works under starved lubrication conditions. During the upstroke, the ring encounters the oil left by itself in the liner wall during the downstroke, plus any possible oil accumulation in the previous crank angle position. Again, the available film thickness at the ring inlet will determine if it is fully flooded with oil or starved.

In order to include the starved lubrication condition, the oil flow rate at two locations of the piston ring-liner domain were selected and compared for equality. The first selected location was at $h=h_{i n}$, with the oil flow rate determined from equation 5.20. The second location was at the point of maximum oil pressure, where $h=h_{m}$ and the oil flow rate can be found with equation 5.19. An iterative process was implemented in the model where the oil flow rate at these locations was compared with equation 5.22 and a tolerance $\epsilon_{Q}$. If this condition was met in the first iteration, the piston ring is fully flooded with oil and the model continues to the next crank angle. Instead, if the conditions was not met, the ring is starved and the oil inlet position is moved inwards the ring domain, one node in each iteration. The oil pressure distribution, load carrying capacity and MOFT are calculated again. This iterative procedure continues until the condition of equation 5.22 is satisfied.

$$
\frac{\left|Q_{i n}-Q_{m}\right|}{Q_{\text {in }}} \leqslant \epsilon_{Q}
$$

In equation 5.22, $Q_{i n}$ and $Q_{m}$ are the non-dimensional terms of $q_{i n}$ and $q_{m}$, respectively.

Once the flow continuity condition is achieved for the complete engine cycle, cyclic convergence of the minimum film thickness is evaluated with equation 5.23 and a tolerance $\epsilon_{h}$. If convergence is not achieved, the lubrication 
model is started again with an updated $h_{o}$; the oil pressure distribution, load carrying capacity and oil flow rate are calculated again for this new condition.

$$
\frac{\left|h_{o, \text { current cycle }}-h_{o, \text { previous cycle }}\right|}{h_{o, \text { current cycle }}}<\epsilon_{h}
$$

The implementation of the lubrication model for the piston compression ring in the mathematical software Matlab, including lubricant starvation, is presented in a flow diagram in Figure 5.6.

\subsubsection{Friction force}

The friction force generated in the interface of the piston compression ring and the liner was modeled as the result of two contributions, one due to the shearing of the lubricant oil film under hydrodynamic lubrication and the other determined by the asperity interactions of the two surfaces under boundary lubrication.

Under hydrodynamic lubrication conditions, the piston compression ring domain consists of a full film region, where the load carrying capacity is developed, and a cavitation region where the oil film ruptures. In this last region, it has been found that bubbles of air are formed due to the pressure drop in the interface. These bubbles keep the oil pressure constant and near to ambient conditions, while the oil flows out of the ring domain in the form of thin streams. A schematic diagram of these regions can be observed in Figure 5.7. Friction force is then the result of the oil shearing in the full film and cavitation regions. Due to the presence of air bubbles in the cavitation region, only a fraction of the radial clearance space between the ring and the liner is filled with oil [5]. This fraction $\hat{z}$ can be obtained from the flow continuity condition evaluated at the cavitation boundaries, where the oil pressure gradient is zero $(d p / d x=0)$. That is, at $x=x_{2}$ with a film thickness defined by $h_{m}$, and at $x=x_{4}$ or $x=x_{3}$ if oil film reformation occurs, as shown in expression 5.24.

$$
\begin{aligned}
q\left(x_{2}\right) & =q\left(x_{3}\right) \\
\frac{U h_{m}}{2} & =\frac{U h}{2} \\
\hat{z} & =\frac{h_{m}}{h}
\end{aligned}
$$




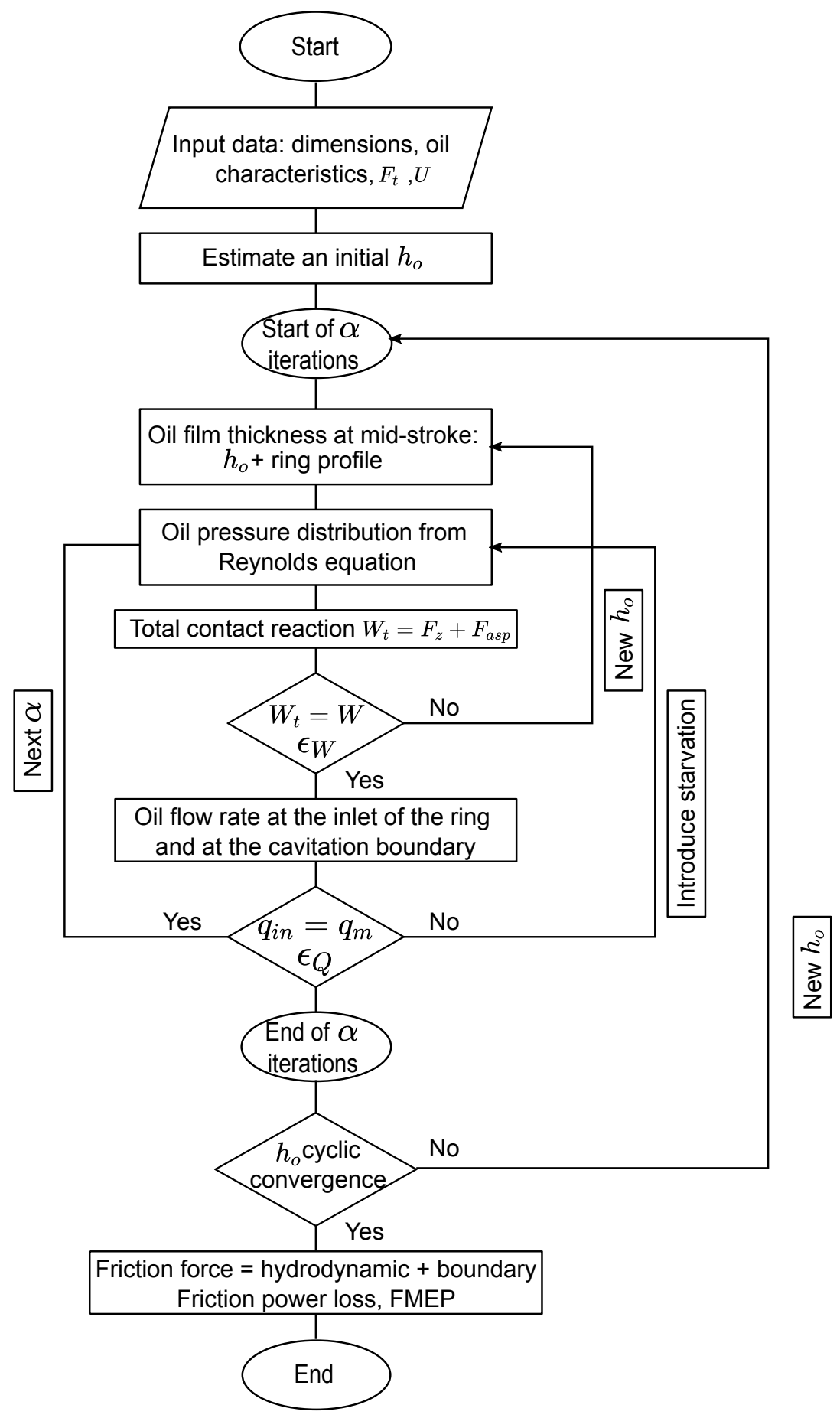

Figure 5.6. Flow diagram of the piston compression ring lubrication model implementation in mathematical software. 


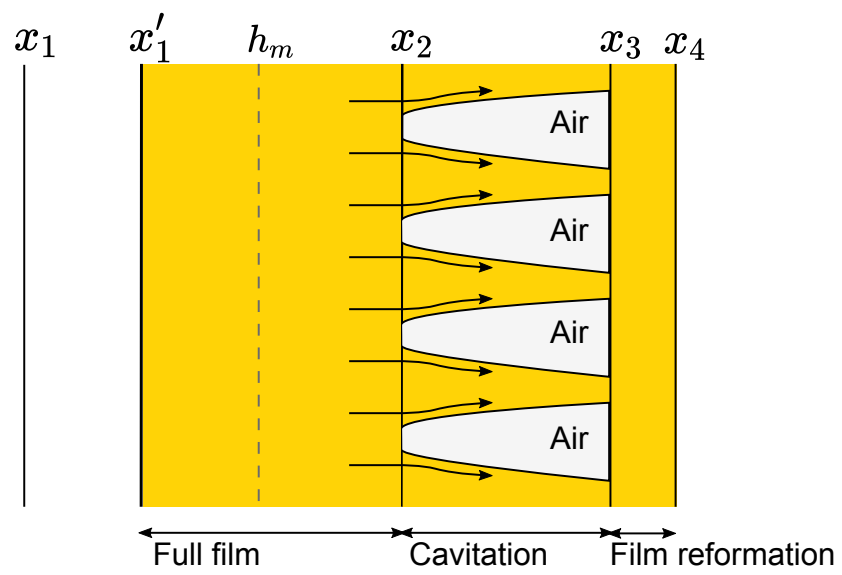

Figure 5.7. Piston ring lubrication regions.

The viscous friction force $f_{v}$ is then determined as the integral of the shear stress in the full film and cavitation regions with equation 5.25, first term and second term, respectively.

$$
f_{v}(x)=\int_{x_{1}}^{x_{2}} \tau d x+\int_{x_{2}}^{x_{3}} \hat{z} \tau d x
$$

Where the shear stress $\tau$ in each region is determined from expression 5.26

$$
\begin{array}{r}
\tau=\frac{-h}{2} \frac{d p}{d x}-\eta \frac{U}{h} \quad, \quad x_{1}<x<x_{2} \\
\tau=-\eta \frac{U}{h} \quad, \quad x_{2}<x<x_{3}
\end{array}
$$

Replacing expression 5.26 in equation 5.25:

$$
f_{v}(x)=\int_{x_{1}}^{x_{2}}\left(\frac{-h}{2} \frac{d p}{d x}-\eta \frac{U}{h}\right) d x+\int_{x_{2}}^{x_{3}}-\hat{z} \eta \frac{U}{h} d x
$$

In equation $5.27, f_{v}$ is the friction force per unit width along the ring axial dimension; in order to implement this expression in Matlab, it was written in non-dimensional terms, as shown in equation 5.28. The oil pressure gradient $(d p / d x)$ in the first integral was approximated using the finite differences method. 


$$
F_{v}(X)=\int_{X_{1}}^{X_{2}}\left(\frac{-H}{2} \frac{d P}{d X}-\frac{1}{H}\right) d X+\int_{X_{2}}^{X_{3}}-\hat{z} \frac{1}{H} d X
$$

With $F_{v}$ defined as:

$$
F_{v}=\frac{f_{v} h_{o}}{\eta U l}
$$

Under boundary lubrication conditions, friction depends on the interaction of the surfaces' asperities and it is modeled from two sources, as described in equation 5.30. The first source accounts for the shearing of the thin oil film absorbed by the asperity peaks, first term in this equation. This oil shearing has a non-Newtonian behavior and is function of the Eyring shear stress of the oil $\tau_{o}$ and the asperity contact area $A_{a s p}[6]$. The second source of boundary friction occurs due to the adhesive friction generated in the cold welded asperities, second term in the equation. $\zeta$ is the coefficient of asperity shear strength [25], which can be found experimentally using an Atomic Force Microscope (AFM) as it is characteristic of the specific lubricant oil and surface combination [3].

$$
f_{b}(x)=\tau_{o} A_{a s p}+\zeta F_{a s p}
$$

The asperity contact area $A_{a s p}$ can be calculated applying the Greenwood and Tripp model [9] with equation 5.31, and the statistical function $F_{2}$ from equation 5.32. This term also depends on the $\lambda$ ratio, therefore $F_{2}=0$ when the lubrication regime is purely hydrodynamic with $\lambda \geqslant 4$. The plot of this statistical function is presented in Figure 5.4 for both the numerical integration solution and its polynomial fit.

$$
\begin{gathered}
A_{a s p}=\pi^{2}\left(\sigma \beta \eta_{s}\right)^{2} A F_{2}(\lambda) \\
F_{2}(\lambda)=\frac{1}{\sqrt{2 \pi}} \int_{\lambda}^{\infty}(s-\lambda)^{2} e^{-s^{2} / 2} d s
\end{gathered}
$$

Given that the area of asperity peaks represents a very small fraction of the total contact area of the ring, the first term of equation 5.30 can be neglected [25]. Finally the total friction force $f$ can be obtained from the contribution of the viscous friction and the boundary friction as in equation 5.33 


$$
f(x)=f_{v}(x)+f_{b}(x) ;
$$

Finally, once the total instantaneous friction force is calculated, the friction power loss and FMEP can be obtained from equations 5.34 and 5.35.

$$
\begin{gathered}
P_{\text {loss }}=f(x) U \\
F M E P=\frac{1}{\omega} \frac{\int_{\text {cycle }} P_{\text {loss }} d \alpha}{V_{d}}
\end{gathered}
$$

\subsubsection{Engine oil rheology}

As previously stated in Section 5.2, the viscosity of the oil is constant thought the film thickness, however, its value is function of the oil working temperature. The pressure generated in the piston-liner interface does not affect the oil viscosity. In this way, the Vogel equation 5.36 was employed to calculate the dynamic viscosity of the oil formulation. $\eta$ is the oil dynamic viscosity at the desired temperature $T_{0}$, and $a, b$ and $c$ are constants specific to the oil that need to be determined. For this purpose, three dynamic viscosity values, measured at know temperatures, are required.

For the experimental test in the floating liner and their comparison with theoretical results from the model presented here, the viscosity of the oil entering the ring varies with the position of the ring along the stroke. To account for this viscosity variation, the temperature measured by the thermocouples installed in the cylinder liner at the TDC, BDC and midstroke (Section 4.4.1) were employed. In order to have the oil temperature along the liner length and for the complete engine cycle, a piecewise cubic hermite interpolating polynomial (PCHIP) was used to find the temperature value at each crank angle.

$$
\eta=a e^{b /\left(T_{0}-c\right)}
$$

\subsubsection{Piston compression ring and liner surface topography}

As previously mentioned in Section 5.2.3, surfaces of the piston compression ring and liner are assumed to follow a Gaussian distribution. The interaction of the asperity summits of the two surfaces results in 
contact pressures that can be estimated with the Greenwood and Trip model. According to this, the contacting surfaces consist of summits of paraboloid shape with a combined standard deviation height $\sigma$, a constant asperity average radius $\beta$, and they are uniformly distributed with a density area $\eta_{s}$. These surface parameters can be calculated from equation 5.37, 5.38 and 5.39, respectively [21]. In this Thesis, the surface parameters of the piston compression ring $\left(\sigma_{r}, \beta_{r}, \eta_{s r}\right)$ were obtained experimentally, as described in the following Section 5.2.8.1; the parameters of the liner $\left(\sigma_{l}, \beta_{l}, \eta_{s l}\right)$ however, were obtained from literature, as presented in Section 5.2.8.2.

$$
\begin{gathered}
\sigma=\sqrt{\sigma_{l}^{2}+\sigma_{r}^{2}} \\
\beta=\sqrt{\frac{\beta_{l}^{2} \beta_{r}^{2}}{\beta_{l}^{2}+\beta_{r}^{2}}} \\
\eta_{s}=\sqrt{\eta_{s l}^{2}+\eta_{s r}^{2}}
\end{gathered}
$$

\subsubsection{Piston compression ring}

For the surface characterization of the piston compression ring, a stylus profilometer, Taylor Hobson Talysurf, was employed to measure the roughness profile of the ring in the axial direction. This measurement was performed during the research stay at the University of Central Lancashire. The results are presented in Figure 5.8. The top plot (Figure 5.8a.) shows the complete roughness profile of the ring; however, for the calculation of the Greenwood and Trip parameters, only a representative section of this measurement was employed, as presented in Figure 5.8b. This procedure removed the ends of the roughness profile, as they correspond to the edges of the ring. Furthermore, as it can be seen from this figure, the curvature of the ring was removed by the usual form filter used on surface characterization, as well as the waviness filter. In the model approach, the influence of the piston compression ring profile, assumed to be parabolic (Figure 5.2 and Figure 5.16 for the parametric simulations), was accounted directly in the $h$ term of the Reynolds equation 5.1, and specifically in the term $h_{s}$ in equation 5.2.

For the Greenwood and Trip parameters, their calculation was developed following the procedure described in the work by Tomanik et al. [28], they are presented in the following Table 5.3. 


\section{a. Roughness profile}

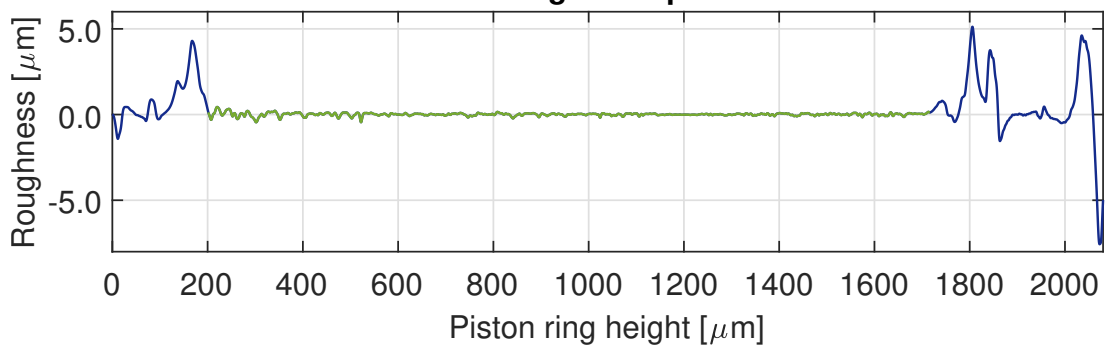

b. Section of the roughness profile

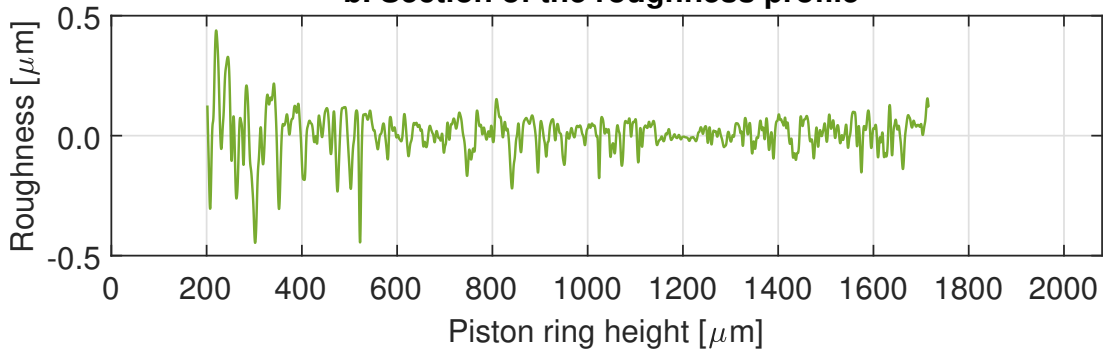

Figure 5.8. Compression ring surface roughness profile.

\begin{tabular}{|r|c|}
\hline Parameter & Value \\
\hline \hline Number of points above datum & 7473 \\
\hline Number of asperity peaks & 134 \\
\hline Mean height of asperity peaks & $0.0515 \mu \mathrm{m}$ \\
\hline Asperity height standard deviation $\sigma_{r}$ & $0.0553 \mu \mathrm{m}$ \\
\hline Asperity average radius of curvature $\beta_{r}$ & $164.54 \mu \mathrm{m}$ \\
\hline Asperity density $\eta_{s r}$ & $7.8 \mathrm{e} 91 / \mathrm{m}^{2}$ \\
\hline
\end{tabular}

Table 5.3. Surface parameters for the piston compression ring.

\subsubsection{Cylinder liner}

Figure 5.9 shows a picture of the internal surface of the liner mounted in the floating liner test rig. As it can be seen, the liner was honed with a cross-hatched texture at $50^{\circ}$ honing angle and a Ra value of $0.3 \mu \mathrm{m}$. Actual measurements of the surface topography were not possible to develop for this Thesis; therefore, it was decided to use values found in literature that could represent the liner characteristics as good as possible. Given that the Ra was 

compression ring and cylinder liner interface

the only known characteristic, this value was used to select the appropiate data from the literature; the surface parameters presented in the work by Tomanik [27] were employed. These parameters are summarized in Table 5.4.

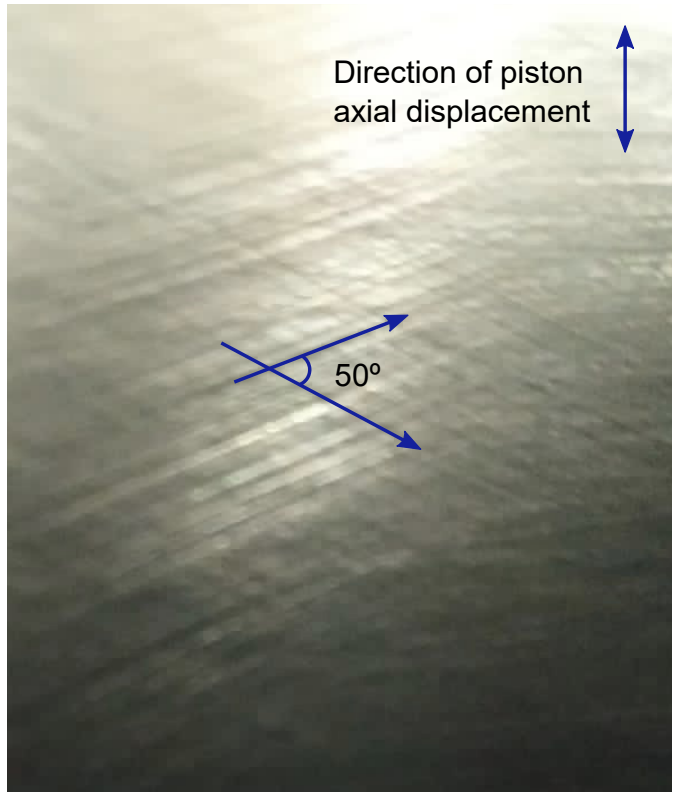

Figure 5.9. Picture of the cylinder liner surface texture.

\begin{tabular}{|r|c|}
\hline Parameter & Value \\
\hline \hline Asperity height standard deviation $\sigma_{l}$ & $0.4 \mu \mathrm{m}$ \\
\hline Asperity average radius of curvature $\beta_{l}$ & $10 \mu \mathrm{m}$ \\
\hline Asperity density $\eta_{s l}$ & $24 \mathrm{e} 91 / \mathrm{m}^{2}$ \\
\hline
\end{tabular}

Table 5.4. Surface parameters for the cylinder liner.

\subsection{Results}

This section gathers some simulation results obtained with the compression ring lubrication model. They are primarily meant to evaluate if the model responds correctly and as expected to changes in the working conditions, the oil formulation and the characteristics of the piston compression ring. For this 
purpose, simulations were developed changing the parameters listed below in Table 5.5; furthermore, these simulations were developed under both fully flooded and starved lubrication conditions with the aim of comparing these two approaches on their effect over the compression ring lubrication performance.

\begin{tabular}{|c|c|c|c|c|c|}
\hline \multirow[b]{2}{*}{ Variables } & \multicolumn{5}{|c|}{ Constants } \\
\hline & $\begin{array}{l}\text { Engine } \\
\text { speed [rpm] }\end{array}$ & Oil & $\begin{array}{l}\text { Oil temper- } \\
\text { ature }\left[{ }^{\circ} \mathrm{C}\right] \\
\text { (Constant } \\
\text { along the } \\
\text { liner) }\end{array}$ & $\begin{array}{l}\text { Compression } \\
\text { ring radius } \\
\text { of curvature } \\
{[\mathrm{mm}]}\end{array}$ & $\begin{array}{l}\text { Tangential } \\
\text { force }[\mathrm{N}]\end{array}$ \\
\hline Engine speed & $\begin{array}{l}\mathbf{5 0 0} \text { to } 3000 \\
\text { in steps of } \\
500\end{array}$ & SAE 5W30 & 60 & 30 & 17.3 \\
\hline $\begin{array}{l}\text { Oil } \\
\text { temperature }\end{array}$ & 1000 & SAE 5W30 & $40,60,80$ & 30 & 17.3 \\
\hline \multirow{4}{*}{ Oil } & \multirow{4}{*}{1500} & C1-10W40 & \multirow{4}{*}{80} & \multirow{4}{*}{30} & \multirow{4}{*}{17.3} \\
\hline & & C2-10W30 & & & \\
\hline & & C5-5W20 & & & \\
\hline & & O1-5W30 & & & \\
\hline $\begin{array}{l}\text { Compression } \\
\text { ring radius of } \\
\text { curvature }\end{array}$ & 3000 & SAE 5W30 & 60 & $\mathbf{3 0}, 60,90$ & 17.3 \\
\hline $\begin{array}{l}\text { Tangential } \\
\text { force }\end{array}$ & 1500 & SAE 5W30 & 80 & 30 & $\begin{array}{ll}7.3, & \mathbf{1 7 . 3} \\
27.3 & \end{array}$ \\
\hline
\end{tabular}

Table 5.5. Compression ring lubrication model simulation parameters. ${ }^{*}$ Parameters in bold correspond to some working conditions defined and/or evaluated experimentally in the floating liner in Chapter 6.

\subsubsection{Engine speed}

The effect of the engine speed on friction and on the MOFT of the piston compression ring was investigated for six engine speed levels at a constant oil temperature of $60^{\circ} \mathrm{C}$, a ring radius of curvature of $30 \mathrm{~mm}$, a tangential force of $17.3 \mathrm{~N}$ and the oil formulation SAE 5W30; the oil dynamic viscosity for this working temperature was previously presented in Table 5.1.

The MOFT results are presented in the following Figure 5.10 for the two lubrication conditions: first, assuming fully flooded lubrication, and second, 
introducing lubricant starvation for the whole engine cycle. Starting with the flooded lubrication condition, the MOFT increases with the engine speed according to the lubrication theory, where a higher relative velocity of the surfaces, in this case the piston speed, promotes the creation of a thicker oil film at the mid-stroke, while at the dead centers, the film thickness is determined by the squeeze effect. For the starved lubrication condition, this MOFT increase with the engine speed is very small at the mid-strokes. In these regions, lubrication of the piston compression ring is determined by the high relative speed of the surfaces and the wedge effect due to the profile of the ring; nevertheless, if the oil supply is not sufficient causing ring starvation, the oil inlet position is moved inwards the ring domain, decreasing the effective load generation region. This smaller region filled with oil needs to generate the appropriate load carrying capacity to equilibrate the applied load, for which, the film thickness decreases more than for fully flooded lubrication.

Comparing the results for fully flooded and starved lubrication from 1500 to $3000 \mathrm{rpm}$ (Figure 5.10c. to 5.10f.) at the dead centers, it can be seen that the film thickness is lower for starved lubrication conditions, possibly leading to asperity contact and therefore to boundary friction. At the dead centers, lubrication of the piston compression ring, and specifically the film thickness, is no longer determined by the wedge effect, due to the small entrainment velocities, but by the squeeze effect arising from the approach of the two surfaces. The difference found in the MOFT at the dead centers between the fully flooded and the starved lubrication conditions is the result of the oil availability, which is determined by the flow continuity condition for the starved lubrication approach.

Results for the friction losses are presented in Figure 5.11 for fully flooded and starved lubrication conditions. As it can be seen, the increase of the engine speed is directly proportional to the friction force under hydrodynamic lubrication conditions, that is, at the mid-stroke regions. As previously mentioned in the MOFT results, the engine speed and the wedge effect help to generate a thicker oil film and therefore, the shear rate is increased proportionally, resulting in higher viscous friction. The opposite occurs at the dead centers, lower engine speeds result in smaller film thicknesses, increasing the possibility that mixed and boundary friction appear, as can be observed for 500 and $1000 \mathrm{rpm}$ (Figure 5.11a. and 5.11 b.). From $1500 \mathrm{rpm}$ to $3000 \mathrm{rpm}$, boundary friction is almost inexistent due to the thicker oil films (Figure 5.10c. to $5.10 \mathrm{f}$.) generated by the squeeze oil effect.

In these results, it is interesting to highlight the importance of including lubricant starvation to the analysis of the piston compression ring lubrication; 

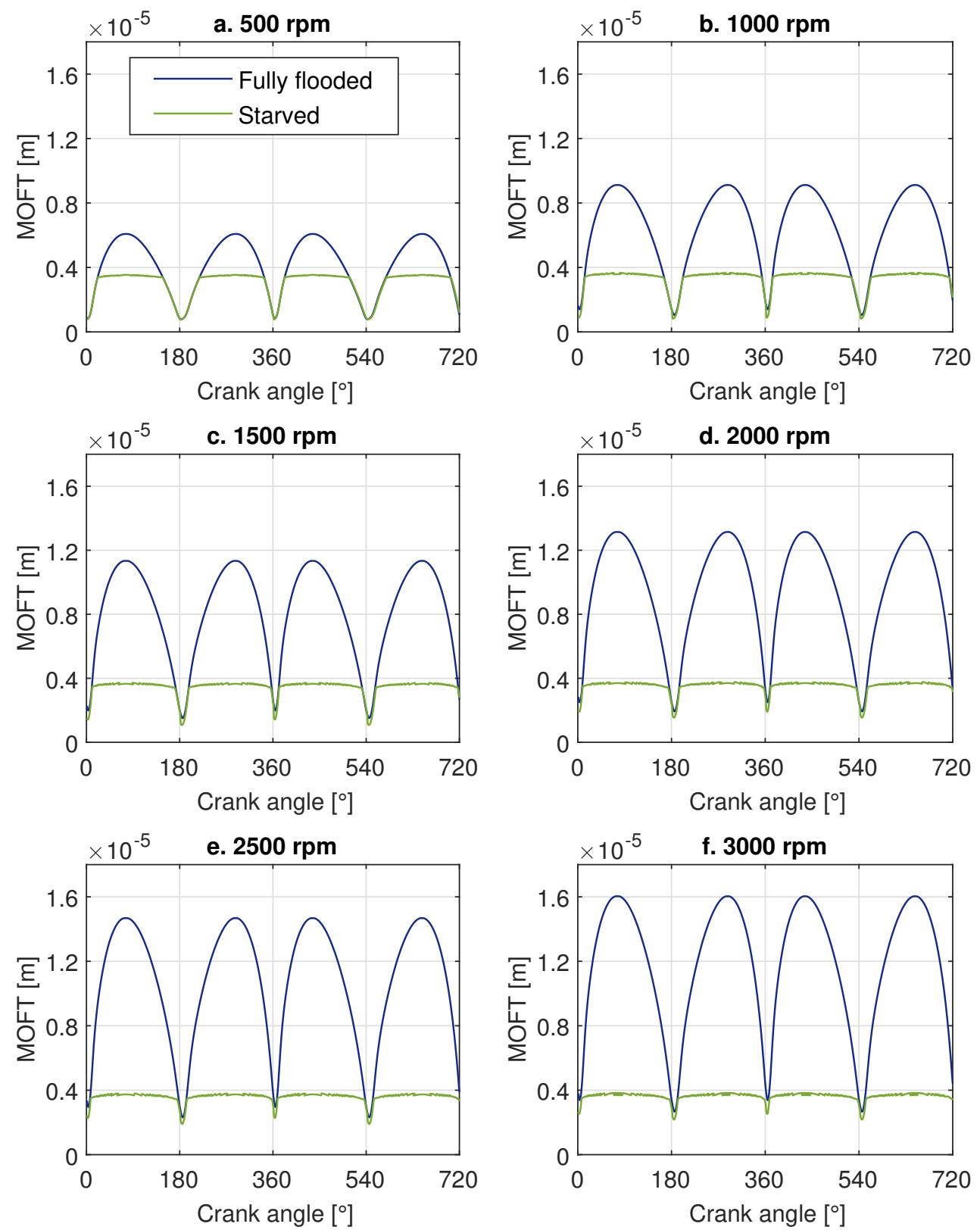

Figure 5.10. MOFT variation with engine speed at constant oil temperature of $60^{\circ} \mathrm{C}$. 
as it can be seen from Figure 5.10 and 5.11, the lubricant available to the ring inlet determines the film thickness between the moving surfaces and therefore the friction losses, specially at the mid-stroke regions. In Figure 5.11, the friction force greatly increases under starved conditions in comparison with the full flooded assumption, although the MOFT is significantly smaller at the mid-stroke. Under the same working conditions, this situation can be explained looking at the expression (Equation 5.27) to calculate friction under hydrodynamic lubrication regime: at the mid-stroke regions and for purely hydrodynamic conditions, the resultant friction force comes from the shearing of the oil film, term $(\eta U / h)[31]$; in this way, if the oil viscosity $\eta$ and velocity $U$ are the same for fully flooded and starved lubrication, the film thickness would determine the friction in this region. Since the film thickness term $h$ is inverse to the viscous friction $f_{v}$, a thinner oil film thickness results in higher viscous friction losses. Simulations comparing the effect of including ring starvation versus fully flooded lubrication on the friction losses and MOFT of a complete ring pack have been previously reported in $[12,30]$, and for the piston compression ring specifically in $[10,19]$.

\subsubsection{Oil temperature}

The effect of the oil temperature on the MOFT and the friction losses of the piston compression ring were evaluated through the dynamic viscosity of the oil formulation; for these tests, the selected oil is the SAE 5W30 used in the previous section. The oil dynamic viscosity at the evaluated temperatures $\left(40,60\right.$ and $\left.80^{\circ} \mathrm{C}\right)$ are presented in Table 5.1. Furthermore, the oil temperature and viscosity was considered constant along the cylinder liner length and throughout the whole engine cycle.

Results for the MOFT are presented in Figure 5.12; as expected, lower oil temperatures, higher oil viscosity, resulted in a thicker oil film. This performance is clearly seen for fully flooded lubrication: at $40^{\circ} \mathrm{C}$ the maximum film thickness at mid-stroke is of about $13 \mu \mathrm{m}$ while at $80^{\circ} \mathrm{C}$, the maximum MOFT is halved to about $6 \mu \mathrm{m}$ at the same location. When the piston reaches the vicinity of the dead centers, given that the oil viscosity determines the film thickness, a higher oil temperature means a smaller film thickness, which in conjunction with the deceleration of the piston, promotes the appearance of mixed and boundary lubrication; this condition is observed for both fully flooded and starved lubrication. The effect of lower MOFT at higher oil temperatures is further observed in the friction force results of Figure 5.13; at $60^{\circ} \mathrm{C}$ boundary lubrication was obtained at the dead centers, and specially for the starved lubrication condition with a major presence at the TDC 

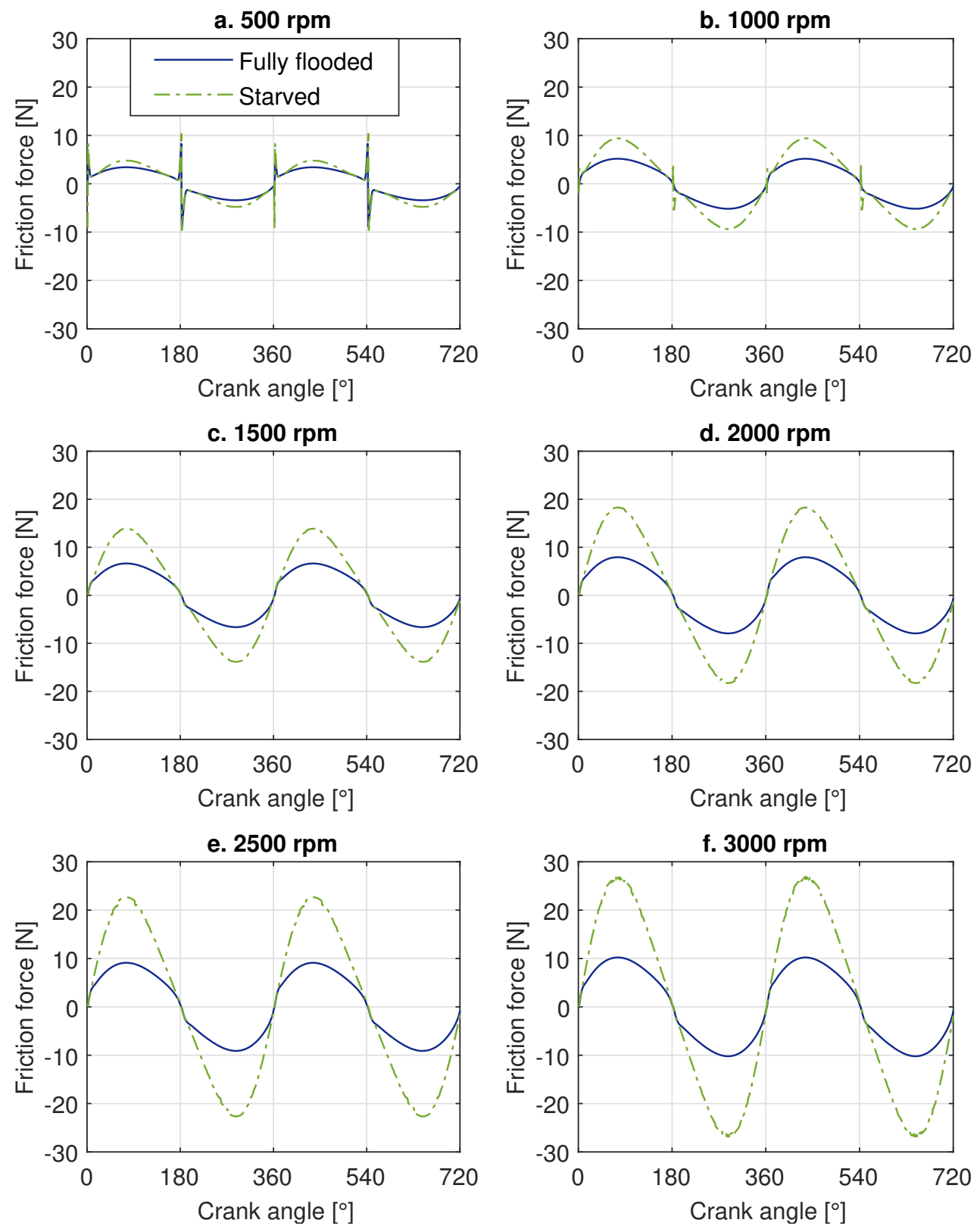

Figure 5.11. Friction force variation with engine speed at constant oil temperature of $60^{\circ} \mathrm{C}$. 
5. Theoretical model to estimate the friction losses in the piston compression ring and cylinder liner interface

locations, which corresponds with the smaller film thicknesses obtained under this lubrication condition in comparison with the fully flooded lubrication. Increasing the oil temperature to $80^{\circ} \mathrm{C}$ further increased boundary friction for both lubrication conditions.
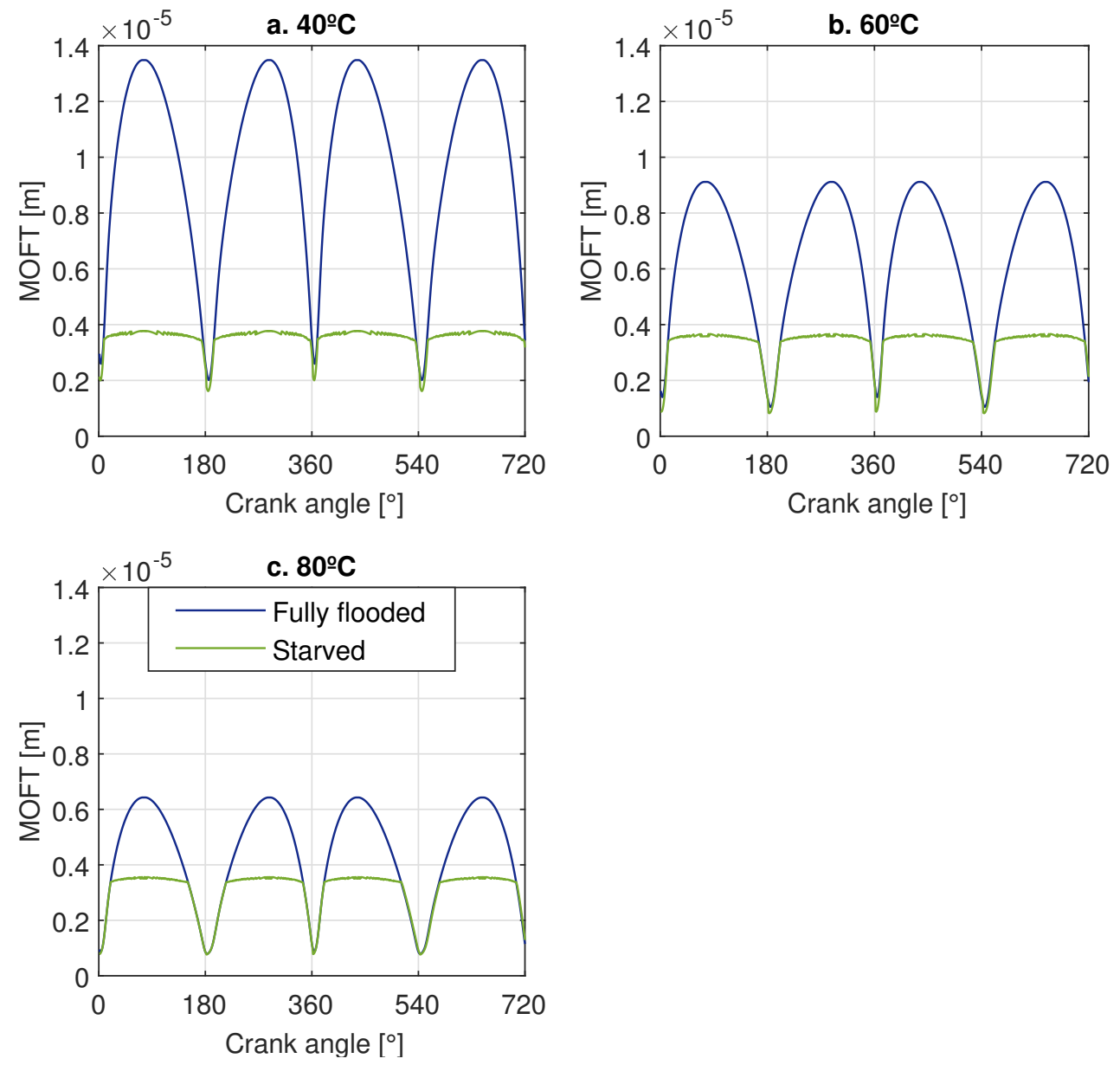

Figure 5.12. MOFT variation with oil temperature at constant engine speed of 1000 rpm.

For fully flooded lubrication and at the mid-stroke regions, the MOFT variation with temperature is significant in comparison with the results for starved lubrication; however, the opposite occurs for the friction force, its variation with the oil temperature is more pronounced for starved lubrication. This indicates that at mid-stroke, under pure hydrodynamic lubrication, the working temperature of the oil and its corresponding viscosity plays a 
determining role in the friction loses of the piston compression ring. A low viscosity oil formulation and the appropriate supply of oil would be desired to find a balance between reduced friction losses and wear protection.
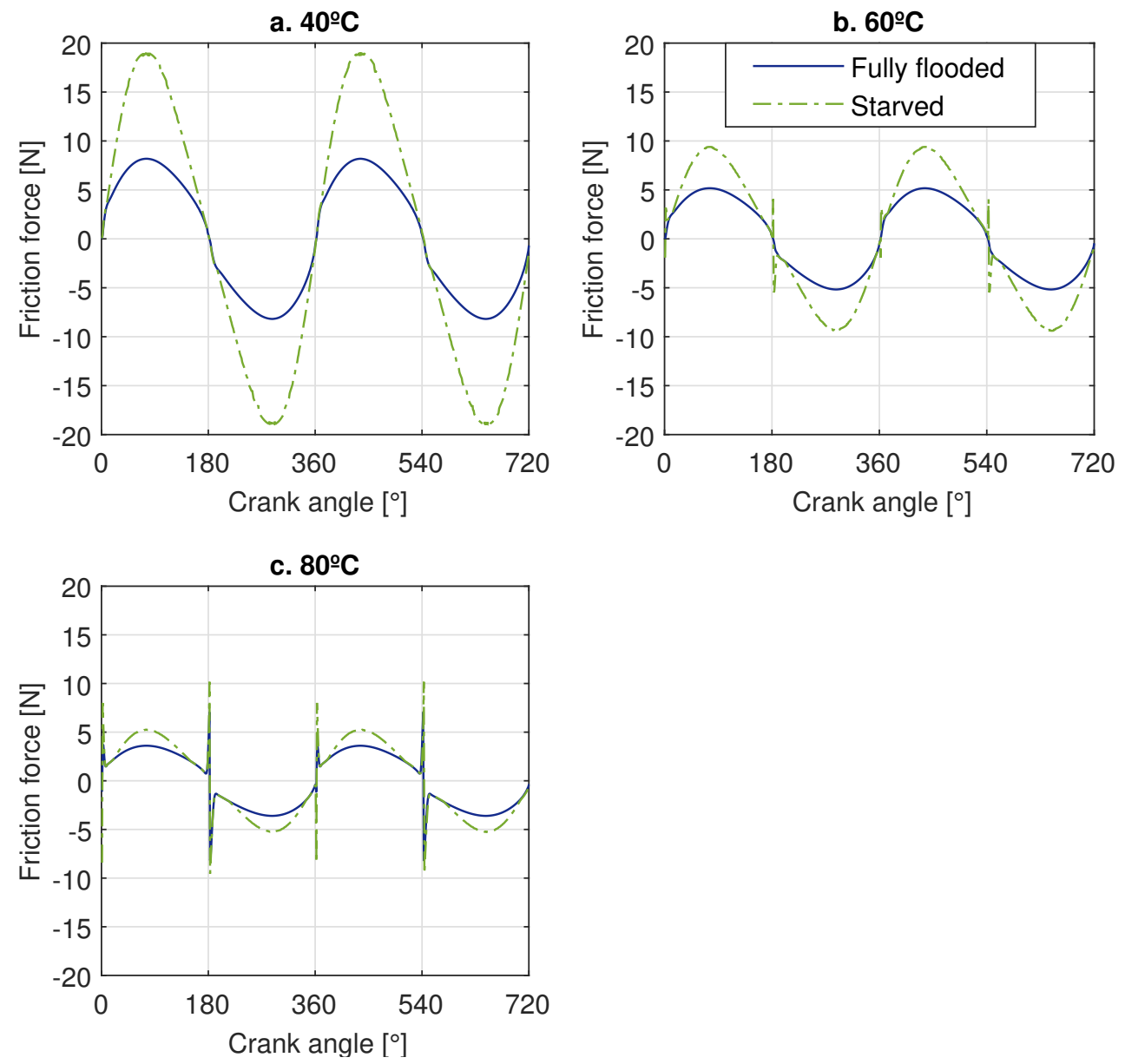

Figure 5.13. Friction force variation with oil temperature at constant engine speed of $1000 \mathrm{rpm}$.

\subsubsection{Oil formulation}

The lubricant oil formulation plays a key role in the tribological performance of the piston compression ring, specially under hydrodynamic lubrication, where the shearing of the oil film and therefore, the oil viscosity determines the resultant friction losses. Under mixed and boundary 
lubrication, the oil formulation can also contribute to the reduction of friction losses, in this situation, through the use of additives such as friction modifiers. In the compression ring model presented here, the effect of using different oil formulations over the MOFT and friction losses was evaluated for oils of different viscosity values at the same working temperature. The oil formulations selected for this analysis, SAE 10W40, SAE 10W30 and SAE $5 \mathrm{~W} 20$, correspond to some oils ( $\mathrm{C} 1, \mathrm{C} 2$, and $\mathrm{C} 5$, respectively) evaluated in the engine bench tests of Chapter 3, and the oil SAE 5W30 (O1) employed in the previous sections. The dynamic viscosity of these formulations at $80^{\circ} \mathrm{C}$ is presented in the following Table 5.6; simulations with the compression ring model were run for the corresponding oil viscosity, constant throughout the engine cycle, and under the same engine speed of $1500 \mathrm{rpm}$.

\begin{tabular}{|r|c|}
\hline Oil formulation & Dynamic viscosity [mPa.s] \\
\hline \hline C1-10W40 & 17.25 \\
\hline C2-10W30 & 12.52 \\
\hline C5-5W20 & 10.12 \\
\hline O1-5W30 & 14.62 \\
\hline
\end{tabular}

Table 5.6. Dynamic viscosity of the oil formulations used in the simulations.

As in the previous Section 5.3.2, the MOFT and friction losses variation was evaluated as function of the oil dynamic viscosity, in this section, through the use of different oil formulations with their corresponding viscosity at the defined temperature. The MOFT and friction losses results are presented in Figure 5.14 and 5.15, respectively. In addition to the analysis presented in the previous section for the viscosity-friction losses relation, these results highlight the potential of the oil formulation to contribute to the reduction of the friction mechanical losses, but also the increased probability of mixed/boundary lubrication and associated wear. The oil C5-5W20 with the lowest viscosity, Figure 5.15c., contributed significantly to the friction losses reduction at the mid-stroke regions; while at the dead centers, its viscosity and resultant film thickness were not sufficient to separate the moving surfaces with the consequent appearance of greater boundary friction. Nevertheless, this oil formulation yielded the lowest FMEP for the whole engine cycle, as shown in Table 5.7. On the other hand, in the friction force results of Figure 5.15a., it can be observed that the oil C1-10W40 with higher viscosity, presented higher viscous friction, specially under starved lubrication, but also yielded lower boundary friction due to the viscosity contribution to a thicker oil film 
(Figure 5.14a.). Given that friction in the hydrodynamic region had a major contribution to the overall losses, this oil formulation had the greatest FMEP, as presented in Table 5.7.
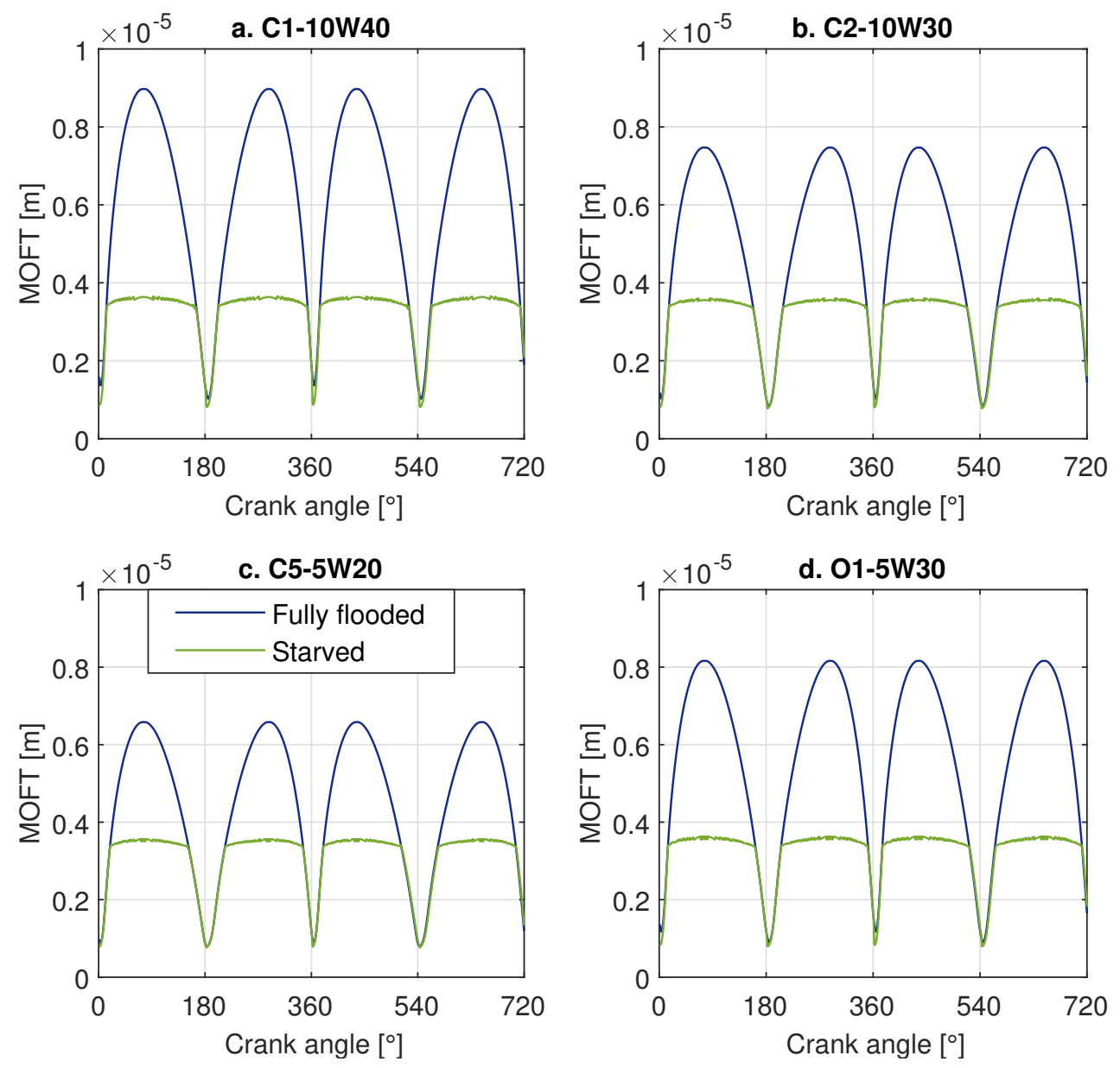

Figure 5.14. MOFT variation with the engine oil formulation at constant engine speed of $1500 \mathrm{rpm}$ and temperature of $80^{\circ} \mathrm{C}$.

\subsubsection{Piston ring radius of curvature}

In this section, a design feature of the piston compression ring was varied in order to investigate its effect on the lubrication performance of the ring. For this purpose, the radius of curvature of the rectangular compression ring 
5. Theoretical model to estimate the friction losses in the piston compression ring and cylinder liner interface
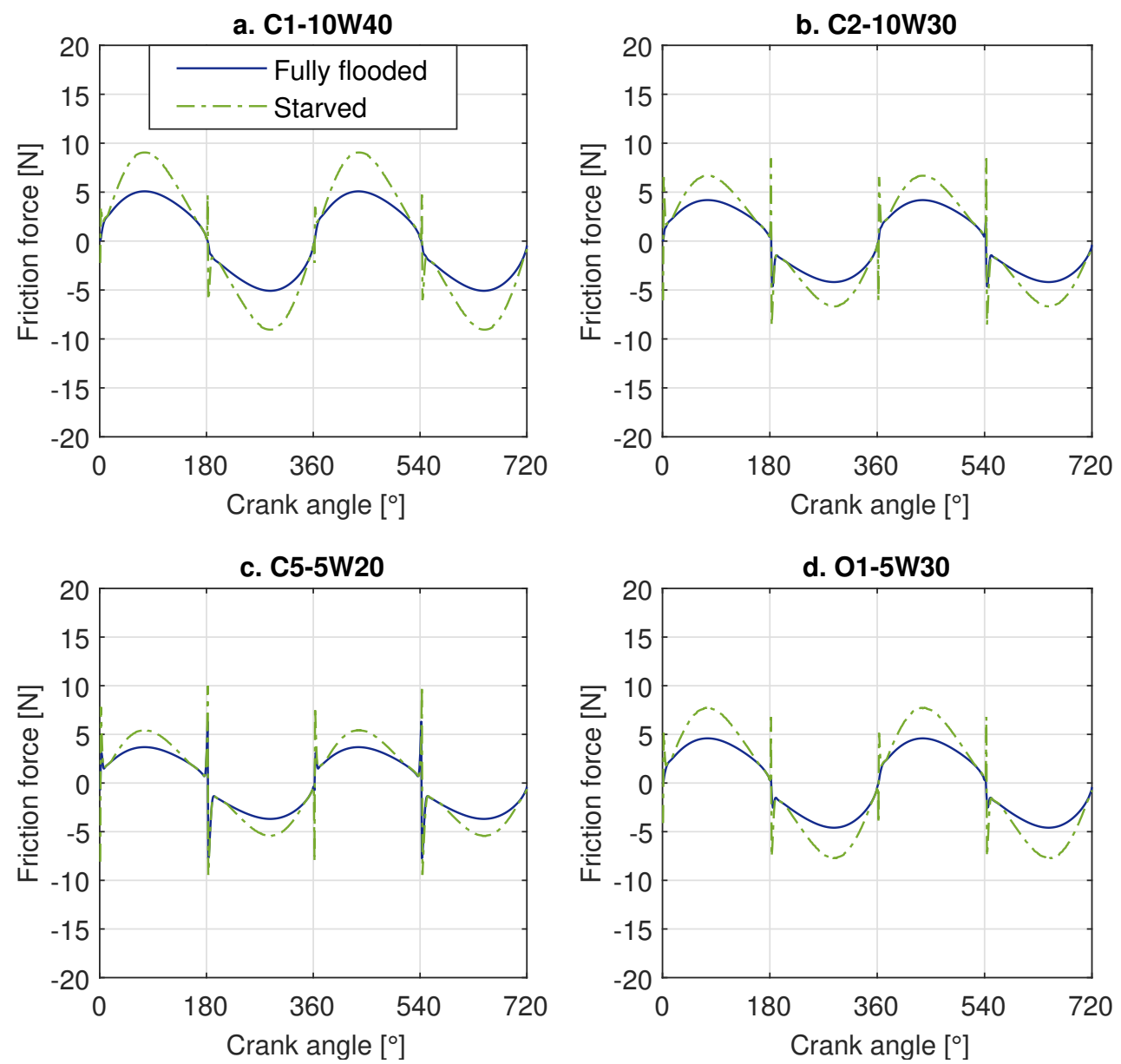

Figure 5.15. Friction force variation with the engine oil formulation at constant engine speed of $1500 \mathrm{rpm}$ and temperature of $80^{\circ} \mathrm{C}$.

\begin{tabular}{|r|c|c|}
\hline Oil formulation & Fully flooded FMEP $[\mathrm{kPa}]$ & Starved FMEP $[\mathrm{kPa}]$ \\
\hline \hline C1-10W40 & 2.59 & 4.32 \\
\hline C2-10W30 & 2.13 & 3.18 \\
\hline C5-5W20 & 1.81 & 2.60 \\
\hline O1-5W30 & 2.34 & 3.68 \\
\hline
\end{tabular}

Table 5.7. FMEP variation as function of the oil formulation for fully flooded and starved lubrication conditions. 
was set for three levels: 30,60 and $90 \mathrm{~mm}$. The corresponding piston ring profiles are presented in the following Figure 5.16.

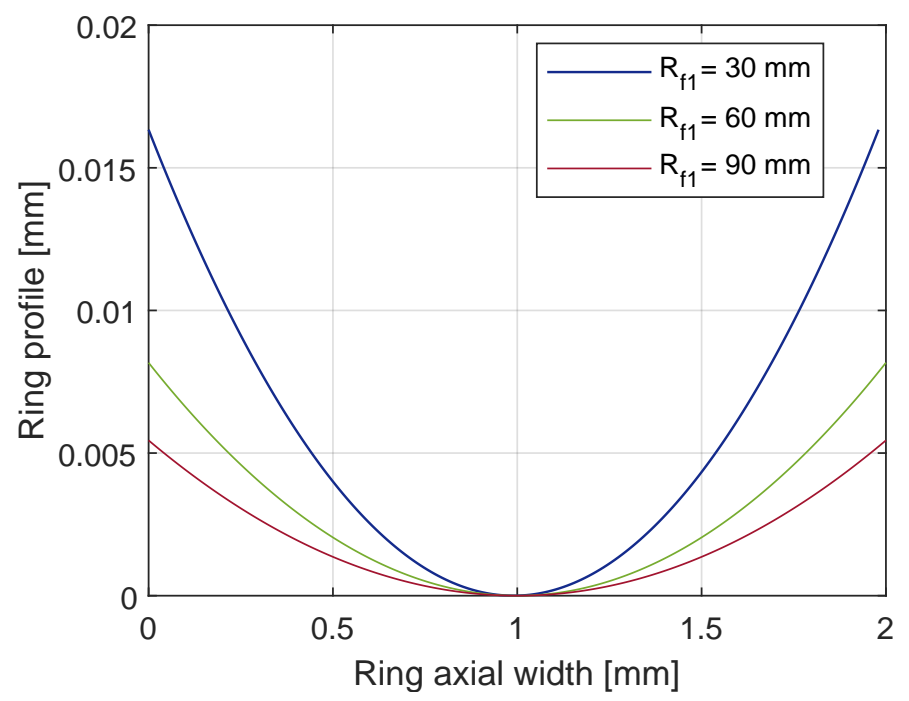

Figure 5.16. Parabolic profile of the compression ring for different values of curvature radius $R_{f 1} .{ }^{*} R_{f 1}=30 \mathrm{~mm}$ is the curvature radius of the piston compression ring employed in the experimental tests in the floating liner for Chapter 6 .

From this previous figure, it can be seen that increasing the radius of curvature makes the ring profile to flatten, which has a significant impact on the wedge effect and therefore, on the lubrication conditions of the ring. For the compression ring with the smallest radius of curvature, $R_{f 1}=30 \mathrm{~mm}$, the heigh of the axial profile is bigger and thus, it is the wedge formed by the two moving surfaces, ring and liner. Given that, for the analysis presented in this section, the engine speed and oil viscosity are the same, the wedge effect is the only variable to contribute to the oil film formation. In this way, the piston ring with smaller radius of curvature presented the thicker MOFT at the mid-stroke regions, as can be observed in Figure 5.17a for fully flooded lubrication. At the dead centers, this performance is inverted as the oil film formation does not longer rely on the wedge effect, but on the squeeze of the oil film. With the piston ring of greater radius of curvature, $R_{f 1}=90 \mathrm{~mm}$, there is a major parallel region between the ring and liner surfaces, which favors the squeeze of the oil film, the load carrying capacity and therefore, resulting in a thicker oil film. This MOFT and radius of curvature relation was also reported by Taylor [24] for a top compression ring of $R_{f 1}=50,100$, 
200 and $400 \mathrm{~mm}$, under fully flooded lubrication conditions and two engine speed levels, 1000 and $2500 \mathrm{rpm}$.

The friction losses results under fully flooded lubrication are shown in Figure 5.18a., where the flatter piston ring, $R_{f 1}=90 \mathrm{~mm}$, presented the highest viscous friction at the mid-stroke regions. This result is in accordance with the MOFT developed by the piston ring profile (Figure 5.18a.).
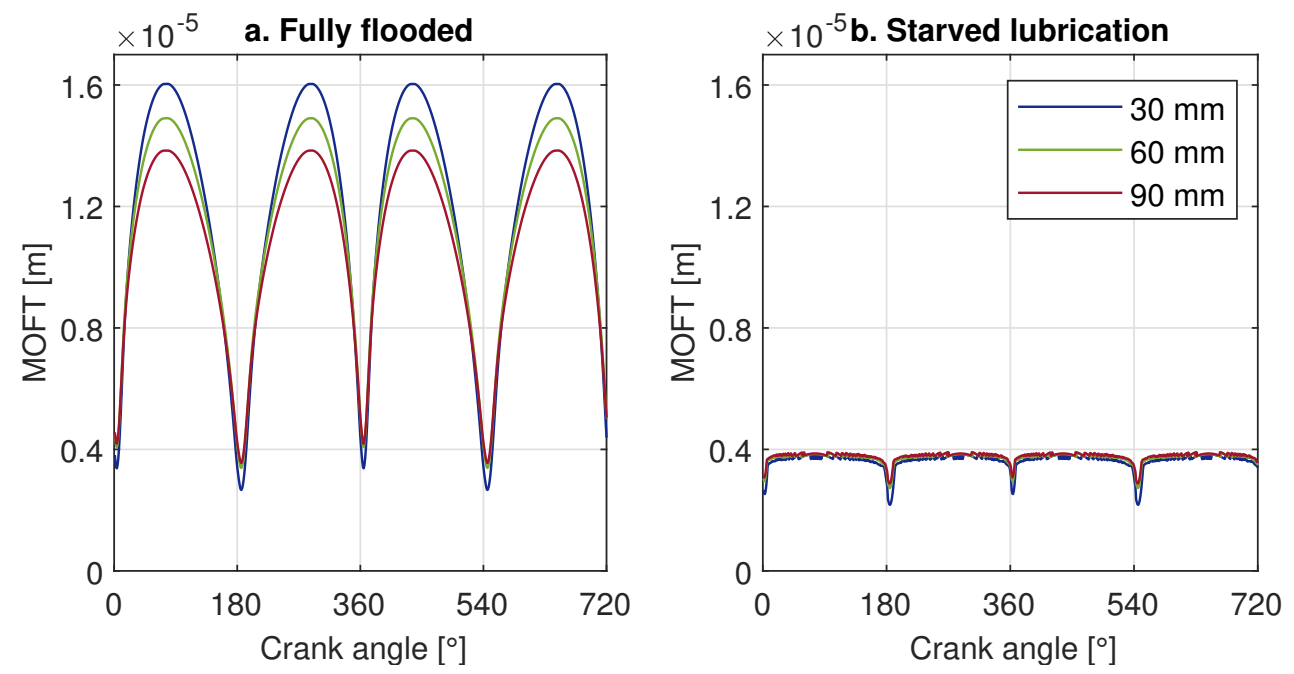

Figure 5.17. MOFT variation with the piston ring radius of curvature at constant engine speed of $3000 \mathrm{rpm}$ and temperature of $60^{\circ} \mathrm{C}$.

For the starved lubrication conditions, Figure $5.17 \mathrm{~b}$, the MOFT and radius of curvature relation was found to be opposite to the results under flooded lubrication at the mid-stroke regions. Although the differences in the film thickness are very small, the flatter ring presented a thicker film along the engine cycle; results that are in accordance with those presented by Overgaard et al. [19], where a comparison of the MOFT under fully flooded and starved lubrication conditions was also presented and discussed for the piston compression ring. This MOFT behavior with the radius of curvature can be explained looking at the effect that starved lubrication has over the wetted length of the ring. For a ring with small radius of curvature, high axial profile, lubricant starvation can have a major effect reducing the wetted area of the ring and thus, the effective load region, which then results in a thinner oil film. Results of the corresponding friction losses are presented in Figure 5.18. As for the fully flooded lubrication condition, the ring of greater radius of curvature, resulted in major viscous friction. 

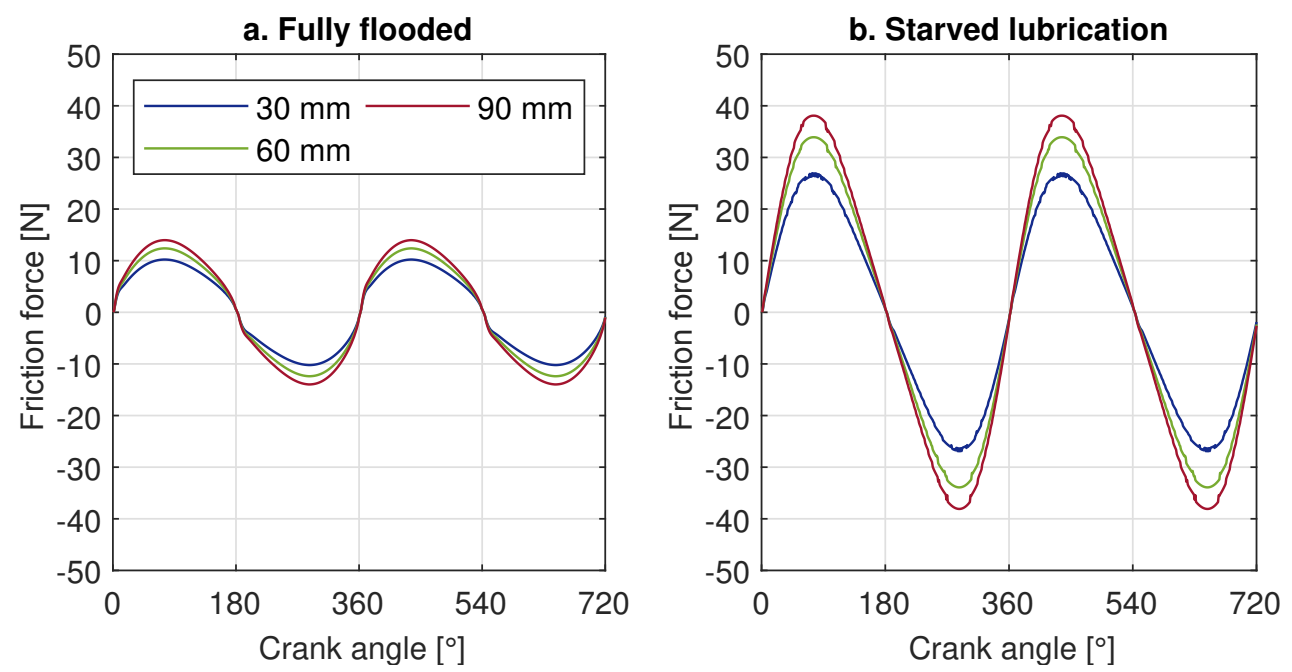

Figure 5.18. Friction force variation with the piston ring radius of curvature at constant engine speed of $3000 \mathrm{rpm}$ and temperature of $60^{\circ} \mathrm{C}$.

\subsubsection{Piston ring tangential force}

The tangential force is a design feature of the piston rings that determines the contact pressure exerted by the ring to the cylinder liner internal wall, as described previously in Section 5.2.3, equation 5.15. For the compression ring, the primary function of the tension force is to provide the appropriate sealing of the combustion chamber, while reducing the oil leakage to the chamber, or oil consumption. In the case of the oil control ring, the tangential force or its corresponding contact pressure, will determine the scrapping capacity of the ring, that is, the oil left by the ring on the liner wall after its passage, corresponding to the oil available to the rest of the ring pack. This design parameter has a direct impact over the lubrication conditions of the ring, the oil film thickness and on the generated friction losses [8]. In the model presented here, the force applied to the back of the ring only comes from the tangential force, determining the minimum film thickness and in turn the friction generated in the interface. In this way, reducing the tangential force of the piston compression ring would contribute to the generation of a thicker oil film with less probability of mixed/boundary lubrication at the dead centers; the drawback however, would be reducing the sealing of the combustion chamber, affecting the combustion efficiency and oil consumption.

In order to evaluate the effect of different tangential forces on the MOFT and friction losses of the piston compression ring, three levels were selected 
5. Theoretical model to estimate the friction losses in the piston compression ring and cylinder liner interface

to be simulated in the model, $F t=7.3,17.3$ and $27.3 \mathrm{~N}$; these tangential force levels include the one corresponding to the compression ring mounted in the floating liner and that has been used in the analysis of the previous sections. Simulations were run at $1500 \mathrm{rpm}$, oil temperature of $80^{\circ} \mathrm{C}$, the corresponding dynamic viscosity of the SAE 5W30 oil (Table 5.1), and a ring radius of curvature of $30 \mathrm{~mm}$.

The MOFT results are shown in Figure 5.19, and the corresponding friction losses in Figure 5.20. As described in the first paragraph, the effect of a higher tangential force is directly seen in the reduction of the minimum oil film thickness along the engine cycle for both fully flooded and starved lubrication conditions. This effect is also seen in the generated friction force, specially at the dead centers and under starved lubrication, where the tangential force is crucial in the reduction of boundary and mixed lubrication.

\subsection{Discussion}

In this chapter a lubrication model was developed and implemented for the piston compression ring of ICEs, this with the main objective of complementing the development of the floating liner test rig, presented in Chapter 4, and compare the simulation results with the experimental tests, as presented in Chapter 6. The model included the calculation of the friction losses under hydrodynamic lubrication, through the solution of the Reynolds equation, and the asperity interaction applying the Greenwood and Tripp model; it also included two approaches for the oil availability, fully flooded and starved lubrication conditions.

Results varying different parameters and comparing these two approaches, fully flooded and starved lubrication, showed significant differences between the two lubrication conditions, specifically in terms of film thickness and friction losses. For this model, the oil availability was estimated from the flow continuity condition applied to the compression ring only; however, this condition is not entirely representative of a piston-cylinder assembly in an ICE, where the oil available to the compression ring is determined by the lubrication condition of the other rings in the pack, specially the OCR. The inclusion of the scraper ring and OCR to the simulation model is one of the proposed future works in Chapter 7.1.

Finally, the simulations carried out under different parameters, as summarized in Table 5.5, helped to perform a fundamental analysis of the friction force generation in the compression ring-liner interface, to identify the 

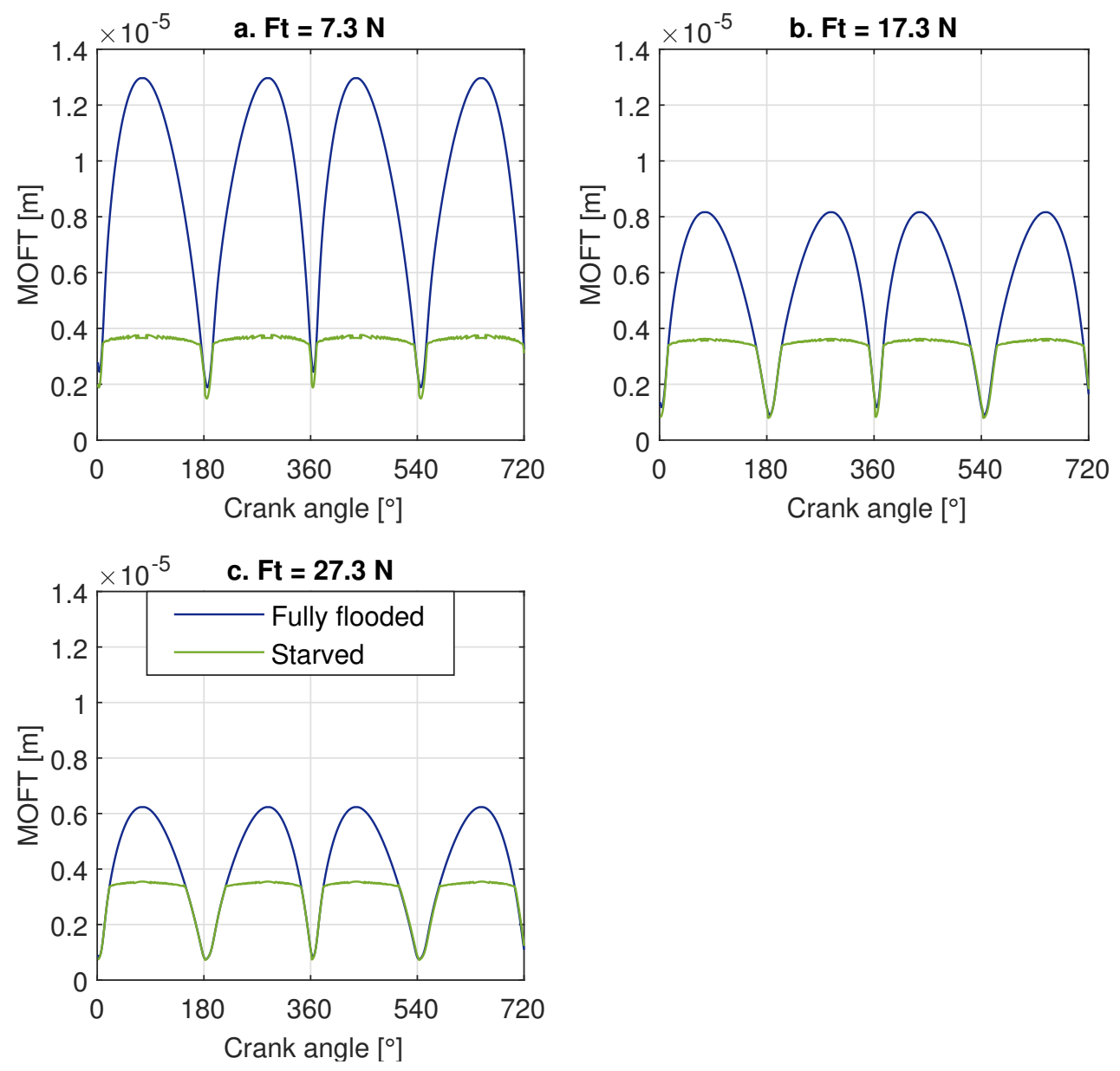

Figure 5.19. MOFT variation with the ring tangential force at constant engine speed of $1500 \mathrm{rpm}$ and temperature of $80^{\circ} \mathrm{C}$.

lubrication regimes along the engine working cycle and to investigate the effect of these parameters on the resultant friction losses, which constitutes one of the main objectives of the Thesis. 

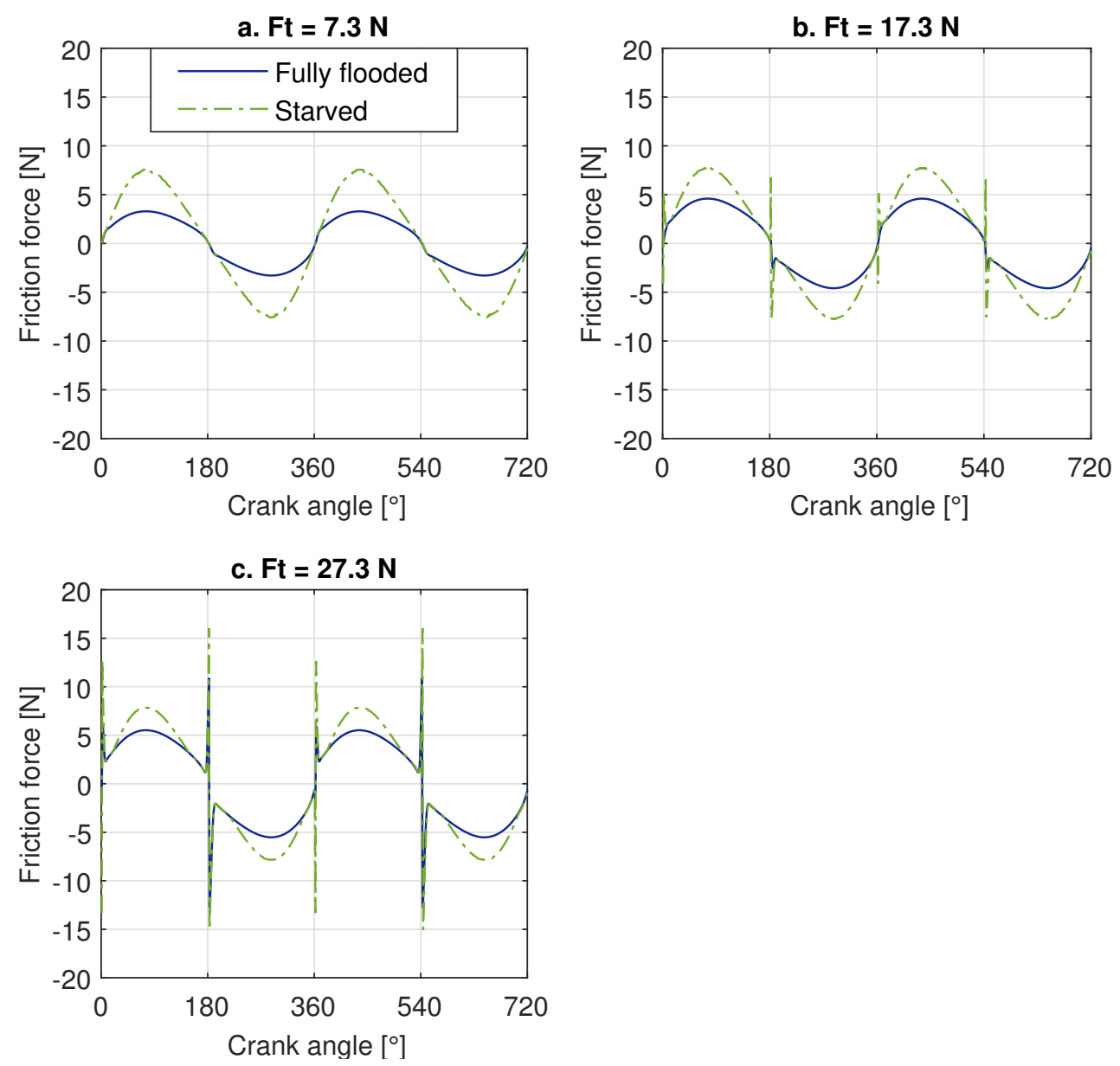

Figure 5.20. Friction force variation with the ring tangential force at constant engine speed of $1500 \mathrm{rpm}$ and temperature of $80^{\circ} \mathrm{C}$. 


\section{A Verification of the oil pressure distribution on an inclined pad}

In order to verify the pressure distribution calculation using the finite differences method, a slider bearing with an inclined pad geometry was used as shown in Figure 5.21. In this one-dimensional geometry, the inclined pad is fixed and the horizontal surface moves with velocity $U$. The oil enters to the interface at location $X=0$ with a film thickness defined by $h_{i n}$, and leaves at location $X=l$ with a film thickness $h_{o}$. The ratio of oil film thickness at the inlet and outlet of the pad is represented by $H$.

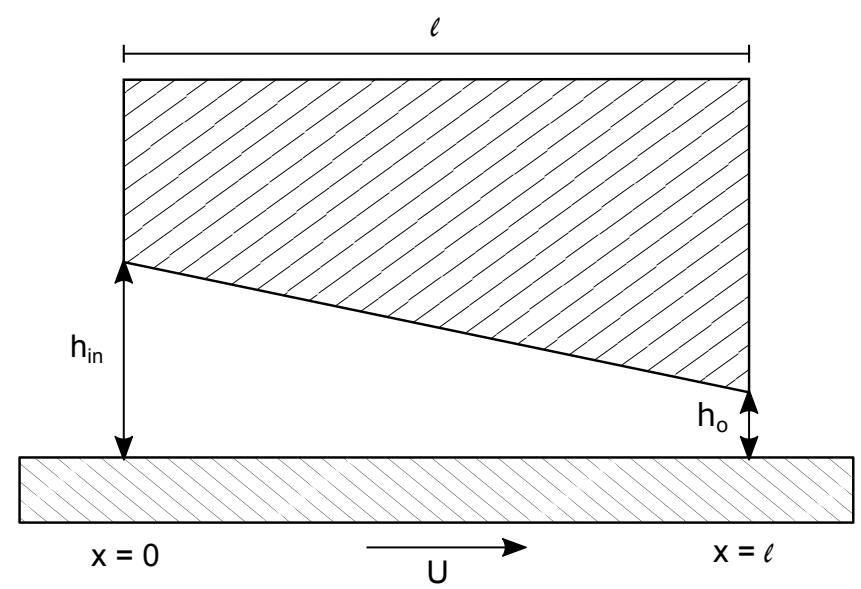

Figure 5.21. Geometry of a slider bearing with inclined pad.

For the geometry of Figure 5.21, the oil film thickness is defined with equation 5.40:

$$
h=\frac{h_{\text {in }}-h_{o}}{l} l-x+h_{o}
$$

Which can be expressed in non-dimensional terms as follows:

$$
H=H_{i n}-H_{i n} X+X
$$

The wedge formed by the inclined geometry, and the oil dragged into the interface by the moving surface, creates a pressure in the oil film, which tries to flow through the exit of the interface. This oil pressure distribution was 

compression ring and cylinder liner interface

found with the non-dimensional Reynolds equation in finite differences form (equation 5.8); in this case however, given that the squeeze term was not included in the studies taken as reference $[4,7,20]$, pressure at the node $i$ was found with equation 5.42 :

$$
P_{i}=\frac{H_{i+1 / 2}^{3} P_{i+1}+H_{i-1 / 2}^{3} P_{i-1}-6 \delta X\left(H_{i+1 / 2}-H_{i-1 / 2}\right)}{\left(H_{i+1 / 2}^{3}+H_{i-1 / 2}^{3}\right)}
$$

Although the analysis presented here was developed in non-dimensional terms, the input parameters for the model written in Matlab are presented in Table 5.8.

\begin{tabular}{|r|c|c|}
\hline Parameter & Nomenclature & Value \\
\hline \hline Inclined pad length & 1 & $2 \mathrm{~mm}$ \\
\hline Pressure tolerance & $\epsilon_{P}$ & $5 \times 10^{-5}$ \\
\hline Number of nodes & $n$ & 200 \\
\hline Velocity & $\mathrm{U}$ & $14.8 \mathrm{~m} / \mathrm{s}$ \\
\hline Lubricant oil & - & SAE $5 \mathrm{~W} 30$ \\
\hline Oil temperature & - & $60^{\circ}$ \\
\hline Oil dynamic viscosity at $60^{\circ} \mathrm{C}$ & - & $26.70 \mathrm{mPa} . \mathrm{s}$ \\
\hline
\end{tabular}

Table 5.8. Data used for the inclined pad bearing lubrication model.

The oil pressure distribution was calculated from equation 5.42 in the same way as the piston compression ring model, described in Section 5.2.2, and employing equation 5.9 until convergence was achieved. The oil pressure distribution was obtained for different values of $H$ ranging from 1 to 6 , some of these results are plotted in Figure 5.22a. Figure 5.22b. shows the results obtained by Frêne et al. [7] for $H=1.2,2.2$ and 6 .

Once the oil pressure distribution was obtained, the load carrying capacity in non-dimensional terms was calculated as the integral of the pressure curve along the domain of the inclined pad with equation 5.43. These results are presented in Figure 5.23a. Figure 5.23b. is an image of the results obtained by Pinkus and Sternlicht [20] for an inclined pad with values of $H$ equal to 1 to 5 .

$$
F z_{n}=\int_{X=0}^{X=1} P d X
$$




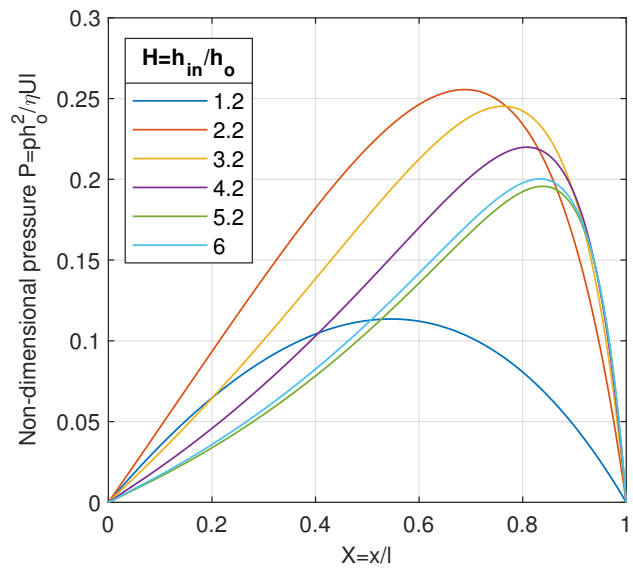

(a)

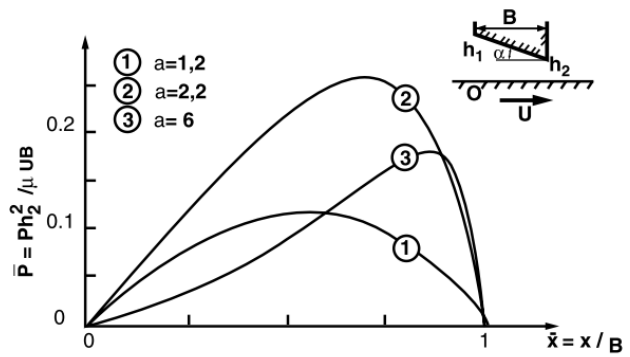

(b)

Figure 5.22. Oil pressure distribution of an inclined pad slider bearing for different values of $H$. a. Own results. b. Results from literature $\left(a=h_{1} / h_{2}\right)$, image taken from [4].

Results of oil pressure distribution and load carrying capacity obtained using the finite differences method showed good agreement with data found in literature. For the pressure distribution, Figure 5.22a., the maximum pressure value was found for $H=2.2$, which corresponds to the results found by Frêne et al. [7] in Figure 5.22b. This $H$ ratio also corresponds to the maximum load carrying capacity that can be obtained with an inclined pad slider bearing. $F z_{n}$ was found to be equal to 0.1601 (Figure 5.23a.), while Pinkus and Sternlicht [20] found this value to be 0.1602 (Figure 5.23).

\section{Bibliography}

[1] M. Ahmed, H. Xianjun, R. Fiifi, and M. Ezzat. An analytical study of tribological parameters between piston ring and cylinder liner in internal combustion engines. Proceedings of the Institution of Mechanical Engineers, Part K: Journal of Multi-body Dynamics, 230(4):329-349, 2016. doi:10.1177/1464419315605922.

[2] C. Arcoumanis, P. Ostovar, and R. Mortier. Mixed lubrication modelling of newtonian and shear thinning liquids in a piston-ring configuration. In International Fuels 86 Lubricants Meeting $\&$ Exposition. SAE International, 10 1997. doi:10.4271/972924.

[3] S. R. Bewsher, M. Leighton, M. Mohammadpour, H. Rahnejat, G. Offner, and O. Knaus. Boundary friction characterisation of a used cylinder liner subject to fired engine conditions and surface deposition. Tribology International, 131:424 - 437, 2019. doi:10.1016/j.triboint.2018.11.005. 


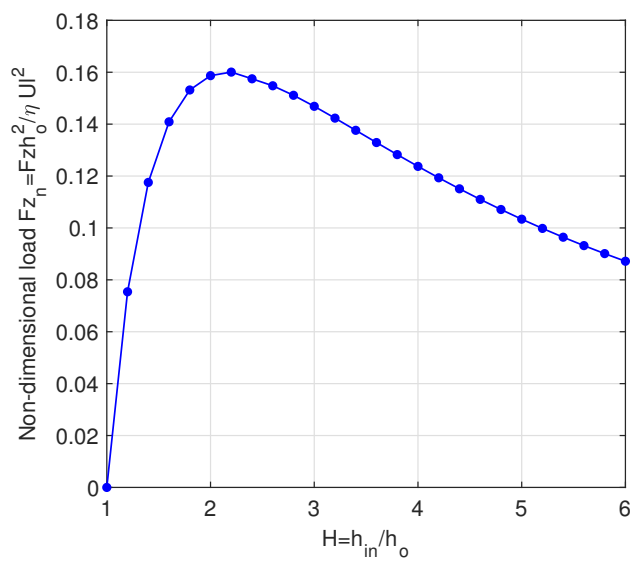

(a)

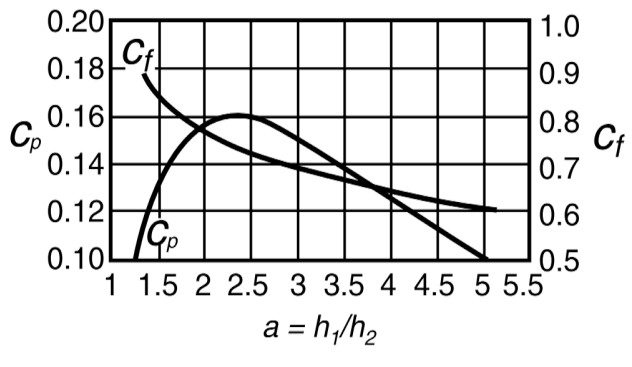

(b)

Figure 5.23. Load carrying capacity on an inclined pad for different ratios of $H$. a. Own results. $b$. Results from literature, $C_{p}=$ load carrying capacity, image taken from [4].

[4] D. E. Brewe. Slider Bearings. In Bharat Bhushan, editor, Modern Tribology Handbook: Volume One: Principles of Tribology, volume 1, pages 969-1039. CRC Press, 2000.

[5] D. Dowson, G. R. Higginson, J. F. Archard, and A. W. Crook. Elasto-hydrodynamic lubrication: international series on materials science and technology. Pergamon Press, 1977.

[6] H. Eyring. Viscosity, plasticity, and diffusion as examples of absolute reaction rates. The Journal of chemical physics, 4(4):283-291, 1936.

[7] J. Frêne, D. Nicolas, B. Degueurce, D. Berthe, and M. Godet. Chapter 3 general equations in hydrodynamic lubrication with a newtonian fluid. In D. Dowson, editor, Hydrodynamic Lubrication, pages 47 - 86. Elsevier, 1990. doi:10.1016/ S0167-8922 (97) 80060-0.

[8] A. Frommer, T. Deub, H. Ehnis, and R. Künzel. Design of the tangential force of the oil control ring - oil emission versus friction. MTZ worldwide, 77:48-53, 2016. doi: 10.1007/s38313-015-0077-8.

[9] J A Greenwood and J H Tripp. The contact of two nominally flat rough surfaces. Proceedings of the Institution of Mechanical Engineers, 185(1):625-633, 1970. doi: 10.1243/PIME_PROC_1970_185_069_02.

[10] Y. Guo, X. Lu, W. Li, T. He, and D. Zou. A mixed-lubrication model considering elastoplastic contact for a piston ring and application to a ring pack. Proceedings of the Institution of Mechanical Engineers, Part D: Journal of Automobile Engineering, 229(2):174-188, 2015. doi:10.1177/0954407014536149.

[11] Y. Hu, H. S. Cheng, T. Arai, Y. Kobayashi, and S. Aoyama. Numerical simulation of piston ring in mixed lubrication. a nonaxisymmetrical analysis. ASME. J. Tribol, 116(3):470-478, 1994. doi:10.1115/1.2928867. 
[12] Y. R. Jeng. Theoretical analysis of piston-ring lubrication Part II-starved lubrication and its application to a complete ring pack. Tribology Transactions, 35(4):707-714, 1992. doi:10.1080/10402009208982175.

[13] M. T. Ma, I. Sherrington, and E. H. Smith. Implementation of an algorithm to model the starved lubrication of a piston ring in distorted bores: prediction of oil flow and onset of gas blow-by. Proceedings of the Institution of Mechanical Engineers, Part J: Journal of Engineering Tribology, 210(1):29-44, 1996. doi:10.1243/PIME\_PROC \_1996\_210 -475\_02.

[14] M.T. Ma, E. H. Smith, and I. Sherrington. Analysis of lubrication and friction for a complete piston-ring pack with an improved oil availability model: Part 2: Circumferentially variable film. Proceedings of the Institution of Mechanical Engineers, Part J: Journal of Engineering Tribology, 211(1):17-27, 1997. doi:10.1243/ 1350650971542282.

[15] P. C. Mishra. Tribodynamic modeling of piston compression ring and cylinder liner conjunction in high-pressure zone of engine cycle. The International Journal of Advanced Manufacturing Technology, 66(5):1075-1085, 2013. doi:10.1007/ s00170-012-4390-y.

[16] P. C. Mishra, S. Balakrishnan, and H. Rahnejat. Tribology of compression ring-tocylinder contact at reversal. Proceedings of the Institution of Mechanical Engineers, Part J: Journal of Engineering Tribology, 222(7):815-826, 2008. doi:10.1243/ 13506501 JET410.

[17] S. L. Moore and G. M. Hamilton. The starved lubrication of piston rings in a diesel engine. Journal of Mechanical Engineering Science, 20(6):345-352, 1978. doi:10.1243/ JMES \_JOUR \_1978\_020\_060\_02.

[18] M. Okamoto and I. Sakai. Contact pressure distribution of piston rings-calculation based on piston ring contour. In SAE 2001 World Congress. SAE International, 03 2001. doi:10.4271/2001-01-0571.

[19] H. Overgaard, P. Klit, and A. Vølund. Investigation of different piston ring curvatures on lubricant transport along cylinder liner in large two-stroke marine diesel engines. Proceedings of the Institution of Mechanical Engineers, Part J: Journal of Engineering Tribology, 232(1):85-93, 2018. doi:10.1177/1350650117744100.

[20] O. Pinkus, B. Sternlicht, and E. Saibel. Theory of hydrodynamic lubrication. McGrawHill, 1962.

[21] F. J. Profito, D. C. Zachariadis, and E. Tomanik. One dimensional mixed lubrication regime model for textured piston rings. In 21st Brazilian Congress of Mechanical Engineering, 102011.

[22] H. Rahnejat. Tribology and dynamics of engine and powertrain: fundamentals, applications and future trends. Woodhead Publishing, Oxford [etc.], 2010.

[23] M. Söderfjäll, A. Almqvist, and R. Larsson. Component test for simulation of piston ring-cylinder liner friction at realistic speeds. Tribology International, 104:57 - 63, 2016. doi:10.1016/j.triboint.2016.08.021.

[24] R. I. Taylor. Squeeze film lubrication in piston rings and reciprocating contacts. Proceedings of the Institution of Mechanical Engineers, Part J: Journal of Engineering Tribology, 229(8):977-988, 2015. doi:10.1177/1350650114564234.

[25] M. Teodorescu, D. Taraza, N.. Henein, and W. Bryzik. Simplified elasto-hydrodynamic friction model of the cam-tappet contact. In SAE 2003 World Congress 83 Exhibition. SAE International, mar 2003. doi:10.4271/2003-01-0985. 
[26] T. Tian, L. B. Noordzij, V. W. Wong, and J. B Heywood. Modeling piston-ring dynamics, blowby, and ring-twist effects. ASME. J. Eng. Gas Turbines Power, 120(4):843-854, 1998. doi:10.1115/1.2818477.

[27] E. Tomanik. Modelling of the asperity contact area on actual 3D surfaces. In SAE 2005 World Congress \& Exhibition. SAE International, 04 2005. doi:10.4271/ 2005-01-1864.

[28] E. Tomanik, H. Chacon, and G. Teixeira. A simple numerical procedure to calculate the input data of Greenwood-Williamson model of asperity contact for actual engineering surfaces. In D. Dowson, M. Priest, G. Dalmaz, and A.A Lubrecht, editors, Tribological Research and Design for Engineering Systems, pages 205 - 215. Elsevier, 2003. doi: 10.1016/S0167-8922(03)80133-5.

[29] R. Turnbull, N. Dolatabadi, R. Rahmani, and H. Rahnejat. An assessment of gas power leakage and frictional losses from the top compression ring of internal combustion engines. Tribology International, 142, 2020. doi:10.1016/j.triboint.2019.105991.

[30] Y. Wakuri, T. Hamatake, M. Soejima, and T. Kitahara. Piston ring friction in internal combustion engines. Tribology International, 25(5):299-308, 1992 . doi: 10.1016/0301-679X (92) 90027-K.

[31] Z. Westerfield, Y. Liu, D. Kim, and T. Tian. A study of the friction of oil control rings using the floating liner engine. In SAE 2016 World Congress 86 Exhibition. SAE International, 04 2016. doi:10.4271/2016-01-1048.

[32] A. Zavos and P. G. Nikolakopoulos. Computational fluid dynamics analysis of top

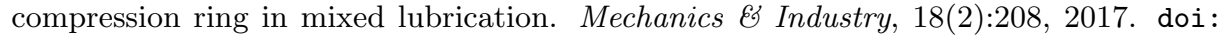
$10.1051 / \mathrm{meca} / 2016024$. 


\section{Chapter 6}

\section{Comparison of experimental results obtained in the Floating Liner and the lubrication model}

Contents

$6.1 \quad$ Introduction $\ldots \ldots \ldots \ldots \ldots \ldots \ldots \ldots \ldots \ldots \ldots, 209$

6.2 Experimental tests in the floating liner for the compression ring................... 209

6.3 Simulation of the compression ring lubrication .. 215

6.4 Comparison of results $\ldots \ldots \ldots \ldots \ldots \ldots \ldots \ldots, 217$

6.5 Discussion ...................... 223

Bibliography $\ldots \ldots \ldots \ldots \ldots \ldots \ldots \ldots \ldots \ldots \ldots .224$ 



\subsection{Introduction}

This chapter of the Thesis is dedicated to the comparison of experimental results obtained in the floating liner test rig and the simulations developed with the piston compression ring lubrication model, described in the previous Chapter 5. To accomplish this objective, a test matrix was defined for the floating liner in order to isolate the contribution of the compression ring to the instantaneous friction force measured by the sensors. The working conditions of the test rig and the characteristics of the cylinder liner and the compression ring, such as geometric dimensions and surface roughness, were then used as input data to the lubrication model. The results and analysis carried out in this chapter have contributed to gain a better understanding of the friction force phenomenon measured experimentally, specifically for the compression ring, and to have a clearer view of the lubrication regimes and their transition throughout the engine cycle. On the other hand, this comparison has helped to validate both the experimental results in the floating liner and the approach of the lubrication model from the view point of assumptions made for its development and the input data.

\subsection{Experimental tests in the floating liner for the compression ring}

As mentioned in the previous Section 6.1, the target of the tests in the floating liner was to obtain the instantaneous friction force of the compression ring by isolating its contribution from the rest of the piston ring pack and skirt. For this purpose, tests were ran with two configurations of the piston, named A and B. The first one corresponded to the original set up of the piston with the complete ring pack consisting of one compression ring, one scrapper ring and the OCR; while configuration B was the piston with the scrapper ring and the OCR. In this way, the compression ring friction force was obtained as the subtraction of the friction force measured with the two piston configurations. These piston configurations and subtraction method were chosen trying to give as much stability to the piston as possible; that is, if tests were ran with the compression ring only, the clearance between the liner and the piston would be increased significantly, affecting the piston slap noise with possible repercussions on the friction force measurement. Apart from this change in the piston configuration, all tests were performed under the same conditions, cylinder liner, piston, rings and oil formulation. 
The main characteristics and dimensions of the piston assembly employed in these tests are presented in Table 6.1; the piston was the same as the one employed for the tests in Chapter 4 (Figure 4.23), the ring pack on the other hand, was another set commercially available for this piston. The tangential force of this ring pack was not possible to be measured for the tests in this chapter. Nonetheless, the tangential force of the compression ring was taken from the measurements shared by the rings' manufacturer specifically for the experimental tests presented in Section 4.7.3, as the two ring packs are from the same manufacturer and correspond to the same article number. Due to this limitation, there may be a small variation in the actual tangential force of this ring, not affecting the experimental tests, as the tangential force of the three rings was the same for the two piston configurations A (with compression ring) and $\mathrm{B}$ (without compression ring).

\begin{tabular}{|c|c|}
\hline Parameter & Value \\
\hline \hline Cylinder liner diameter & $91.64 \mathrm{~mm}$ \\
\hline Stroke & $90 \mathrm{~mm}$ \\
\hline Piston diameter & $91.42 \mathrm{~mm}$ \\
\hline Piston length & $86.27 \mathrm{~mm}$ \\
\hline Compression ring $F t_{1}$ & $17.3 \mathrm{~N}$ \\
\hline
\end{tabular}

Table 6.1. Characteristics of the piston assembly for the experimental tests and simulations.

The ring pack used here, compression ring, scrapper ring and OCR were measured with a stylus profilometer (Taylor Hobson Talysurf) before the tests, as described in Section 5.2.8.1, in order to obtain their running face profile; these measurements were performed during the research stay at the University of Central Lancashire; the results are shown in the following Figure 6.1. For the compression ring in Figure 6.1a. the plot also shows the fitted parabola used in the simulation model. This running profile of the compression ring was assumed to be symmetrical, and the radius of curvature $(30 \mathrm{~mm})$ was obtained from these measurements; nonetheless, it can be see in Figure 6.1a. that the actual running profile of the piston ring is asymmetrical with a larger slope on the top side.

The test matrix for this study consisted of three engine speed levels 500, 600 and $800 \mathrm{rpm}$ and three oil temperature levels, 40,60 and $80^{\circ} \mathrm{C}$ measured at the crankcase; the lubricant oil used for these tests was a commercial formulation 

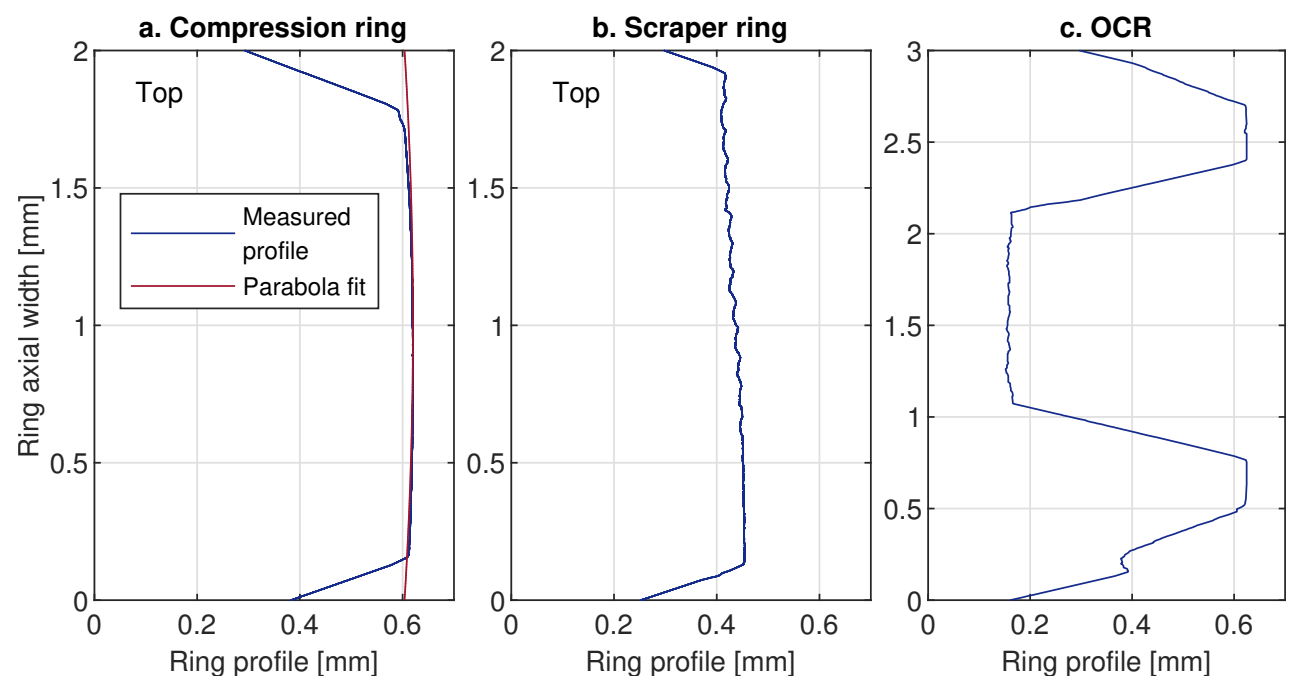

Figure 6.1. Measured axial profile of the ring pack.

SAE 5W30, its viscosity and density properties were presented previously in Figure 4.26.

As for the tests in the floating liner presented in Chapter 4, here it was also important to measure and record the temperature of the oil in the crankcase and along the cylinder liner throughout the engine cycle, specially because this data was employed for the simulations with the compression ring lubrication model; it is assumed that the temperature measured by the thermocouples installed in the liner corresponds to the temperature of the oil at this location, similar assumptions to reference and calculate the oil viscosity were also applied by different authors [1-5]. These oil temperature measurements are presented in the following Figure 6.2, 6.3 and 6.4 for each engine speed level. They correspond to the mean oil temperature and standard deviation of the measurements between the two piston configurations A (with compression ring) and $\mathrm{B}$ (without compression ring); in the $y$ right axis was plotted the corresponding relative standard deviation. From these figures it can be seen that the temperature at the different locations of the liner varies significantly from that measured at the crankcase due to the setup of the floating liner being open to the ambient temperature conditions; nevertheless, these temperature values were well maintained for the tests with small standard deviation between the measurements for the two piston configurations, the maximum relative STD was almost $2 \%$ which is equivalent to about $1.5^{\circ} \mathrm{C}$. 
6. Comparison of experimental results obtained in the Floating Liner and 212 the lubrication model
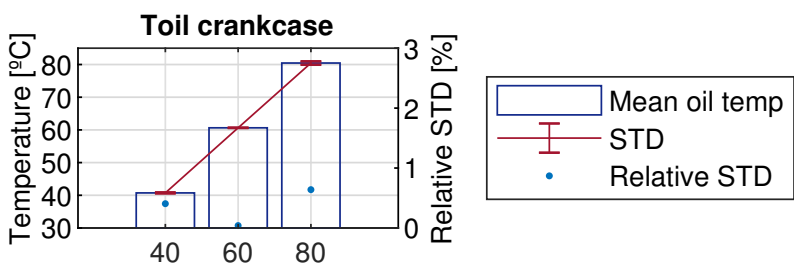

Test oil temperature $\left[{ }^{\circ} \mathrm{C}\right]$

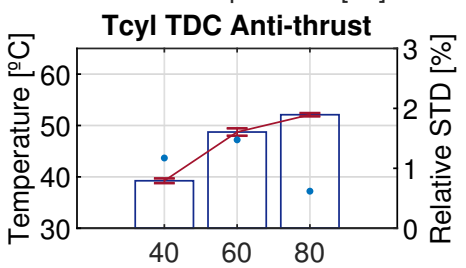

Test oil temperature $\left[{ }^{\circ} \mathrm{C}\right]$
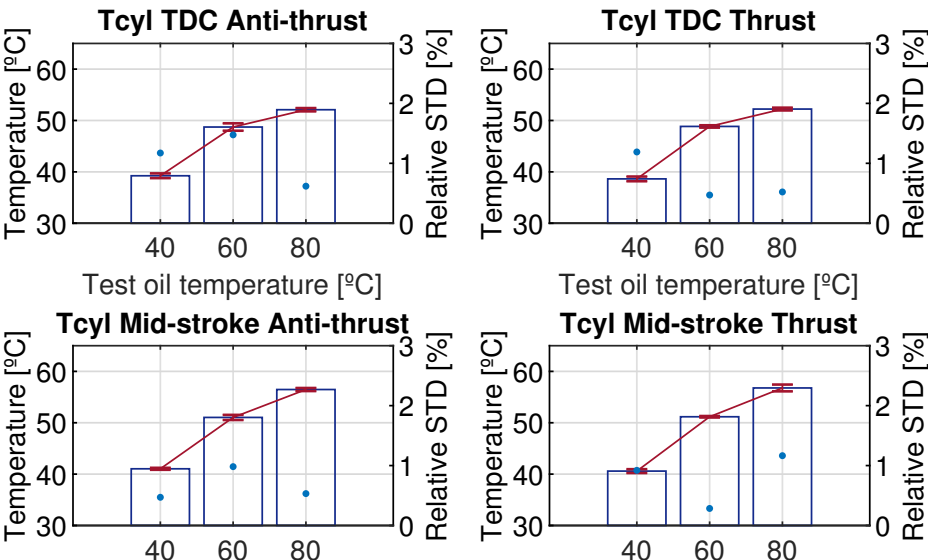

Test oil temperature $\left[{ }^{\circ} \mathrm{C}\right]$

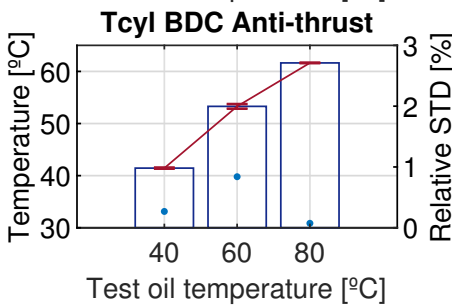

Test oil temperature $\left[{ }^{\circ} \mathrm{C}\right]$

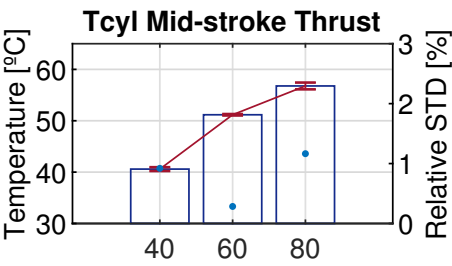

Test oil temperature $\left[{ }^{\circ} \mathrm{C}\right]$

Tcyl BDC Thrust

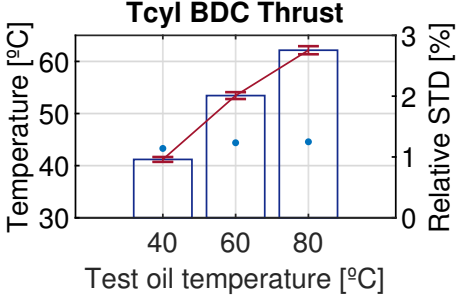

Figure 6.2. Oil temperature at the crankcase and liner at constant engine speed of 500 rpm. ${ }^{*}$ Tcyl: temperature at the cylinder liner.

The results of the instantaneous friction force measured in the floating liner are presented in the following Figure 6.5, 6.6 and 6.7 comparing the two piston configurations $\mathrm{A}$ (with compression ring) and $\mathrm{B}$ (without compression ring) for the three oil temperature levels 40,60 and $80^{\circ} \mathrm{C}$, respectively. The contribution of the piston compression ring to the total friction losses can be observed in the gap between the friction curves of the two piston configurations, extended throughout the engine cycle for all the test conditions, which demonstrates the significant effect of the compression ring to the overall lubrication performance of the piston. Given the configuration of the floating liner, motored and open to the ambient pressure conditions, the pressure acting 

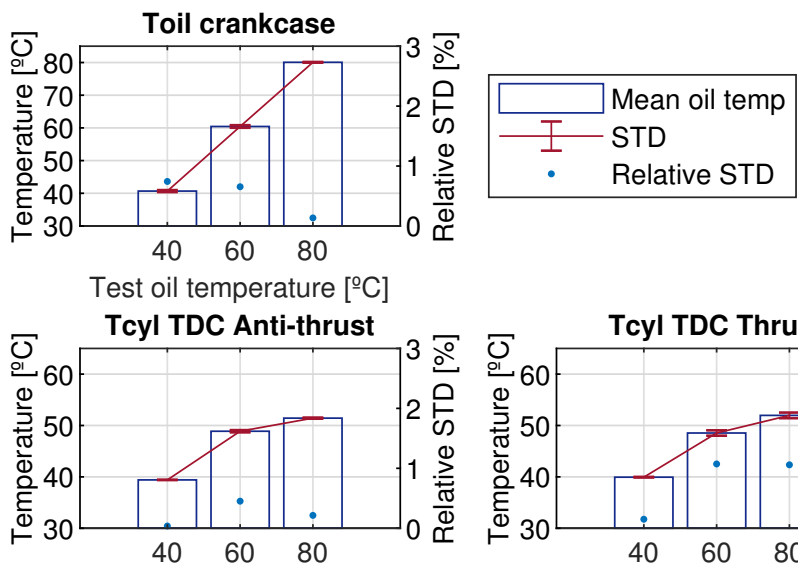

Test oil temperature $\left[{ }^{\circ} \mathrm{C}\right]$
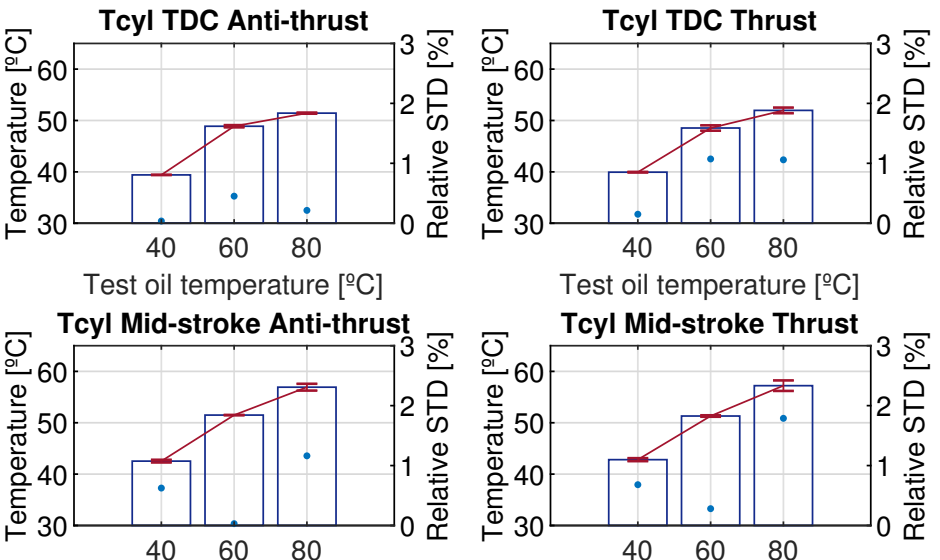

Test oil temperature $\left[{ }^{\circ} \mathrm{C}\right]$

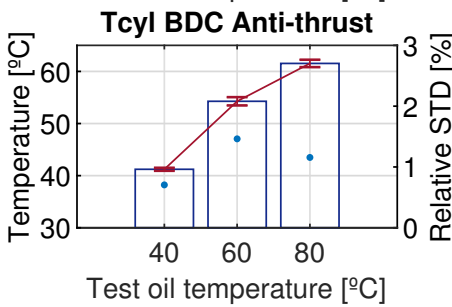

Test oil temperature $\left[{ }^{\circ} \mathrm{C}\right]$

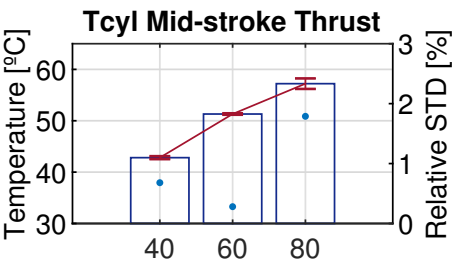

Test oil temperature $\left[{ }^{\circ} \mathrm{C}\right]$

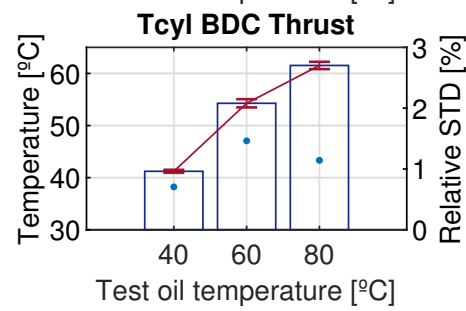

Figure 6.3. Oil temperature at the crankcase and liner at constant engine speed of $600 \mathrm{rpm}$. ${ }^{*}$ Tcyl: temperature at the cylinder liner.

behind the ring pack only depends on the tangential force of the rings, which is constant throughout the engine cycle. Instead, if tests were performed under compressed conditions or with combustion, the contribution of the compression ring would be expected to be more marked at the TDC, especially during the compression and power strokes, due to the higher in-cylinder pressure acting in the back face of the ring.

Comparing the results for the different oil temperature levels, it can also be observed that the gap between the friction curves of piston configurations A (with compression ring) and $\mathrm{B}$ (without compression ring) is reduced with the increase of the oil temperature. Due to the parabolic axial profile of 
6. Comparison of experimental results obtained in the Floating Liner and 214 the lubrication model
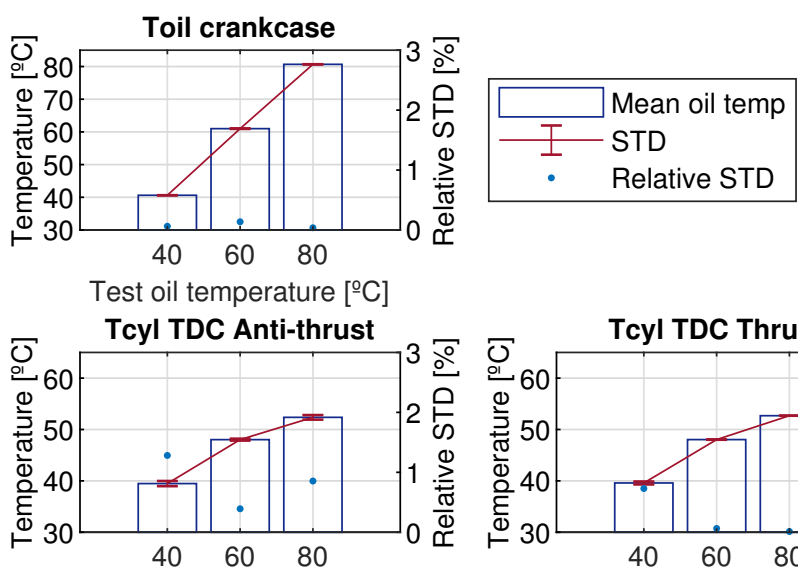

Test oil temperature $\left[{ }^{\circ} \mathrm{C}\right]$
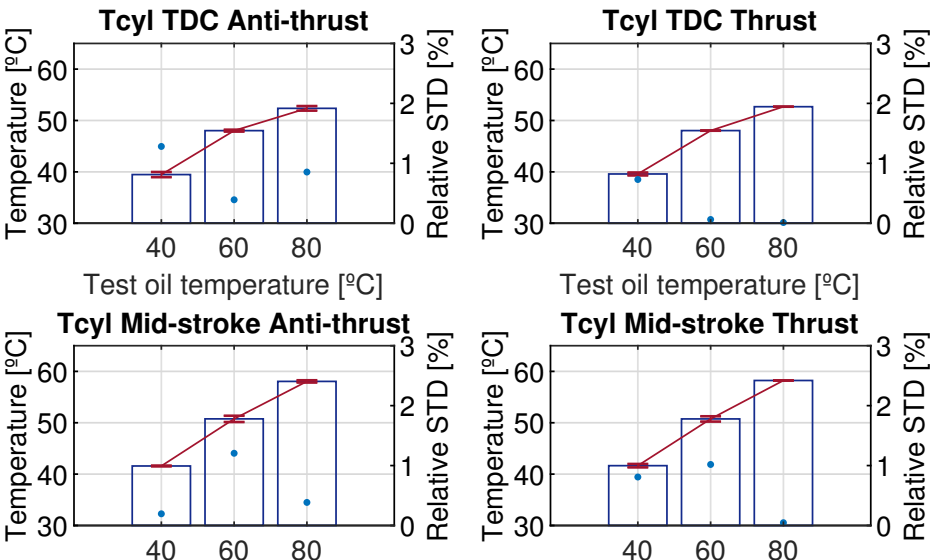

Test oil temperature $\left[{ }^{\circ} \mathrm{C}\right]$
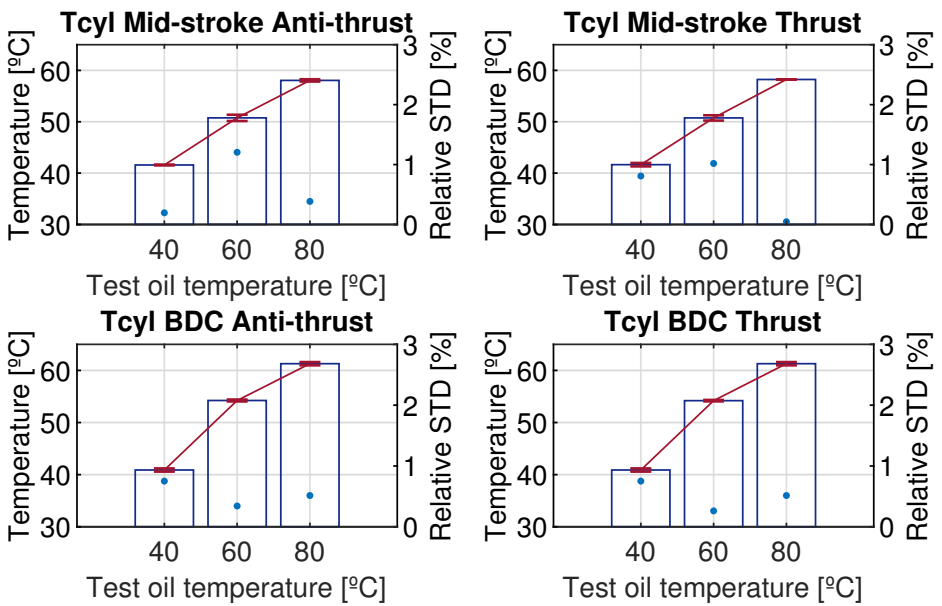

Test oil temperature $\left[{ }^{\circ} \mathrm{C}\right]$

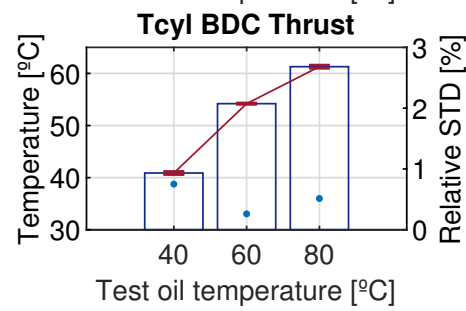

Figure 6.4. Oil temperature at the crankcase and liner at constant engine speed of $800 \mathrm{rpm}$. ${ }^{*}$ Tcyl: temperature at the cylinder liner.

the compression ring, that enhances the wedge effect and the entrainment of oil to the conjunction, hydrodynamic lubrication is expected for this ring for the most part of the engine stroke; which seems to indicate the results obtained at $40^{\circ} \mathrm{C}$ with higher oil viscosity, and that can be better observed in Figure 6.9a., 6.10a. and 6.11a. showing the experimental friction force obtained for the compression ring under the three engine speed levels. These figures will be addressed in more detail later in this chapter. For 60 and $80^{\circ} \mathrm{C}$, this viscous friction contribution from the compression ring diminishes at the mid-stroke regions, shown in Figure 6.6 and 6.7, due to the lower oil viscosity promoting the creation of a thinner oil film and less friction share. 

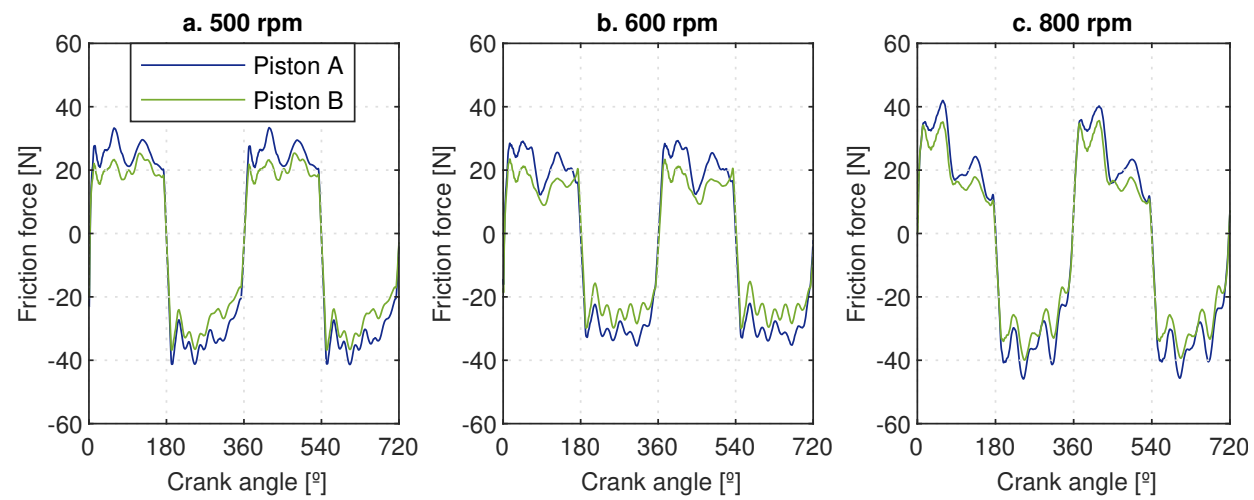

Figure 6.5. Instantaneous friction force for the piston configuration $A$ (with compression ring) and $B$ (without compression ring) at $40^{\circ} \mathrm{C}$.
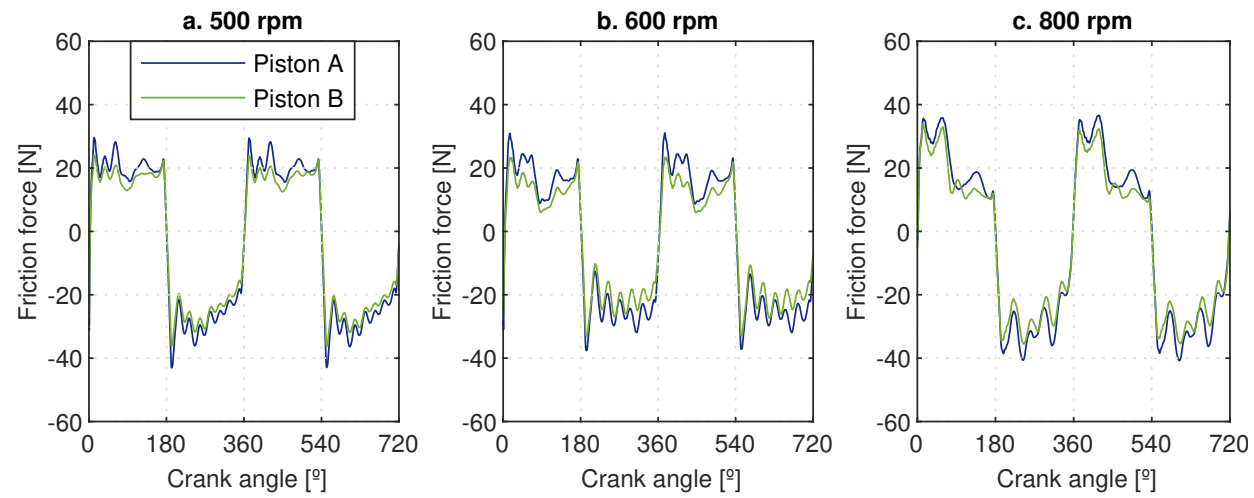

Figure 6.6. Instantaneous friction force for the piston configuration $A$ (with compression ring) and $B$ (without compression ring) at $60^{\circ} \mathrm{C}$.

\subsection{Simulation of the compression ring lubrication}

Most of the input data employed in this section was already presented in Chapter 5, where the compression ring lubrication model was described, and it was gathered in Table 5.1; the same applies for the surface characteristics of the piston compression ring, presented in Table 5.3, and for the cylinder liner in Table 5.4. As mentioned previously in Section 6.2, the temperature of the oil measured in the liner was employed for the simulations to obtain the oil viscosity at the different locations of the compression ring during one engine cycle. In order to obtain this oil temperature distribution at each 
6. Comparison of experimental results obtained in the Floating Liner and
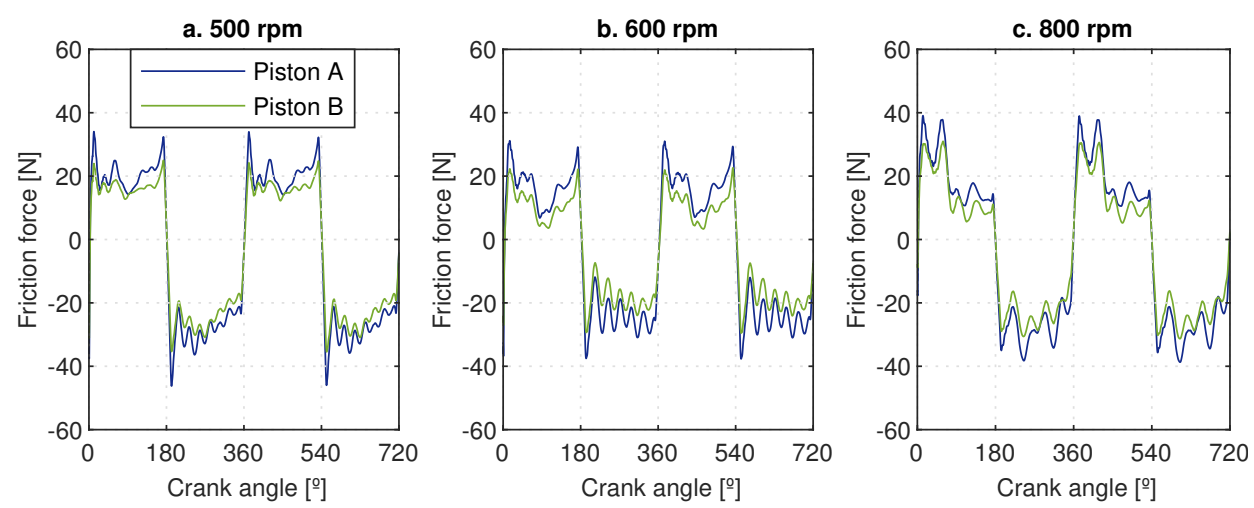

Figure 6.7. Instantaneous friction force for the piston configuration $A$ (with compression ring) and $B$ (without compression ring) at $80^{\circ} \mathrm{C}$.

crank angle, a piecewise cubic hermite interpolating polynomial (PCHIP) was implemented using the temperature data at the TDC, mid-stroke and BDC locations. Using this data, the Vogel equation 5.36 was applied to obtain the corresponding oil dynamic viscosity. An example of the oil temperature distribution and dynamic viscosity is presented in the following Figure 6.8 for $60^{\circ} \mathrm{C}$ oil temperature measured at the crankcase.

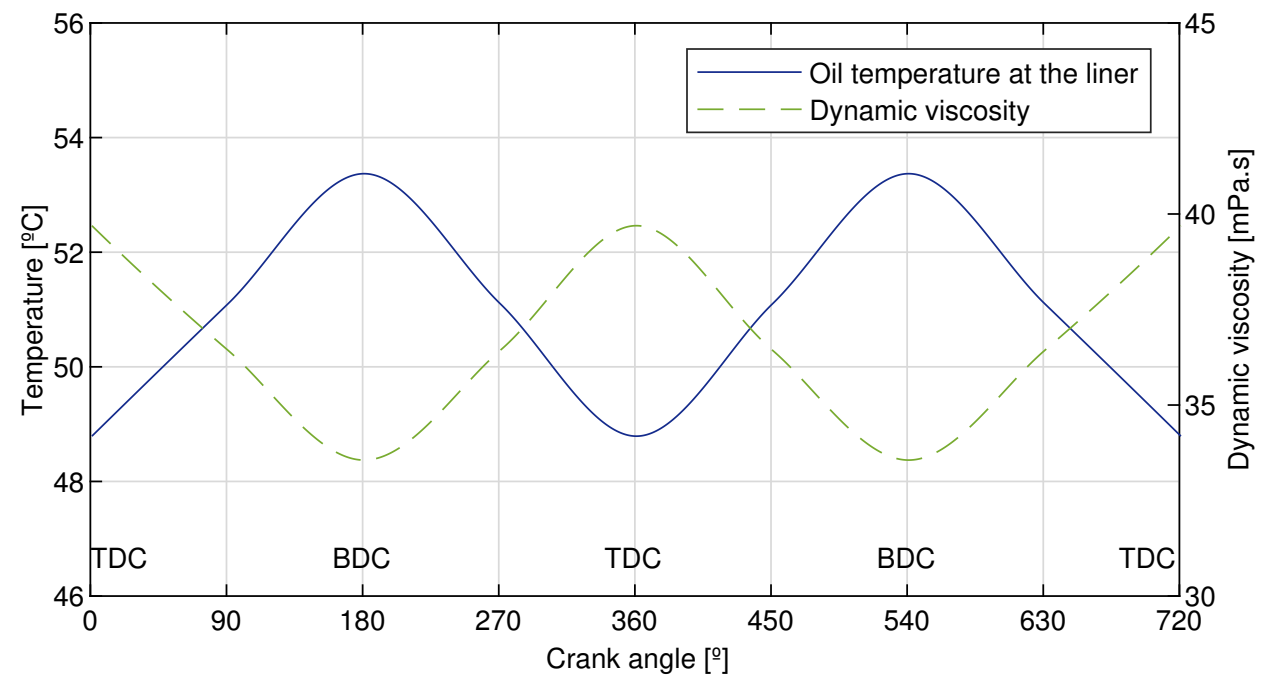

Figure 6.8. Oil temperature and dynamic viscosity variation at the cylinder liner for one engine cycle (oil temperature at the crankcase $=60^{\circ} \mathrm{C}$ ). 
Lubrication of the piston compression ring of ICEs has been demonstrated to be starved for the most part of the engine cycle due to the oil distributing function of the OCR, specially when the ring pack is subjected to high in-cylinder pressure conditions, which makes the lubrication analysis under flooded conditions not entirely realistic. In the Chapter 5 of this Thesis, the fully flooded and starved lubrication approaches were addressed and compared for different working conditions, showing the significant differences between their results in terms of MOFT and friction force. For this chapter, it was thought to be interesting to compare the experimental results of the compression ring friction force with the theoretical simulations under the two lubrication approaches, specially due to the floating liner working characteristics being under ambient pressure conditions that could favor fully flooded lubrication. The results of the simulations are presented in comparison with the experimental test in the following Section 6.4.

\subsection{Comparison of results}

Here is presented the experimental friction force of the piston compression ring in comparison with the theoretical estimations under fully flooded and starved lubrication conditions. These results are shown in Figure 6.9, 6.10 and 6.11 corresponding to the tests points under 500, 600 and $800 \mathrm{rpm}$, respectively and the three oil temperature levels. Furthermore, each figure includes the estimated MOFT generated in the interface of the piston ring and the liner; in these plots, the Stribeck oil film parameter $\lambda$ (dashed line) represents the limit defined for hydrodynamic lubrication, below this limit asperity contact occurs leading towards boundary lubrication.

From the experimental results in these figures, it can be observed that the compression ring experienced hydrodynamic lubrication for the most part of the engine cycle, still boundary lubrication appeared at the dead centers for all the test points, and increased with the oil temperature as expected with the reduction of the oil viscosity. The opposite behavior was observed at the mid-stroke regions, at $500 \mathrm{rpm}$ by instance, the maximum friction force reached about $10 \mathrm{~N}$, while as the oil viscosity was decreased, the same occurred with friction. For the same engine speed and applied load, this behavior is an indicative that friction losses in this region are determined by the lubricant oil shear, and thus by the oil viscosity.

On the other hand, the variation of the compression ring friction losses with the engine speed is not clear from the experimental results. According to the lubrication theory, the increase of the relative velocity between the 
6. Comparison of experimental results obtained in the Floating Liner and
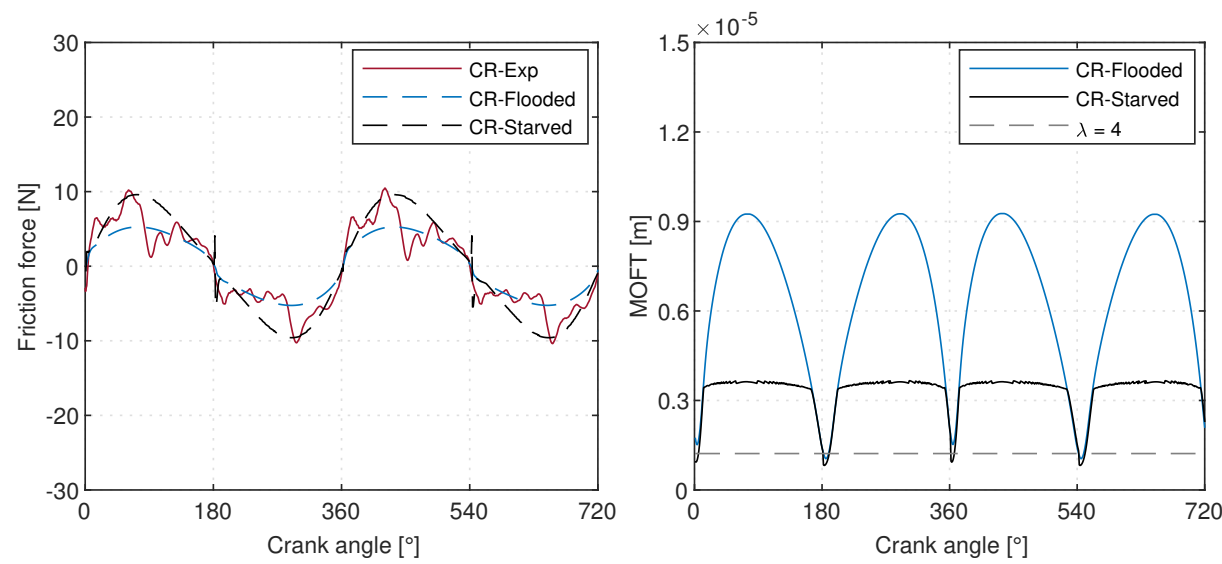

(a) $500 \mathrm{rpm}, 40^{\circ} \mathrm{C}$
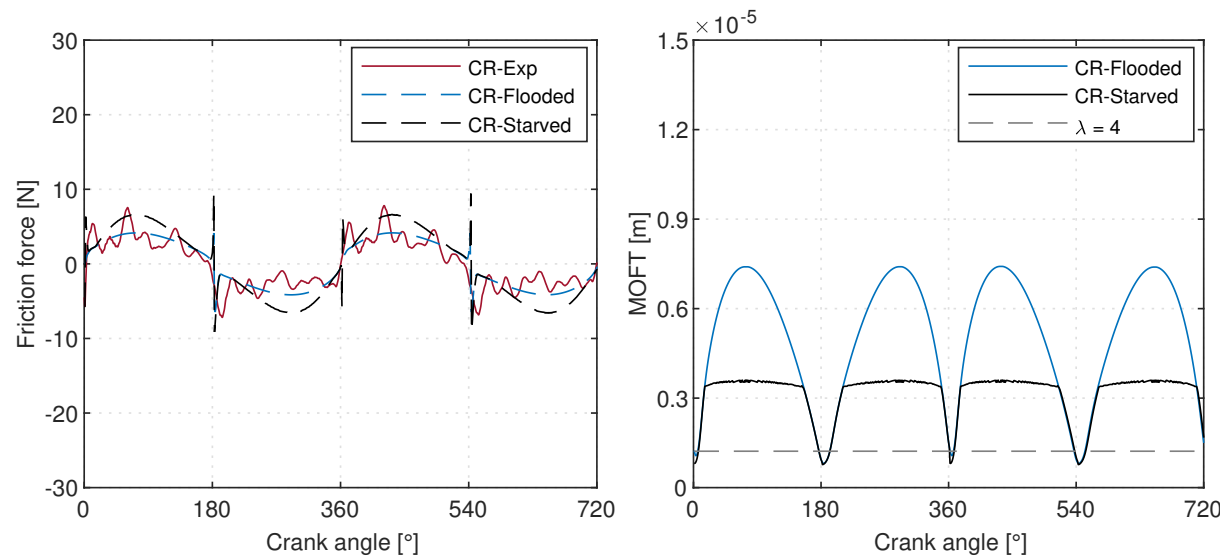

(b) $500 \mathrm{rpm}, 60^{\circ} \mathrm{C}$
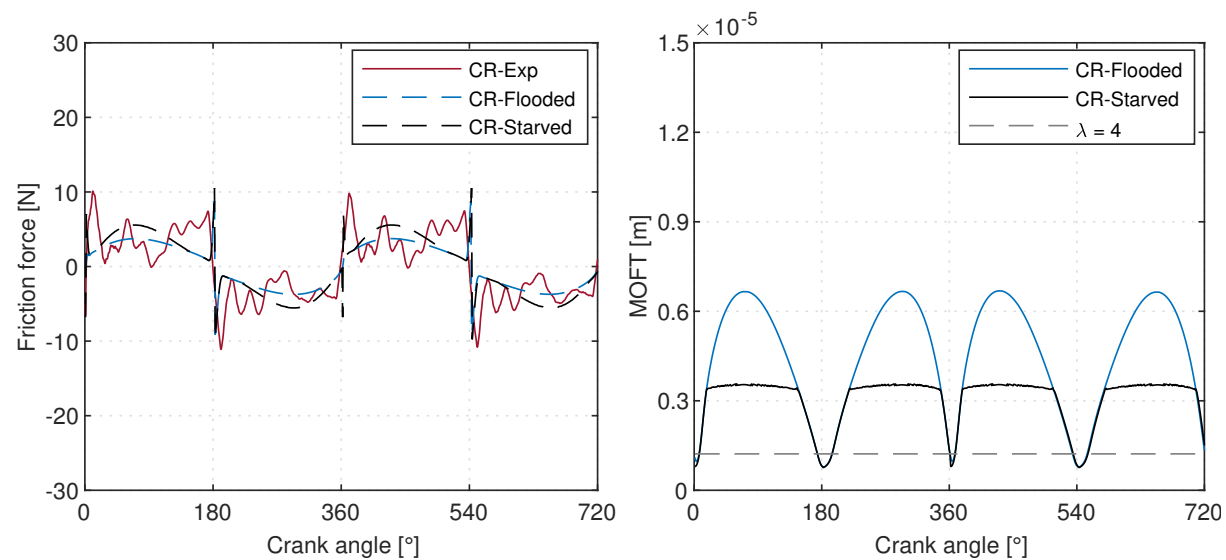

(c) $500 \mathrm{rpm}, 80^{\circ} \mathrm{C}$

Figure 6.9. Experimental and theoretical compression ring friction force and estimated MOFT for fully flooded and starved lubrication conditions at $500 \mathrm{rpm}$. 

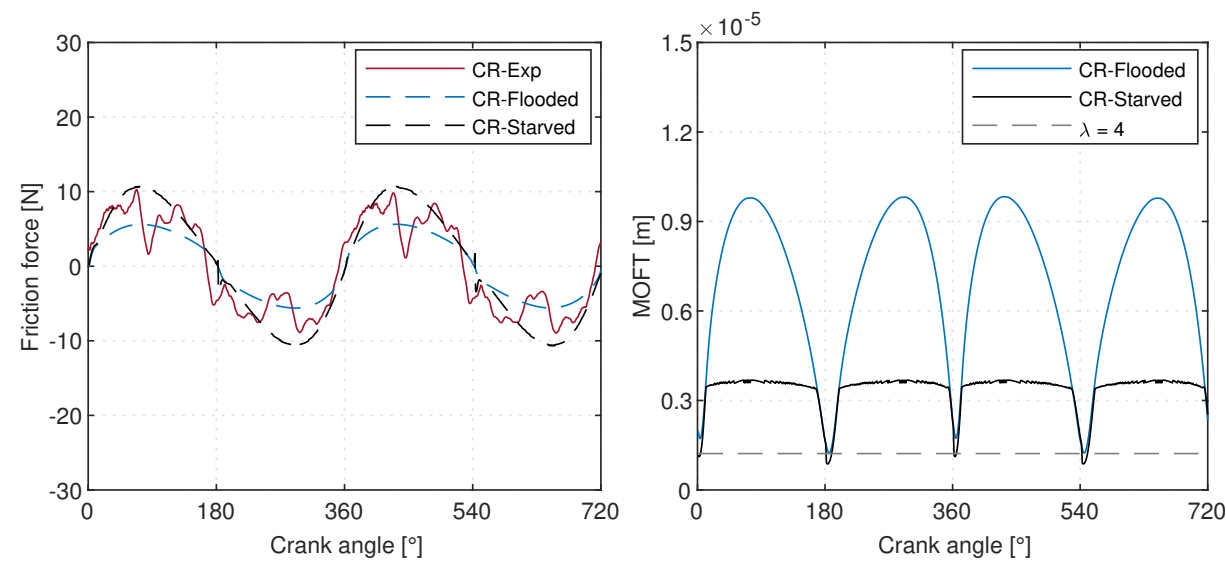

(a) $600 \mathrm{rpm}, 40^{\circ} \mathrm{C}$
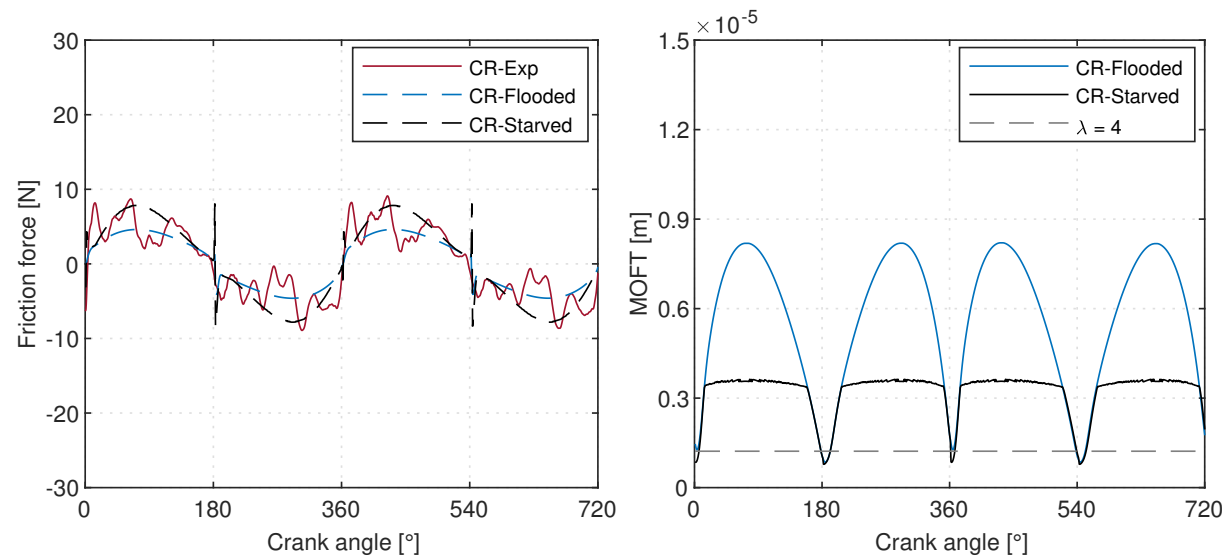

(b) $600 \mathrm{rpm}, 60^{\circ} \mathrm{C}$
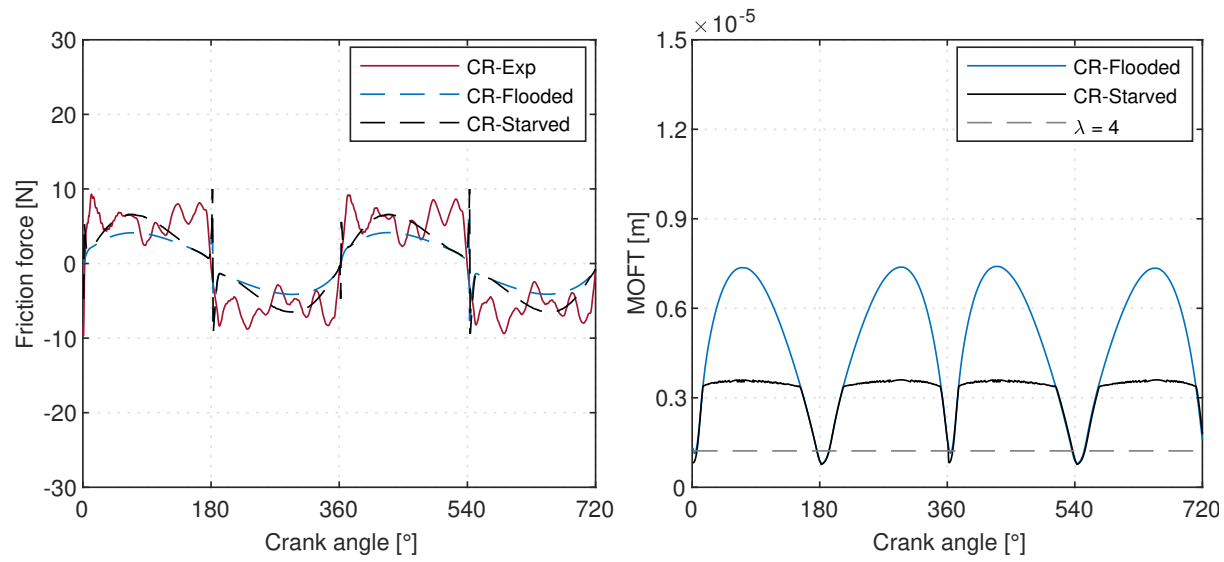

(c) $600 \mathrm{rpm}, 80^{\circ} \mathrm{C}$

Figure 6.10. Experimental and theoretical compression ring friction force and estimated MOFT for fully flooded and starved lubrication conditions at $600 \mathrm{rpm}$. 
6. Comparison of experimental results obtained in the Floating Liner and
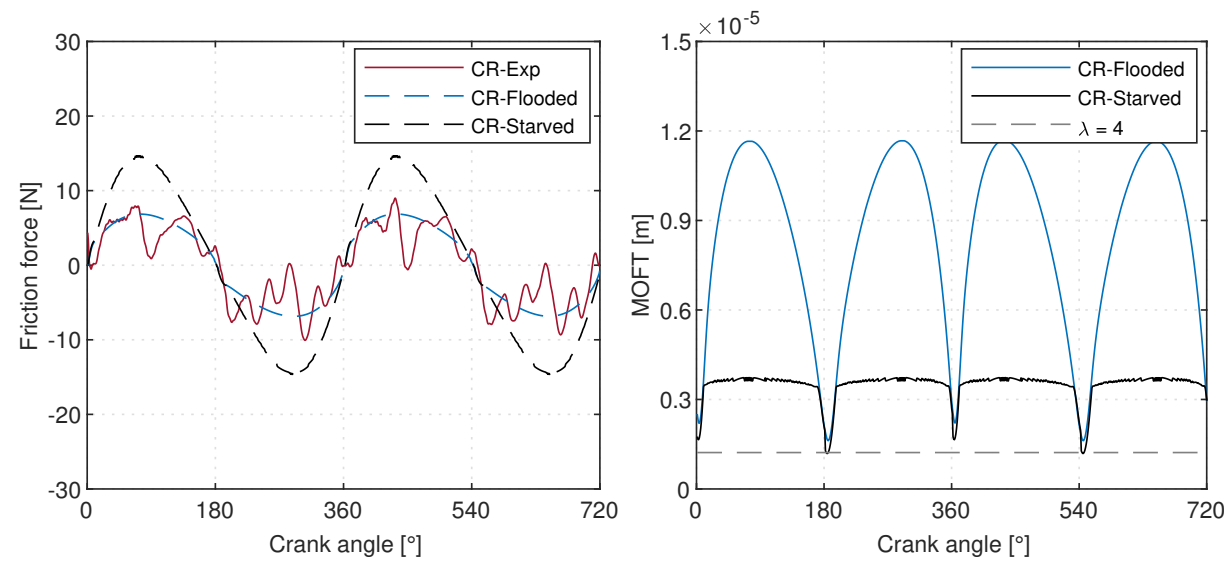

(a) $800 \mathrm{rpm}, 40^{\circ} \mathrm{C}$
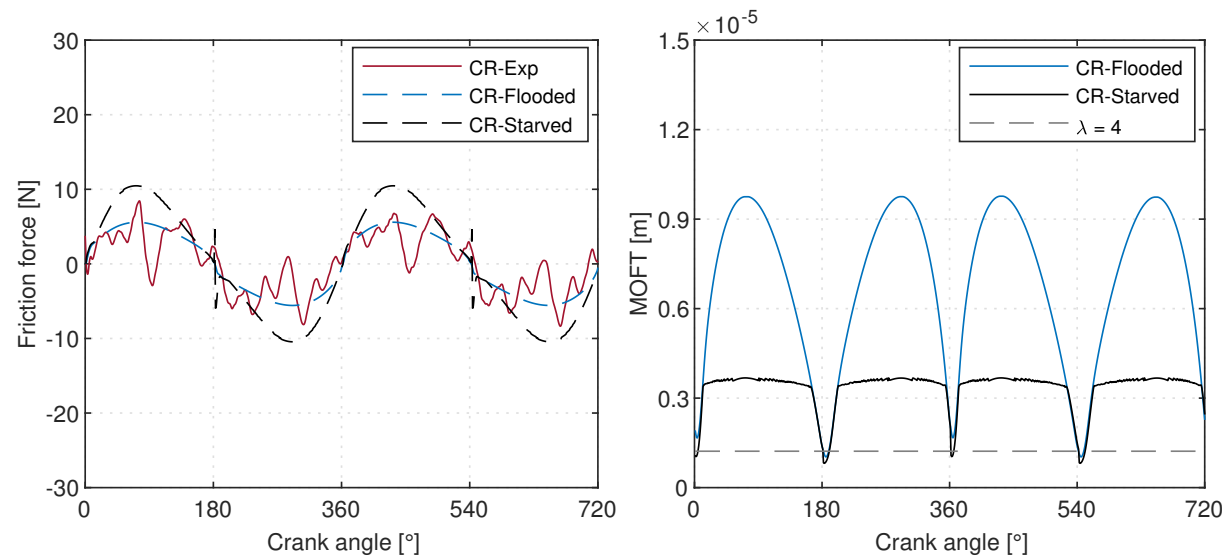

(b) $800 \mathrm{rpm}, 60^{\circ} \mathrm{C}$
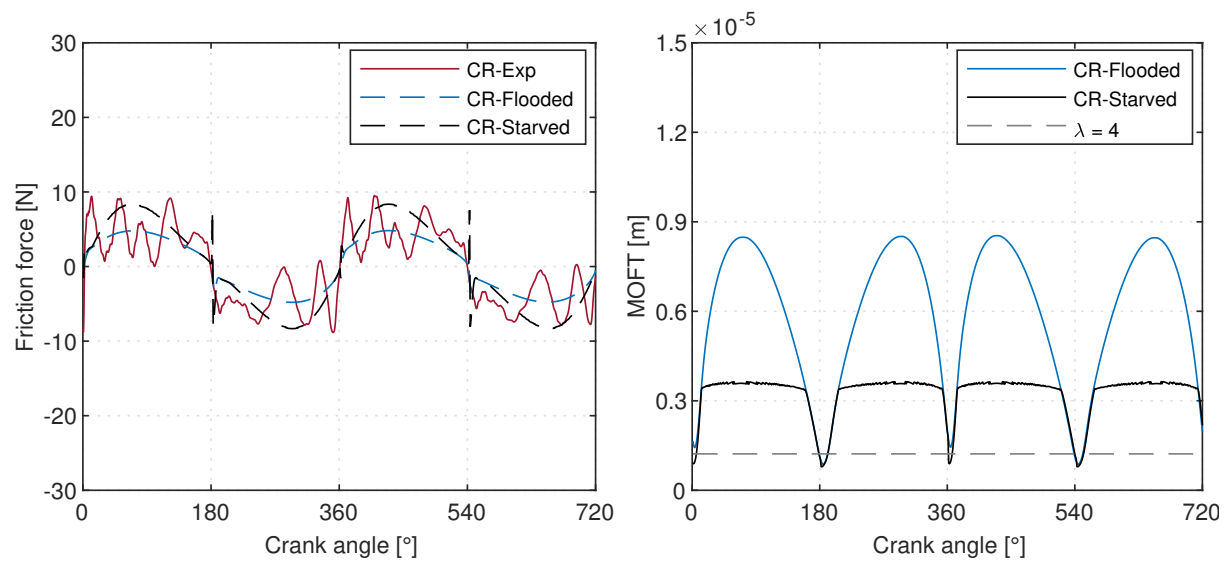

(c) $800 \mathrm{rpm}, 80^{\circ} \mathrm{C}$

Figure 6.11. Experimental and theoretical compression ring friction force and estimated MOFT for fully flooded and starved lubrication conditions at $800 \mathrm{rpm}$. 
surfaces contributes to the creation of a thicker oil film, as can be seen in the MOFT estimations for fully flooded lubrication in Figure 6.9 to 6.11, so that if the compression ring was already working under hydrodynamic lubrication, the viscous friction is increased and thus the resultant FMEP. However, this expected behavior was not observed in the FMEP results of the compression ring for any of the oil temperature levels, as shown in Figure 6.12. Looking back to the experimental measurements for the piston configurations A (with compression ring) and B (without compression ring), specially for 60 and $80^{\circ} \mathrm{C}$ in Figure 6.6 and 6.7 , it can be seen that the two friction curves touch and intersect each other at some points, which negatively affects the accurate acquisition of the compression ring friction force. For this project, it was not possible to measure the friction force solely for the compression ring, as this would require an under-sized piston to neglect the friction share of the piston skirt; furthermore, this would increase the piston slap noise due to the increased clearance between the piston and the liner. The variation of the compression ring FMEP with the engine speed was clearly observed for the theoretical simulations under both fully flooded and starved lubrication in Figure 6.12.

Regarding the comparison between experimental and theoretical results in terms of instantaneous friction force, Figure 6.9 to 6.11 show that the lubrication model under fully flooded conditions estimated a friction force close to the average friction measured experimentally in the floating liner, specifically around the mid-stroke region and for most of the test points. With the increase of the crankcase oil temperature to $80^{\circ} \mathrm{C}$, it can be observed that the starved lubrication model yielded a friction force curve closer to the experimental one than the fully flooded model. Nonetheless, looking at Figure 6.12, even for the high temperature conditions, the fully flooded model gave FMEP values more similar to the experimental ones. Under this high oil temperature of $80^{\circ} \mathrm{C}$, it can be expected that the lubrication conditions of the compression ring to be more severe, with less oil available at the liner and smaller MOFT, as shown in the left side of Figure 6.9 to 6.11, and thus it could be more appropriate to predict the friction losses under starved lubrication.

Differences in friction force and FMEP between the experimental measurements and the starved lubrication model seem to be more concentrated on the mid-stroke region. For the experimental results, these differences can be affected by deviations in the friction measurement and thus on the subtraction method; while for the model, these differences can be the result of the degree of starvation estimated in the model and the lack of interaction with the other piston rings. From these comparisons, it can also be noted that overall, the starved lubrication model overestimates the friction force at the dead centers, 
6. Comparison of experimental results obtained in the Floating Liner and
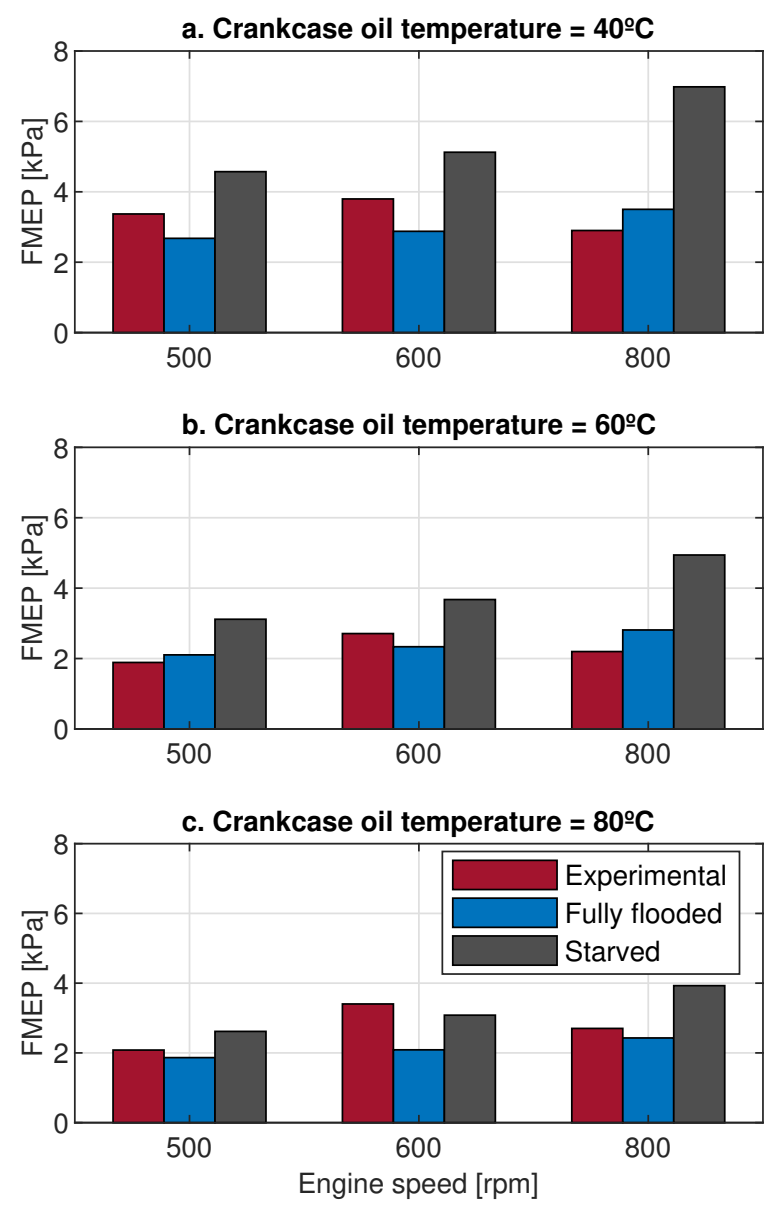

Figure 6.12. Experimental and theoretical compression ring friction losses in terms of FMEP.

this is an indicative of the importance of improving the boundary lubrication model with a better characterization of the surface roughness of the ring and the liner.

From Figure 6.12, it can be concluded that overall, the friction losses estimated with the fully flooded lubrication model are more in accordance with those obtained experimentally, as well as in the trend of the instantaneous friction force curves. The starved lubrication model instead, presented more discrepancies compared to the experimental results, especially with the increase of the engine speed. Looking back to the assumption applied to the model regarding the oil availability to the compression ring, which stated 
that the oil available to the leading edge of the ring during the downstroke corresponds to that left by the ring itself during the upstroke, it could not exactly reflect the lubrication conditions of the compression ring in the floating liner. During the tests in the floating liner, the oil available to the compression ring is determined by the oil flow rate resultant of the interaction of the complete ring pack; furthermore, the OCR is supplied with oil from the oil jet located near the bottom of the liner. This, in addition to the ambient pressure conditions of the test rig could promote better lubrication conditions for the compression ring than those estimated by the starved lubrication model.

\subsection{Discussion}

The experimental tests, simulations and comparisons developed in this chapter allowed to validate the measurements in the floating liner test ring and the approach of the lubrication model. For the experimental part, the friction force results presented here showed that the subtraction method to obtain the compression ring friction share gave good results, although the method could be improved with the use of a slightly over-sized piston that could help to reduce the piston-cylinder liner clearance and the piston slap noise.

For the simulation part, the comparison of experimental and theoretical results showed that the approach, input data and assumptions were appropriate for the objective of the study; however, it also highlighted some limitations and areas of improvements in the model. These are manly two, the first one related to the flow continuity condition implemented for the piston compression ring lubrication; the simulations under starved lubrication, specially under the higher engine speed levels, overestimated the friction losses in comparison with the experimental results as a consequence of the high degree of starvation calculated for this ring. In order to make a more accurate simulation, the flow continuity condition should include the lubrication performance of the complete ring pack. The second limitation is related to the lack of experimental data on the surface characteristics of the cylinder liner. In this Thesis, this data had to be extracted from literature; however if, by instance, different surface finishes or friction modifiers are going to be investigated, these surface characteristics need be measured for the actual components to be tested. Due to this lack of experimental data, discrepancies between the measured and simulated friction force, specifically at the dead centers and their vicinity, were expected. 
6. Comparison of experimental results obtained in the Floating Liner and

\section{Bibliography}

[1] M. R Islam. A floating liner facility and studies of friction at a reciprocating pistoncylinder wall interface. PhD thesis, The University of Nottingham, 2016.

[2] S. J. Söchting and I. Sherrington. The effect of load and viscosity on the minimum operating oil film thickness of piston-rings in internal combustion engines. Proceedings of the Institution of Mechanical Engineers, Part J: Journal of Engineering Tribology, 223(3):383-391, 2009. doi:10.1243/13506501JET556.

[3] Markus Söderfjäll. Friction in piston ring - cylinder liner contacts. PhD thesis, Luleå University of Technology, 2017.

[4] C. Sung-Woo, C. Sang-Min, and B. Choong-Sik. Frictional modes of barrel shaped piston rings under flooded lubrication. Tribology International, 33(8):545 - 551, 2000. doi:10.1016/S0301-679X (00)00103-1.

[5] Y. Wakuri, T. Hamatake, M. Soejima, and T. Kitahara. Piston ring friction in internal combustion engines. Tribology International, 25(5):299-308, 1992 . doi:10. 1016/0301-679X (92) 90027-K. 


\section{Chapter 7}

\section{Conclusions and future work}

\section{Contents}

7.1 Introduction .................... 227

7.2 Conclusions and main contributions ........ 227

7.2.1 LVEOs evaluation for fuel economy......... 227

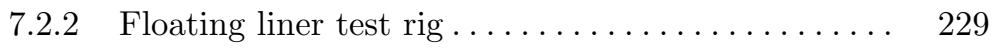

7.2.3 Compression ring simulation model......... 230

7.3 Future work .................... 231

7.3 .1 Experimental work ................ 231

7.3 .2 Theoretical work ................. 232 



\subsection{Introduction}

In this last chapter of the Thesis are summarized the main conclusions of the research presented here, which go in hand with the objectives presented in Section 1.3. Additionally, the next section gathers some future work proposals that can be developed to continue and improve the work developed in this thesis; this last section was divided in two subsections for the experimental and the theoretical future work proposals.

\subsection{Conclusions and main contributions}

Here are summarized the main conclusions found during the development of this Thesis and the scientific contributions made to the study of the friction mechanical losses in the piston-cylinder liner assembly of ICEs and the use of low viscosity oils for the reduction of the engine friction losses and for fuel economy.

\subsubsection{LVEOs evaluation for fuel economy}

- For the first part of this Thesis, low viscosity oil formulations were evaluated for fuel economy, including some formulations with molybdenum-based FM to expand the contribution of these LVEOs to more severe working conditions of mixed and boundary lubrication. Expected results were found when comparing the candidate formulations without Mo FM to the reference oil, the higher HTHS viscosity of the oil $\mathrm{C} 1$ resulted in an overall higher fuel consumption, while the oils $\mathrm{C} 2$ and C5 provided a $1.6 \%$ and $5.3 \%$, respectively of fuel consumption reduction due to their lower HTHS viscosity, especially in regions of the engine map that can favor hydrodynamic lubrication, that is, low load and medium to high engine speed. On the other hand, unexpected results were found with the oils $\mathrm{C} 3$ and $\mathrm{C} 4$ of the same HTHS viscosity, different base oil group and formulated with Mo FM. For the oil C4 fuel consumption reduction was measured for almost the entire engine map, even at idle conditions and high load, demonstrating the significant effect of the FM under conditions characteristic of boundary/mixed lubrication regimes. The oil C3 however, showed significant fuel consumption increase, specially at low load and medium-high speed, where the effect of its lower HTHS viscosity should have appeared. Instead, at idle conditions a small reduction in fuel consumption was observed, indicating the possible 
contribution of the Mo FM. Given that the only difference between the oils C3 and C4 was the base oil group, it was concluded that a poor synergy between the base and the FM was obtained in the formulation of the $\mathrm{C} 3$ oil.

- Extensive research has been developed on LVEOs for fuel economy in LDVs and HDVs, including studies under controlled conditions of an engine test bench and those performed under real working conditions; some of these studies have concluded that the potential of the oil formulations is closely linked to the vehicle and engine design, as well as the driving conditions. This last relationship between the oil and the vehicle driving conditions had not been directly investigated and quantified and therefore, it became one of the research targets and contributions of this Thesis. The vehicle model adapted for this study was applied to obtain the fuel consumption as function of the oil formulation and the working conditions of three real driving cycles, including rural and urban conditions, characteristic of a freight transport vehicle. Due to the favorable working conditions of the urban cycles, low speed and low-medium load, to achieve most of the potential of the LVEOs, higher fuel consumption reduction was obtained for these cycles than for the rural one. Nonetheless, good benefits were reported for the oils with the lowest HTST viscosity for the three driving cycles, followed by the $\mathrm{C} 4$ oil with Mo FM.

- The combined study and results with experimental tests and simulations with the vehicle model highlighted the importance of finding a good synergy between the vehicle, its working conditions and the oil formulation to be used, specially when dealing with vehicle fleets which fuel savings and associated costs are not negligible. In this way, the methodology employed in this study can be further applied to other driving cycles of specific vehicle fleets, as well as for the optimization of the oil formulation for its application to pre-defined working conditions.

- Looking at the results for the oils C2 and C5, of lower HTHS viscosity, in comparison with the fuel economy contribution of the oil $\mathrm{C} 4$ with Mo FM, it was interesting to observe that under both stationary conditions and the simulations with the driving cycles, the lower HTHS viscosity had a greater contribution to fuel economy than the FM additive. This can be explained looking at the regions of the engine map where the effect of these two parameters appeared the most. In the case of the HTHS viscosity, its effect appeared in the central/lower region of the 
map, covering a relatively extensive area; instead, the effect of the Mo FM was limited to low engine speeds and high loads.

- The contribution of the LVEOs due to their lower HTHS viscosity was analyzed under different working conditions of the engine through the fuel consumption maps, that helped to determine the regions where the contribution to fuel economy is greater and more likely to appear, the same for the Mo FM. The test methodology and setup for these tests however, could not allow a more detailed analysis of the friction losses in the engine tribo-pairs and the specific effect of the LVEOs on each of them. This limitation led to the development of a test rig for the study of the friction mechanical losses specific for the piston assembly, being this the tribo-pair of higher friction share, but also the one showing the greatest variability of lubrication regimes in one engine cycle.

\subsubsection{Floating liner test rig}

- A floating liner test rig was developed during this Thesis for the in-situ measurement of the instantaneous friction force in the piston-cylinder liner assembly of ICEs; which included its design, structural analysis and performance evaluation. This test rig allowed to evaluate the effect of different parameters over the friction force generated in the conjunction, but most importantly, it allowed a deeper analysis and understanding of the lubrication regimes experienced by this tribo-pair and the friction losses associated to them.

- This floating liner type of test rig is not new, different authors have developed and improved the method attending to their own research targets and limitations, as presented in Section 2.5.2. In this way, the floating liner developed here has its own design based on the requirements and objectives defined in the initial stage of its construction, as described in Section 4.3. Its design included the use of ball transfer units to minimize as much as possible the contribution of the lateral support to the friction measurement, these elements had not been used before for this purpose.

- The development of this floating liner test rig represents a contribution to the Fuels and Lubricants research line and an initial step towards future experimental studies in the research area of the piston-liner tribology, as well as the possibility to improve the test rig to better simulate real working conditions of ICEs; an overview of these suggestions for future work is presented in the following Section 7.3. 
- From the different tests performed in the floating liner, it was found that with the actual configuration of the test rig, it was more appropriate to limit the engine speed up to $800 \mathrm{rpm}$, without the risk of compromising the integrity of the rig and the measuring devices. Although this engine speed is below the representative regimes of common ICEs, it still allowed to perform the fundamental analysis of the piston lubrication and friction phenomenon covering all the lubrication regimes of the Stribeck curve.

- The parametric tests for different levels of engine speed, oil temperature, oil formulation of different SAE grade and OCR tangential force, showed the expected performance and results according to the lubrication theory and comparisons with results found in the literature, which helped to validate and assure the appropriate response of the test rig to deliberate changes in the testing conditions. The friction force curves obtained with these tests and the analysis of results through the FMEP and Stribecklike curves gave the insight required to better understand the lubrication performance of this assembly, identifying the appearance and transition of the lubrication regimes as function of the variable working conditions throughout the engine cycle. This capability was missing in the engine bench tests of Chapter 3 .

\subsubsection{Compression ring simulation model}

- A theoretical model to simulate the lubrication performance of the piston compression ring was developed and implemented in this thesis based on the finite differences method. It was made with the aim of creating a combined approach, between the experimental tests and simulations, for the analysis of the friction losses in the piston-cylinder liner assembly. This combined approach helped to validate the tests in the floating liner test rig, but also to validate the model from the point of view of input data and assumptions.

- The simulation model was developed for fully flooded conditions as well as for starved lubrication. These two approaches showed significant differences in terms of minimum film thickness and friction force, demonstrating the importance of including the ring starvation for more realistic results. In this model ring starvation was estimated complying with the flow continuity condition if there was only one piston ring; however, for a more realistic approach, the interaction of the complete ring pack should be considered. 
- For the simulations of Chapter 5 and Chapter 6, it is important to highlight that no actual data of the cylinder liner roughness was employed, instead it was obtained from literature, as mentioned in Section 5.2.8.2. Given that friction losses, in this case of the piston compression ring, are highly affected by the characteristics of the contacting surfaces, discrepancies between the experimental and theoretical results can be expected associated to this circumstance. Future works to improve the simulation model should include these data, specially if different surface finishes or friction modifiers, by instance, are going to be investigated.

- Overall, the comparison developed in Chapter 6 between the experimental friction losses of the piston compression ring and the estimations obtained with the lubrication model showed good agreement for different working conditions of the floating liner, especially under the assumption of fully flooded lubrication. This was an indication of the validity of the model and the input data; still, for a better simulation of the boundary lubrication it is necessary to have real measurements of the surface roughness of the cylinder liner and the piston rings, particularly after they have been wore out to their final surface characteristics.

- The comparison performed between the experimental tests in the floating liner and the compression ring lubrication model under both fully flooded and starved lubrication conditions had not been previously reported in literature in a combined analysis as presented in Chapter 6. Usually, the friction losses in the piston assembly are either studied experimentally or theoretically. For this Thesis, the combined analysis of experimental tests and the two lubrication conditions assumed in the model was thought to be important due to the working conditions of the floating liner, motored and open to the ambient pressure and temperature conditions and therefore, with better possibilities for fluid lubrication.

\section{3 $\quad$ Future work}

\subsubsection{Experimental work}

- Given the great potential of LVEOs to reduce fuel consumption and the trend towards employing formulations of lower SAE grade especially for LDV applications, the use of additives to expand the range of friction reduction, such as FMs, would require deeper research studies. Based 
on the results presented in Chapter 3, further research work is proposed on the synergy between the base oil and the Mo FM additive to better understand their interaction.

- Improve the lateral support of the floating liner test rig that allows to better counteract the impulse force from the secondary motion of the piston. This improvement would let the rig to be run under higher engine speed conditions, more common of automotive ICEs.

- Continue the development of the floating liner with the sealing of the combustion chamber that permits the measurement of the instantaneous friction force under high pressure conditions. For this purpose, compressed air can be supplied directly to the combustion chamber by means of an injector or valve during the intake stroke, and to refill the air lost through the sealing and due to blow by in the following strokes. As it was expressed in Section 4.3.3, the floating liner structure was already designed to support the in-cylinder pressure that could be reached with the supplied compressed air, up to 90 bar in the compression stroke. It is expected that some modifications are needed to add this feature to the rig, specifically to the component that will act as cylinder head and as housing of the device selected to inject the air.

- Improve the temperature control in the cylinder liner. As it was described in Section 4.7, the experimental tests in the floating liner were developed taking the oil temperature at the crankcase as reference for the control of the heating element, while the temperature along the cylinder liner was only measured, recorded and taken as reference for the tests. It is advised to improve the control of the oil temperature at the liner by adding heating elements directly to the outer face of the cylinder. This would allow to have more realistic temperature values at the liner and to improve the assessment of oils with different viscosity characteristics or under broader ranges of temperature. Furthermore, with the sealing of the combustion chamber and the supply of compressed air, the temperature of the oil would increase significantly, which in addition to the high in-cylinder pressure present more severe working conditions where the potential of the FM additives can be further evaluated and compared.

\subsubsection{Theoretical work}

- Continue with the development and improvement of the piston compression ring lubrication model with the addition of the other piston 
rings and skirt for a better simulation of the oil flow in the ring pack and therefore, have a better estimation of their lubrication conditions, minimum film thickness and friction losses.

- The simulation model can also benefit from experimental data of the surface roughness characteristics of the liner and the rings, specially for the comparison of theoretical results with those obtained experimentally with the floating liner.

- Evaluate the possibility of employing a commercial software specific for the simulation of the lubrication in piston-cylinder liner assembly. Commercial models have the advantage of including different features to simulate the performance of the piston assembly under more realistic conditions including for example, the ring dynamics, non-circular bores, piston tilt and the oil viscosity variation with shear rate; therefore, depending on the targets of the research study, this approach would allow to have a better and quicker comparison with experimental results in the floating liner. 



\section{Appendix: Publications}

The following publications are the result of the research work developed and presented in this Thesis:

- Fuel economy optimization from the interaction between engine oil and driving conditions

Tribology International 138 (2019) 263-270

DOI: $10.1016 /$ j.triboint.2019.05.042

Authors: Bernardo Tormos, Benjamín Pla, Sophia Bastidas, Leonardo Ramírez, Tomás Pérez

Abstract: Low viscosity engine oils have shown to be an effective solution to the fuel consumption reduction target, however, their potential is closely linked to the vehicle and engine design and to the real driving conditions. In this study the interaction between engine oil and driving conditions of two urban routes and one rural route in Spain and the United Kingdom has been put to test with the aim to evaluate their joint effect over fuel economy of a freight transport vehicle. In a first approximation, six different oil formulations, three of them belonging to the new API CK-4 and FA-4 categories and two with molybdenum-based friction modifier, were tested under stationary conditions with a mediumduty diesel engine. Followed by tests under real driving conditions of a freight transport vehicle, developed by means of computer simulations with an adjusted vehicle model, taking the fuel consumption maps of the six oil formulations, vehicle characteristics and the selected driving cycles as inputs to the model. Results of engine bench tests and simulations with oils of lower HTHS viscosity showed fuel consumption reduction values as expected. However unexpected results were found between the oils with molybdenum-based friction modifier added to their formulation. 
- Development of a floating liner test rig and lubrication model for the study of the piston compression ring friction force under fully flooded and starved lubrication

Tribology International 160 (2021) 107034

DOI: 10.1016/j.triboint.2021.107034

Authors: Vicente Macián, Bernardo Tormos, Vicente Bermúdez, Sophia Bastidas

Abstract: Advances in internal combustion engines make it necessary to study in depth their contribution to engine efficiency, and thus to friction mechanical losses, especially those generated in the pistoncylinder liner assembly. In this paper, the design of a novel test rig is presented, based on the floating liner principle, with the key objective of having the capability of developing multiple parameters tests in a relatively quick and easy way. The final design integrates a singlecylinder internal combustion engine, a mechanical solution that allows the liner to float, three piezoelectric force sensors and a novel design of lateral support based on ball transfer units. Reproducibility and repeatability of tests were assessed demonstrating the capability of the test rig to develop reliable friction measurements. Some parameters tests were developed to evaluate the sensitivity of the friction force measurements to variations in the working conditions, oil temperature and engine speed. A theoretical model for the piston compression ring is presented for both fully flooded and starved lubrication conditions, including asperity interactions and lubricant rheology. Comparisons of these approaches with experimental results showed that, for the working conditions of the test rig, lubrication of the compression ring is better estimated under fully flooded lubrication condition, as the starved lubrication analysis results in over-estimated friction force values at higher engine speed regimes.

- Fuel Consumption reduction with LVEO and Mo FM under stationary and real driving conditions

Congress publication: IBERTRIVA 2019-X Iberian Conference on Tribology / XI Iberian Vacuum Conference

Date and location: June 26-28, 2019. Seville, Spain

ISBN: 978-84-09-12421-3

Authors: Vicente Macián, Bernardo Tormos, Sophia Bastidas, Tomás Pérez

Abstract: The study presented here consists of evaluating the effect of new engine oil formulations over fuel consumption of a mediumduty diesel engine, under stationary and real driving conditions. Six 
formulations were chosen with different HTHS viscosities ranging from 2.7 to $3.85 \mathrm{cP}$. Two of them were formulated with molybdenum friction modifier (Mo FM) with the aim to expand the fuel consumption reduction zone of low viscosity engine oils (LVEOs) to the mixed and boundary lubrication. Real driving conditions of a transport vehicle were simulated by means of a vehicle model. Results of engine bench tests and simulations showed fuel consumption reduction due to lower HTHS viscosity, however opposite results were found with formulations where Mo FM was added.

\section{Other publications}

The next publications are the result of other research studies in which the author of this Thesis worked during the doctoral studies; although this work is not included in this document, the research subject is still related to this Thesis and have contributed on the study and understanding of the lubrication performance of the piston assembly and on the use of LVEOs for fuel economy.

- Improved fleet operation and maintenance through the use of low viscosity engine oils: fuel economy and oil performance

Eksploatacja i Niezawodnosc - Maintenance and reliability 2020; 22 (2): 201-211

DOI: 10.17531/ein.2020.2.3

Authors: Vicente Macián, Bernardo Tormos, Sophia Bastidas, Tomás Pérez

Abstract: For heavy-duty vehicles and road transportation, fuel consumption and associated $\mathrm{CO}_{2}$ emissions have been of great concern, which has led to the development and implementation of technologies to reduce their impact on the environment. Low viscosity engine oils have arisen as one proven cost-effective solution to increase the engine efficiency; however, for the heavy-duty vehicle segment, engine protection against wear is a priority for end-users, and therefore there is some reluctance to the use of that new oil formulations. In this study, eight lubricant oils, representative of the HTHS viscosity reduction that heavy-duty oils have been undergoing and new API CK-4 and FA-4 categories, were evaluated for fuel economy, oil performance and engine wear, in a long-term test involving a fleet of 49 heavy-duty vehicles of four different engine technologies, some of them with diesel fuel and others with compressed natural gas. Results of fuel economy were positive for 
most of the buses' models. Regarding oil performance and wear, most of the formulations were found to be suitable for extended oil drain intervals (ODI); and although no alarming results were found, overall performance of the formulations of the fourth stage could lead to significant wear if the oil drain interval is extended. In this study, it should be noted that some of the information has been presented by the authors in other publications, here they are presented with the purpose of complementing the new results and summarize the entire test.

- Investigation on low-speed pre-ignition from the quantification and identification of engine oil droplets release under ambient pressure conditions

Measurement 163 (2020) 107961

DOI: $10.1016 /$ j.measurement.2020.107961

Authors: Bernardo Tormos, Jose M. Garcia-Oliver, Sophia Bastidas, Beatriz Domínguez, Fermin Oliva, Dolores Cárdenas

Abstract: One source of low-speed pre-ignition in turbocharged gasoline direct injection engines is the presence of oil droplets in the combustion chamber. In this study, oil droplets released due to the piston reciprocating motion, have been quantified as function of oil viscosity and engine speed, by means of a motored test rig under ambient pressure conditions. Oil droplets were collected using a sandwich-like support and absorbing paper. An image processing methodology was developed to identify critical regions of the pis- ton prone to the appearance of oil. Results show that oil is scrapped by the piston rings and released to the combustion chamber in zones transverse to the piston pin, at speeds as low as $500 \mathrm{rpm}$. Oil viscosity does not have a determining effect on the oil amount reaching the combustion chamber, while engine speed greatly increases this phenomenon, with a critical point at $2500 \mathrm{rpm}$ and oil temperature of $80^{\circ} \mathrm{C}$.

- Assessment of new engine oil formulations based on fuel consumption reduction in a medium-duty diesel engine

Congress publication: $21^{\text {st }}$ International Colloquium. TribologyIndustrial and Automotive Lubrication

Date and location: January 9-11, 2018. Stuttgart/Ostfildern, Germany Authors: Bernardo Tormos, Leonardo Ramírez, Sophia Bastidas, Guillermo Miró, Tomás Pérez

Abstract: The study presented here analyses the fuel consumption reduction of a medium-duty diesel engine obtained due to the use of low viscosity engine oils (LVEO). 17 stationary points of the engine working 
map were chosen for the analysis, representative of common engine operation, and six different engine oil formulations were tested, one SAE 10W40 and five SAE 5W30. Two of the formulations developed under the specifications of new CK-4 and FA-4 categories of the American Petroleum Institute (API), the last one thought to enable fuel economy benefits reducing HTHS viscosity. Results found at the end of the tests showed the significant impact of lower HTHS oil viscosity on fuel consumption reduction, even when SAE grade is the same.

- Low viscosity engine oils: fuel economy and performance. What can be expected on real world?

Congress publication: Lubmat 2018

Date and location: June 5-6, 2018. San Sebastián, Spain

Authors: Vicente Macián, Bernardo Tormos, Sophia Bastidas, Tomás Pérez, Luis Fernández

Abstract: $\mathrm{CO}_{2}$ emissions and fuel consumption reduction in road transportation has become one of the most relevant concerns. For vehicles with internal combustion engines fuel consumption rates are directly related to $\mathrm{CO}_{2}$. One proven cost-effective way to reduce fuel consumption is the use of low viscosity oils (LVO) to reduce the engine inner friction. Currently, limited data is available regarding "real-world" performance of LVO in a service fleet. This paper presents a study where the effect of use of LVO on urban transport buses on fuel consumption savings and oil performance is assessed. LVO presented benefits in fuel economy, closely linked to own engine design, and an excellent performance along the oil drain intervals. 



\section{Bibliography}

ACEA.

ACEA European oil sequences.

European Union, 2016.

(cited in p. 54)

Ahmed M., Xianjun H., Fiifi R. and Ezzat M.

An analytical study of tribological parameters between piston ring and cylinder liner in internal combustion engines.

Proceedings of the Institution of Mechanical Engineers, Part K: Journal of Multi-body Dynamics, Vol. 230 n $^{\circ}$ 4, pp. 329-349, 2016.

(cited in pp. 43, 172)

Akiyama K., Ueda F., Miyake J., Tasaka K. and Sugiyama S.

Fuel economy performance of the highly efficient fuel economy oils using chassis dynamometer test.

In International Fuels $\&$ Lubricants Meeting $\&$ Exposition. SAE International, oct 1993.

(cited in p. 53)

Arcoumanis C., Ostovar P. and Mortier R.

Mixed lubrication modelling of Newtonian and shear thinning liquids in a piston-ring configuration.

In International Fuels \& Lubricants Meeting \& Exposition. SAE International, 101997.

(cited in p. 172)

ASTM International.

D341-17 Standard Practice for Viscosity-Temperature Charts for Liquid Petroleum Products.

West Conshohocken, PA, 2017.

(cited in p. 23)

\section{ASTM International.}

D6278-17e1 Standard Test Method for Shear Stability of Polymer Containing Fluids Using a European Diesel Injector Apparatus.

West Conshohocken, PA, 2017.

(cited in pp. 26, 79)

Bergmann P. and Grun F.

Modeling wear of journal bearings.

In COMSOL Conference Munich 2016. COMSOL, oct 2016.

(cited in p. 19)

Bewsher S. R., Leighton M., Mohammadpour M., Rahnejat H., Offner G. and Knaus $\mathbf{O}$.

Boundary friction characterisation of a used cylinder liner subject to fired engine conditions and surface deposition.

Tribology International, Vol. 131, pp. 424 - 437, 2019.

(cited in pp. 172, 180) 
Brewe D. E.

Slider Bearings.

In Bhushan Bharat, editor, Modern Tribology Handbook: Volume One: Principles of Tribology, volume 1, pp. 969-1039. CRC Press, 2000.

(cited in pp. 202, 203, 204)

Browne D., Dewey M., Graham S., Sutton M., Munday M. and et al.

Novel fuel efficiency engine lubricants for urban transit applications.

In SAE 2014 International Powertrain, Fuels $\&$ Lubricants Meeting. SAE International, oct 2014 .

(cited in p. 58)

Calvo Ambel C.

Roadmap to climate-friendly land freight and buses in Europe.

Transport and Environment, 2017.

(cited in p.3)

\section{Cambridge Econometrics.}

Trucking into a Greener Future: the economic impact of decarbonizing goods vehicles in Europe.

European Climate Foundation, 2018.

(cited in p. 3)

Cameron A.

Basic Lubrication Theory, Third Edition.

Ellis Horwood Limited, Sussex, 1981.

(cited in p. 24)

Carden P., Bell D., Priest M. and Barrell D.

Piston assembly friction losses: comparison of measured and predicted data.

In SAE 2006 World Congress \& Exhibition. SAE International, apr 2006.

(cited in p. 44)

Carreño Arango R.

A comprehensive methodology to analyse the global energy balance in reciprocating internal combustion engines.

Universitat Politècnica de València, 2016.

(cited in p. 159)

Cho S. H., Ahn S. T. and Kim Y. H.

A simple model to estimate the impact force induced by piston slap.

Journal of Sound and Vibration, Vol. 255 n $^{\circ}$ 2, pp. 229 - 242, 2002.

(cited in p. 28)

Cui J., Oberoi S., Goldmints I. and Briggs S.

Field and bench study of shear stability of heavy duty diesel lubricants.

SAE Int. J. Fuels Lubr., Vol. $7 \mathrm{n}^{\circ}$ 3, pp. 882-889, 2014.

(cited in p. 79)

Cui J., Yang P., Jin Z. M. and Dowson D.

Transient elastohydrodynamic analysis of elliptical contacts. Part 3: Non-Newtonian lubricant solution under isothermal and thermal conditions.

Proceedings of the Institution of Mechanical Engineers, Part J: Journal of Engineering Tribology, Vol. $221 \mathrm{n}^{o}$ 1, pp. 63-73, 2007.

(cited in p. 26)

D'Agostino V., Della Valle S., Ruggiero A. and Senatore A.

A study on the piston top ring lubrication using the open-end boundary condition.

In Aimeta International Tribology Conference, Italy, sep 2002.

(cited in p. 37)

D'Agostino V. and Senatore A.

10 - Fundamentals of lubrication and friction of piston ring contact.

In Rahnejat H., editor, Tribology and Dynamics of Engine and Powertrain, pp. $343-386$.

Woodhead Publishing, 2010.

(cited in p. 33) 
Dai W., Kheireddin B., Gao H. and Liang H.

Roles of nanoparticles in oil lubrication.

Tribology International, Vol. 102, pp. 88 - 98, 2016.

(cited in p.61)

Delprete C., Razavykia A. and Baldissera P.

Detailed analysis of piston secondary motion and tribological performance.

International Journal of Engine Research, Vol. $0 \mathrm{n}^{\circ}$ 0, pp. 1-15, 2019. （cited in p. 30)

Dolatabadi N., Forder M., Morris N., Rahmani R., Rahnejat H. and HowellSmith S.

Influence of advanced cylinder coatings on vehicular fuel economy and emissions in piston compression ring conjunction.

Applied Energy, Vol. 259, pp. 114129, 2020.

(cited in p. 32)

Dowson D.

Piston Assemblies; Background and Lubrication Analysis.

In Taylor C M, editor, Engine Tribology, volume 26, pp. 213 - 240. Elsevier, 1993.

(cited in p. 35)

Dowson D., Economou P. N., Ruddy B. L., Strachan P. J. and Baker A. J. S.

Piston ring lubrication. Part II. Theoretical analysis of a single ring and a complete ring pack.

Energy conservation through fluid film lubrication technology: frontiers in research and design, pp. 23-52, 1979.

(cited in pp. 34, 35, 36)

Dowson D. and Higginson G. R.

Elasto-hydrodynamic Lubrication: The Fundamentals of Roller and Gear Lubrication.

Pergamon Press, 1965.

(cited in p. 26)

Dowson D., Higginson G. R., Archard J. F. and Crook A. W.

Elasto-hydrodynamic lubrication: international series on materials science and technology.

Pergamon Press, 1977.

(cited in p. 177)

Dursunkaya Z., Keribar R. and Ganapathy V.

A model of piston secondary motion and elastohydrodynamic skirt lubrication.

Journal of Tribology, Vol. $116 \mathrm{n}^{\circ}$ 4, pp. 777-785, $1994 . \quad$ (cited in p. 28)

Elrod H. G.

A Cavitation Algorithm.

Journal of Tribology, Vol. $103 \mathrm{n}^{\circ}$ 3, pp. 350-354, 1981.

(cited in p. 40)

Eyring H.

Viscosity, plasticity, and diffusion as examples of absolute reaction rates.

The Journal of chemical physics, Vol. $4 \mathrm{n}^{\circ}$ 4, pp. 283-291, 1936.

(cited in p. 180)

Fan C., Song C., Lv G., Wei J., Zhang X. and et al.

Impact of post-injection strategy on the physicochemical properties and reactivity of diesel in-cylinder soot.

Proceedings of the Combustion Institute, Vol. $37 \mathrm{n}^{\circ}$ 4, pp. 4821-4829, 2019.

(cited in p.60)

Fatjo G. Garcia-Atance, Smith E.H. and Sherrington I.

Piston-ring film thickness: Theory and experiment compared.

Proceedings of the Institution of Mechanical Engineers, Part J: Journal of Engineering

Tribology, Vol. $232 \mathrm{n}^{\circ}$ 5, pp. 550-567, 2018.

(cited in p. 43) 
Ferguson C. R. and Kirkpatrick A. T.

Internal combustion engines: applied thermosciences.

John Wiley \& Sons, New York [etc.], 2015.

(cited in p. 18)

Ferreira R., Martins J., Carvalho A., Sobral L., Carvalho S. and Silva F.

Tribological solutions for engine piston ring surfaces: an overview on the materials and manufacturing.

Materials and Manufacturing Processes, Vol. 35 n $^{\circ}$ 5, pp. 498-520, 2020. (cited in p. 3)

FEV.

VIRTUAL ENGINE. Powertrain dynamics in your hands. (cited in p. 43)

Fontaras G., Vouitsis E. and Samaras Z.

Experimental evaluation of the fuel consumption and emissions reduction potential of low viscosity lubricants.

In Powertrains, Fuels $\&$ Lubricants Meeting. SAE International, jun 2009.

(cited in p. 55)

Fox I. E.

Numerical evaluation of the potential for fuel economy improvement due to boundary friction reduction within heavy-duty diesel engines.

Tribology International, Vol. $38 \mathrm{n}^{\circ} 3$, pp. 265-275, 2005.

(cited in p.44)

Frêne J., Nicolas D., Degueurce B., Berthe D. and Godet M.

Chapter 3 General equations in hydrodynamic lubrication with a Newtonian fluid.

In Dowson D., editor, Hydrodynamic Lubrication, pp. 47 - 86. Elsevier, 1990.

(cited in pp. 202, 203)

Frommer A., Deub T., Ehnis H. and Künzel R.

Design of the tangential force of the oil control ring - oil emission versus friction.

MTZ worldwide, Vol. 77, pp. 48-53, $2016 . \quad$ (cited in pp. 3, 151, 197)

Fuentes E. and Kanase K.

Friction and wear in engine bearings.

In Lakshminarayanan P.A. and Nayak N.S., editors, Critical Component Wear in Heavy

Duty Engines, pp. 197-252. John Wiley \& Sons, Ltd, $2011 . \quad$ (cited in pp. 18, 19)

Furuhama S.

A dynamic theory of piston ring lubrication.

Bull. JSME, Vol. 3, pp. 291-297, 011960.

(cited in p. 34)

Furuhama S. and Sasaki S.

New device for the measurement of piston frictional forces in small engines.

In 1983 SAE International Off-Highway and Powerplant Congress and Exposition. SAE

International, sep 1983.

(cited in p. 46)

Furuhama S. and Sasaki S.

Effect of oil properties on piston frictional forces.

International Journal of vehicle design, Vol. $7 \mathrm{n}^{\circ} 1-2$, pp. 133-150, $1986 . \quad$ (cited in p. 46)

Furuhama S. and Takiguchi M.

Measurement of piston frictional force in actual operating diesel engine.

SAE Transactions, pp. 2896-2914, 1979.

(cited in p. 46)

Gebretsadik D. W., Hardell J. and Prakash B.

Tribological performance of tin-based overlay plated engine bearing materials.

Tribology International, Vol. 92, pp. 281- 289, 2015.

(cited in p. 29) 
Gore M, Rahmani R, Rahnejat $\mathbf{H}$ and King $\mathbf{P} \mathbf{D}$.

Assessment of friction from compression ring conjunction of a high-performance internal combustion engine: A combined numerical and experimental study.

Proceedings of the Institution of Mechanical Engineers, Part C: Journal of Mechanical Engineering Science, Vol. $230 \mathrm{n}^{\circ}$ 12, pp. 2073-2085, $2016 . \quad$ (cited in pp. 34, 39, 50)

Gore M., Theaker M., Howell-Smith S., Rahnejat H. and King P. D.

Direct measurement of piston friction of internal-combustion engines using the floating-liner principle.

Proceedings of the Institution of Mechanical Engineers, Part D: Journal of Automobile Engineering, Vol. 228 n $^{\circ}$ 3, pp. 344-354, 2014.

(cited in p. 50)

\section{Green D.A., Selby K., Mainwaring R. and Herrera R.}

The effect of engine, axle and transmission lubricant, and operating conditions on heavy duty diesel fuel economy: Part 1: Measurements.

SAE Int. J. Fuels Lubr., Vol. $5 \mathrm{n}^{\circ}$ 1, pp. 480-487, 2012.

(cited in p. 30)

Greenwood J A and Tripp J H.

The contact of two nominally flat rough surfaces.

Proceedings of the Institution of Mechanical Engineers, Vol. $185 \mathrm{n}^{\circ}$ 1, pp. 625-633, 1970.

(cited in pp. 33, 38, 41, 171, 172, 180)

Guo Y., Lu X., Li W., He T. and Zou D.

A mixed-lubrication model considering elastoplastic contact for a piston ring and application to a ring pack.

Proceedings of the Institution of Mechanical Engineers, Part D: Journal of Automobile Engineering, Vol. 229 n $^{\circ}$ 2, pp. 174-188, 2015.

(cited in p. 188)

Guzzella L. and Onder C.

Introduction to modeling and control of internal combustion engine systems.

Springer-Verlag Berlin Heidelberg, 2009.

(cited in p. 85)

Guzzella L. and Sciarretta A.

Vehicle propulsion systems. Introduction to modeling and optimization.

Springer-Verlag Berlin Heidelberg, 2013.

(cited in p. 84)

Ha K. P., Kim J. S., Cho M. R. and Oh D. Y.

Development of piston friction force measurement system.

In SAE Powertrain $\&$ Fluid Systems Conference $\mathscr{E}$ Exhibition. SAE International, oct 2002.

(cited in p.49)

Hamilton G. M. and Moore S. L.

Second Paper: Comparison between measured and calculated thicknesses of the oil-film lubricating piston rings.

Proceedings of the Institution of Mechanical Engineers, Vol. 188 n $^{\circ}$ 1, pp. 262-268, 1974.

(cited in p. 40)

Heywood J. B.

Internal combustion engine fundamentals.

McGraw-Hill, 1988.

(cited in pp. 19, 26, 41)

Holmberg K., Andersson P. and Erdemir A.

Global energy consumption due to friction in passenger cars.

Tribology International, Vol. 47, pp. 221-234, 2012.

(cited in p. 16) 
Holmberg K., Andersson P., Nylund N. O., Makela K. and Erdemir A.

Global energy consumption due to friction in trucks and buses.

Tribology International, Vol. 78, pp. 94 - 114, 2014.

(cited in p. 16)

Hoshi M.

Reducing friction losses in automobile engines.

Tribology International, Vol. $17 \mathrm{n}^{\circ}$ 4, pp. 185 - 189, 1984.

(cited in p. 16)

\section{Houpert L.}

New results of traction force calculations in elastohydrodynamic contacts.

Journal of Tribology, Vol. $107 \mathrm{n}^{\circ}$ 2, pp. 241-245, 1985.

(cited in p. 24)

Howell-Smith S., Rahnejat H., King P. D. and Dowson D.

Reducing in-cylinder parasitic losses through surface modification and coating.

Proceedings of the Institution of Mechanical Engineers, Part D: Journal of Automobile

Engineering, Vol. 228 n $^{o}$ 4, pp. 391-402, 2014.

(cited in p. 3)

Hsu C. S. and Robinson P. R.

Springer handbook of petroleum technology.

Springer, Cham, 2017.

(cited in p. 20)

Hu Y., Cheng H. S., Arai T., Kobayashi Y. and Aoyama S.

Numerical simulation of piston ring in mixed lubrication. A nonaxisymmetrical analysis. ASME. J. Tribol, Vol. $116 \mathrm{n}^{\circ}$ 3, pp. 470-478, 1994.

(cited in pp. 171, 172)

Hutchings I. and Shipway P.

4 - Lubricants and lubrication.

In Hutchings Ian and Shipway Philip, editors, Tribology (Second Edition), pp. 79-105.

Butterworth-Heinemann, 2017.

(cited in pp. 21, 22, 23)

Iniesta Gómez E.

Estudio y validación de una metodología de ensayo para el análisis experimental de la fuerza de fricción en el bloque pistón-camisa-segmentos de un MCIA.

Universitat Politècnica de València, 2016.

(cited in p.5)

INSIGHT.

$A C E A$ revisions coming soon.

(cited in p. 54)

Islam M. R.

A floating liner facility and studies of friction at a reciprocating piston-cylinder wall interface.

The University of Nottingham, 2016.

(cited in pp. 30, 51, 211)

James C. J.

Analysis of parasitic losses in heavy duty diesel engines.

Massachusetts Institute of Technology, 2012.

(cited in p. 16)

Jang J. Y. and Khonsari M. M.

Lubrication with a non-Newtonian fluid.

In Wang Q. J. and Chung Y. W., editors, Encyclopedia of Tribology, pp. 2146-2151. Springer US, 2013.

(cited in p. 25)

Jeng Y. R.

Theoretical analysis of piston-ring lubrication Part II-starved lubrication and its application to a complete ring pack.

Tribology Transactions, Vol. $35 \mathrm{n}^{\circ}$ 4, pp. 707-714, 1992.

(cited in p. 188) 
Kaneko T., Yamashita M., Ohori M. and Murakami M.

Development of low sulfated ash and fuel economy diesel engine oil.

In Powertrains, Fuels \& $\&$ Lubricants Meeting. SAE International, jun 2009.

(cited in pp. 53, 54, 60)

Keribar R., Dursunkaya Z. and Flemming M.F.

An integrated model of ring pack performance.

ASME. J. Eng. Gas Turbines Power, Vol. 113 n $^{\circ}$ 3, pp. 382-389, 1991. (cited in p. 43)

Kim K. S., Godward T., Takiguchi M. and Aoki S.

Part 2: The effects of lubricating oil film thickness distribution on gasoline engine piston friction.

In SAE World Congress 83 Exhibition. SAE International, apr 2007. $\quad$ (cited in pp. 47, 49)

Kim K. S., Shah P., Takiguchi M. and Aoki S.

Part 3: A study of friction and lubrication behavior for gasoline piston skirt profile concepts. In SAE World Congress 83 Exhibition. SAE International, apr 2009. $\quad$ (cited in pp. 47, 49)

Kistler.

Force sensors.

Switzerland, 2019.

(cited in p. 105)

Kushwaha M. and Rahnejat $\mathbf{H}$.

Transient elastohydrodynamic lubrication of finite line conjunction of cam to follower concentrated contact.

Journal of Physics D: Applied Physics, Vol. 35 n ${ }^{\circ}$ 21, pp. 2872-2890, 2002.

(cited in p. 20)

Law T., MacMillan D., Shayler P. J., Kirk G., Pegg I. and Stark R.

A new floating-liner test rig design to investigate factors influencing piston-liner friction. In SAE 2012 World Congress \& Exhibition. SAE International, apr 2012.

(cited in p. 51)

Liao K., Liu Y., Kim D., Urzua P. and Tian T.

Practical challenges in determining piston ring friction.

Proceedings of the Institution of Mechanical Engineers, Part J: Journal of Engineering Tribology, Vol. $227 \mathrm{n}^{\circ}$ 2, pp. 112-125, 2013.

(cited in p. 47)

Liu K., Xie Y. B. and Gui C. L.

Two-dimensional lubrication study of the piston ring pack.

Proceedings of the Institution of Mechanical Engineers, Part J: Journal of Engineering Tribology, Vol. $212 \mathrm{n}^{\circ}$ 3, pp. 215-220, 1998.

(cited in p.41)

Liu L. and Tian T.

Implementation and improvements of a flow continuity algorithm in modeling ring/liner lubrication.

SAE Transactions, Vol. 114, pp. 1165-1173, 2005.

(cited in p. 42)

Luján J. M., Guardiola C., Pla B. and Reig A.

Fuel and pollutant efficient vehicle speed optimization in real driving conditions.

IFAC-PapersOnLine, Vol. $51 \mathrm{n}^{\circ}$ 31, pp. 225 - 232, 2018.

(cited in p. 82)

Ma M. T., Sherrington I. and Smith E. H.

Implementation of an algorithm to model the starved lubrication of a piston ring in distorted bores: prediction of oil flow and onset of gas blow-by.

Proceedings of the Institution of Mechanical Engineers, Part J: Journal of Engineering

Tribology, Vol. $210 \mathrm{n}^{\circ}$ 1, pp. 29-44, 1996.

(cited in pp. 40, 42, 175) 
Ma M.T., Smith E. H. and Sherrington I.

Analysis of lubrication and friction for a complete piston-ring pack with an improved oil availability model: Part 2: Circumferentially variable film.

Proceedings of the Institution of Mechanical Engineers, Part J: Journal of Engineering Tribology, Vol. $211 \mathrm{n}^{\circ}$ 1, pp. 17-27, 1997.

(cited in p. 173)

Macián V., Tormos B., Bermúdez V. and Ramírez L.

Assessment of the effect of low viscosity oils usage on a light duty diesel engine fuel consumption in stationary and transient conditions.

Tribology International, Vol. 79, pp. 132-139, 2014.

(cited in pp. 30, 56)

Macián V., Tormos B., Miró G. and Pérez T.

Assessment of low-viscosity oil performance and degradation in a heavy duty engine realworld fleet test.

Proceedings of the Institution of Mechanical Engineers, Part J: Journal of Engineering Tribology, Vol. $230 \mathrm{n}^{\circ}$ 6, pp. 729-743, 2016.

(cited in p. 59)

Macián V., Tormos B., Ruiz S. and Miró G.

Low viscosity engine oils: Study of wear effects and oil key parameters in a heavy duty engine fleet test.

Tribology International, Vol. 94, pp. 240-248, 2016.

(cited in pp. 30, 59)

Macián V., Tormos B., Ruíz S. and Ramírez L.

Potential of low viscosity oils to reduce $\mathrm{CO}_{2}$ emissions and fuel consumption of urban buses fleets.

Transportation Research Part D: Transport and Environment, Vol. 39, pp. 76-88, 2015.

(cited in pp. 30, 59)

Madden D., Kim K. and Takiguchi M.

Part 1: Piston friction and noise study of three different piston architectures for an automotive gasoline engine.

In SAE 2006 World Congress $\&$ Exhibition. SAE International, apr 2006.

(cited in pp. 30, 47, 49)

Malik M. A., Rashid B., Qasim S. A. and Khushnood S.

Modeling and simulation of elastohydrodynamic lubrication of piston skirts considering elastic deformation in the initial engine start-up.

In ASME/STLE 2004 International Joint Tribology Conference, Parts A and B. ASME, 10 2004 .

(cited in p. 28)

Mansouri S. H. and Wong V. W.

Effects of piston design parameters on piston secondary motion and skirt - liner friction. Proceedings of the Institution of Mechanical Engineers, Part J: Journal of Engineering Tribology, Vol. $219 \mathrm{n}^{\circ}$ 6, pp. 435-449, 2005.

(cited in p. 30)

Marx N., Ponjavic A., Taylor R. I. and Spikes H. A.

Study of permanent shear thinning of VM polymer solutions.

Tribology Letters, Vol. $65 \mathrm{n}^{\circ}$ 3, pp. 106, 2017.

(cited in p. 79)

Milliken W. F., Milliken D. L. and et al.

Race car vehicle dynamics.

Society of Automotive Engineers, Warrendale, PA, 1995.

(cited in pp. 83, 84)

Miltsios G. K., Patterson D. J. and Papanastasiou T. C.

Solution of the lubrication problem and calculation of the friction force on the piston rings. Journal of Tribology, Vol. $111 \mathrm{n}^{\circ}$ 4, pp. 635-641, 1989.

(cited in p. 40) 


\section{Miró Mezquita G.}

Estudio del comportamiento y de la influencia en el desgaste de los aceites lubricantes de baja viscosidad en MCIA.

Universitat Politècnica de València, 2017.

(cited in p. 4)

Mishra P. C.

Tribodynamic modeling of piston compression ring and cylinder liner conjunction in highpressure zone of engine cycle.

The International Journal of Advanced Manufacturing Technology, Vol. $66 \mathrm{n}^{\circ}$ 5, pp. 10751085, 2013.

(cited in pp. 171, 172)

Mishra P. C., Balakrishnan S. and Rahnejat $\mathbf{H}$.

Tribology of compression ring-to-cylinder contact at reversal.

Proceedings of the Institution of Mechanical Engineers, Part J: Journal of Engineering Tribology, Vol. $222 \mathrm{n}^{\circ}$ 7, pp. 815-826, 2008.

(cited in p. 166)

Moore S. L. and Hamilton G. M.

The Starved Lubrication of Piston Rings in a Diesel Engine.

Journal of Mechanical Engineering Science, Vol. 20 n 6, pp. 345-352, 1978.

(cited in p. 167)

Morris N., Mohammadpour M., Rahmani R. and Rahnejat H.

Optimisation of the piston compression ring for improved energy efficiency of high performance race engines.

Proceedings of the Institution of Mechanical Engineers, Part D: Journal of Automobile Engineering, Vol. 231 n $^{o}$ 13, pp. 1806-1817, 2017.

(cited in p. 30)

Morris N., Rahmani R., Rahnejat H., King P. D. and Fitzsimons B.

The influence of piston ring geometry and topography on friction.

Proceedings of the Institution of Mechanical Engineers, Part J: Journal of Engineering Tribology, Vol. $227 \mathrm{n}^{\circ}$ 2, pp. 141-153, 2013.

(cited in p. 38)

Morris N., Rahmani R., Rahnejat H., King P. D. and Fitzsimons B.

Tribology of piston compression ring conjunction under transient thermal mixed regime of lubrication.

Tribology International, Vol. 59, pp. 248-258, 2014.

(cited in p. 39)

\section{Moughon L.}

Effects of piston design and lubricant selection on reciprocating engine friction.

Massachusetts Institute of Technology, 2006.

(cited in p. 42)

Mufti R. A., Priest M. and Chittenden R. J.

Analysis of piston assembly friction using the indicated mean effective pressure experimental method to validate mathematical models.

Proceedings of the Institution of Mechanical Engineers, Part D: Journal of Automobile Engineering, Vol. 222 n $^{\circ}$ 8, pp. 1441-1457, 2008.

(cited in p.44)

NAFEMS.

The importance of mesh convergence - Part 1.

(cited in pp. 109, 111)

Norris J. and Escher G.

Heavy duty vehicles technology potential and cost study.

Ricardo Energy and Environment, 2017.

(cited in p.3)

Oh, K. P. Li C. H. and Goenka P. K.

Elastohydrodynamic lubrication of piston skirts.

ASME. J. Tribol., Vol. 109 n $^{\circ}$ 2, pp. 356 - 362, 1987.

(cited in p. 28) 


\section{Okamoto M. and Sakai I.}

Contact pressure distribution of piston rings-calculation based on piston ring contour.

In SAE 2001 World Congress. SAE International, 032001.

(cited in p. 173)

O'Rourke B., Radford D. and Stanglmaier R.

Tri-Axial force measurements on the cylinder of a motored SI engine operated on lubricants of differing viscosity.

Journal of Engineering for Gas Turbines and Power, Vol. $132 \mathrm{n}^{\circ}$ 9, 2010.

(cited in pp. 50, 51)

O'Rourke B., Stanglmaier R. and Radford D.

Development of a floating-liner engine for improving the mechanical efficiency of high performance engines.

In Motorsports Engineering Conference 83 Exposition. SAE International, dec 2006.

(cited in p. 50)

\section{Overgaard H., Klit P. and Vølund A.}

Investigation of different piston ring curvatures on lubricant transport along cylinder liner in large two-stroke marine diesel engines.

Proceedings of the Institution of Mechanical Engineers, Part J: Journal of Engineering Tribology, Vol. $232 \mathrm{n}^{\circ}$ 1, pp. 85-93, 2018.

(cited in pp. 31, 43, 188, 196)

Patir N. and Cheng H. S.

An average flow model for determining effects of three-dimensional roughness on partial hydrodynamic lubrication.

Journal of Tribology, Vol. 100, pp. 12-17, 1978.

(cited in pp. $33,38,43$ )

Paydas A. and Smith E. H.

A flow-continuity approach to the analysis of hydrodynamic journal bearings.

Proceedings of the Institution of Mechanical Engineers, Part C: Mechanical Engineering Science, Vol. $206 \mathrm{n}^{\circ}$ 1, pp. 57-69, 1992.

(cited in p. 40)

\section{Payri González F. and Desantes Fernández J.M ${ }^{\mathrm{a}}$.}

Motores de combustión interna alternativos.

Reverté: Universitat Politècnica de València, Barcelona [etc.], 2011.

(cited in pp. 13, 15, 18, 19, 21, 115, 154, 157)

Perera M. S. M., Theodossiades S. and Rahnejat $\mathbf{H}$.

A multi-physics multi-scale approach in engine design analysis.

Proceedings of the Institution of Mechanical Engineers, Part K: Journal of Multi-body Dynamics, Vol. 221 n $^{\circ}$ 3, pp. 335-348, 2007.

(cited in p. 38)

Perera M. S. M., Theodossiades S. and Rahnejat $\mathbf{H}$.

Elasto-multi-body dynamics of internal combustion engines with tribological conjunctions. Proceedings of the Institution of Mechanical Engineers, Part K: Journal of Multi-body Dynamics, Vol. 224 n $^{o}$ 3, pp. 261-277, 2010.

(cited in p. 38)

Permude A., Pathak M., Kumar V. and Singh S.

Influence of low viscosity lubricating oils on fuel economy and durability of passenger car diesel engine.

SAE Int. J. Fuels Lubr., Vol. $5 \mathrm{n}^{\circ}$ 3, pp. 1426-1435, 2012.

(cited in pp. 30, 56)

Piao Y. and Gulwadi S.D.

Numerical investigation of the effects of axial cylinder bore profiles on piston ring radial dynamics.

ASME. J. Eng. Gas Turbines Power, Vol. 125 n $^{\circ}$ 4, pp. 1081-1089, $2003 . \quad$ (cited in p. 44) 
Pinkus O., Sternlicht B. and Saibel E.

Theory of hydrodynamic lubrication.

McGraw-Hill, 1962.

(cited in pp. 202, 203)

Pirro D. M., Webster M. and Daschner E.

Lubrication fundamentals, revised and expanded.

CRC Press, Boca Raton, 2017.

(cited in pp. 21, 22, 60)

Porter R.

New API certified CK-4 and FA-4 diesel engine oils are available beginning December 1.

(cited in p. 54)

Profito F. J., Zachariadis D. C. and Tomanik E.

One dimensional mixed lubrication regime model for textured piston rings.

In 21st Brazilian Congress of Mechanical Engineering, 102011.

(cited in p. 182)

Pulkrabek W. W.

Engineering fundamentals of the internal combustion engine.

Prentice hall, New Jersey, 2000.

(cited in p. 20)

Rahmani R., Rahnejat H., Fitzsimons B. and Dowson D.

The effect of cylinder liner operating temperature on frictional loss and engine emissions in piston ring conjunction.

Applied Energy, Vol. 191, pp. 568-581, 2017.

(cited in pp. 17, 18)

Rahnejat $\mathbf{H}$.

Tribology and dynamics of engine and powertrain: fundamentals, applications and future trends.

Woodhead Publishing, Oxford [etc.], $2010 . \quad$ (cited in pp. 14, 20, 24, 27, 32, 167)

Rajamani Rajesh.

Vehicle dynamics and control.

Springer US, 2011.

(cited in p. 84)

Ramirez Roa L. A.

Contribution to the assessment of the potential of low viscosity engine oils to reduce ICE fuel consumption and $\mathrm{CO}_{2}$ emissions.

Universitat Politècnica de València, 2016.

(cited in p.4)

Rao L., Zhang Y., Kook S., Kim K. S. and Kweon C. B.

Understanding in-cylinder soot reduction in the use of high pressure fuel injection in a smallbore diesel engine.

Proceedings of the Combustion Institute, Vol. 37 n $^{\circ}$ 4, pp. 4839 - 4846, 2019.

(cited in p.60)

Reitz R. D., Ogawa H., Payri R., Fansler T., Kokjohn S. and et al.

IJER editorial: The future of the internal combustion engine.

International Journal of Engine Research, Vol. $21 \mathrm{n}^{\circ}$ 1, pp. 3-10, $2020 . \quad$ (cited in p. 3)

Rejowski E. D., Mordente Sr P., Pillis M. F. and Casserly T.

Application of DLC coating in cylinder liners for friction reduction.

In SAE 2012 World Congress \& Exhibition. SAE International, apr 2012.

(cited in p. 32)

Ricardo Energy and Environment.

Lubricant's contribution to fuel economy.

United Kingdom, 2019.

(cited in pp. 61, 62) 
Rizzoni G., Guzzella L. and Baumann B. M.

Unified modeling of hybrid electric vehicle drivetrains.

IEEE/ASME Transactions on Mechatronics, Vol. 4 n 3 , pp. 246 - 257, 1999.

(cited in p. 83)

Roelands C. J. A.

Correlation aspects of the viscosity-temperature-pressure relationships of lubricant oils.

Technische Universiteit Delft, 1966.

(cited in p. 24)

Ruddy B. L., Dowson D., Economou P. N. and Baker A. J. S.

Piston-ring lubrication. Part III. The influence of ring dynamics and ring twist.

Energy conservation through fluid film lubrication technology: frontiers in research and design, pp. 191-215, 1979.

(cited in p. 35)

Rudnick L. R.

Lubricant additives: chemistry and applications.

CRC press, Boca Raton, 2017.

(cited in p. 21)

SAE International.

SAE J300 Engine oil viscosity classification.

United States, 2015.

(cited in pp. 53, 54, 55)

Sagawa T., Ueno T., Nakamura K., Ishikawa T., Ando T. and Ishikawa M.

Development of 0W-20 ILSAC GF-3 gasoline engine oil.

In Spring Fuels $\&$ Lubricants Meeting $\mathscr{E}$ Exhibition. SAE International, may 2002.

(cited in p.60)

Sander D. E., Allmaier H., Knauder C. and Strömstedt F.

Potentials and risks of reducing friction with future ultra-low-viscosity engine oils.

MTZ worldwide, Vol. $79 \mathrm{n}^{\circ}$ 12, pp. 20-27, 2018.

(cited in pp. 53, 57)

Sander D. E., Allmaier H. and Priebsch H. H.

Friction and wear in automotive journal bearings operating in todays severe conditions.

In Darji Pranav H, editor, Advances in Tribology, pp. 143-172. InTech, 2016.

(cited in p. 19)

Sander D.E., Allmaier H., Priebsch H.H., Reich F.M., Witt M. and et al. Impact of high pressure and shear thinning on journal bearing friction.

Tribology International, Vol. 81, pp. 29-37, 2015.

(cited in pp. 23, 24)

Sasaki M., Kishi Y., Hyuga T., Omata H., Takeshima S., Kurihara I. and et al.

Development of high performance heavy-duty diesel engine oil to extend oil drain intervals: 5 W30 fully synthetic oil containing MoDTC.

In CEC/SAE Spring Fuels \& L Lubricants Meeting $\&$ Exposition. SAE International, 2000.

(cited in p.60)

Sato O., Takiguchi M., Takayuki A., Seki Y., Fujimura K. and Tateishi Y.

Improvement of Piston Lubrication in a Diesel Engine By Means of Cylinder Surface Roughness.

In SAE 2004 World Congress $\mathcal{E}$ Exhibition. SAE International, mar 2004.

(cited in p. 32)

Sawicki J. T. and Yu B.

Analytical solution of piston ring lubrication using mass conserving cavitation algorithm.

Tribology Transactions, Vol. $43 \mathrm{n}^{\circ}$ 4, pp. 587-594, 2000.

(cited in p. 37) 


\section{Söchting S. J. and Sherrington I.}

The effect of load and viscosity on the minimum operating oil film thickness of piston-rings in internal combustion engines.

Proceedings of the Institution of Mechanical Engineers, Part J: Journal of Engineering Tribology, Vol. $223 \mathrm{n}^{\circ}$ 3, pp. 383-391, 2009.

(cited in p. 211)

\section{Schwarze H.}

Lubricants and the lubrication system.

In Mollenhauer K. Tschöke H, editor, Handbook of Diesel Engines, pp. 359-376. Springer, 2010 .

(cited in p. 22)

\section{Söderfjäll M., Almqvist A. and Larsson R.}

Component test for simulation of piston ring-Cylinder liner friction at realistic speeds.

Tribology International, Vol. 104, pp. 57 - 63, 2016.

(cited in p. 52)

Söderfjäll M., Herbst H. M., Larsson R. and Almqvist A.

Influence on friction from piston ring design, cylinder liner roughness and lubricant properties.

Tribology International, Vol. 116, pp. 272 - 284, 2017.

(cited in p. 52)

Söderfjäll M., Larsson R., Marklund P. and Almqvist A.

Texture-induced effects causing reduction of friction in mixed lubrication for twin land oil control rings.

Proceedings of the Institution of Mechanical Engineers, Part J: Journal of Engineering Tribology, Vol. $232 \mathrm{n}^{\circ} 2$, pp. 166-178, 2018.

(cited in p.3)

\section{Söderfjäll Markus.}

Friction in piston ring - cylinder liner contacts.

Luleå University of Technology, 2017.

(cited in p.211)

Sherrington I. and Smith E. H.

The measurement of piston-ring friction by the "floating-liner" method.

SAE paper, $\mathrm{n}^{\circ}$ 884707, 1988.

(cited in p. 47)

Singh S. K., Singh S. and Sehgal A. K.

Impact of low viscosity engine oil on performance, fuel economy and emissions of light duty diesel engine.

In SAE 2016 International Powertrains, Fuels \& Lubricants Meeting. SAE International, oct 2016 .

(cited in p. 56)

Skjoedt M., Butts R., Assanis D. N. and Bohac S. V.

Effects of oil properties on spark-ignition gasoline engine friction.

Tribology International, Vol. $41 \mathrm{n}^{\circ}$ 6, pp. 556-563, 2008.

(cited in p.60)

Smith E. H., Clark C. A. and Sherrington I.

The measurement of piston assembly friction in a motored engine.

In IMechE Conference on Universal and Poly Research on IC Engines, pp. 185-190, 1991.

(cited in p. 48)

Souza De Carvalho M. J., Seidl P., Rodriguez Pereira Belchior C. and Sodre J. R.

Lubricant viscosity and viscosity improver additive effects on diesel fuel economy.

Tribology international, Vol. $43 \mathrm{n}^{\circ}$ 12, pp. 2298-2302, 2010. $\quad$ (cited in pp. 30, 53, 56)

Spikes $\mathbf{H}$.

Friction modifier additives.

Tribology Letters, Vol. $60 \mathrm{n}^{\circ}$ 1, pp. 5, 2015.

(cited in p. 22) 
Stachowiak Gwidon W. and Batchelor Andrew W.

Engineering Tribology.

Butterworth-Heinemann, Boston, 2014.

(cited in pp. 18, 23)

Stanley R., Taraza D., Henein N. and Bryzik W.

A simplified friction model of the piston ring assembly.

In International Congress \& Exposition. SAE International, 1999.

(cited in p. 41)

Stefanescu D. M.

Handbook of force transducers: principles and components.

Springer-Verlag Berlin Heidelberg, 2011.

(cited in p. 105)

Sung-Woo C., Sang-Min C. and Choong-Sik B.

Frictional modes of barrel shaped piston rings under flooded lubrication.

Tribology International, Vol. $33 \mathrm{n}^{\circ}$ 8, pp. $545-551,2000 . \quad$ (cited in pp. 48, 211)

Takiguchi M, Machida $\mathrm{K}$ and Furuhama S.

Piston friction force of a small high speed gasoline engine.

Journal of Tribology, Vol. $110 \mathrm{n}^{\circ}$ 1, pp. 112-118, 1988.

(cited in pp. 46, 49)

Tang Z. and Li S.

A review of recent developments of friction modifiers for liquid lubricants (2007-present). Current Opinion in Solid State and Materials Science, Vol. 18 n $^{\circ}$ 3, pp. 119 - 139, 2014.

(cited in p.61)

Taraza D., Henein N. and Bryzik W.

Friction losses in multi-cylinder diesel engines.

In SAE 2000 World Congress. SAE International, mar 2000. $\quad$ (cited in pp. 16, 29, 149)

Taylor C.M.

Lubrication Regimes and the Internal Combustion Engine.

In Taylor C.M., editor, Engine Tribology, volume 26, pp. 75-87. Elsevier, 1993.

(cited in p. 15)

Taylor R., Selby K., Herrera R. and Green D. A.

The effect of engine, axle and transmission lubricant, and operating conditions on heavy duty diesel fuel economy: Part 2: Predictions.

In SAE International Powertrains, Fuels and Lubricants Meeting. SAE International, aug 2011.

(cited in p. 58)

Taylor R. I.

Squeeze film lubrication in piston rings and reciprocating contacts.

Proceedings of the Institution of Mechanical Engineers, Part J: Journal of Engineering

Tribology, Vol. $229 \mathrm{n}^{\circ}$ 8, pp. 977-988, 2015.

(cited in pp. 31, 166, 195)

Taylor R.I. and de Kraker B.R.

Shear rates in engines and implications for lubricant design.

Proceedings of the Institution of Mechanical Engineers, Part J: Journal of Engineering Tribology, Vol. $231 \mathrm{n}^{\circ}$ 9, pp. 1106-1116, 2017.

(cited in p. 53)

Teodorescu M., Kushwaha M., Rahnejat H. and Rothberg S. J.

Multi-physics analysis of valve train systems: From system level to microscale interactions. Proceedings of the Institution of Mechanical Engineers, Part K: Journal of Multi-body Dynamics, Vol. 221 n $^{o}$ 3, pp. 349-361, 2007.

(cited in p. 29) 
Teodorescu M., Taraza D., Henein N.. and Bryzik W.

Simplified elasto-hydrodynamic friction model of the cam-tappet contact.

In SAE 2003 World Congress \& Exhibition. SAE International, mar 2003.

(cited in pp. 29, 180)

Teraguchi S., Suzuki W., Takiguchi M. and Sato D.

Effects of lubricating oil supply on reductions of piston slap vibration and piston friction. In SAE 2001 World Congress. SAE International, mar 2001.

(cited in p.47)

Tian T., Noordzij L. B., Wong V. W. and Heywood J. B.

Modeling piston-ring dynamics, blowby, and ring-twist effects.

ASME. J. Eng. Gas Turbines Power, Vol. 120 n 4 , pp. 843-854, 1998.

(cited in pp. 171, 172)

\section{Tomanik E.}

Modelling of the asperity contact area on actual 3D surfaces.

In SAE 2005 World Congress \& Exhibition. SAE International, 042005.

(cited in p. 184)

Tomanik E., Chacon H. and Teixeira G.

A simple numerical procedure to calculate the input data of Greenwood-Williamson model of asperity contact for actual engineering surfaces.

In Dowson D., Priest M., Dalmaz G. and Lubrecht A.A, editors, Tribological Research and Design for Engineering Systems, pp. 205 - 215. Elsevier, $2003 . \quad$ (cited in p. 182)

Tomanik E., Profito F., Sheets B. and Souza R.

Combined lubricant-surface system approach for potential passenger car $\mathrm{CO}_{2}$ reduction on piston-ring-cylinder bore assembly.

Tribology International, Vol. 149, pp. 105514, 2020.

(cited in p. 43)

Tormos B., Martín J., Blanco-Cavero D. and Jiménez-Reyes A.J.

One-dimensional modeling of mechanical and friction losses distribution in a four-stroke internal combustion engine.

ASME. J. of Tribology, Vol. $142 \mathrm{n}^{\circ}$ 1, pp. 011703, 2020.

(cited in p. 44)

Tormos B, Miró G., Ramirez L. and Pérez T.

Real world fleet test to determine the impact of low viscosity engine oils from heavy-duty CNG and diesel buses - Part II: Oil performance.

In International Powertrains, Fuels \& Lubricants Meeting. SAE International, oct 2017.

(cited in p. 59)

Tormos B., Ramirez L., Miró G. and Pérez T.

Real world fleet test to determine the impact of low viscosity engine oils from heavy-duty CNG and diesel buses - Part I: Fuel consumption.

In International Powertrains, Fuels \& Lubricants Meeting. SAE International, oct 2017.

(cited in pp. 30, 59)

Tormos B., Ramírez L., Johansson J., Björling M. and Larsson R.

Fuel consumption and friction benefits of low viscosity engine oils for heavy duty applications.

Tribology International, Vol. 110, pp. 23-34, 2017.

(cited in p. 30)

Transport and Environment Reporting Mechanism (TERM).

Progress of EU transport sector towards its environment and climate objectives.

European Environment Agency, 2018.

(cited in p. 3) 
Transport and Environment Reporting Mechanism (TERM).

Transport: increasing oil consumption and greenhouse gas emissions hamper EU progress towards environment and climate objectives.

European Environment Agency, 2020.

(cited in p. 3)

Tung S. C. and McMillan M. L.

Automotive tribology overview of current advances and challenges for the future.

Tribology International, Vol. 37 n 7 , pp. 517 - 536, 2004.

(cited in p.17)

Turnbull R., Dolatabadi N., Rahmani R. and Rahnejat H.

An assessment of gas power leakage and frictional losses from the top compression ring of internal combustion engines.

Tribology International, Vol. 142, 2020.

(cited in pp. 171, 172)

Urabe M., Tomomatsu T., Ishiki K., Takiguchi M. and Someya T.

Variation of piston friction force and ring lubricating condition in a diesel engine with EGR. In International Fall Fuels and Lubricants Meeting and Exposition. SAE International, oct 1998.

(cited in pp. 47, 48)

Uras H. M. and Patterson D. J..

Measurement of piston and ring assembly friction instantaneous IMEP method.

In SAE International Congress and Exposition. SAE International, feb 1983.

(cited in p. 44)

Van Dam W., Booth J. and Parsons G.

Taking heavy duty diesel engine oil performance to the next level, Part 1: Optimizing for improved fuel economy.

In SAE 2014 International Powertrain, Fuels 8 Lubricants Meeting. SAE International, oct 2014.

(cited in p. 59)

Van Dam W., Cooper M. W., Oxorn K. and Richards S.

Observations from cylinder liner wear studies in heavy duty diesel engines and the evolution towards lower viscosity heavy duty engine lubricants.

In SAE 2011 World Congress \& Exhibition. SAE International, apr 2011.

(cited in p. 58)

Van Dam W., Kleijwegt P., Torreman M. and Parsons G.

The lubricant contribution to improved fuel economy in heavy duty diesel engines.

In SAE 2009 Commercial Vehicle Engineering Congress 83 Exhibition. SAE International, oct 2009 .

(cited in pp. 57, 92)

Van Dam W.., Miller T., Parsons G. M. and Takeuchi Y.

The impact of lubricant viscosity and additive chemistry on fuel economy in heavy duty diesel engines.

In Powertrains, Fuels \& Lubricants Meeting. SAE International, aug 2011.

(cited in pp. $3,53,58$ )

Wakabayashi R., Kawanishi M., Yoshida H. and Ozaki Y.

The effects of piston rings and liner break-in on lubricating condition.

In SAE World Congress $\mathcal{E}$ Exhibition. SAE International, apr 2007. $\quad$ (cited in pp. 47, 49)

Wakabayashi R., Takiguchi M., Shimada T., Mizuno Y. and Yamauchi T.

The effects of crank ratio and crankshaft offset on piston friction losses.

In SAE 2003 World Congress \& Exhibition. SAE International, mar 2003.

(cited in pp. 47, 49) 
Wakuri Y., Hamatake T., Soejima M. and Kitahara T.

Piston ring friction in internal combustion engines.

Tribology International, Vol. $25 \mathrm{n}^{\circ}$ 5, pp. 299-308, $1992 . \quad$ (cited in pp. 48, 188, 211)

Wakuri Y., Soejima M., Kitahara T., Nunotani M. and Kabe Y.

Characteristics of piston ring friction: influences of lubricating oil properties.

JSME international journal. Ser. C, Dynamics, control, robotics, design and manufacturing, Vol. 38 n $^{\circ}$ 3, pp. 593-600, 1995.

(cited in p. 48)

Wang Q Jane and Chung Yip-Wah.

Encyclopedia of Tribology.

Springer, 2013.

(cited in p. 37)

Wannatong K., Chanchaona S. and Sanitjai S.

Simulation algorithm for piston ring dynamics.

Simulation Modelling Practice and Theory, Vol. $16 \mathrm{n}^{\circ}$ 1, pp. 127-146, 2008.

(cited in p. 42)

Westerfield Z., Liu Y., Kim D. and Tian T.

A study of the friction of oil control rings using the floating liner engine.

In SAE 2016 World Congress \& Exhibition. SAE International, 042016.

(cited in pp. 143, 149, 188)

Wong V. W., Tian T., Lang H., Ryan J. P., Sekiya Y. and et al.

A numerical model of piston secondary motion and piston slap in partially flooded elastohydrodynamic skirt lubrication.

In International Congress \& Exposition. SAE International, mar 1994. （cited in p. 28)

Zavos A. and Nikolakopoulos P. G.

Computational fluid dynamics analysis of top compression ring in mixed lubrication.

Mechanics $\mathcal{E}$ Industry, Vol. $18 \mathrm{n}^{\circ}$ 2, pp. 208, 2017.

(cited in p. 171)

Zavos A. and Nikolakopoulos P. G.

Tribology of new thin compression ring of fired engine under controlled conditions-A combined experimental and numerical study.

Tribology International, Vol. 128, pp. 214 - 230, 2018.

(cited in p. 30) 